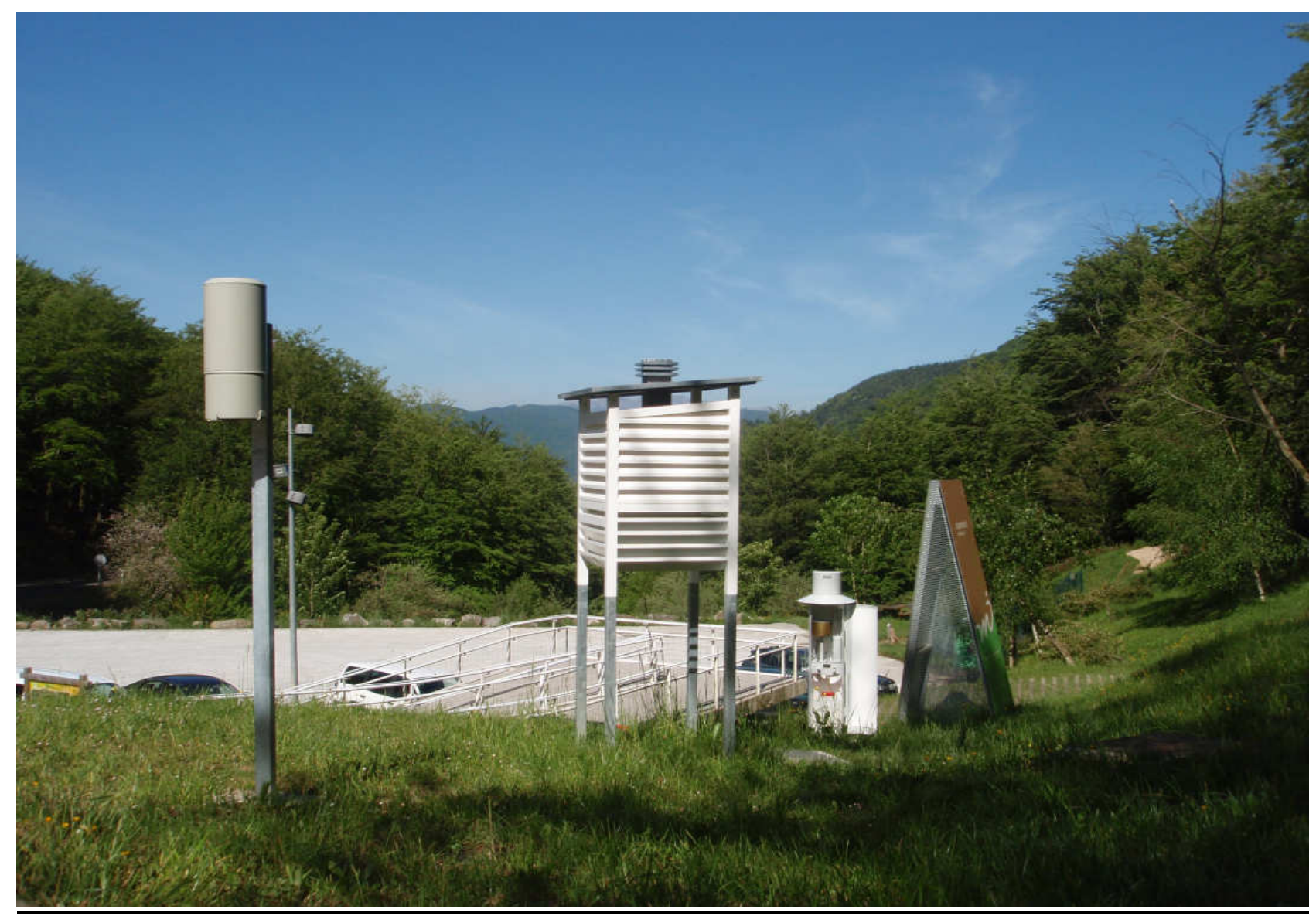

\title{
ANÁLISIS DE LA HOMOGENEIDAD DE LAS SERIES DE PRECIPITACIÓN DE GUIPÚZCOA
}

Nota técnica $\mathrm{N}^{\mathrm{o}} 13$ de AEMET

Iñigo Javier Caballero López

Jefe Unidad de Estudios y Desarrollos

Delegación Territorial de AEMET en el País Vasco

San Sebastián, a 11 de junio de 2013.

A $=A$ Met 


\section{datos \\ abiertos}

Aviso Legal: los contenidos de esta publicación podrán ser reutilizados, citando la fuente y la fecha, en su caso, de la última actualización

\section{Edita:}

(C) Ministerio de Agricultura, Alimentación y Medio Ambiente Agencia Estatal de Meteorología

Madrid, 2013

Catálogo de Publicaciones de la Administración General del Estado: https://cpage.mpr.gob.es

NIPO: 281-13-010-3

https://doi.org/10.31978/281-13-010-3

Agencia Estatal de Meteorología (AEMET)

C/ Leonardo Prieto Castro, 8

28040 Madrid

http://www.aemet.es/

@Aemet_Esp

https://www.facebook.com/AgenciaEstataldeMeteorologia 


\section{Índice}

1.- Introducción

2.- Series analizadas: Emplazamientos, gráficas e histogramas

3.- Método: Test de Thom y de Mann-Kendall.

4.- Resultados

4.1.- Rupturas detectadas en series de precipitación.

4.2.- Análisis evolución temporal inhomogeneidades.

4.2.1.- Evolución temporal inhomogeneidades Test Thom.

4.2.2.- Evolución temporal inhomogeneidades Test Mann -Kendall.. $\quad 58$

4.2.3.- Caída homogeneidad últimos años de medida.

4.3.- Comparativa homogeneidad entre la precipitación anual y primaveral.

5.- Conclusiones

6.- Agradecimientos.

7.- Referencias.

8.- Anexos: Nomenclátor y distribución comarcal series 


\section{Introducción:}

La serie de precipitación 1024E Igueldo ha sido muy estudiada; sin embargo apenas hay trabajos sobre el resto de series de precipitación de la provincia de Guipúzcoa.

El objetivo de esta nota técnica es analizar de un modo objetivo la calidad y homogeneidad de las series de precipitación actuales y antiguas de Guipúzcoa.

En el extenso periodo temporal del que se dispone de medidas (desde 1878), se analiza la homogeneidad aplicando sucesivamente los tests de Thom y de Mann-Kendall a las series actuales y antiguas.

El fin es discriminar entre las homogeneidades de tipo "climatológico" debidas a variaciones de la atmósfera, de las homogeneidades "no climatológicas" observadas en las series de datos debidas a alteraciones de la observación, las cuáles causan rupturas abruptas en los datos: cambio de instrumentos medidores; de observador; de instalación; de lugar; de modificaciones próximas del entorno; caídas en la calidad de las observaciones... (Martínez Molina 1986).

Según Conrad y Pollack (1962): "Una muestra es homogénea si sus variaciones responden exclusivamente a las variaciones de la atmósfera."

Martínez Molina al aplicar el test de las rachas expone: "muchas alternancias indican oscilación y muchas permanencias indican una tendencia o cambio". Así, un número de rachas elevado indica oscilaciones en torno a la mediana de la serie, mientras que un número de rachas bajo indica tendencias.

En periodos de 10, 20, 30, 40, 50, 60 y 80 años, se han seguido para el test de las rachas los valores críticos expuestos en "Homogeneidad y variabilidad de los registros históricos de precipitación de España."

Un número de tendencias elevado según el test de Mann-Kendall revela una ruptura de la serie.

Para diferenciar las inhomogeneidades "climatológicas" de las restantes, se realiza una comparativa de las observaciones frente a los observatorios y colaboradores más cercanos: de ahí la necesidad de analizar también el comportamiento de las series antiguas de precipitación.

Se ha realizado un trabajo de campo para verificar las rupturas detectadas por los tests: consulta bibliográfica, entrevista a colaboradores de AEMET, consulta en los archivos de la Sección de Sistemas Básicos de la DT de AEMET en el País Vasco.

Se han detectado rupturas en las series aplicando los tests a una escala anual y un número superior de rupturas, aplicando el test con una mayor resolución temporal, en los periodos Marzo-Abril-Mayo y Abril-Mayo-Junio. 
Se detectan tendencias de tipo climatológico tanto a nivel de toda la provincia (sequía de los años 40, sequía a mediados de los 70, precipitaciones intensas a fines de los 70 y comienzos de los $80 \ldots$ ) como a nivel comarcal (disminución de las precipitaciones a finales de la década de los 90 en primavera en las comarcas del interior de la provincia...)

Tras el análisis consecutivo por los 2 test, se establece un criterio objetivo para catalogar la homogeneidad de cada serie de datos de precipitación, a nivel anual y primaveral, útil para proponer una serie de estaciones de referencia, tanto a nivel provincial (1024E) como comarcal $(1021 \mathrm{E}, 1036 \mathrm{O}, 1049 \ldots)$

En este criterio, se ha tenido en cuenta el \% de datos, al ser en algunas series las lagunas "críticas" para el estudio de su homogeneidad.

\section{$\underline{\text { 2.- Series analizadas Emplazamientos, gráficas e histogramas: }}$}

Se analiza el comportamiento de las series de precipitación de Guipúzcoa con un número de datos mayor o igual a 10 de precipitación media anual (anual en lo sucesivo), precipitación media en el periodo Marzo - Abril - Mayo (MAM en lo sucesivo) o precipitación media en el periodo Abril - Mayo - Junio (AMJ en lo sucesivo), atendidas por personal de AEMET, por colaboradores y automáticas, en funcionamiento y antiguas.

El periodo de datos estudiado abarca desde 1878 a 2012. Se incluyen las series 1044D (Aramayona) y 1049U (Ermua) por estar en una zona climática similar a Guipúzcoa y situarse en subcuencas hidrográficas que vierten a Guipúzcoa.

Se toma como criterio para contabilizar los años de duración de la serie, el de descartar para el cálculo de años el primer año y el último si en éstos no comienzan las medidas en enero ni acaban en diciembre.

Así una serie sin lagunas como 1049 (Vergara) que comienza en marzo de 1983 y acaba en junio de 2009, su cómputo empieza en 1984 y termina en 2008 y se la considera con un $100 \%$ datos.

Se aplica el mismo criterio, cuando se interrumpe una serie y se retoma. Por ejemplo, 1032 (Villabona) comienza en enero de 1926, se abandona en julio de 1936, se retoma en septiembre de 1938 hasta noviembre de 1987. Para el cómputo de años completos de 1032 se comienza el cálculo de años en 1926, se interrumpe en 1935, se reanuda en 1939 y se termina en 1986.

Por brevedad, en lo sucesivo se designa cada serie por su indicativo climatológico. Se adjunta un listado de indicativos en la tabla 59 del anexo y de la distribución por comarcas de la provincia en la tabla 60 del anexo.

Se estudian 50 series de precipitación anual, 54 series en el periodo MAM y 53 series en el periodo AMJ con un número de datos mayor o igual a 10 años.

La figura 1 muestra el emplazamiento de las series analizadas. 


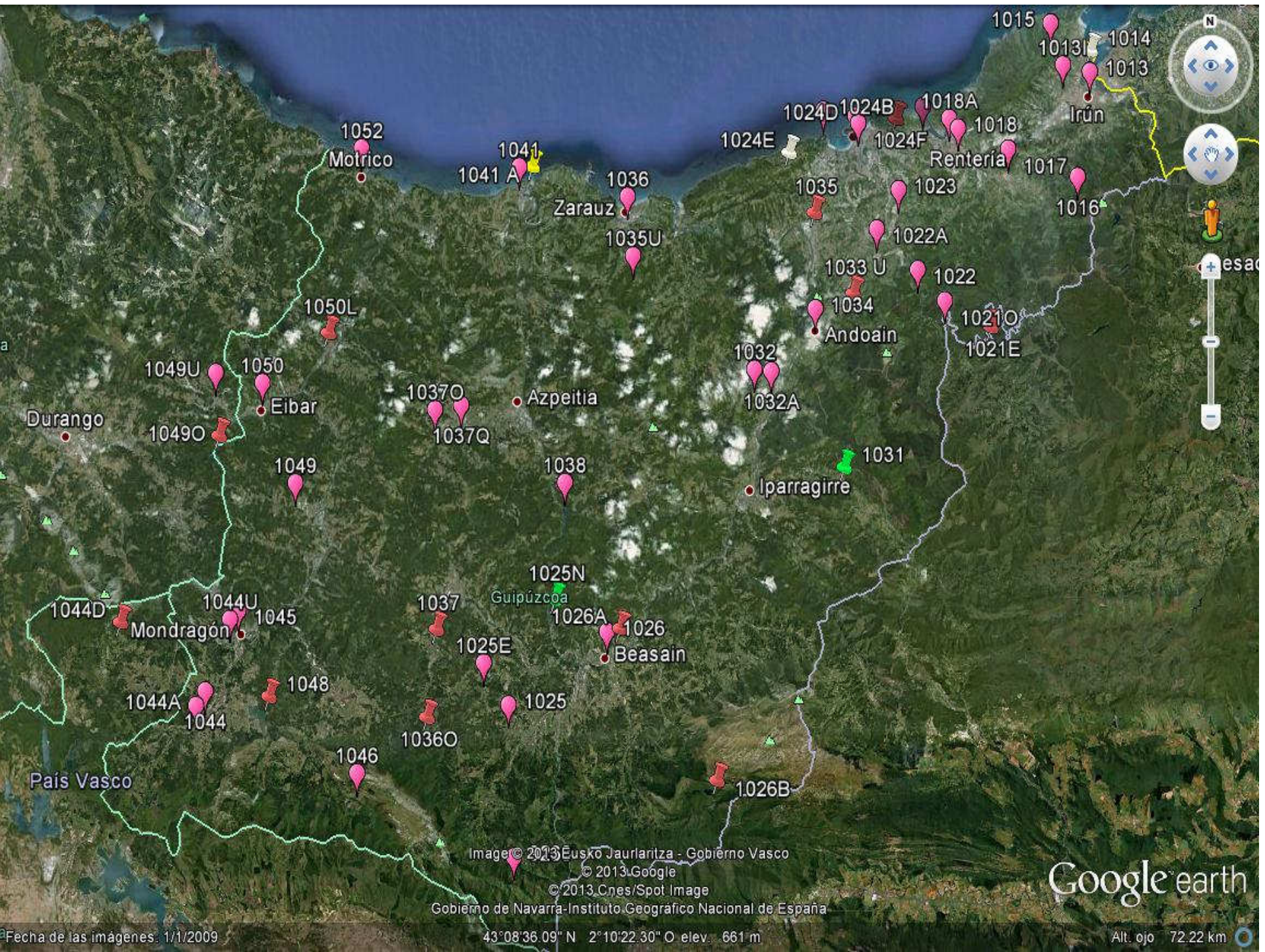

Leyenda:

$\S$ Colaboradores TP actuales.

$\S$ Colaboradores $\mathrm{P}$ actuales.

$\{$ Estaciones automáticas.

Colaboradores antiguos.

Esta leyenda será la empleada en las sucesivas figuras.

La gráfica 1 muestra la evolución temporal del número de series de precipitación anual analizadas. 
Gráfica 1: Número de series de precipitación anual

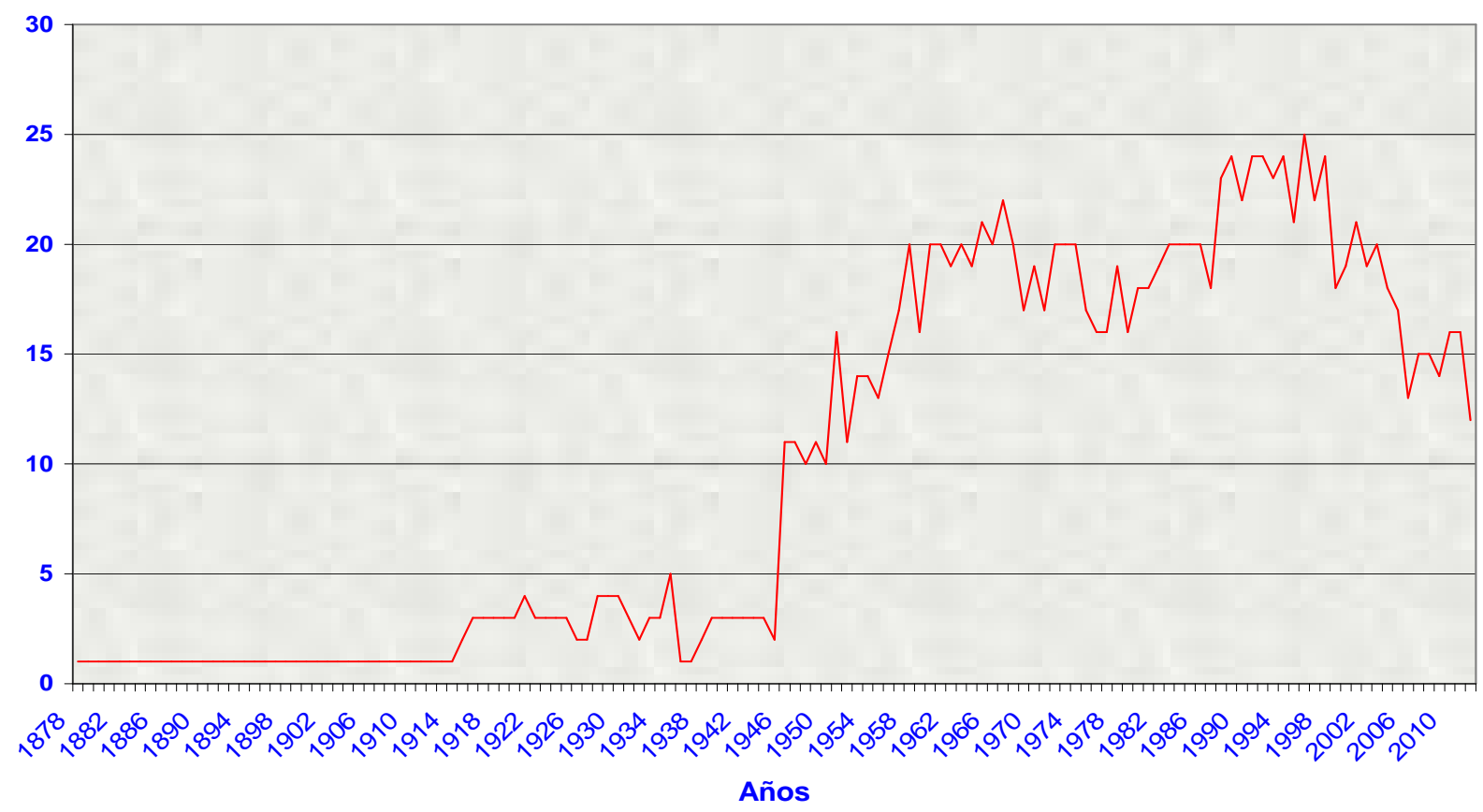

La gráfica 2 expone el histograma de duración temporal de las series de precipitación anual estudiadas.

Gráfica 2: Histograma de duración series de precipitación anual:

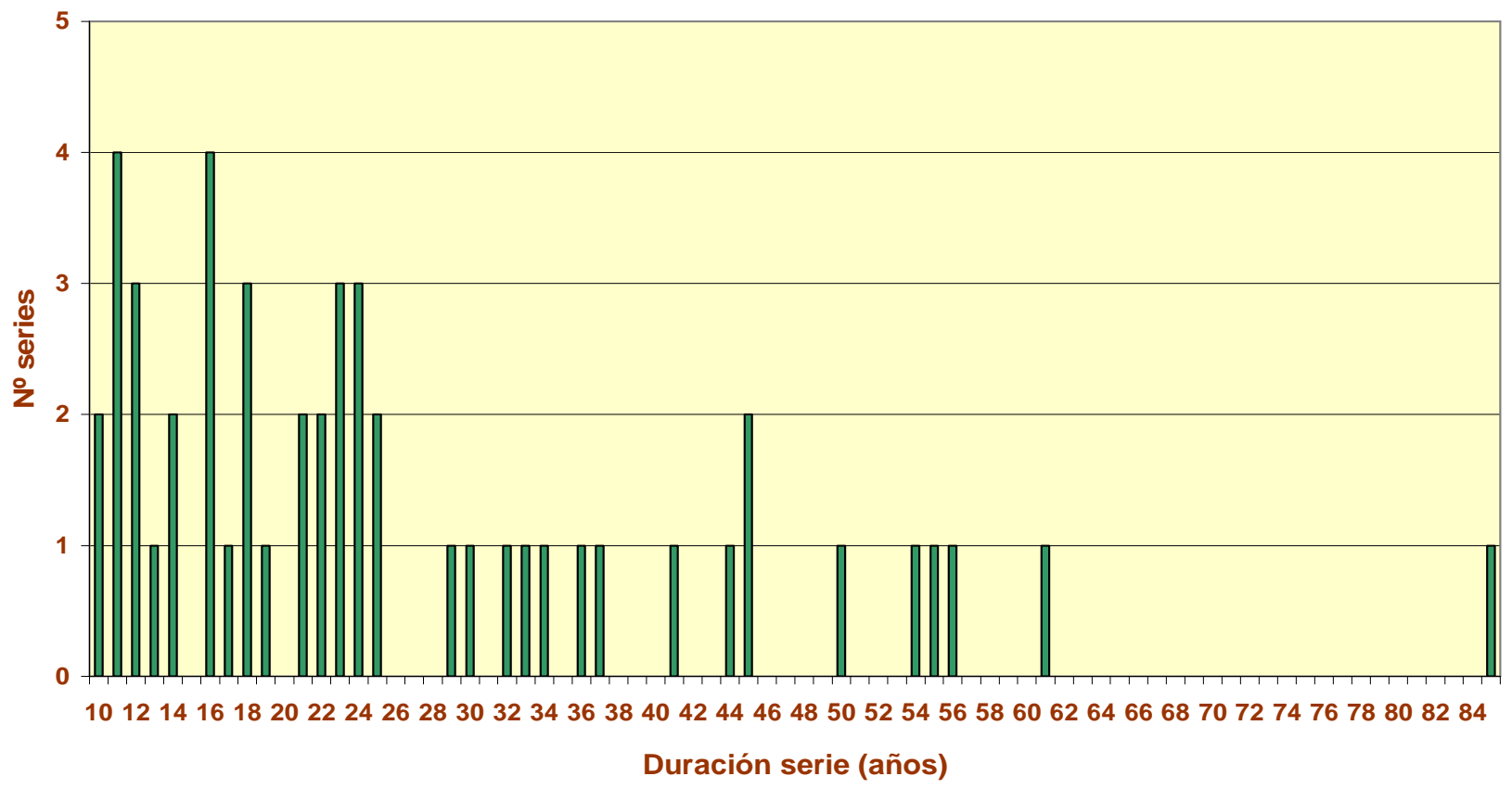


MAM.

La gráfica 3 representa la evolución temporal del número de series de precipitación

Gráfica 3: № series de precipitación Marzo-Abril-Mayo

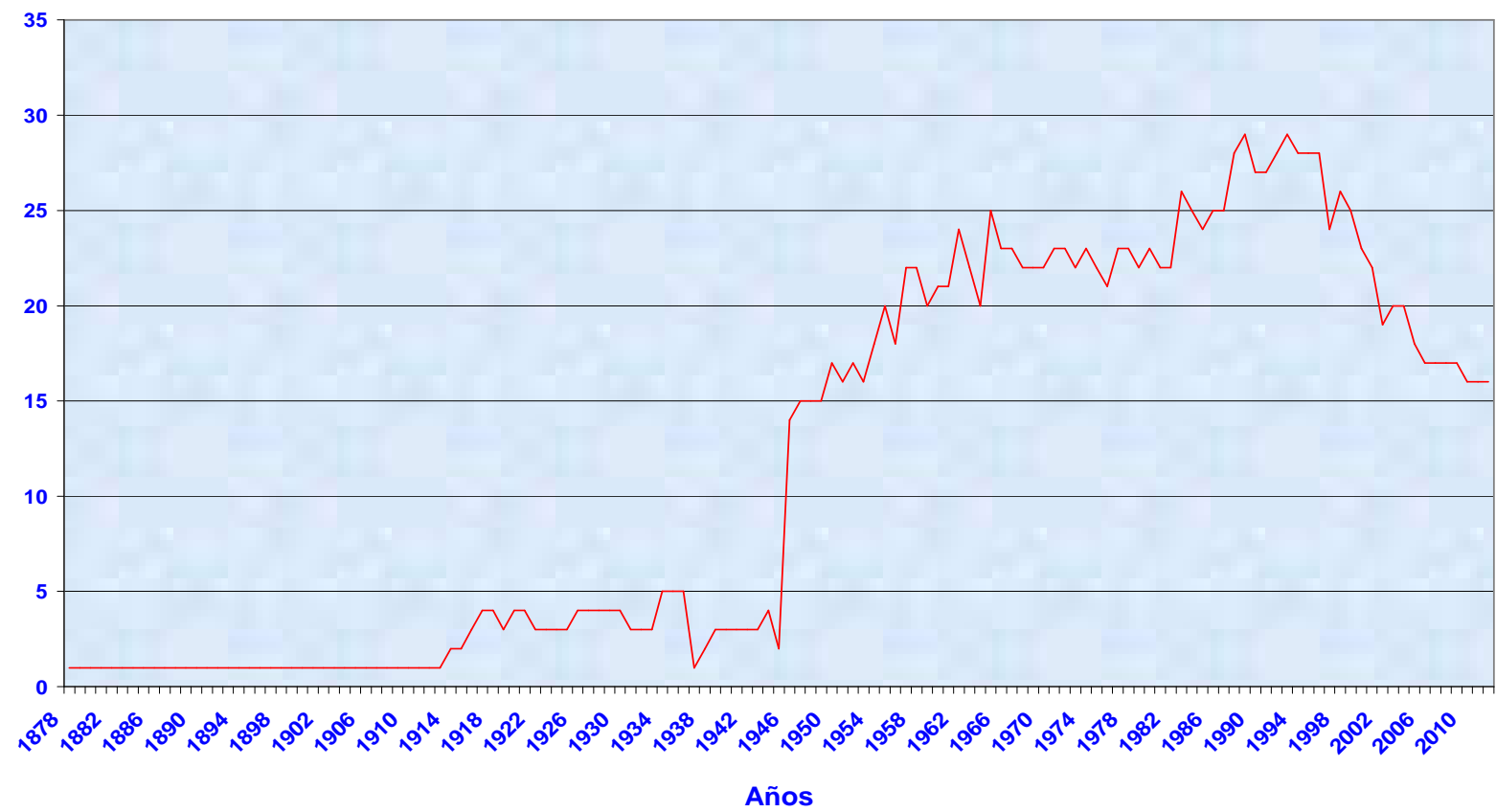

Y la gráfica 4 el histograma de duración temporal de las series de precipitación MAM.

Gráfica 4: Histograma de duración series de precipitación Marzo-Abril-Mayo:

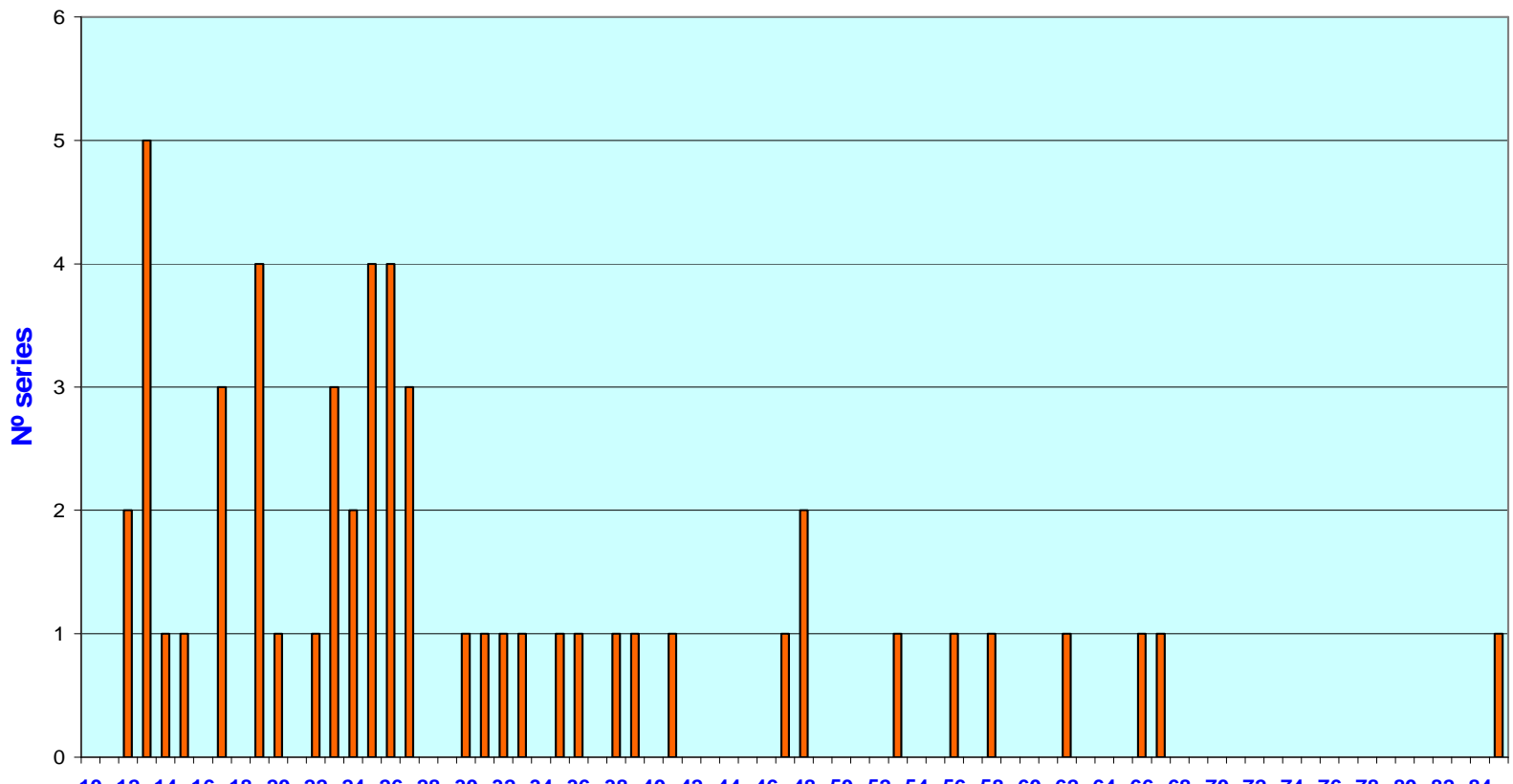

Duración serie (años) 
La gráfica 5 representa la evolución temporal del número de series analizadas en el periodo AMJ.

Gráfica 5: No series de precipitación Abril-Mayo- Junio:

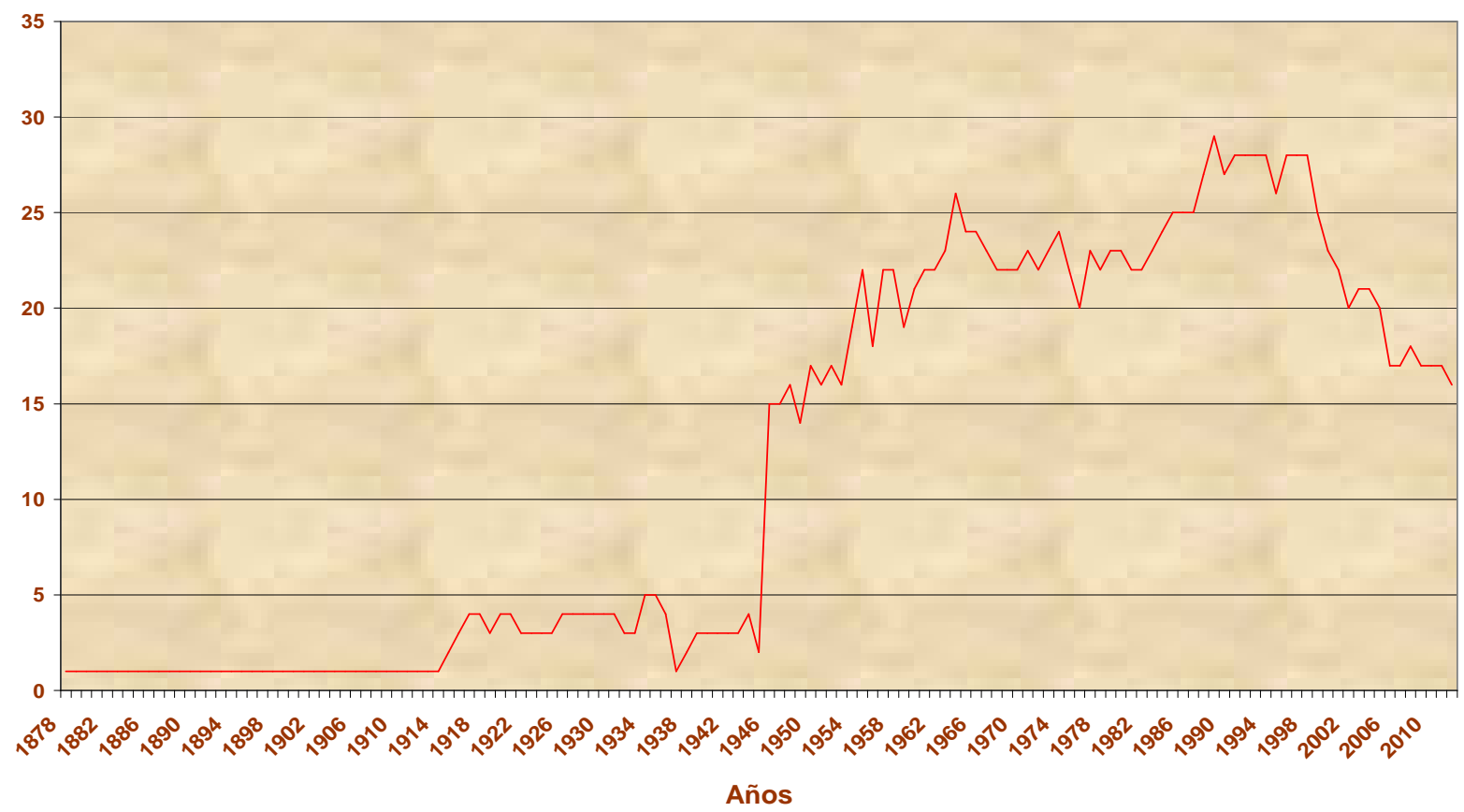

Y la gráfica 6 el histograma en el periodo AMJ:

Gráfica 6: Histograma de duración series de precipitación Abril-Mayo- Junio:

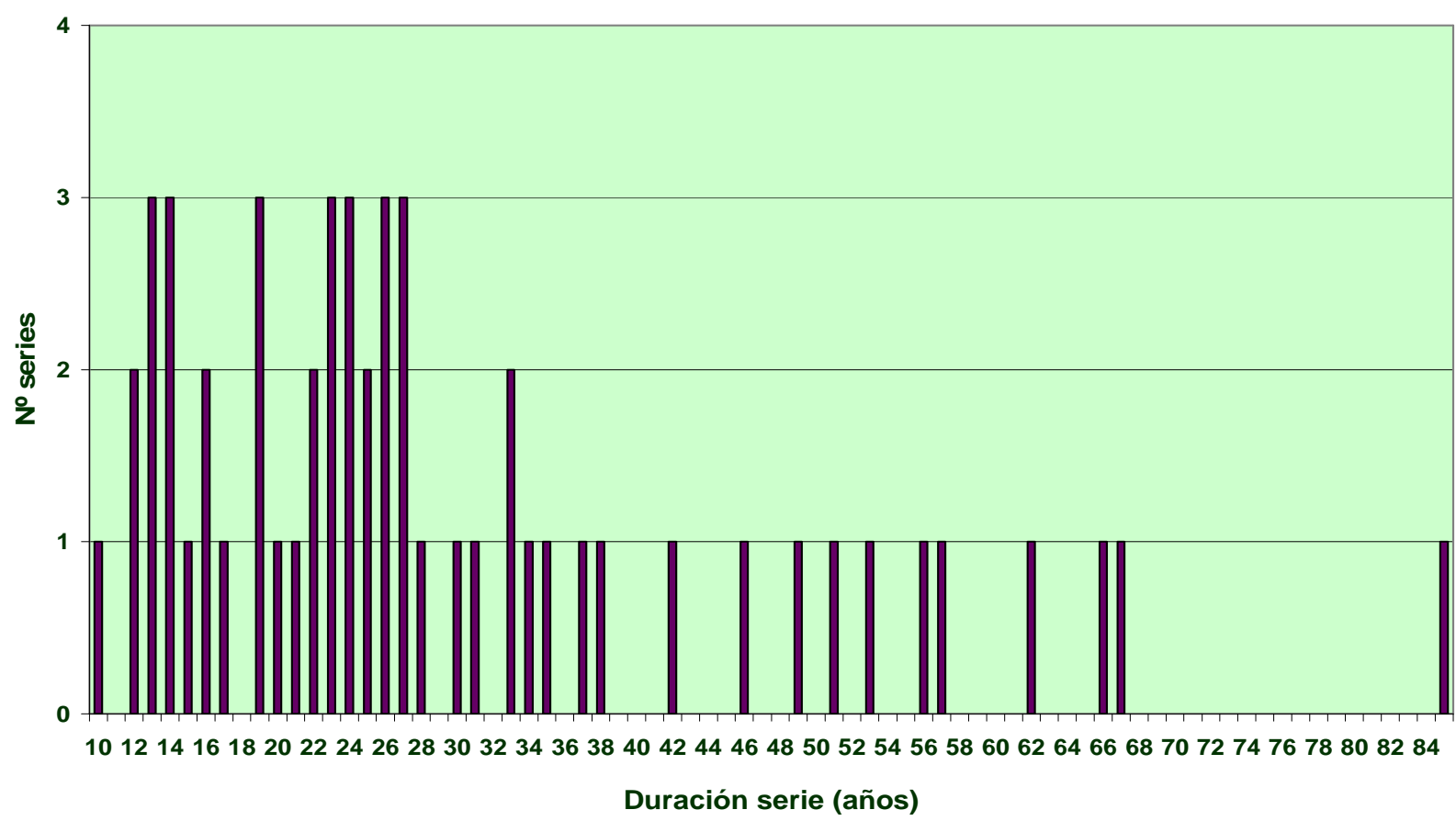




\section{3.- Método}

Para su análisis, se emplean dos tests de homogeneidad absoluta: el test de las rachas de Thom y el test de Tendencia de Mann- Kendall.

Las series que cumplan la homogeneidad según los tests indican cierto factor de calidad, superior al de aquellas series no homogéneas de acuerdo a los dos tests.

En primer lugar se aplica el test de Thom a periodos de 10, 20, 30, 40, 50, 60 y 80 años y después, el test de Mann-Kendall.

Cuando se detecta ruptura en la serie de datos, se vuelven a analizar cada uno de los periodos con los tests de Thom y de Mann Kendall.

Siguiendo las obras "Homogeneidad y variabilidad de los registros históricos de precipitación de España." Monografía Técnica A-143 del INM y "Climatología de Extremadura".Publicación A-153 del INM, se describen en los puntos 3.1. el test de las rachas y en el punto 3.2. el test de Mann-Kendall.

\section{1.- Test de las rachas de Thom:}

El estadístico del test es el número de secuencias o grupos de elementos consecutivos de la serie que están por encima o por debajo de la mediana.

En la tabla I se representan en función del número de datos de la serie los valores límite que determinan el dominio de aceptación del test.

Tabla I: Valores críticos test rachas.

\begin{tabular}{|c|c|c|c|c|c|c|c|}
\hline \multicolumn{7}{|c|}{ Test de las rachas de Thom } \\
\hline \multicolumn{7}{|c|}{ Valores críticos. Nivel de confianza del 95\% } \\
\hline $\mathrm{N}^{\circ}$ de datos & 10 & 20 & 30 & 40 & 50 & 60 & 80 \\
\hline $\mathrm{N}^{\circ}$ mínimo de rachas & 2 & 6 & 10 & 14 & 18 & 22 & 31 \\
\hline $\begin{array}{c}\mathrm{N}^{\circ} \text { máximo de } \\
\text { rachas }\end{array}$ & 6 & 15 & 21 & 27 & 33 & 39 & 50 \\
\hline
\end{tabular}

Los valores que aparecen en la tabla son los correspondientes a una serie aleatoria, en la que el número de rachas es menor que el umbral inferior con una probabilidad del $2,5 \% \mathrm{y}$ mayor que el umbral superior con una probabilidad del $2,5 \%$, por lo que si el valor del estadístico está comprendido entre los dos límites del test, se concluye que la serie es homogénea con un nivel de significación del $5 \%$.

En lo sucesivo y salvo que se especifique lo contrario, cuando se indique una inhomogeneidad según el test de Thom en un año, se refiere al análisis en el periodo de 10 años posteriores contados desde el año de inicio. Las inhomogeneidades a 20, 30, 40 y 50 años resultan muy útiles para detectar rupturas en la serie. 


\section{2.- Test de tendencia de Mann - Kendall:}

Este test estudia la homogeneidad desde el punto de vista de la existencia de tendencia lineal, creciente o decreciente, en las series.

El estadístico del test se define por $\mathrm{t}=\sum_{i} n_{i}$

donde $\mathrm{n}_{\mathrm{i}}$ es el número de elementos de las serie $X_{j}$ que preceden al elemento $X_{i}(i>j)$ de tal forma que $X_{i}>X_{j}$.

En una serie aleatoria simple la distribución del estadístico es t es asintóticamente normal. Una vez calculado el valor de t y éste estandarizado se calcula la probabilidad con ayuda de la ley normal. La hipótesis de aleatoriedad se conserva para un nivel del 5\% cuando el valor absoluto del estadístico es menor que 1,960.

\section{4.- Resultados}

\section{1.- Rupturas detectadas en las series de precipitación:}

Se han detectado rupturas en las series debidas a cambios de emplazamiento, de observador, del entorno... Las tablas 1 a 3 reflejan las rupturas detectadas aplicando los test de rachas (Thom) y de Mann-Kendall a la precipitación media anual, MAM y AMJ.

En cada tabla se indican el nombre, indicativo e intervalo de años con registros y se identifican para cada serie los periodos en que es homogénea aplicando los tests de Thom y de Mann-Kendall.

Tabla 1 Rupturas detectadas en la precipitación anual:

\begin{tabular}{|c|c|c|c|c|}
\hline Nombre & Indicativo & Periodo años & $\begin{array}{l}\text { Periodos homogéneos } \\
\text { (Thom) }\end{array}$ & $\begin{array}{l}\text { Periodos homogéneos } \\
\text { (Mann Kendall) }\end{array}$ \\
\hline OMA Fuenterrabía & 1014 & $1957-2012$ & $\begin{array}{l}1957-1968 \\
1969-2012\end{array}$ & $\begin{array}{l}1957-2012 \\
\text { (no detecta) }\end{array}$ \\
\hline Rentería & 1018 & 1951-1983 & $\begin{array}{l}1951-1972 \\
1973-1983\end{array}$ & $\begin{array}{c}1951-1983 \\
\text { (no detecta) }\end{array}$ \\
\hline Presa Añarbe & $1021 \mathrm{E}$ & $1972-2012$ & $\begin{array}{l}1972-1988 \\
1989-2012\end{array}$ & $\begin{array}{l}1972-1988 \\
1989-2012\end{array}$ \\
\hline Ategorrieta & 1024 & $1960-2012$ & $\begin{array}{l}\text { 1960-2012 (no detecta, } \\
\text { si bien hay dudas) }\end{array}$ & $\begin{array}{l}1960-1985 \\
1987-2012\end{array}$ \\
\hline $\begin{array}{l}\text { San Sebastián } \\
\text { (Igueldo) }\end{array}$ & $1024 \mathrm{E}$ & $1916-2012$ & $1928-2012$ & $\begin{array}{c}1928-2012 \\
\text { (no detecta) }\end{array}$ \\
\hline $\begin{array}{l}\text { San Sebastián } \\
\text { (Observatorio) }\end{array}$ & $1024 \mathrm{~F}$ & 1901-1935 & $\begin{array}{l}1901-1913 \\
1918-1935\end{array}$ & $\begin{array}{l}1901-1917 \\
1918-1935\end{array}$ \\
\hline Lareo & $1026 \mathrm{~B}$ & $1990-2012$ & $1990-2001$ & $1990-2012$ (no detecta) \\
\hline Urnieta & $1033 \mathrm{U}$ & $1986-2012$ & $1998-2008$ & 1986-2012 (no detecta) \\
\hline Legazpia & 1037 & 1946-2011 & $\begin{array}{l}\text { 1946-2011 } \\
\text { (no detecta) }\end{array}$ & $\begin{array}{l}1946-1980 \\
1981-2011\end{array}$ \\
\hline Aramayona & 1044D & $1986-2012$ & $1996-2012$ & 1986-2012 (no detecta) \\
\hline
\end{tabular}


Tabla 2 Rupturas detectadas en la precipitación MAM:

\begin{tabular}{|c|c|c|c|c|}
\hline Nombre & Indicativo & Periodo años & $\begin{array}{l}\text { Periodos homogéneos } \\
\text { (Thom) }\end{array}$ & $\begin{array}{l}\text { Periodos homogéneos } \\
\text { (Mann Kendall) }\end{array}$ \\
\hline Irún Fitosanitaria & 1013 & $\begin{array}{c}1914-1930, \\
1936 \text { y } 1938-65\end{array}$ & $\begin{array}{l}1914-1927 \\
1938-1965\end{array}$ & $\begin{array}{l}1914-1930 \\
1938-1965\end{array}$ \\
\hline OMA Fuenterrabía & 1014 & $1957-2012$ & $\begin{array}{l}1957-1967 \\
1969-2012\end{array}$ & $\begin{array}{c}1957-2012 \\
\text { (no detecta) }\end{array}$ \\
\hline Rentería & 1018 & 1950-1984 & $\begin{array}{l}1954-1972 \\
1973-1984\end{array}$ & $\begin{array}{l}1950-1969 \\
1973-1984\end{array}$ \\
\hline Presa Añarbe & $1021 \mathrm{E}$ & $1972-2012$ & $\begin{array}{l}\text { 1972-2012 } \\
\text { (no detecta) }\end{array}$ & $\begin{array}{l}1972-1988 \\
1989-2012\end{array}$ \\
\hline Ategorrieta & 1024 & $1960-2012$ & $\begin{array}{l}\text { 1960-2012 } \\
\text { (no detecta) }\end{array}$ & $\begin{array}{l}1960-1985 \\
1986-2012\end{array}$ \\
\hline $\begin{array}{l}\text { San Sebastián } \\
\text { (Igueldo) }\end{array}$ & $1024 \mathrm{E}$ & 1916-2012 & $\begin{array}{l}\text { 1928-2012 } \\
\text { (no detecta) }\end{array}$ & $1928-2012$ \\
\hline $\begin{array}{c}\text { San Sebastián } \\
\text { (Observatorio) }\end{array}$ & $1024 \mathrm{~F}$ & 1901-1936 & $\begin{array}{l}1901-1936 \\
\text { (no detecta) }\end{array}$ & $\begin{array}{l}1901-1917 \\
1918-1936\end{array}$ \\
\hline Lareo & $1026 \mathrm{~B}$ & 1989-2012 & $\begin{array}{l}1989-2001 \\
2002-2012\end{array}$ & $\begin{array}{c}1989-2012 \\
\text { (no detecta) }\end{array}$ \\
\hline Elduayen & 1031 & $1946-2012$ & $\begin{array}{l}1947-1957 \\
1958-1988 \\
1989-2012\end{array}$ & $\begin{array}{l}1946-1958 \\
1959-1988 \\
1993-2012\end{array}$ \\
\hline Urnieta & $1033 \mathrm{U}$ & 1986-2012 & $\begin{array}{l}1986-2012 \\
\text { (no detecta) }\end{array}$ & $\begin{array}{l}1986-1995 \\
1998-2012\end{array}$ \\
\hline Legazpia & 1037 & 1946-2012 & $\begin{array}{l}1946-1980 \\
1981-2012\end{array}$ & $\begin{array}{c}1946-2012 \\
\text { (no detecta) }\end{array}$ \\
\hline Escoriaza & 1044 & $\begin{array}{c}1917-1920 \mathrm{y} \\
1955-1973\end{array}$ & $\begin{array}{c}1917-1920 \text { y } 1955- \\
1973 \text { (no detecta) }\end{array}$ & $1955-1973$ \\
\hline Aramayona & 1044D & 1986-2012 & $\begin{array}{l}\text { 1986-2012 } \\
\text { (no detecta) }\end{array}$ & $\begin{array}{l}1977-1994 \\
1995-2012\end{array}$ \\
\hline Aránzazu & 1046 & $1921-2001$ & $\begin{array}{l}1934-1968 \\
1969-1990\end{array}$ & $\begin{array}{c}\text { 1921-2001 } \\
\text { (no detecta) }\end{array}$ \\
\hline Elgueta & 10490 & $1985-2012$ & 1985-2004 & $\begin{array}{l}\text { 1985-2012 } \\
\text { (no detecta) }\end{array}$ \\
\hline Eibar & 1050 & 1951-1991 & $\begin{array}{l}1946-1997 \\
\text { (no detecta) }\end{array}$ & $\begin{array}{l}1946-1964 \\
1965-1997\end{array}$ \\
\hline
\end{tabular}


Tabla 3 Rupturas detectadas en la precipitación AMJ:

\begin{tabular}{|c|c|c|c|c|}
\hline Nombre & Indicativo & Periodo años & $\begin{array}{c}\text { Periodos homogéneos } \\
\text { (Thom) }\end{array}$ & $\begin{array}{l}\text { Periodos homogéneos } \\
\text { (Mann Kendall) }\end{array}$ \\
\hline OMA Fuenterrabía & 1014 & $1957-2012$ & $\begin{array}{l}1957-1968 \\
1969-2012\end{array}$ & $\begin{array}{c}1957-2012 \\
\text { (no detecta) }\end{array}$ \\
\hline Presa Añarbe & $1021 \mathrm{E}$ & 1971-2012 & $\begin{array}{l}1971-1988 \\
1989-2012\end{array}$ & $\begin{array}{c}1971-2012 \\
\text { (no detecta) }\end{array}$ \\
\hline Ategorrieta & 1024 & $1960-2012$ & $\begin{array}{l}1961-1985 \\
1993-2012\end{array}$ & $\begin{array}{l}1960-1985 \\
1986-2012\end{array}$ \\
\hline $\begin{array}{l}\text { San Sebastián } \\
\text { (Igueldo) }\end{array}$ & $1024 \mathrm{E}$ & 1916-2012 & $1928-2012$ & $\begin{array}{c}1928-2012 \\
\text { (no detecta) }\end{array}$ \\
\hline $\begin{array}{c}\text { San Sebastián } \\
\text { (Observatorio) }\end{array}$ & $1024 \mathrm{~F}$ & 1901-1935 & $\begin{array}{l}1901-1935 \\
\text { (no detecta) }\end{array}$ & $\begin{array}{l}1901-1917 \\
1918-1935\end{array}$ \\
\hline Elduayen & 1031 & $1946-2012$ & $\begin{array}{l}1946-1958 \\
1959-1988 \\
1989-2012\end{array}$ & $\begin{array}{l}1946-1957 \\
1959-1988 \\
1992-2012\end{array}$ \\
\hline Legazpia & 1037 & 1946-2012 & $\begin{array}{l}1946-1977 \\
1981-2009\end{array}$ & $\begin{array}{l}\text { 1946-2012 } \\
\text { (no detecta) }\end{array}$ \\
\hline Aramayona & 1044D & 1986-2012 & $\begin{array}{l}1977-1994 \\
1995-2010\end{array}$ & $\begin{array}{l}1978-1994 \\
1996-2012\end{array}$ \\
\hline $\begin{array}{l}\text { Arechavaleta- } \\
\text { Urkulu }\end{array}$ & 1048 & $1979-2012$ & $1987-2011$ & $\begin{array}{c}\text { 1979-2012 } \\
\text { (no detecta) }\end{array}$ \\
\hline Eibar & 1050 & 1946-1997 & $\begin{array}{l}1946-1964 \\
1965-1997\end{array}$ & $\begin{array}{c}\text { 1946-1997 } \\
\text { (no detecta) }\end{array}$ \\
\hline $\begin{array}{c}\text { Elgoibar - Santa } \\
\text { Clara }\end{array}$ & $1050 \mathrm{~L}$ & $1987-2012$ & $\begin{array}{c}1987-2012 \\
\text { (no detecta) }\end{array}$ & $1987-2008$ \\
\hline Otzaurte & 9268 & $1944-1974$ & $\begin{array}{l}1946-1957 \\
1958-1972\end{array}$ & $\begin{array}{c}1946-1972 \\
\text { (no detecta) }\end{array}$ \\
\hline
\end{tabular}

Tras una labor de investigación de campo y bibliográfica, se aportan los resultados obtenidos en los comentarios siguientes:

1.- 1013 Irún: De 1913 a 1932 las medidas se realizan en las escuelas Viteri de Irún.

Desde mayo de 1935, la serie prosigue en el emplazamiento "Irún Fitosanitaria", con un periodo sin datos desde agosto de 1936 a agosto de 1937 inclusive y un cambio de colaborador en agosto de 1937, siendo continuas desde entonces las medidas de precipitación y sin lagunas en primavera.

Test rachas MAM: Detecta cambio emplazamiento en 1935 y de colaborador en 1937.

Test Mann-Kendall MAM: Detecta cambio de colaborador en 1937. 
Mann-Kendall aplicado al periodo MAM de la serie conjunta (1914 a 1965) revela una tendencia negativa de 1944 a 1964.

Al analizar Mann-Kendall el periodo MAM de 1938 a 1965 no se revelan tendencias; Mann Kendall en AMJ en el intervalo 1938-1965 sí detecta una tendencia negativa en 1948 y 1949, correspondientes a un periodo de sequía climatológica.

2.- 1014 Fuenterrabía: Hubo un cambio de emplazamiento del jardín meteorológico de la OMA de Fuenterrabía al construirse la nueva terminal de pasajeros, inaugurada en 1969.

Test rachas en todos los periodos: Aflora un cambio de emplazamiento a finales de 1968.

3.- 1018 Rentería: Los tests de rachas anual y MAM detectan una ruptura de la serie a finales de 1972.

Test Mann-Kendall MAM: Muestran una discontinuidad en 1972.

Al aplicar Mann-Kendall al periodo MAM de la serie conjunta (1950 a 1984) se revela una tendencia positiva de 1970 a 1984, la cuál sólo se manifiesta en esta serie; MannKendall MAM aplicado a los periodos 1951-1972 y 1973-1984, sólo detecta tendencia positiva de 1970 a 1972.

4.- 1021E Añarbe: Los tests de las rachas en los periodos anual y AMJ indican ruptura en 1988. Consideradas 2 series (1972-1988) y (1989-2012), la homogeneidad de las 2 se incrementa hasta rozar el $100 \%$ en la precipitación anual y alcanzar el 100 en la precipitación AMJ.

Aplicando a todo el periodo de datos (desde abril de 1971 a diciembre de 2012):

a) El test de rachas anual indica que la serie es homogénea de 1974 a 2004.

b) El test de rachas AMJ muestra que la serie es homogénea de 1971 a 2003.

Aplicando a los 2 periodos de datos (desde 1972 en anual y desde 1971 en AMJ):

1.- Test rachas anual: Las series 1972-1988 y 1989 -2012 son homogéneas al 88 y al $100 \%$, respectivamente.

2.- Test rachas AMJ: Las series 1972-1988 y 1989 -2012 son homogéneas al 100\%

Los tests de Mann-Kendall anual y MAM aplicados a todo el intervalo de medidas (1972 a 2012) indican ruptura en 1988: Mann-Kendall anual indica una tendencia negativa de precipitación desde 1989 a 2012, sólo detectada en 1021E; Mann-Kendall MAM la muestra de 1996 a 2012. Ambas tendencias no son congruentes con lo observado en el resto de series analizadas.

Considerar una ruptura de la serie a finales de 1988 - comienzos de 1989 elimina estas tendencias. El test de Mann-Kendall es útil para señalar donde se produce la ruptura. 
5.- 1024 Ategorrieta: En los archivos de SS.BB ${ }^{1}$. de la Delegación Territorial figura un cambio de colaborador en 1985, de padre a hijo. El colaborador, en una entrevista personal, informó que comienza las medidas en noviembre de 1981 al enfermar su padre. De 1981 a 1985, las medidas las realizan padre e hijo.

Test Rachas AMJ: Detecta ruptura de la serie en 1985.

El test de rachas anual no la manifiesta claramente, si bien hay dudas de la homogeneidad de la serie anual de 1960 a 2012.

Test Mann-Kendall anual: Aplicado desde 1960 a 2012, muestra tendencia positiva en 1980, 1982, 1984, 1986, 1987, 1994 y de 1996 a 2012. Consideradas 2 series: 1972-1985 y 1986-2012, desaparece la tendencia positiva posterior a 1986.

Test Mann-Kendall MAM: Aplicado desde 1960 a 2012, indica tendencia positiva en 1975, 1976, 1978 a 1981 y 1983 a 1995, no detectado en ninguna otra serie. Considerar 2 series elimina el incremento "ficticio" posterior a 1985.

Test Mann-Kendall AMJ: Aplicado desde 1960 a 2012, detecta tendencia positiva de 1990 a 1995 y 1997 a 2002, la cuál desaparece al considerar ruptura de la serie en 1985.

6.- 1024E Igueldo: Hay evidencia documental de:

6.1.- Comienzo de las observaciones en el Observatorio de Igueldo en diciembre de 1927 (Doporto La lluvia en Igueldo durante el año meteorológico 1928 Diciembre 1927Noviembre 1928).

6.2.- Los datos registrados en 1916, 1917 y 1918 corresponden al tejado del domicilio de Orcolaga, emplazamiento en la ciudad de San Sebastián a una altitud inferior al monte Igueldo.

Test rachas anual y AMJ indican cambio de emplazamiento en 1928.

Test Mann-Kendall MAM detecta cambio emplazamiento en 1928.

7.- 1024F San Sebastián Observatorio: Se cambió de altitud el pluviómetro, bajándolo un piso - 14 m - en febrero y marzo de 1918 (Doporto Cincuenta y cinco años de observaciones pluviométricas en San Sebastián).

El test de rachas anual percibe el cambio del pluviómetro.

Aplicando a todo el intervalo de datos (1901 a 1935), Mann-Kendall anual muestra tendencia positiva de 1927 a 1935, Mann-Kendall MAM tendencia negativa en 1904 y positiva de 1923 a 1936, Mann-Kendall AMJ tendencia positiva en 1927 y de 1931 a 1935.

Estas tres tendencias no son detectadas en ninguna otra serie de las estudiadas, según refleja la tabla 46.

\footnotetext{
${ }^{1}$ SS.BB.: Sistemas Básicos
} 
Considerada una ruptura de la serie en 1918, se eliminan estas "falsas" tendencias de la precipitación posteriores a 1918.

\section{8.- 1026B Lareo:}

En 2005, 2006 y 2012 no hay datos completos de precipitación anual. En marzo de 2013 finaliza la serie.

8.1.- El test de rachas anual muestra 10 rachas en 21 años con datos.

8.2.- El test de rachas MAM indica 16 rachas en 23 años.

8.3.- Los tests de rachas anual y MAM detectan la ruptura de la serie en 2001.

8.4.- El test de Mann-Kendall no detecta ninguna tendencia ni ningún cambio de emplazamiento y/o de colaborador: al oscilar las precipitaciones en torno a su mediana, no hay tendencia y sí un número elevado de rachas.

9.- 9268 Otzaurte: El test de rachas AMJ:

9.1.- Señala ruptura de la serie de datos a finales de 1957 - comienzos de 1958.

9.2.- Indica que hay que descartar los datos de 1944, quizá debido a otra ruptura de la serie de datos por cambio de emplazamiento y/o de colaborador (sin datos de diciembre de 19944 a noviembre de 1945).

10.- 1031 Elduayen: Según los datos del Supervisor de SS.BB., el colaborador primigenio fallece en marzo de 1988 y le sustituye su mujer, hermana del actual colaborador, el cuál asume las medidas pluviométricas al fallecer su hermana.

Los tests de rachas MAM y AMJ señalan 3 periodos: 1946 a 1958 (lagunas en noviembre de 1955, junio de 1956 y octubre de 1957), 1959 a 1988 (concordante con el cambio de colaborador en 1988) y 1989 a 2012.

Test Mann-Kendall MAM aplicado a todo el intervalo (1946 a 2012): Indica una tendencia positiva de 1972 a 1983, en 1985, en 1986, en 1988 y de 1990 a 1994 . Una tendencia positiva de 23 años de la precipitación es absurda, comparando con los resultados obtenidos en el resto de series (tabla 50).

Considerando 3 intervalos, Test Mann-Kendall MAM señala tendencia positiva en 1979 y negativa en 1997, 2001 y 2003.

De acuerdo a la tabla 50, estos resultados sí son congruentes con los detectados en el resto de series analizadas.

11.- 1033U Urnieta: Según informes del Supervisor de SS.BB:

11.1.- El colaborador trasladó el pluviómetro unos 10 años antes de una visita realizada en 2007. Esta información fue corroborada “in situ" el 19 de febrero de 2013. 
11.2.- Cambio de pluviómetro en 1033 U entre abril de 2010 y julio de 2012.

11.3.- El test de rachas anual detecta los 2 cambios; el test de Mann-Kendall MAM aflora el cambio de 1997.

12.- 1037 Legazpia:

12.1.- Los tests de rachas MAM y AMJ detectan la ruptura a finales de 1980 comienzos de 1981.

12.2.- El test de Mann-Kendall anual aplicado a todo el periodo (1946 a 2012) muestra tendencia negativa de 1987 a 2008 y tendencia positiva en 1951 y 1952.

12.3.- Mann-Kendall anual muestra discontinuidad de la serie en 1980:

De 1946 a 1980 detecta tendencia positiva en 1951 y 1952, efecto tras sequía años 40 , congruente con los resultados de la tabla 49

De 1981 a 2012 sin tendencia.

12.4.- El estudio de las precipitaciones de 1037 es un ejemplo de la concordancia temporal en el análisis de los dos tests en los 2 periodos temporales (anual y primavera) para determinar rupturas.

13.- 1044 Escoriaza: Datos de 1917 a 1920 y de 1956 a 1976.

El test de Mann-Kendall MAM de las precipitaciones desde 1917 a 1976 produce tendencias no detectadas en el resto de series. Estas tendencias desaparecen al considerar que los datos de 1917 a 1920 se realizaron en un emplazamiento diferente respecto a los registros de 1956 a 1976.

\section{4.- 1044D Aramayona:}

14.1.- Evidencia en SS.BB. de "necesidad de cambio de pluviómetro" a finales de 1994. Sin datos de precipitación en diciembre de 1995.

14.2.- Los tests de rachas anual y AMJ señalan ruptura en 1995.

14.3.- Los tests de Mann-Kendall MAM y AMJ detectan ruptura de la serie en 1995: al aplicarlos a todo el periodo de datos (1977 a 2012) muestran tendencias que no aparecen en las restantes series analizadas.

14.4.- Considerando una discontinuidad en las precipitaciones en 1995, MannKendall MAM no muestra tendencia y Mann-Kendall AMJ indica tendencia positiva en 1998.

15.- 1046 Aránzazu: El test de rachas MAM detecta rupturas en 1934 y en 1969; los datos de 1921 se midieron en otro emplazamiento o con otro colaborador diferente a los de 1934-5 (Doporto "Resumen de las observaciones efectuadas en la red termo pluviométrica durante el año 1934."). 
El test de rachas no detecta ruptura de la serie entre 1935 y 1946.

16.- 1048 Arechavaleta:

16.1.- Hacia Mayo, Junio o Julio de 1986, según información suministrada telefónicamente por el colaborador de 1048 al Supervisor de SS.BB., se cambian de emplazamiento la garita y el pluviómetro por la entrada en funcionamiento de la nueva depuradora. El nuevo emplazamiento está más expuesto a las precipitaciones.

16.2.- El test de rachas AMJ indica cambio de emplazamiento en 1986.

16.3.- En 1048 los datos de precipitación media de 1992, 1991, 1990, 1988 y 1987 son superiores a los de 1980 y 1979, a diferencia de los registros de precipitación del resto de Guipúzcoa, los cuáles son efemérides en 1979, lo cuál corrobora el cambio de emplazamiento de 1048.

17.- 1049O Elgueta: Según los datos de SS.BB., se registra un cambio de colaborador en septiembre de 2004, sustituyendo al que realizaba las medidas desde el comienzo de la serie.

El test de rachas MAM detecta ruptura en 2004.

18.- 1050 Eibar: Test rachas AMJ indica ruptura en 1964.

Test Mann-Kendall MAM aplicado a toda la serie (1946 a 1997) muestra tendencia positiva de 1971 a 1996, lo cuál es absurdo. Considerando 2 periodos, Mann-Kendall MAM no detecta tendencia.

\section{9.- 1050L Elgoibar:}

19.1.- Evidencia de cambio de emplazamiento del pluviómetro a uno más expuesto a la precipitación el 11 de septiembre de 2008 (información suministrada por el Supervisor de SS.BB.)

19.2.- El test de Mann-Kendall AMJ sugiere cambio de emplazamiento en 2008.

El análisis estacional, con una mayor resolución temporal, es más preciso que el anual, permitiendo detectar cambios de emplazamiento, inadvertidos para el análisis anual; quizá sea debido a la existencia de más datos de precipitación en los periodos MAM y AMJ que en el anual o quizá a que la precipitación en primavera muestre un comportamiento más "homogéneo".

Se observa una concordancia entre los resultados aplicando los 2 tests a los 3 periodos temporales. 


\section{2.- Evolución temporal de inhomogeneidades:}

\subsection{1.- Evolución temporal inhomogeneidades Test Thom:}

En las tablas siguientes $(4,10,23$ y 35$)$ se describen:

a) Los periodos de inhomogeneidades detectados.

b) Los indicativos de las series.

c) El periodo (anual, MAM o AMJ) en que se detecta la inhomogeneidad.

d) El origen de la inhomogeneidad:

Climatológico (debida a variaciones atmosféricas) o no climatológico (cambios de emplazamiento, de entorno, de colaborador, caída de calidad en últimos años de la serie...).

e) Se emplean signos de interrogación cuando se sospecha sobre la naturaleza de la inhomogeneidad -climatológica o no -, si bien las evidencias son escasas para clasificarla y un blanco cuando no hay certezas suficientes para discriminar si la inhomogeneidad es "climatológica" o no.

f) La última columna indica el \% de series en que se produce sobre el total de series analizadas en ese periodo de años - con un intervalo cuando se abarca un periodo de años-. Un número entre paréntesis indica el total de series analizadas, cuando éste es muy bajo.

\subsubsection{1.- Periodo de 1878 a 1940:}

Debido al bajo número de series con más de 10 años existentes anteriores a 1940, se estudian conjuntamente los resultados del test de Thom aplicados a la precipitación anual, MAM y AMJ.

Puntualmente se realizan comparativas con 1077C (Bilbao) entre 1905 y 1917, ya que sólo la serie 1024F cubre completamente ese intervalo.

En las gráficas 7 a 9 se representa la evolución temporal de las inhomogeneidades detectadas aplicando el test de las rachas a la precipitación anual, MAM y AMJ desde 1878 a 1940 . 
Gráfica 7: Evolución temporal de las inhomogeneidades test rachas de las series de precipitación anual de 1878 a 1940:

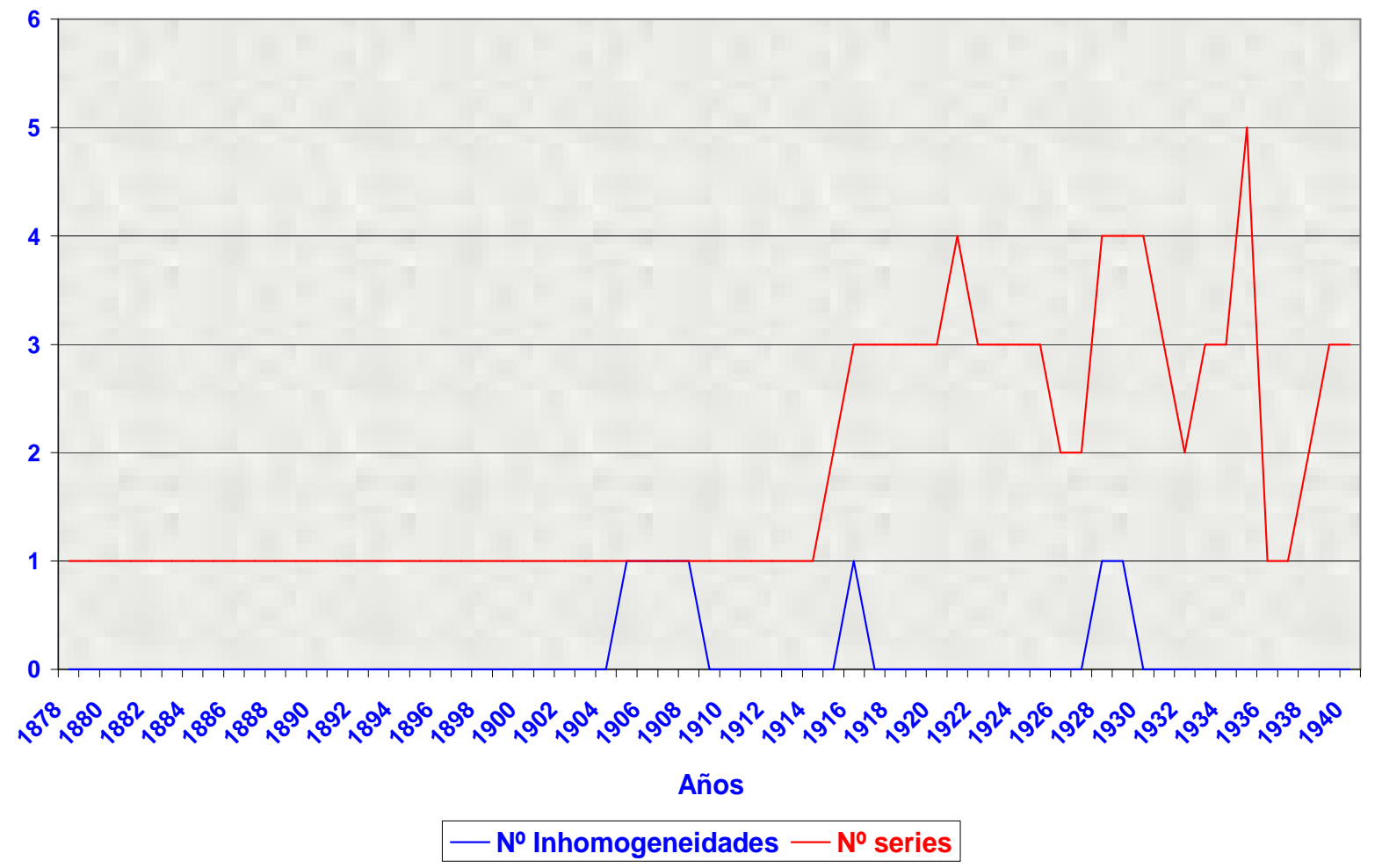

Gráfica 8: Evolución temporal de las inhomogeneidades test rachas de las series de precipitación MAM de 1878 a 1940:

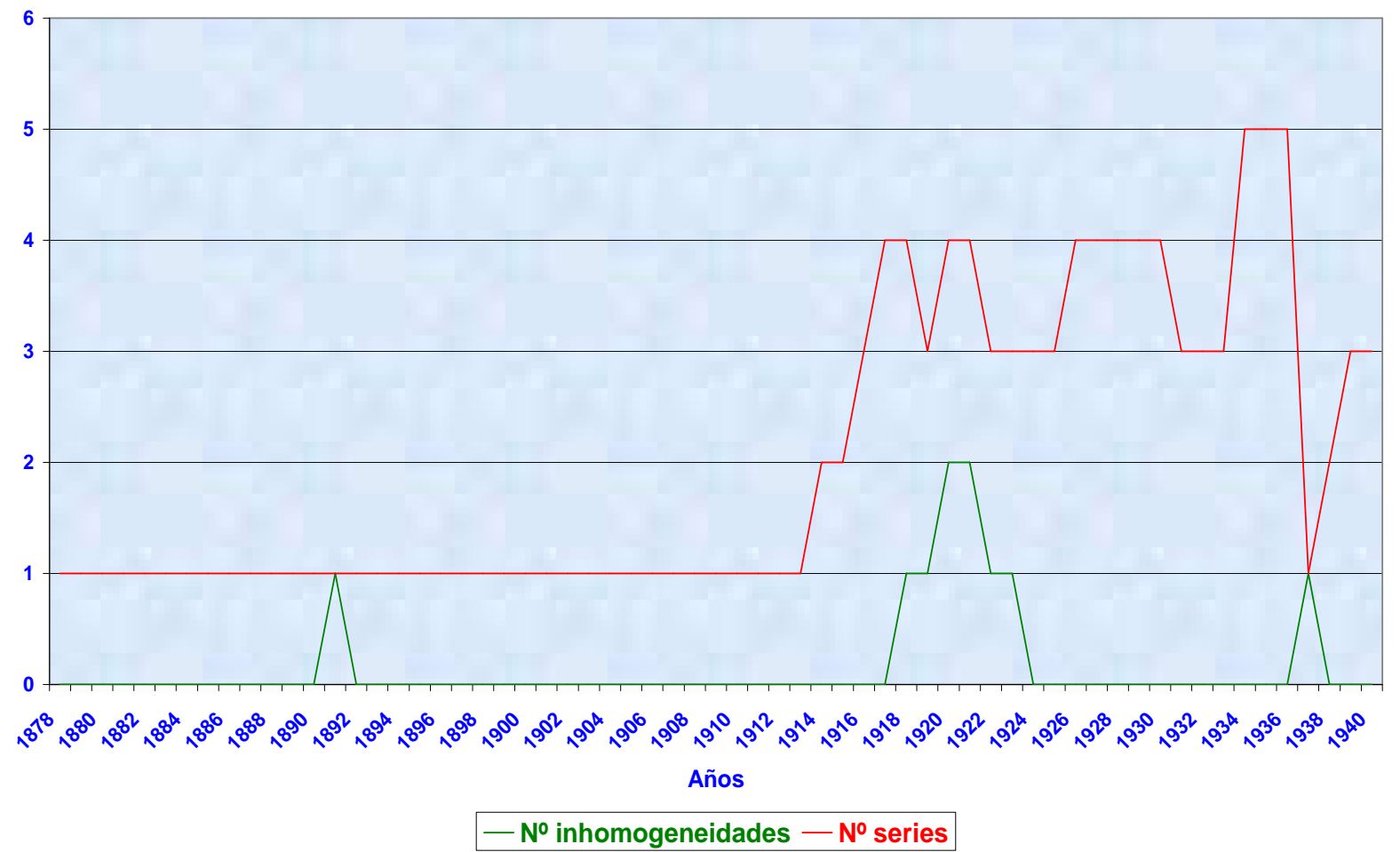


Gráfica 9: Evolución temporal de las inhomogeneidades test rachas de las series de precipitación AMJ de 1878 a 1940:

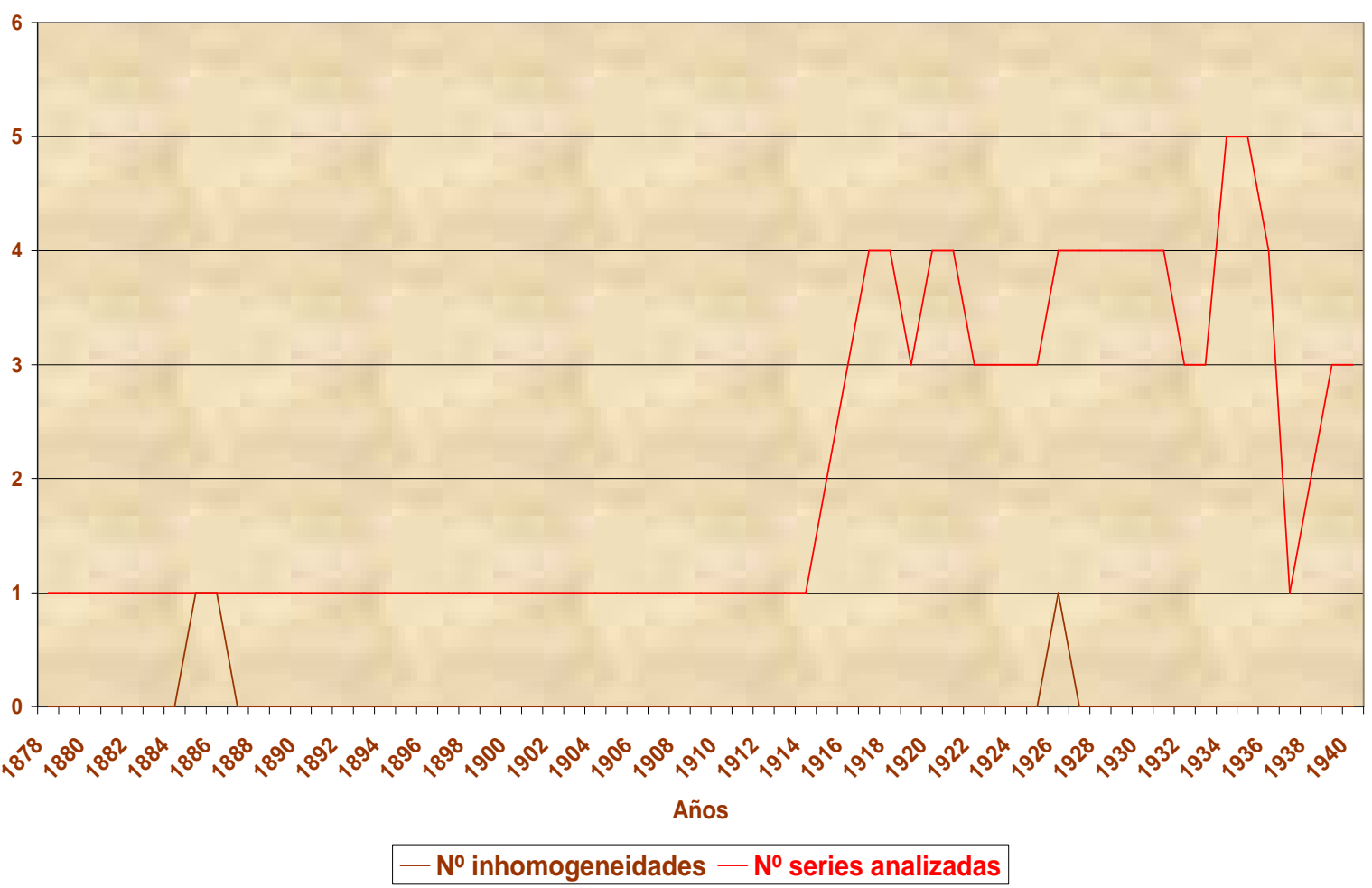

Tabla 4: Inhomogeneidades detectadas aplicando el test de rachas a las medidas de precipitación anual, MAM y AMJ desde 1878 a 1940:

\begin{tabular}{|c|c|c|c|c|}
\hline $\begin{array}{c}\text { Periodo } \\
\text { inhomogeneidad (Años) }\end{array}$ & Indicativos & $\begin{array}{c}\text { Detectado en } \\
\text { periodo }\end{array}$ & $\begin{array}{c}\text { Inhomogeneidad } \\
\text { "climatológica" }\end{array}$ & $\begin{array}{c}\text { \% series } \\
\text { sobre total }\end{array}$ \\
\hline $1885-1995$ & $1024 \mathrm{D}$ & AMJ & Sí & $100(1)$ \\
\hline $1891-1900$ & $1024 \mathrm{D}$ & MAM & Sí & $100(1)$ \\
\hline $1905-1917$ & $1024 \mathrm{~F}$ & Anual & Sí & $100(1)$ \\
\hline $1916-1925$ & 1013 & Anual & Sí & $25(3)$ \\
\hline $1918-1927$ & 1013 & MAM & Sí & $33(3)$ \\
\hline $1919-1928$ & $1024 \mathrm{~F}$ & MAM & Sí & $50(4)$ \\
\hline $1920-1930$ & $1013,1024 \mathrm{~F}$ & MAM & Sí & $33(3)$ \\
\hline $1922-1932$ & $1024 \mathrm{~F}$ & MAM & Sí & $25(4)$ \\
\hline $1926-1935$ & 1032 & AMJ & No & $25(4)$ \\
\hline $1928-1938$ & $1024 \mathrm{E}$ & Anual & &
\end{tabular}

\section{1.- Última década del s. XIX en 1024D (MAM y AMJ):}

1.1.- 1024D San Sebastián Instituto, con comienzo en 1878 y fin en 1900, es la única serie con más de 10 años de datos en Guipúzcoa del siglo XIX.

1.2.- Hay registros en prensa detallando los efectos de la sequía en esa época. 
1.3.- El test de Thom aplicado a 1024D sólo alerta de 3 inhomogeneidades en 22 años: 2 en AMJ y una en MAM.

Las tablas 5 a 9 reflejan:

a) Indicativo y nombre del emplazamiento.

b) Duración en años detallando los años sin datos sd.

c) Los años en que se registran máximos y mínimos de precipitaciones en el intervalo en que se detecta la inhomogeneidad, con el ordinal entre paréntesis referido al intervalo anual total de medidas de la serie.

d) La precipitación media mensual en el periodo de interés (anual, MAM o AMJ).

En lo sucesivo, al analizar las inhomogeneidades detectadas, se emplearán las series de precipitaciones teniendo en cuenta las rupturas detectadas en el apartado 4.1.

Tabla 5: Años con precipitaciones medias en AMJ máximas y mínimas:

\begin{tabular}{|c|c|c|c|c|c|}
\hline Indicativo & Duración serie & Año Máximo & $\begin{array}{c}\text { Precipitación } \\
\left(1 / \mathrm{m}^{2}\right)\end{array}$ & Año Mínimo & $\begin{array}{c}\text { Precipitación } \\
\left(1 / \mathrm{m}^{2}\right)\end{array}$ \\
\hline \multirow{3}{*}{$\begin{array}{c}\text { 1024D } \\
\text { San Sebastián }\end{array}$} & \multirow{3}{*}{$1878-1900$} & $1889\left(1^{\circ}\right)$ & 183,0 & $1892\left(1^{\circ}\right)$ & 53,7 \\
\cline { 3 - 5 } & & $1885\left(4^{\circ}\right)$ & 152,0 & $1893\left(3^{\circ}\right)$ & 75,0 \\
\cline { 3 - 5 } & $1888\left(6^{\circ}\right)$ & 124,0 & $1896\left(4^{\circ}\right)$ & 76,0 \\
\cline { 2 - 5 } & & & $1898\left(5^{\circ}\right)$ & 84,7 \\
\hline
\end{tabular}

De la tabla anterior, se observa que a un máximo pluviométrico en 1888 y en 1889 le siguen 4 años con precipitaciones muy escasas 1892, 1893, 1896 y 1898, siendo 4 de los 5 años más secos en 1024D en AMJ de 1878 a 1900.

Por tanto, se trata de una inhomogeneidad "climatológica" reflejo de la sequía de 1892, 1893, 1896 y 1898 en AMJ.

Tabla 5 bis: Años con precipitaciones medias en MAM máximas y mínimas:

\begin{tabular}{|c|c|c|c|c|c|}
\hline Indicativo & Duración serie & Año Máximo & $\begin{array}{c}\text { Precipitación } \\
\left(1 / \mathrm{m}^{2}\right)\end{array}$ & Año Mínimo & $\begin{array}{c}\text { Precipitación } \\
\left(1 / \mathrm{m}^{2}\right)\end{array}$ \\
\hline \multirow{3}{*}{$\begin{array}{c}\text { 1024D } \\
\text { San Sebastián }\end{array}$} & \multirow{3}{*}{$1878-1900$} & $1895\left(3^{\circ}\right)$ & 148,7 & $1893\left(1^{\circ}\right)$ & 58,0 \\
\cline { 3 - 6 } & & $1894\left(4^{\mathbf{o}}\right)$ & 135,0 & $1899\left(3^{\circ}\right)$ & 75,3 \\
\cline { 3 - 6 } & $1897\left(7^{\circ}\right)$ & 130,0 & $1892\left(4^{\circ}\right)$ & 84,3 \\
\cline { 3 - 6 } & & & $1898\left(6^{\circ}\right)$ & 95,7 \\
\hline
\end{tabular}

De la tabla 5 bis se observa un máximo pluviométrico en 1894 y en 1895 separando las sequías de 1892 - 1893 y las sequías de 1898 - 1899, 4 de los 6 años más secos en 1024D en MAM de 1878 a 1900.

Por tanto, se trata de una inhomogeneidad "climatológica” reflejo de la sequía de 1892, 1893, 1898 y 1899 en MAM. 
1.4.- Dada la excelente homogeneidad de los datos de la serie 1024D, se las considera a ambas como "inhomogeneidad climatológica", fruto de la sequía de la última década del siglo XIX.

2.- 1905 a 1917 en 1024F (Anual): 1077C presenta también inhomogeneidades en la precipitación anual de 1905 a 1916.

Tabla 6: Años con precipitaciones medias mensuales máximas y mínimas:

\begin{tabular}{|c|c|c|c|c|c|}
\hline Indicativo & Duración serie & Año Máximo & $\begin{array}{c}\text { Precipitación } \\
\left(1 / \mathrm{m}^{2}\right)\end{array}$ & Año Mínimo & $\begin{array}{c}\text { Precipitación } \\
\left(1 / \mathrm{m}^{2}\right)\end{array}$ \\
\hline $\begin{array}{c}\text { 1024F } \\
\text { San Sebastián }\end{array}$ & $1901-1917$ & $1910\left(1^{\circ}\right)$ & 132,5 & $1916\left(1^{\circ}\right)$ & 55,8 \\
\hline & & $1917\left(2^{\circ}\right)$ & 126,4 & $1912\left(2^{\circ}\right)$ & 74,5 \\
\hline \multirow{3}{*}{$\begin{array}{c}\text { 1077C } \\
\text { Bilbao }\end{array}$} & \multirow{2}{*}{$1885-1919$} & $1906\left(7^{\circ}\right)$ & 115,5 & $1912\left(2^{\circ}\right)$ & 71,6 \\
\cline { 3 - 6 } & & $1908\left(9^{\circ}\right)$ & 114,5 & $1916\left(7^{\circ}\right)$ & 82,5 \\
\cline { 2 - 5 } & $1910\left(10^{\circ}\right)$ & 114,3 & & \\
\hline
\end{tabular}

La precipitación media anual en San Sebastián es superior a la de Bilbao y ambas son inferiores a la de Irún (Font, Climatología de España y Portugal).

Sin embargo en 1912 y en 1916, las precipitaciones registradas en San Sebastián (1024F) fueron inferiores a las de Bilbao (1077C); en 1013 (Irún), a 15 Km de distancia al Este de San Sebastián, se recogen en 1916 128,1 1/ $\mathrm{m}^{2}$ de precipitación media.

Todo esto arroja dudas sobre las cantidades medidas en 1024F, cautela recogida también en "Homogeneidad y variabilidad de los registros históricos de precipitación de España.” Monografía Técnica A-143 INM.

Se detecta una alternancia entre años muy lluviosos con años muy secos de 1905 a 1917 en 1024F y en 1077C: En este lapso de tiempo, hubo una oscilación de las medidas en torno a la mediana de la serie. Por tanto, cabe calificarla como una inhomogeneidad de tipo "climatológico".

\section{3.- 1916 a 1925 en 1013 (Anual):}

Tabla 7: Años con precipitaciones medias mensuales máximas y mínimas:

En el apartado 4.1 se analizó la ruptura de la serie $1024 \mathrm{~F}$ por cambio de altitud del pluviómetro en febrero y marzo de 1918.

\begin{tabular}{|c|c|c|c|c|c|}
\hline Indicativo & Duración serie & Año Máximo & $\begin{array}{c}\text { Precipitación } \\
\left(1 / \mathrm{m}^{2}\right)\end{array}$ & Año Mínimo & $\begin{array}{c}\text { Precipitación } \\
\left(1 / \mathrm{m}^{2}\right)\end{array}$ \\
\hline \multirow{3}{*}{$\begin{array}{c}1013 \\
\text { Irún }\end{array}$} & \multirow{2}{*}{$1915-1930$} & $1923\left(1^{\circ}\right)$ & 213,4 & $1921\left(1^{\circ}\right)$ & 110,8 \\
\cline { 3 - 6 } & & $1917\left(2^{\circ}\right)$ & 201,4 & $1924\left(2^{\circ}\right)$ & 114,3 \\
\cline { 3 - 6 } $\begin{array}{c}\text { 1024F } \\
\text { San Sebastián }\end{array}$ & $1918-1935$ & $1923\left(1^{\circ}\right)$ & 251,0 & $1920\left(3^{\circ}\right)$ & 123,8 \\
\cline { 2 - 5 } & $1922\left(2^{\circ}\right)$ & 162,7 & $1920\left(1^{\circ}\right)$ & 89,5 \\
\hline
\end{tabular}


Se observa que si bien los años lluviosos y secos coinciden en 1024F y en 1013, el cociente de las precipitaciones medidas en 1024F respecto a las registradas en 1013 no es constante, por lo que hay que tomar con cierta cautela los datos registrado por $1024 \mathrm{~F}$.

Al haber una alternancia en 1013 y en 1024F, de años "muy lluviosos" con años "muy secos", cabe considerar que se trata de una inhomogeneidad "climatológica".

\section{4.- 1918 a 1930 en 1013 y 1919 a 1932 en 1024F (MAM):}

Tabla 8: Años con precipitaciones medias en MAM máximas y mínimas

\begin{tabular}{|c|c|c|c|c|c|}
\hline Indicativo & Duración serie & Año Máximo & $\begin{array}{c}\text { Precipitación } \\
\left(1 / \mathrm{m}^{2}\right)\end{array}$ & Año Mínimo & $\begin{array}{c}\text { Precipitación } \\
\left(1 / \mathrm{m}^{2}\right)\end{array}$ \\
\hline \multirow{3}{*}{$\begin{array}{c}1013 \\
\text { Irún }\end{array}$} & \multirow{3}{*}{$1914-1930$} & $1925\left(1^{\mathbf{o}}\right)$ & 205,9 & $1924\left(2^{\circ}\right)$ & 103,7 \\
\cline { 3 - 5 } & & $1927\left(2^{\mathbf{o}}\right)$ & 199,4 & $1929\left(3^{\circ}\right)$ & 103,9 \\
\cline { 3 - 5 } & $1923\left(3^{\circ}\right)$ & 198,4 & $1921\left(4^{\circ}\right)$ & 110,5 \\
\hline \multirow{3}{*}{$\begin{array}{c}\text { 1024F } \\
\text { San Sebastián }\end{array}$} & \multirow{3}{*}{$1918-1936$} & $1923\left(1^{\circ}\right)$ & 225,3 & $1921\left(2^{\circ}\right)$ & 81,5 \\
\cline { 3 - 6 } & & $1922\left(2^{\mathbf{o}}\right)$ & 215,1 & $1929\left(3^{\circ}\right)$ & 88,6 \\
\cline { 3 - 6 } & & $1918\left(3^{\circ}\right)$ & 167,0 & $1924\left(4^{\circ}\right)$ & 101,6 \\
\cline { 3 - 6 } & $1927\left(4^{\circ}\right)$ & 161,1 & & \\
\hline
\end{tabular}

Esta alternancia simultánea en 2 estaciones próximas (1013 y 1024F) entre años secos $(1921,1924,1929)$ y lluviosos $(1923,1927)$ permite calificar a la inhomogeneidad como "climatológica".

Las precipitaciones en 1923 de $1024 \mathrm{~F}$ vuelven a superar a las de 1013. Esto refuerza la reserva sobre la calidad de las medidas de 1024F posteriores a 1918.

\section{5.- 1926 a 1935 en 1032 (AMJ):}

Esta inhomogeneidad sólo se detecta en 1032 (Villabona).

La tabla 9 refleja los datos de 1032 junto con los de 1024E Igueldo, tomada como una referencia por su calidad y extensa duración sin lagunas. Ambas series están a menos de $14 \mathrm{Km}$ en línea recta.

1013 tiene datos completos de AMJ sólo hasta 1931.

Tabla 9: Años con precipitaciones medias en AMJ máximas y mínimas:

\begin{tabular}{|c|c|c|c|c|c|}
\hline Indicativo & Duración serie & Año Máximo & $\begin{array}{c}\text { Precipitación } \\
\left(1 / \mathrm{m}^{2}\right)\end{array}$ & Año Mínimo & $\begin{array}{c}\text { Precipitación } \\
\left(1 / \mathrm{m}^{2}\right)\end{array}$ \\
\hline \multirow{3}{*}{$\begin{array}{c}1032 \\
\text { Villabona }\end{array}$} & \multirow{2}{*}{$1926-1987$} & $1933\left(3^{\circ}\right)$ & 176,9 & $1934\left(5^{\circ}\right)$ & 70,6 \\
\hline & & $1930\left(6^{\circ}\right)$ & 167,7 & & \\
\cline { 3 - 6 } $\begin{array}{c}\text { 1024E } \\
\text { Igueldo }\end{array}$ & $1931\left(12^{\circ}\right)$ & 141,3 & & \\
\cline { 3 - 6 } & $1928-2012$ & $1933\left(3^{\circ}\right)$ & 175,3 & $1934\left(17^{\circ}\right)$ & 90,2 \\
\cline { 3 - 6 } & $1931\left(11^{\circ}\right)$ & 152,1 & & \\
\hline
\end{tabular}


Teniendo en cuenta que:

5.1.- En el punto 4, se expone que 1929 fue un año muy seco en 1013 y en 1024F.

5.2.- La concordancia de años lluviosos y años secos con 1024E (serie de excelente calidad) así como la coherencia entre las precipitaciones recogidas en ambos emplazamientos.

Se puede calificarla como inhomogeneidad "climatológica".

6.- 1928 a 1938 en 1024E (Anual): En septiembre de 1936 cambia el personal que realiza las observaciones en 1024 E Igueldo. Hay una inhomogeneidad en los datos "no climatológica"

\subsubsection{2.- Precipitación anual de 1941 a 2012:}

La gráfica 10 representa la evolución temporal de las inhomogeneidades detectadas aplicando el test de las rachas a la precipitación anual de 1941 a 2012.

Gráfica 10: Evolución temporal de las inhomogeneidades test rachas de las series de precipitación anual de 1941 a 2012:

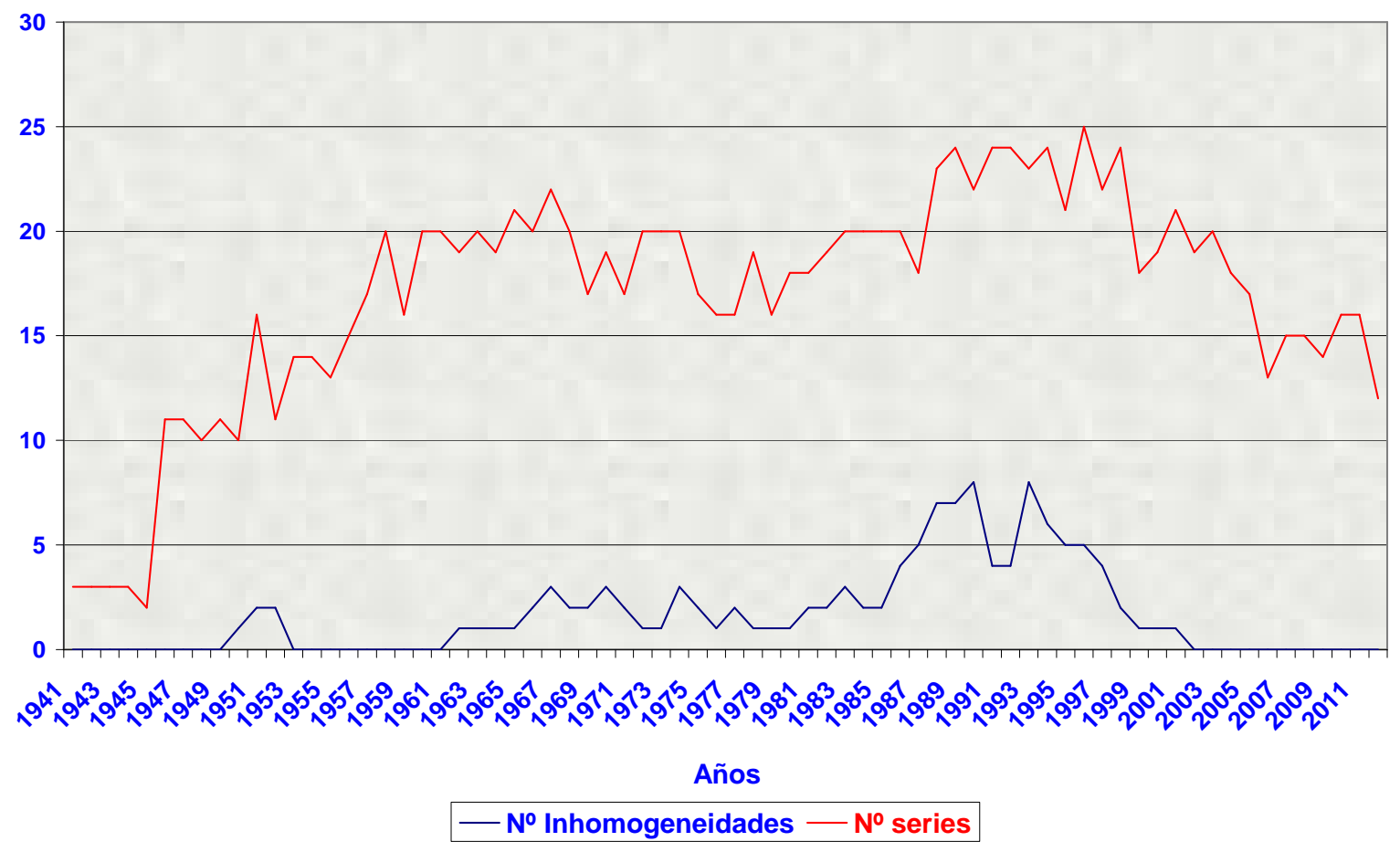
2006.

De la gráfica 10 se observa que el máximo de inhomogeneidades se da entre 1986 y

Se representan las inhomogeneidades detectadas en un periodo de 10 años. Así, una inhomogeneidad detectada en 1986 abarca desde 1986 a 1995. 
Al aplicar el test de las rachas se considera el periodo de 10 años de datos consecutivos. Cuando aparecen lagunas en las series (como en 1016) el periodo anotado se amplía hasta alcanzar el de 10 años consecutivos de datos.

Por brevedad, en la tabla 10 se agrupan en la columna de la izquierda periodos en que las inhomogeneidades se solapan y en la columna de la derecha se agrupan el \% de series que se solapan en el mismo periodo de años.

Tabla 10: Inhomogeneidades detectadas aplicando el test de rachas a las medidas de precipitación anual desde 1941 a 2012:

\begin{tabular}{|c|c|c|c|}
\hline $\begin{array}{l}\text { Periodo inhomogeneidad } \\
\text { (Años) }\end{array}$ & Indicativos & $\begin{array}{l}\text { Inhomogeneidad } \\
\text { "climatológica" }\end{array}$ & $\begin{array}{c}\% \text { series sobre } \\
\text { total }\end{array}$ \\
\hline $1950-1959$ & 1016 & Sí & $9-10$ \\
\hline $1951-1961$ & $1016,1024 \mathrm{E}$ & Sí & $13-18$ \\
\hline $1962-1975$ & 1017 & No & 5 \\
\hline $1966-1975$ & 1022 & Sí & 5 \\
\hline $1967-1978$ & 1016,1022 & Sí & $9-11$ \\
\hline $1967-1984$ & 1026 & Sí & 5 \\
\hline $1970-1980$ & $1016,1022,1036$ & Sí & $12-16$ \\
\hline $1972-1981$ & 1016 & Sí & 5 \\
\hline $1973-1983$ & 1022 & Sí & 5 \\
\hline $1974-1985$ & $1022,1035,1036$ & Sí & $12-15$ \\
\hline $1976-1986$ & 1036 & Sí & 6 \\
\hline $1977-1986$ & $1021 \mathrm{E}, 1035$ & Sí & 13 \\
\hline $1978-1989$ & 1036 & Sí & $5-6$ \\
\hline $1981-1994$ & $1014,1024 \mathrm{E}$ & Sí & $10-11$ \\
\hline $1983-1992$ & $1049 \mathrm{U}$ & Sí & 5 \\
\hline $1986-1997$ & 1014, 1024E, 1033U, 1037Q & Sí & \multirow[b]{2}{*}{$20-22$} \\
\hline $1987-1998$ & 1037O, 1037Q & Sí & \\
\hline $1987-2008$ & 1050L & No & $4-6$ \\
\hline $1988-1997$ & 1013I, 1019A & \multirow[t]{2}{*}{ Sí } & \multirow[t]{2}{*}{$21-22$} \\
\hline $1989-1999$ & 1013I, 1014, 1019A, 1024E & & \\
\hline $1988-2001$ & 1041 & Sí & 4 \\
\hline $1989-1998$ & 1031 & Sí & 4 \\
\hline $1990-1999$ & 1026B, 1031 & Sí & \multirow[b]{2}{*}{16} \\
\hline $1990-2001$ & $1037 \mathrm{O}$ & Sí & \\
\hline $1991-2001$ & 1014, 1026B, 1031 & Sí & 17 \\
\hline $1992-2003$ & $1035 \mathrm{U}$ & Sí & 4 \\
\hline $1993-2002$ & 1031,10360 & Sí & \multirow[b]{2}{*}{30} \\
\hline $1993-2003$ & $\begin{array}{c}1014,1026 \mathrm{~B}, 1037,1041, \\
1049\end{array}$ & Sí & \\
\hline $1994-2006$ & 1041 & Sí & 4 \\
\hline $1995-2004$ & $10360,1037,1049$ & Sí & 19 \\
\hline $1996-2006$ & 10360,1049 & Sí & $18-20$ \\
\hline $1996-2011$ & $1025 \mathrm{~N}$ & Sí & $4-5$ \\
\hline $1998-2011$ & $1033 \mathrm{U}$ & ¿No? & $5-6$ \\
\hline
\end{tabular}


Las tablas 11 a 21 exponen:

a) Indicativo y nombre del emplazamiento.

b) Duración en años detallando los años sin datos sd.

c) Los años en que se registran precipitaciones elevadas y escasas en el intervalo detectado por la inhomogeneidad, con el ordinal entre paréntesis referido al intervalo anual total de medidas de la serie.

d) La precipitación media mensual en el periodo anual.

Al analizar un periodo de inhomogeneidades, se emplearán las series de precipitaciones teniendo en cuenta las rupturas detectadas en el apartado 4.1.

1.- Inhomogeneidad de 1950 a 1961 en 1016 y de 1951 a 1961 en 1024E:

Tabla 11: Años con precipitaciones máximas y mínimas:

\begin{tabular}{|c|c|c|c|c|c|}
\hline Indicativo & Duración serie & Año Máximo & $\begin{array}{c}\text { Precipitación } \\
\left(1 / \mathrm{m}^{2}\right)\end{array}$ & Año Mínimo & $\begin{array}{c}\text { Precipitación } \\
\left(1 / \mathrm{m}^{2}\right)\end{array}$ \\
\hline \multirow{2}{*}{$\begin{array}{c}1016 \\
\text { Oyarzun }\end{array}$} & $\begin{array}{c}1947-1984 \\
(\mathrm{sd} 1955)\end{array}$ & $1954\left(3^{\circ}\right)$ & 247,3 & $1957\left(3^{\circ}\right)$ & 157,3 \\
\cline { 3 - 6 } & $1951\left(4^{\circ}\right)$ & 243,0 & $1956\left(8^{\circ}\right)$ & 167,7 \\
\hline $\begin{array}{c}\text { 1024E } \\
\text { Igueldo }\end{array}$ & $1928-2012$ & $1960\left(8^{\circ}\right)$ & 218,1 & & \\
\hline
\end{tabular}

Aquí se refleja la importancia del estudio de series antiguas para dilucidar si una inhomogeneidad es "climatológica" o no:

La inhomogeneidad se debe a un número de rachas elevado, al oscilar las precipitaciones recogidas en torno a su mediana: el periodo de inhomogeneidades arranca con máximos en 1951 y en 1954, disminuyendo la precipitación en 1956-1957 y recuperándose en 1960.

Asimismo son coherentes las cantidades de precipitación recogidas en 1024E y 1016, reflejando que 1016 Oyarzun es más lluvioso que 1024E Igueldo.

La sincronía temporal de la inhomogeneidad de ambas series, marcando máximos en 1960 y mínimo en 1957, permite calificar a las inhomogeneidades de 1016 y de $1024 \mathrm{E}$ como "climatológicas." 
2.- Inhomogeneidad de 1962 a 1975 en 1017 e inhomogeneidad de 1966 a 1978 en 1022 y de 1967 a 1978 en $1016:$

Tabla 12: Años con precipitaciones máximas y mínimas de la serie 1017:

\begin{tabular}{|c|c|c|c|c|c|}
\hline Indicativo & Duración serie & Año Máximo & $\begin{array}{c}\text { Precipitación } \\
\left(1 / \mathrm{m}^{2}\right)\end{array}$ & Año Mínimo & $\begin{array}{c}\text { Precipitación } \\
\left(1 / \mathrm{m}^{2}\right)\end{array}$ \\
\hline \multirow{4}{*}{$\begin{array}{c}1017 \\
\text { Oyarzun }\end{array}$} & \multirow{3}{*}{$1954-1979$} & $1966\left(3^{\circ}\right)$ & 205,9 & $1972\left(1^{\circ}\right)$ & 109,8 \\
\cline { 3 - 6 } & & $1969\left(5^{\circ}\right)$ & 192,0 & $1973\left(2^{\circ}\right)$ & 125,7 \\
\cline { 3 - 6 } & & $1968\left(6^{\circ}\right)$ & 187,3 & $1975\left(3^{\circ}\right)$ & 133,9 \\
\cline { 3 - 6 } & $1974\left(7^{\circ}\right)$ & 183,8 & $1970\left(5^{\circ}\right)$ & 148,2 \\
\cline { 2 - 5 } & $1965\left(8^{\circ}\right)$ & 182,1 & $1967\left(11^{\circ}\right)$ & 169,1 \\
\hline
\end{tabular}

Tabla 13: Años con precipitaciones máximas y mínimas de las series 1016 y 1022:

\begin{tabular}{|c|c|c|c|c|c|}
\hline Indicativo & Duración serie & Año Máximo & $\begin{array}{c}\text { Precipitación } \\
\left(1 / \mathrm{m}^{2}\right)\end{array}$ & Año Mínimo & $\begin{array}{c}\text { Precipitación } \\
\left(1 / \mathrm{m}^{2}\right)\end{array}$ \\
\hline \multirow{3}{*}{$\begin{array}{c}1016 \\
\text { Oyarzun }\end{array}$} & \multirow{3}{*}{$\begin{array}{c}1947-1984 \\
(\text { sd 1955) }\end{array}$} & $1974\left(1^{\circ}\right)$ & 256,1 & $1970\left(2^{\circ}\right)$ & 148,3 \\
\hline & & $1976\left(5^{\circ}\right)$ & 233,4 & $1972\left(7^{\circ}\right)$ & 164,6 \\
\hline & & $1978\left(6^{\circ}\right)$ & 229,3 & $1967\left(9^{\circ}\right)$ & 169,1 \\
\hline \multirow{3}{*}{$\begin{array}{c}1022 \\
\text { Hernani }\end{array}$} & \multirow{3}{*}{$\begin{array}{c}1955-1985 \\
(\mathrm{sd} 1963,1964, \\
1981,1984)\end{array}$} & $1974\left(2^{\circ}\right)$ & 195,2 & $1970\left(4^{\circ}\right)$ & 126,7 \\
\hline & & $1976\left(4^{\circ}\right)$ & 180,6 & $1968\left(5^{\circ}\right)$ & 133,8 \\
\hline & & $1978\left(5^{\circ}\right)$ & 176,7 & $1972\left(7^{\circ}\right)$ & 139,7 \\
\hline
\end{tabular}

De las tablas 12 y 13 :

a) En 1017 se observa un máximo de precipitaciones entre 1965 y 1969 y de 1970 a 1975 un periodo de años más secos.

b) Por el contrario, en 1016 y en 1022 se observa un mínimo de precipitación entre 1968 y 1972 y un aumento de precipitación a partir de 1974. En ambas coinciden plenamente los años de precipitaciones máximas y mínimas.

c) Cabe pensar que 1017 tiene una "inhomogeneidad no climatológica":

c1) De la tabla 10, es la única serie que manifiesta esta inhomogeneidad.

c2) No coinciden los años de máximos y mínimos de precipitación en 1017 con los registrados en las series vecinas de 1016 y de 1022. Así, 1968 fue un máximo relativo de precipitación en 1017 y un mínimo en 1022. Resulta sospechoso que en 1967, 1016 y 1017 registren la misma precipitación media anual.

Por tanto, la inhomogeneidad de 1016 y 1022 se puede calificar de "climatológica".

d) Las 3 series parecen una reflejar una "sequía" a nivel de la comarca de San Sebastián desde 1970 a 1973. 
3.- Inhomogeneidad de 1967 a 1984 en 1026: El test advierte de una única inhomogeneidad en un periodo de 21 años analizados en 1026.

Tabla 14: Años con precipitaciones máximas y mínimas en 1026:

\begin{tabular}{|c|c|c|c|c|c|}
\hline Indicativo & Duración serie & Año Máximo & $\begin{array}{c}\text { Precipitación } \\
\left(1 / \mathrm{m}^{2}\right)\end{array}$ & Año Mínimo & $\begin{array}{c}\text { Precipitación } \\
\left(1 / \mathrm{m}^{2}\right)\end{array}$ \\
\hline \multirow{5}{*}{1026} & $1954-1984$ & $1979\left(1^{\circ}\right)$ & 160,8 & $1983\left(7^{\circ}\right)$ & 95,7 \\
\cline { 3 - 6 } & $(\sin$ datos & $1971\left(2^{\circ}\right)$ & 144,3 & $1972\left(9^{\circ}\right)$ & 105,1 \\
\cline { 3 - 6 } Beasain & 1973,1974, & $1969\left(6^{\circ}\right)$ & 132,7 & & \\
\cline { 3 - 6 } & 1975,1976, & $1968\left(7^{\circ}\right)$ & 124,3 & & \\
\cline { 3 - 6 } & 1977,1978, & $1984\left(8^{\circ}\right)$ & 117,7 & & \\
\cline { 3 - 6 } & 1980 y 1982) & $1967\left(9^{\circ}\right)$ & 117,3 & & \\
\hline
\end{tabular}

Comparando las tablas 14 y 15 , se observa que los máximos $(1979,1984)$ y mínimos $(1983,1972)$ de 1026 coinciden con las series restantes, en especial los máximos con $1024 \mathrm{E}$ y los mínimos con 1016, 1022 y 1024.

Por tanto, cabe calificarla como una inhomogeneidad "climatológica".

4.- Inhomogeneidades de 1970 a 1994:

Tabla 15: Años con precipitaciones máximas y mínimas:

\begin{tabular}{|c|c|c|c|c|c|}
\hline Indicativo & Duración serie & Año Máximo & $\begin{array}{c}\text { Precipitación } \\
\left(1 / \mathrm{m}^{2}\right)\end{array}$ & Año Mínimo & $\begin{array}{c}\text { Precipitación } \\
\left(1 / \mathrm{m}^{2}\right)\end{array}$ \\
\hline \multirow{4}{*}{$\begin{array}{c}1014 \text { OMA } \\
\text { Fuenterrabía }\end{array}$} & \multirow{4}{*}{$1969-2012$} & $1994\left(2^{\circ}\right)$ & 181,1 & $1989\left(2^{\circ}\right)$ & 101,0 \\
\hline & & $1981\left(4^{\circ}\right)$ & 165,3 & $1993\left(3^{\circ}\right)$ & 109,3 \\
\hline & & $1986\left(6^{\circ}\right)$ & 162,8 & $1985\left(6^{\circ}\right)$ & 116,7 \\
\hline & & $1984\left(8^{\circ}\right)$ & 161,8 & $1983\left(7^{\circ}\right)$ & 117,2 \\
\hline \multirow{4}{*}{$\begin{array}{c}1016 \\
\text { Oyarzun }\end{array}$} & \multirow{4}{*}{$\begin{array}{c}1947-1984 \\
(\mathrm{sd} 1955)\end{array}$} & $1974\left(1^{\circ}\right)$ & 256,1 & $1970\left(2^{\circ}\right)$ & 148,3 \\
\hline & & $1979\left(2^{\circ}\right)$ & 247,8 & $1983\left(5^{\circ}\right)$ & 161,8 \\
\hline & & $1976\left(5^{\circ}\right)$ & 233,4 & $1972\left(7^{\circ}\right)$ & 164,6 \\
\hline & & $1978\left(6^{\circ}\right)$ & 229,3 & $1971\left(10^{\circ}\right)$ & 172,6 \\
\hline \multirow{4}{*}{$\begin{array}{c}1022 \\
\text { Hernani }\end{array}$} & \multirow{4}{*}{$\begin{array}{c}1955-1985 \\
\text { (sd 1963, } \\
1964,1981 \\
1984)\end{array}$} & $1979\left(1^{\circ}\right)$ & 203,4 & $1985\left(2^{\circ}\right)$ & 111,6 \\
\hline & & $1974\left(2^{\circ}\right)$ & 195,2 & $1970\left(4^{\circ}\right)$ & 126,7 \\
\hline & & $1980\left(3^{\circ}\right)$ & 182,0 & $1983\left(6^{\circ}\right)$ & 139,1 \\
\hline & & $1976\left(4^{\circ}\right)$ & 180,6 & $1972\left(7^{\circ}\right)$ & 139,7 \\
\hline \multirow{4}{*}{$\begin{array}{c}1024 \\
\text { San Sebastián } \\
\text { (Ategorrieta) }\end{array}$} & \multirow{4}{*}{$\begin{array}{c}1960-1985 \\
(\operatorname{sd} 1981)\end{array}$} & $1979\left(1^{\circ}\right)$ & 186,0 & $1970\left(3^{\circ}\right)$ & 118,7 \\
\hline & & $1984\left(2^{\circ}\right)$ & 163,9 & $1983\left(5^{\circ}\right)$ & 121,6 \\
\hline & & $1974\left(4^{\circ}\right)$ & 160,5 & $1972\left(7^{\circ}\right)$ & 125,2 \\
\hline & & $1982\left(5^{\circ}\right)$ & 156,0 & & \\
\hline
\end{tabular}


Tabla 15 (continuación): Años con precipitaciones máximas y mínimas:

\begin{tabular}{|c|c|c|c|c|c|}
\hline Indicativo & Duración serie & Año Máximo & $\begin{array}{c}\text { Precipitación } \\
\left(1 / \mathrm{m}^{2}\right)\end{array}$ & Año Mínimo & $\begin{array}{c}\text { Precipitación } \\
\left(1 / \mathrm{m}^{2}\right)\end{array}$ \\
\hline \multirow{4}{*}{$\begin{array}{c}\text { 1024E } \\
\text { Igueldo }\end{array}$} & \multirow{4}{*}{$1928-2012$} & $1979\left(1^{\circ}\right)$ & 183,9 & $1989\left(3^{\circ}\right)$ & 90,7 \\
\hline & & $1974\left(9^{\circ}\right)$ & 153,4 & $1988\left(14^{\circ}\right)$ & 112,6 \\
\hline & & $1981\left(12^{\circ}\right)$ & 150,2 & $1985\left(15^{\circ}\right)$ & 112,7 \\
\hline & & $1984\left(14^{\circ}\right)$ & 147,1 & & \\
\hline \multirow{4}{*}{$\begin{array}{c}1035 \\
\text { Lasarte }\end{array}$} & \multirow{4}{*}{$\begin{array}{c}1946-2011 \\
(\mathrm{sd} 1976)\end{array}$} & $1984\left(2^{\circ}\right)$ & 181,2 & $1989\left(2^{\circ}\right)$ & 96,3 \\
\hline & & $1979\left(3^{\circ}\right)$ & 174,9 & $1970\left(5^{\circ}\right)$ & 105,6 \\
\hline & & $1986\left(8^{\circ}\right)$ & 166,4 & $1985\left(7^{\circ}\right)$ & 111,0 \\
\hline & & $1974\left(11^{\circ}\right)$ & 162,6 & $1993\left(10^{\circ}\right)$ & 113,0 \\
\hline \multirow{4}{*}{$\begin{array}{c}1036 \\
\text { Zarauz }\end{array}$} & \multirow{4}{*}{$\begin{array}{c}1956-1986 \\
(\text { sd 1979) }\end{array}$} & $1974\left(3^{\circ}\right)$ & 127,3 & $1983\left(3^{\circ}\right)$ & 92,7 \\
\hline & & $1971\left(5^{\circ}\right)$ & 123,4 & $1985\left(4^{\circ}\right)$ & 94,6 \\
\hline & & $1973\left(7^{\circ}\right)$ & 120,6 & $1970\left(5^{\circ}\right)$ & 95,9 \\
\hline & & $1978\left(9^{\circ}\right)$ & 118,8 & & \\
\hline \multirow{4}{*}{$\begin{array}{l}1049 \mathrm{U} \\
\text { Ermua }\end{array}$} & \multirow{4}{*}{$1983-2005$} & $1992\left(1^{\circ}\right)$ & 160,0 & $1989\left(1^{\circ}\right)$ & 81,3 \\
\hline & & $1984\left(2^{\circ}\right)$ & 159,3 & $1985\left(3^{\circ}\right)$ & 97,8 \\
\hline & & $1993\left(3^{\circ}\right)$ & 142,9 & $1987\left(6^{\circ}\right)$ & 110,3 \\
\hline & & $1986\left(5^{\circ}\right)$ & 137,0 & $1983\left(7^{\circ}\right)$ & 110,8 \\
\hline
\end{tabular}

De la tabla 15 , se observa que:

a) A pesar de la diferente duración temporal de las series de datos, coinciden en señalar simultáneamente máximos de precipitación en 1974, 1976, 1978, 1979, 1981, 1984 y 1992.

En este periodo registran efemérides de precipitación series como 1014, 1016, 1022, $1024,1024 \mathrm{E}$ y $1049 \mathrm{U}$. 1987, 1989.

b) Asimismo, concuerdan los mínimos de precipitación: 1970, 1972, 1983, 1985,

c) Coherencia espacial de los valores extremos de precipitación registrados.

c) Las inhomogeneidades se detectan en un número de elevado de series, todas en la comarca de San Sebastián, salvo 1049 U Ermua.

d) Se registra un episodio de sequía en 1970 y 1972, seguido por un intervalo de precipitaciones muy elevadas de 1976 a 1981, sucedido por unos años de estiajes de 1985 a 1989 con un máximo intercalado en 1986, a los cuáles siguen 1990 y 1992 con precipitaciones elevadas.

Estas variaciones en la precipitación son la causa de las inhomogeneidades detectadas por el test de las rachas.

Por tanto, se trata de una inhomogeneidad "climatológica". 
5.- Inhomogeneidades de 1986 a 1999:

Tabla 16: Años con precipitaciones máximas y mínimas:

\begin{tabular}{|c|c|c|c|c|c|}
\hline Indicativo & Duración serie & Año Máximo & $\begin{array}{c}\text { Precipitación } \\
\left(1 / \mathrm{m}^{2}\right)\end{array}$ & Año Mínimo & $\begin{array}{c}\text { Precipitación } \\
\left(1 / \mathrm{m}^{2}\right)\end{array}$ \\
\hline \multirow{3}{*}{$\begin{array}{c}1013 \mathrm{I} \\
\text { Fuenterrabía }\end{array}$} & \multirow{3}{*}{$1988-1998$} & $1994\left(1^{\circ}\right)$ & 162,2 & $1989\left(1^{\circ}\right)$ & 102,5 \\
\hline & & $1990\left(2^{\circ}\right)$ & 161,9 & $1993\left(2^{\circ}\right)$ & 108,8 \\
\hline & & $1992\left(3^{\circ}\right)$ & 153,2 & $1991\left(3^{\circ}\right)$ & 124,2 \\
\hline \multirow{3}{*}{$\begin{array}{c}1014 \text { OMA } \\
\text { Fuenterrabía }\end{array}$} & \multirow{3}{*}{$1969-2012$} & $1994\left(2^{\circ}\right)$ & 181,1 & $1989\left(2^{\circ}\right)$ & 101,0 \\
\hline & & $1986\left(6^{\circ}\right)$ & 162,8 & $1993\left(3^{\circ}\right)$ & 109,3 \\
\hline & & $1990\left(10^{\circ}\right)$ & 160,4 & $1988\left(12^{\circ}\right)$ & 123,4 \\
\hline \multirow{3}{*}{$\begin{array}{l}\text { 1019A } \\
\text { Pasajes }\end{array}$} & \multirow{3}{*}{1988 - 1999} & $1996\left(1^{\circ}\right)$ & 162,1 & $1989\left(1^{\circ}\right)$ & 94,4 \\
\hline & & $1994\left(2^{\circ}\right)$ & 155,6 & $1995\left(2^{\circ}\right)$ & 108,2 \\
\hline & & $1992\left(3^{\circ}\right)$ & 147,1 & $1988\left(3^{\circ}\right)$ & 116,1 \\
\hline \multirow{3}{*}{$\begin{array}{l}\text { 1024E } \\
\text { Igueldo }\end{array}$} & \multirow{3}{*}{$1928-2012$} & $1994\left(16^{\circ}\right)$ & 145,7 & $1989\left(3^{\circ}\right)$ & 90,7 \\
\hline & & $1997\left(18^{\circ}\right)$ & 144,5 & $1988\left(14^{\circ}\right)$ & 112,6 \\
\hline & & $1986\left(19^{\circ}\right)$ & 144,4 & $1985\left(15^{\circ}\right)$ & 112,7 \\
\hline \multirow{3}{*}{$\begin{array}{l}\text { 1033U } \\
\text { Urnieta }\end{array}$} & \multirow{3}{*}{$\begin{array}{c}1986-1997 \\
(\text { sd 1987, } \\
1988)\end{array}$} & $1992\left(1^{\circ}\right)$ & 161,4 & $1989\left(1^{\circ}\right)$ & 88,3 \\
\hline & & $1996\left(2^{\circ}\right)$ & 153,6 & $1995\left(2^{\circ}\right)$ & 113,1 \\
\hline & & $1986\left(3^{\circ}\right)$ & 146,5 & $1991\left(3^{\circ}\right)$ & 132,4 \\
\hline \multirow{3}{*}{$\begin{array}{c}10370 \\
\text { Azcoitia }\end{array}$} & \multirow{3}{*}{$\begin{array}{c}1978-2001 \\
(\text { sd 1986, } \\
1995,1999)\end{array}$} & $1992\left(1^{\circ}\right)$ & 167,2 & $1989\left(1^{\circ}\right)$ & 90,7 \\
\hline & & $1996\left(3^{\circ}\right)$ & 139,1 & $1997\left(4^{\circ}\right)$ & 106,1 \\
\hline & & $1993\left(5^{\circ}\right)$ & 133,9 & $1990\left(5^{\circ}\right)$ & 106,3 \\
\hline \multirow{3}{*}{$\begin{array}{c}\text { 1037Q } \\
\text { Azcoitia }\end{array}$} & \multirow{3}{*}{$\begin{array}{c}1986-1998 \\
(\text { sd 1992, } \\
1995)\end{array}$} & $1991\left(1^{\circ}\right)$ & 133,3 & $1989\left(1^{\circ}\right)$ & 80,3 \\
\hline & & $1996\left(2^{\circ}\right)$ & 129,7 & $1987\left(3^{\circ}\right)$ & 105,4 \\
\hline & & $1993\left(3^{\circ}\right)$ & 125,6 & $1994\left(4^{\circ}\right)$ & 106,2 \\
\hline
\end{tabular}

La tabla 16 muestra que:

5.1. Hay una gran similitud entre los picos y valles de 1033 U Urnieta, 10370 Azcoitia y 1037Q Azcoitia. Las 3 distan de la costa entre 9 y 14 Km. en línea recta y están en las comarcas del Oria y del Urola Medios.

5.2.- Coinciden los máximos de precipitación en 1986 y mínimos en 1988 y en 1989.

5.3.- A partir de 1990 se rompe la relación entre los registros pluviométricos costeros y los datos del interior:

1990 es un máximo relativo de precipitación en 1013I y en 1014 y un mínimo relativo en 10370 .

1993 es un año de "sequía" en 1013I y en 1014 y de precipitaciones elevadas en $1037 \mathrm{O}$ y en $1037 \mathrm{Q}$.

1994 se corresponde a un año de precipitaciones máximas en 1013I, en 1014, en 1019A y en 1024E y de mínimas en 1037Q. 
1997 marca un máximo relativo de precipitaciones en 1024E y un mínimo relativo en $1037 \mathrm{O}$.

Por el número de series afectadas (20\% del total según refleja la tabla 10) y la coincidencia de máximos y mínimos de la precipitación, se la considera como una "inhomogeneidad climatológica".

\section{6.- Inhomogeneidades de 1987 a 2009 en 1050L Elgoibar:}

Tabla 16 bis: Años con precipitaciones máximas y mínimas:

\begin{tabular}{|c|c|c|c|c|c|}
\hline Indicativo & Duración serie & Año Máximo & $\begin{array}{c}\text { Precipitación } \\
\left(1 / \mathrm{m}^{2}\right)\end{array}$ & Año Mínimo & $\begin{array}{c}\text { Precipitación } \\
\left(1 / \mathrm{m}^{2}\right)\end{array}$ \\
\hline \multirow{3}{*}{ 1050L } & \multirow{2}{*}{$\begin{array}{c}1987-2008 \\
\text { Elgoibar }\end{array}$} & $2008\left(1^{\circ}\right)$ & 154,1 & $1989\left(1^{\circ}\right)$ & 84,0 \\
\cline { 3 - 6 } & $(\mathrm{sd} 1992)$ & $2002\left(2^{\mathbf{o}}\right)$ & 136,9 & $2006\left(2^{\circ}\right)$ & 92,0 \\
\cline { 3 - 6 } & $1988\left(3^{\mathbf{o}}\right)$ & 136,4 & $2001\left(3^{\circ}\right)$ & 99,2 \\
\hline
\end{tabular}

6.1.- El test de las rachas detecta inhomogeneidad en todo el periodo, con un número de rachas muy elevado: la precipitación oscila en torno a la mediana durante 21 años.

6.2.- 1050L es la única serie del entorno en la que afloran inhomogeneidades. el tiempo.

6.3.- Ninguna serie de las analizadas presenta una inhomogeneidad tan prolongada en

6.4.- De las tablas 16 y 16 bis, 1988 es un máximo de precipitación en 1050L y un mínimo en 1014, en 1019A y en 1024E.

Por tanto, cabe calificarla como inhomogeneidad "no climatológica".

7.- Inhomogeneidad de 1988 a 2001 en 1041 Zumaya:

Tabla 17: Años con precipitaciones máximas y mínimas:

\begin{tabular}{|c|c|c|c|c|c|}
\hline Indicativo & Duración serie & Año Máximo & $\begin{array}{c}\text { Precipitación } \\
\left(1 / \mathrm{m}^{2}\right)\end{array}$ & Año Mínimo & $\begin{array}{c}\text { Precipitación } \\
\left(1 / \mathrm{m}^{2}\right)\end{array}$ \\
\hline \multirow{2}{*}{1041} & $1988-2007$ & $1993\left(1^{\circ}\right)$ & 113,4 & $1989\left(1^{\circ}\right)$ & 68,5 \\
\cline { 3 - 6 } Zumaya & $(\mathrm{sd} \mathrm{1990,1991,}$ & $1996\left(2^{\circ}\right)$ & 110,2 & $2001\left(2^{\circ}\right)$ & 76,3 \\
\cline { 3 - 6 } & $1992,1997)$ & $1994\left(3^{\circ}\right)$ & 109,2 & $1975\left(3^{\circ}\right)$ & 89,6 \\
\hline
\end{tabular}

La similitud del comportamiento de máximos y mínimos y la proximidad geográfica con las series de la comarca de San Sebastián analizadas en las tablas 16 y 18, permiten catalogar la inhomogeneidad de 1041 como "climatológica". 


\section{8.- Inhomogeneidades de 1989 a 2003:}

Tabla 18: Años con precipitaciones máximas y mínimas:

\begin{tabular}{|c|c|c|c|c|c|}
\hline Indicativo & Duración serie & Año Máximo & $\begin{array}{c}\text { Precipitación } \\
\left(1 / \mathrm{m}^{2}\right)\end{array}$ & Año Mínimo & $\begin{array}{c}\text { Precipitación } \\
\left(1 / \mathrm{m}^{2}\right)\end{array}$ \\
\hline \multirow{3}{*}{$\begin{array}{c}1014 \text { OMA } \\
\text { Fuenterrabía }\end{array}$} & \multirow{3}{*}{$1969-2012$} & $1994\left(2^{\circ}\right)$ & 181,1 & $2001\left(1^{\circ}\right)$ & 98,0 \\
\hline & & $2000\left(9^{\circ}\right)$ & 161,0 & $1989\left(2^{\circ}\right)$ & 101,0 \\
\hline & & $1990\left(10^{\circ}\right)$ & 160,4 & $1993\left(3^{\circ}\right)$ & 109,3 \\
\hline \multirow{3}{*}{$\begin{array}{l}\text { 1026B } \\
\text { Lareo }\end{array}$} & \multirow{3}{*}{$1990-2012$} & $2002\left(2^{\circ}\right)$ & 176,9 & $1990\left(1^{\circ}\right)$ & 112,9 \\
\hline & & $1996\left(3^{\circ}\right)$ & 174,3 & $2001\left(2^{\circ}\right)$ & 120,3 \\
\hline & & $1998\left(4^{\circ}\right)$ & 172,3 & $1995\left(3^{\circ}\right)$ & 131,7 \\
\hline \multirow{3}{*}{$\begin{array}{c}1031 \\
\text { Elduayen }\end{array}$} & \multirow{3}{*}{$1989-2011$} & $1992\left(1^{\circ}\right)$ & 201,2 & $1989\left(1^{\circ}\right)$ & 107,1 \\
\hline & & $2002\left(5^{\circ}\right)$ & 168,1 & $2001\left(2^{\circ}\right)$ & 109,4 \\
\hline & & $1991\left(6^{\circ}\right)$ & 166,3 & $1995\left(4^{\circ}\right)$ & 122,3 \\
\hline \multirow{3}{*}{$\begin{array}{c}1035 \mathrm{U} \\
\text { Aya }\end{array}$} & \multirow{3}{*}{$\begin{array}{c}1992-2003 \\
(\text { sd 1999, } \\
2000)\end{array}$} & $1992\left(1^{\circ}\right)$ & 151,0 & $2001\left(1^{\circ}\right)$ & 96,6 \\
\hline & & $1996\left(2^{\circ}\right)$ & 145,3 & $1995\left(2^{\circ}\right)$ & 106,6 \\
\hline & & $1998\left(3^{\circ}\right)$ & 139,6 & $1993\left(3^{\circ}\right)$ & 133,2 \\
\hline \multirow{3}{*}{$\begin{array}{c}10360 \\
\text { Legazpia }\end{array}$} & \multirow{3}{*}{$1984-2012$} & $1992\left(1^{\circ}\right)$ & 179,7 & $1989\left(1^{\circ}\right)$ & 88,5 \\
\hline & & $1996\left(4^{\circ}\right)$ & 151,2 & $2001\left(3^{\circ}\right)$ & 98,7 \\
\hline & & $1993\left(6^{\circ}\right)$ & 147,5 & $1995\left(4^{\circ}\right)$ & 102,8 \\
\hline \multirow{3}{*}{$\begin{array}{c}1037 \\
\text { Legazpia }\end{array}$} & \multirow{3}{*}{$\begin{array}{c}1981-2011 \\
(\mathrm{sd} 1990, \\
2006,2012)\end{array}$} & $1992\left(2^{\circ}\right)$ & 153,2 & $1989\left(1^{\circ}\right)$ & 79,1 \\
\hline & & $1996\left(4^{\circ}\right)$ & 139,5 & $2001\left(2^{\circ}\right)$ & 89,2 \\
\hline & & $1993\left(8^{\circ}\right)$ & 129,0 & $1995\left(4^{\circ}\right)$ & 97,1 \\
\hline \multirow{3}{*}{$\begin{array}{c}10370 \\
\text { Azcoitia }\end{array}$} & \multirow{3}{*}{$\begin{array}{c}1978-2001 \\
(\text { sd } 1986, \\
1995,1999)\end{array}$} & $1992\left(1^{\circ}\right)$ & 167,2 & $1989\left(1^{\circ}\right)$ & 90,7 \\
\hline & & $1996\left(3^{\circ}\right)$ & 139,1 & $2001\left(3^{\circ}\right)$ & 105,3 \\
\hline & & $1993\left(5^{\circ}\right)$ & 133,9 & $1997\left(4^{\circ}\right)$ & 106,1 \\
\hline \multirow{3}{*}{$\begin{array}{c}1049 \\
\text { Vergara }\end{array}$} & \multirow{3}{*}{$1984-2008$} & $1992\left(2^{\circ}\right)$ & 161,2 & $1989\left(1^{\circ}\right)$ & 82,8 \\
\hline & & $1996\left(3^{\circ}\right)$ & 146,7 & $2001\left(2^{\circ}\right)$ & 98,4 \\
\hline & & $1998\left(8^{\circ}\right)$ & 132,8 & $1995\left(4^{\circ}\right)$ & 107,4 \\
\hline
\end{tabular}

De la tabla 18 se desprende:

1.- Concordancia de máximos $(1992,1993,1996,1998)$ y mínimos $(1989,1993$, 1995, 2001) de precipitación y de las cuantías de las mismas recogidas.

2.- Gradiente de las precipitaciones: Aumentan de Oeste a Este y de Norte a Sur.

Por tanto, se clasifica esta inhomogeneidad como "climatológica".

3.- De las tablas 15,16 y 18 se observa como las series con inhomogeneidades “climatológicas" pasan de estar en la Comarca de San Sebastián al Alto Oria, Alto y Medio Urola y Medio Deba. 


\section{9.- Inhomogeneidades de 1995 a 2006 :}

Tabla 19: Años con precipitaciones máximas y mínimas:

\begin{tabular}{|c|c|c|c|c|c|}
\hline Indicativo & Duración serie & Año Máximo & $\begin{array}{c}\text { Precipitación } \\
\left(1 / \mathrm{m}^{2}\right)\end{array}$ & Año Mínimo & $\begin{array}{c}\text { Precipitación } \\
\left(1 / \mathrm{m}^{2}\right)\end{array}$ \\
\hline \multirow{3}{*}{$\begin{array}{c}10360 \\
\text { Legazpia }\end{array}$} & \multirow{3}{*}{$1984-2012$} & $1996\left(4^{\circ}\right)$ & 151,2 & $2006\left(2^{\circ}\right)$ & 94,3 \\
\hline & & $2002\left(8^{\circ}\right)$ & 140,9 & $2001\left(3^{\circ}\right)$ & 98,7 \\
\hline & & & & $1995\left(4^{\circ}\right)$ & 102,8 \\
\hline \multirow{3}{*}{$\begin{array}{c}1037 \\
\text { Legazpia }\end{array}$} & \multirow{3}{*}{$\begin{array}{c}1981-2011 \\
(\text { sd 1990, } \\
2006,2012) \\
\end{array}$} & $1996\left(4^{\circ}\right)$ & 139,5 & $2001\left(2^{\circ}\right)$ & 89,2 \\
\hline & & $2005\left(5^{\circ}\right)$ & 134,1 & $1995\left(4^{\circ}\right)$ & 97,1 \\
\hline & & & & $1997\left(8^{\circ}\right)$ & 107,6 \\
\hline \multirow{3}{*}{$\begin{array}{c}1049 \\
\text { Vergara }\end{array}$} & \multirow{3}{*}{$1984-2008$} & $1996\left(3^{\circ}\right)$ & 146,7 & $2001\left(2^{\circ}\right)$ & 98,4 \\
\hline & & $2005\left(6^{\circ}\right)$ & 134,6 & $2006\left(3^{\circ}\right)$ & 99,6 \\
\hline & & $1998\left(8^{\circ}\right)$ & 132,8 & $1995\left(4^{\circ}\right)$ & 107,4 \\
\hline
\end{tabular}

La tabla 19 muestra:

1.- Son series en el Alto Urola y Medio Deba, a una distancia máxima de $15 \mathrm{Km}$.

2.- Coinciden máximos $(1996,2005)$ y mínimos $(1995,2001,2006)$.

3.- Las precipitaciones medias mensuales recogidas son muy similares.

Por tanto, se la clasifica como inhomogeneidad "climatológica comarcal".

10.- Inhomogeneidades de 1996 a 2011 en $1025 \mathrm{~N}$ :

Tabla 20: Años con precipitaciones máximas y mínimas:

\begin{tabular}{|c|c|c|c|c|c|}
\hline Indicativo & Duración serie & Año Máximo & $\begin{array}{c}\text { Precipitación } \\
\left(1 / \mathrm{m}^{2}\right)\end{array}$ & Año Mínimo & $\begin{array}{c}\text { Precipitación } \\
\left(1 / \mathrm{m}^{2}\right)\end{array}$ \\
\hline & $1993-2012$ & $2010\left(2^{\mathbf{o}}\right)$ & 113,3 & $2001\left(2^{\circ}\right)$ & 84,8 \\
\cline { 3 - 6 } & $(\mathrm{sd} 1994$ y de & $1998\left(4^{\circ}\right)$ & 112,3 & $1997\left(3^{\circ}\right)$ & 98,0 \\
\cline { 3 - 6 } & $2025 \mathrm{~N}$ & $2002\left(5^{\circ}\right)$ & 112,1 & $2004\left(4^{\mathbf{o}}\right)$ & 101,6 \\
\hline
\end{tabular}

De la tabla 20 se observa:

1.- $1025 \mathrm{~N}$ está a una distancia de 7 y $10 \mathrm{Km}$ de $1036 \mathrm{O}$ y de 1037 , respectivamente, en un valle con la misma orientación: Norte a Sur.

2.- Coinciden los años en que se registran máximos (2002) y mínimos (1997, 2004) de precipitación con los expuestos en la tabla 19 y las cantidades son del mismo orden de magnitud.

Por tanto, se la puede englobar en la inhomogeneidad "climatológica comarcal" del punto anterior. 
11.- Inhomogeneidades en $1033 \mathrm{U}$ de 1998 a 2011:

Tabla 21: Años con precipitaciones máximas y mínimas:

\begin{tabular}{|c|c|c|c|c|c|}
\hline Indicativo & Duración serie & Año Máximo & $\begin{array}{c}\text { Precipitación } \\
\left(1 / \mathrm{m}^{2}\right)\end{array}$ & Año Mínimo & $\begin{array}{c}\text { Precipitación } \\
\left(1 / \mathrm{m}^{2}\right)\end{array}$ \\
\hline \multirow{3}{*}{$\begin{array}{c}1033 \mathrm{U} \\
\text { Urnieta }\end{array}$} & $1993-2012$ & $2008\left(1^{\circ}\right)$ & 171,8 & $2001\left(1^{\circ}\right)$ & 97,5 \\
\cline { 3 - 6 } & $(\mathrm{sd} 2009)$ & $2002\left(2^{\circ}\right)$ & 151,2 & $2006\left(2^{\circ}\right)$ & 109,6 \\
\cline { 3 - 6 } & & $2007\left(3^{\circ}\right)$ & 144,6 & $2003\left(3^{\circ}\right)$ & 126,1 \\
\hline
\end{tabular}

1.- En SS.BB. figura un cambio de pluviómetro en 1033U entre abril de 2010 y julio de 2012.

2.- 1033 U es la única serie en la que se detecta de 1998 a 2011 de todas las series analizadas (tabla 10).

Cabe pensar que se trata de una inhomogeneidad "no climatológica".

Como conclusiones del análisis temporal de las rachas de precipitación anuales,

Tras detectar las rupturas de las series de precipitación, se aplica el test de las rachas a cada intervalo (caso de rupturas) y a la serie completa (caso de no rupturas), encontrándose:

1.- Un número muy pequeño de inhomogeneidades "no climatológicas": 1017 (1962 a 1975), 1050L (1987 a 2008) y $1033 \mathrm{U}$ (1998 a 2011).

2.- El número máximo de inhomogeneidades se detecta entre 1986 y 2006.

3.- Es importante incluir en el estudio a las series de datos antiguas, para poder clasificar las inhomogeneidades entre "climatológicas" y no "climatológicas", mediante una comparativa del comportamiento de la precipitación entre emplazamientos cercanos.

Esto es, para conocer la evolución temporal de la homogeneidad de una serie larga es preciso realizar un estudio global incluyendo las series de datos antiguas.

4.- Gran similitud entre los comportamientos de series próximas (tablas 15, 16, 17, 18,19 y 20), pudiendo hablar no sólo de inhomogeneidades "climatológicas" a nivel provincial, sino de inhomogeneidades "climatológicas" a nivel comarcal.

Esto refleja características climáticas similares a escala comarcal.

5.- De la tabla 10, las inhomogeneidades entre 1986 y 2003 se observan primero en la comarca de San Sebastián, pareciendo desplazarse en años posteriores al interior de la provincia. 
6.- De los datos de las tablas 4, 6, 7 y 10 a 20, se insinúa un ciclo en la precipitación anual a 10 y 30 años. Las tablas 22 y 22 bis reflejan los años con precipitaciones máximas y mínimas desde 1878.

Tabla 22: Años con máximos pluviométricos:

\begin{tabular}{|l|c|c|c|c|c|c|c|}
\hline Máximos & 1879 & 1889 & 1900 & 1910 & $\mathbf{1 9 1 7}$ & $\mathbf{1 9 2 3}$ & $1930-33$ \\
\hline Máximos & $1940-42$ & $\mathbf{1 9 5 0}$ & $\mathbf{1 9 5 4}$ & 1960 & $1965-66$ & 1969 & 1974 \\
\hline Máximos & $\mathbf{1 9 7 8 - 8 4}$ & 1986 & 1990,2 & 2002 & 2013 & & \\
\hline
\end{tabular}

Tabla 22 bis: Años con mínimos de precipitación:

\begin{tabular}{|l|c|c|c|c|c|c|c|}
\hline Mínimos & 1880 & 1891 & 1899 & $\mathbf{1 9 1 2 , 1 6}$ & $1920-21$ & 1934 & $\mathbf{1 9 4 5}$ \\
\hline Mínimos & $\mathbf{1 9 4 8}$ & $1956-57$ & 1962 & & $\mathbf{1 9 7 0 - 7 2}$ & & 1983 \\
\hline Mínimos & 1989 & 1995 & $\mathbf{2 0 0 1 , 0 3}$ & $2005-06$ & & & \\
\hline
\end{tabular}

Se señalan en negrita los años con valores extremos de la serie de datos.

6.1.- Por su duración y elevada homogeneidad, los datos no incluidos en las citadas tablas se han extraído de los correspondientes a 1024D (Siglo XIX) y 1024E (desde 1928).

6.2.- Los resultados de la tabla 45 son verificados en las series 1024B, 1032, 1036O, 1046, 1049 y $1077 \mathrm{C}$.

6.3.- Asimismo, se vislumbra un segundo ciclo en la precipitación anual, más marcado en los años lluviosos:

a) Con máximos en 1954, 1965-66, 1974, 1984...

b) Mínimos en 1995, 2005-2006...

6.4.- Se insinúa un ciclo de aproximadamente 30 años en la precipitación:

a) Máximos muy significativos en precipitación: 1922-23, 1950-54 y 1978-85

b) Años muy secos: 1916, 1945-48 y 1970-72.

Se analiza con más detalle este ciclo de 10 y 30 años en la precipitación anual tras el análisis de Mann Kendall de las tendencias de la precipitación anual.

6.5.- Respecto a 2013 , se ha registrado el $2^{\circ}$ enero y febrero más lluvioso en 1024E (desde 1928), en 1037 el febrero más lluvioso desde 1981, en 1035 el enero más lluvioso y el $2^{\circ}$ febrero más lluvioso, $3^{\text {er }}$ enero y $4^{\circ}$ febrero más lluviosos en 1014 desde 1969. 


\subsubsection{3.- Precipitación MAM de 1937 a 2012:}

La gráfica 11 muestra la evolución temporal de las inhomogeneidades detectadas aplicando el test de las rachas a la precipitación MAM desde 1937 a 2012.

Gráfica 11: Evolución temporal inhomogeneidades test rachas de las series de precipitación MAM desde 1937 a 2012:

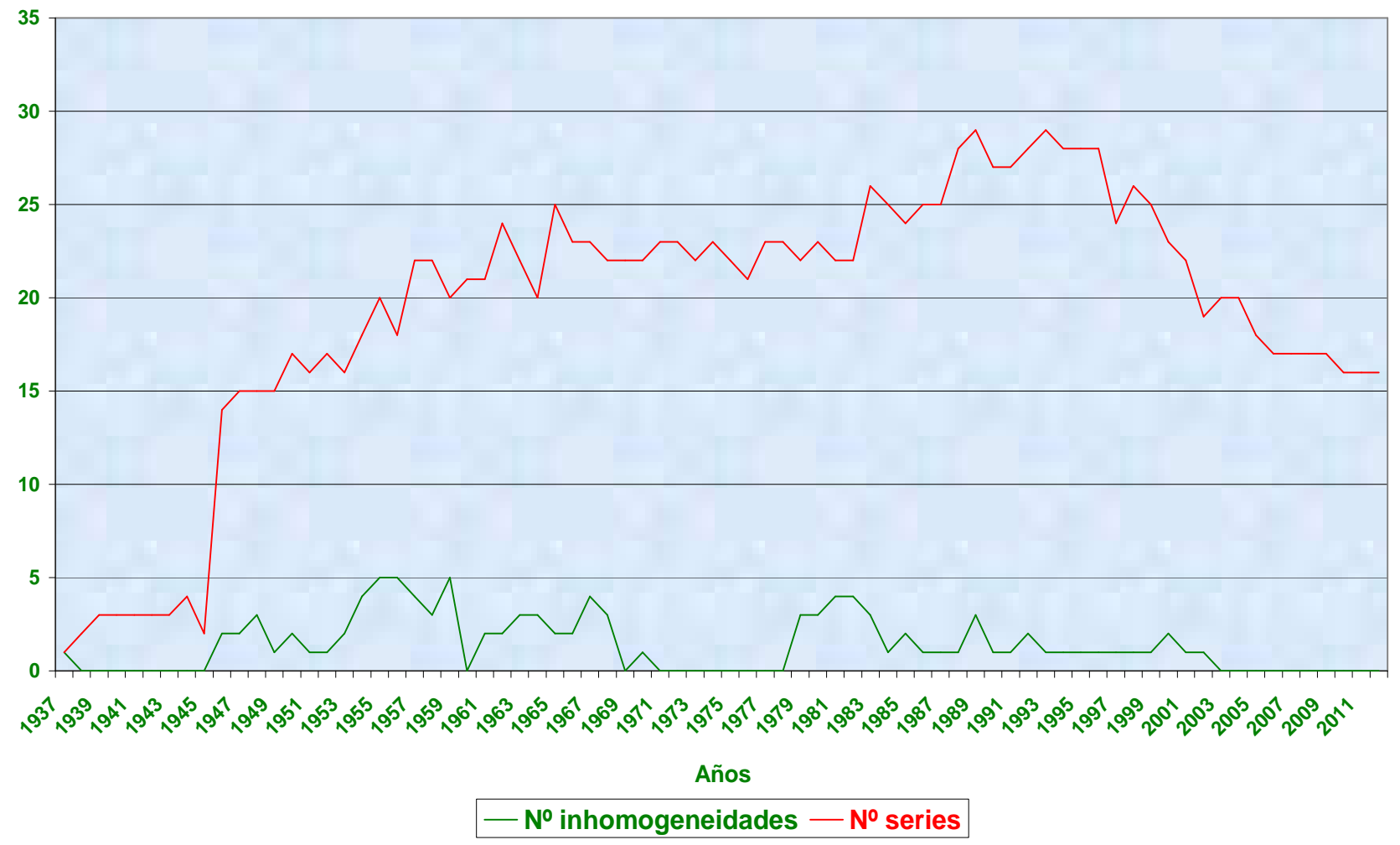

Se observan 2 máximos: entre 1954 y 1959 (correspondientes al periodo 1954 a 1968) y entre 1979 y 1983 (correspondientes al periodo 1979 a 1992).

Se representan las inhomogeneidades detectadas en un periodo de 10 años. Así, una inhomogeneidad detectada en 1981 abarca desde 1981 a 1990.

Al aplicar el test de las rachas se considera el periodo de 10 años de datos consecutivos. Cuando aparecen lagunas en las series (como en 1016) el periodo anotado se amplía hasta alcanzar el de 10 años consecutivos de datos.

Por brevedad, en la tabla 23 se agrupan en la columna de la izquierda periodos en que las inhomogeneidades se solapan y en la columna de la derecha se agrupan el \% de series que se solapan en el mismo periodo de años. 
Tabla 23: Inhomogeneidades detectadas aplicando el test de rachas a las medidas de precipitación MAM desde 1937 a 2012:

\begin{tabular}{|c|c|c|c|}
\hline $\begin{array}{l}\text { Periodo inhomogeneidad } \\
\text { (Años) }\end{array}$ & Indicativos & $\begin{array}{l}\text { Inhomogeneidad } \\
\text { "climatológica" }\end{array}$ & $\begin{array}{c}\% \text { series sobre } \\
\text { total }\end{array}$ \\
\hline $1937-1946$ & $1024 \mathrm{E}$ & Sí & $100(1)$ \\
\hline $1946-1983$ & 1045 & No & $4-7$ \\
\hline 1946 - 1959, 1948 - 1961 & 1050 & Sí & 7 \\
\hline $1947-1961$ & 1016 & Sí & $6-7$ \\
\hline $1948-1957$ & 1031 & Sí & 7 \\
\hline $1953-1962$ & 1016,1032 & Sí & 13 \\
\hline $1954-1963$ & $1016,1018,1032,1035$ & Sí & 22 \\
\hline $1955-1965$ & $\begin{array}{c}1016,1018,1032,1035 \\
1052\end{array}$ & Sí & $25-28$ \\
\hline $1957-1966$ & $1014,1018,1046$ & Sí & 14 \\
\hline $1958-1967$ & 1014,1018 & Sí & 9 \\
\hline $1959-1968$ & $1014,1018,1046,1052$ & Sí & 20 \\
\hline $1961-1970$ & 1016 & Sí & 5 \\
\hline $1962-1972$ & 1017 & Sí & 4 \\
\hline $1963-1973$ & 9268 & Sí & 5 \\
\hline $1964-1973$ & 1017,1023 & Sí & 10 \\
\hline $1965-1975$ & 1017 & Sí & 4 \\
\hline $1967-1976$ & 1036 & Sí & \multirow{3}{*}{$9-14$} \\
\hline $1967-1977$ & 1037,1050 & Sí & \\
\hline $1968-1977$ & 1023 & Sí & \\
\hline $1979-1988$ & $1025 \mathrm{E}, 1046$ & Sí & 9 \\
\hline $1979-1992$ & $1022 \mathrm{~A}$ & Sí & 4 \\
\hline $1979-1989$ & 1046 & Sí & \multirow[t]{2}{*}{9} \\
\hline $1980-1989$ & 1050 & Sí & \\
\hline $1981-1991$ & $1025 \mathrm{E}, 1037 \mathrm{O}, 1046,1050$ & Sí & 18 \\
\hline $1983-1992$ & $1037 \mathrm{O}, 1046,1050$ & Sí & 12 \\
\hline $1984-1994$ & 10370 & Sí & 4 \\
\hline $1985-1995$ & $1049 \mathrm{U}$ & Sí & 4 \\
\hline $1987-1997$ & 10370 & Sí & 4 \\
\hline $1988-1998$ & 1037Q & Sí & 4 \\
\hline $1989-1998$ & $1049 \mathrm{U}$ & Sí & 4 \\
\hline $1989-1999$ & 1037O, 1037Q & Sí & 7 \\
\hline $1990-2000$ & 1026B & Sí & $4-5$ \\
\hline $2001-2011$ & 1026B & No & 5 \\
\hline $1992-2001$ & $1021 \mathrm{E}$ & Sí & 7 \\
\hline $2000-2012$ & 1044D & ¿Sí? & 4 \\
\hline
\end{tabular}


Las tablas 24 a 33 reflejan:

a) Indicativo y nombre de la serie.

b) Duración en años detallando los años sin datos sd.

c) Los años en que se registran precipitaciones elevadas y escasas en el intervalo detectado por la inhomogeneidad, con el ordinal entre paréntesis referido al intervalo anual total de medidas de la serie.

d) La precipitación media mensual en el periodo MAM.

Al analizar un periodo de inhomogeneidades, se emplearán las series de precipitaciones teniendo en cuenta las rupturas detectadas en el apartado 4.1.

\section{1.- Inhomogeneidades de 1937 a 1946 en 1024E:}

Es la única serie de las analizadas con datos completos en este intervalo en Guipúzcoa y en Vizcaya.

Tabla 24: Años con precipitaciones máximas y mínimas:

\begin{tabular}{|c|c|c|c|c|c|}
\hline Indicativo & Duración serie & Año Máximo & $\begin{array}{c}\text { Precipitación } \\
\left(1 / \mathrm{m}^{2}\right)\end{array}$ & Año Mínimo & $\begin{array}{c}\text { Precipitación } \\
\left(1 / \mathrm{m}^{2}\right)\end{array}$ \\
\hline \multirow{3}{*}{$\begin{array}{c}\text { 1024E } \\
\text { Igueldo }\end{array}$} & \multirow{2}{*}{$1928-2012$} & $1939\left(14^{\circ}\right)$ & 152,5 & $1944\left(2^{\circ}\right)$ & 56,9 \\
\cline { 3 - 6 } & & $1940\left(24^{\circ}\right)$ & 140,7 & $1938\left(4^{\circ}\right)$ & 68,7 \\
\cline { 3 - 6 } & & & $1943\left(6^{\circ}\right)$ & 75,2 \\
\hline
\end{tabular}

Se observa una sequía: 1944, 1938 y 1943 son los años con menores precipitaciones en el periodo MAM desde 1928 a 2012 en 1024E.

Por tanto, se trata de una inhomogeneidad climatológica.

\section{2.- Inhomogeneidades de 1946 a 1983 en 1045 :}

Tiene un $24 \%$ de lagunas ( $\sin$ datos en 1948, 1949, 1951 a 1955, 1960, 1969, 1977 y 1979 a 1981). No hay registros de cambio de emplazamiento ni de colaborador.

El test de rachas no detecta ruptura de la serie y sí indica inhomogeneidad en 15 de las 16 veces en que se puede aplicar el test.

Es imposible una inhomogeneidad de origen "climatológico" que dure tantos años. Por tanto, cabe pensar en una causa "no climatológica". 
3.- Inhomogeneidades de 1946 a 1959 y 1948 a 1961 en 1050,1947 a 1961 en 1016 y 1948 a 1957 en 1031:

Tabla 25: Años con precipitaciones máximas y mínimas:

\begin{tabular}{|c|c|c|c|c|c|}
\hline Indicativo & Duración serie & Año Máximo & $\begin{array}{c}\text { Precipitación } \\
\left(1 / \mathrm{m}^{2}\right)\end{array}$ & $\begin{array}{c}\text { Año } \\
\text { Mínimo }\end{array}$ & $\begin{array}{c}\text { Precipitación } \\
\left(1 / \mathrm{m}^{2}\right)\end{array}$ \\
\hline \multirow{4}{*}{$\begin{array}{l}1050 \\
\text { Eibar }\end{array}$} & \multirow{4}{*}{$\begin{array}{c}1946-1964 \\
(\mathrm{sd} 1945,1946 \\
1955 \text { y } 1956)\end{array}$} & $1958\left(1^{\circ}\right)$ & 159,5 & $1960\left(1^{\circ}\right)$ & 56,5 \\
\hline & & $1946\left(2^{\circ}\right)$ & 140,7 & $1947\left(2^{\circ}\right)$ & 58,3 \\
\hline & & $1954\left(3^{\circ}\right)$ & 127,7 & $1953\left(3^{\circ}\right)$ & 59,8 \\
\hline & & $1951\left(5^{\circ}\right)$ & 126,5 & $1948\left(4^{\circ}\right)$ & 68,5 \\
\hline \multirow{4}{*}{$\begin{array}{c}1016 \\
\text { Oyarzun }\end{array}$} & \multirow{4}{*}{$1947-1984$} & $1958\left(5^{\circ}\right)$ & 258,0 & $1955\left(1^{\circ}\right)$ & 80,3 \\
\hline & & $1951\left(10^{\circ}\right)$ & 224,7 & $1948\left(2^{\circ}\right)$ & 106,7 \\
\hline & & & & $1947\left(3^{\circ}\right)$ & 113,0 \\
\hline & & & & $1953\left(4^{\circ}\right)$ & 131,3 \\
\hline \multirow{3}{*}{$\begin{array}{c}1031 \\
\text { Elduayen }\end{array}$} & \multirow{3}{*}{$1946-1958$} & $1958\left(1^{\circ}\right)$ & 248,9 & $1955\left(1^{\circ}\right)$ & 42,5 \\
\hline & & $1954\left(2^{\circ}\right)$ & 215,6 & $1947\left(2^{\circ}\right)$ & 72,3 \\
\hline & & $1951\left(3^{\circ}\right)$ & 206,0 & $1948\left(3^{\circ}\right)$ & 92,9 \\
\hline
\end{tabular}

a) Se observan en las 3 localidades mínimos de precipitación en 1947-1948, en 1953 y en 1955; máximos secundarios de precipitación en 1951, en 1954 y en 1958.

b) Coinciden la sucesión de máximos y mínimos registrados de precipitación, siendo coherentes entre sí y con la orografía las precipitaciones registradas.

c) Este comportamiento de alternancia entre años muy lluviosos y muy secos origina una inhomogeneidad en las 3 series (el $20 \%$ de las analizadas en ese periodo).

Por tanto, se la califica como inhomogeneidad "climatológica".

4.- Inhomogeneidades de 1953 a 1970:

Tabla 26: Años con precipitaciones máximas y mínimas:

\begin{tabular}{|c|c|c|c|c|c|}
\hline Indicativo & $\begin{array}{c}\text { Duración } \\
\text { serie }\end{array}$ & $\begin{array}{c}\text { Año } \\
\text { Máximo }\end{array}$ & $\begin{array}{c}\text { Precipitación } \\
\left(1 / \mathrm{m}^{2}\right)\end{array}$ & Año Mínimo & Precipitación $\left(1 / \mathrm{m}^{2}\right)$ \\
\hline \multirow{3}{*}{$\begin{array}{c}1014 \text { OMA } \\
\text { Fuenterrabía }\end{array}$} & \multirow{3}{*}{$1957-1968$} & $1958\left(1^{\circ}\right)$ & 177,5 & $1957\left(1^{\circ}\right)$ & 82,2 \\
\hline & & $1965\left(2^{\circ}\right)$ & 158,9 & $1966\left(2^{\circ}\right)$ & 98,8 \\
\hline & & $1964\left(3^{\circ}\right)$ & 157,2 & $1961\left(3^{\circ}\right)$ & 100,1 \\
\hline \multirow{3}{*}{$\begin{array}{c}1016 \\
\text { Oyarzun }\end{array}$} & \multirow{3}{*}{$1947-1984$} & $1958\left(5^{\circ}\right)$ & 258,0 & $1955\left(1^{\circ}\right)$ & 80,3 \\
\hline & & $1962\left(11^{\circ}\right)$ & 213,6 & $1953\left(4^{\circ}\right)$ & 131,3 \\
\hline & & & & $1960\left(5^{\circ}\right)$ & 139,2 \\
\hline \multirow{3}{*}{$\begin{array}{c}1018 \\
\text { Rentería }\end{array}$} & \multirow{3}{*}{$1950-1972$} & $1958\left(1^{\circ}\right)$ & 220,6 & $1955\left(1^{\circ}\right)$ & 55,5 \\
\hline & & $1964\left(6^{\circ}\right)$ & 174,5 & $1963\left(3^{\circ}\right)$ & 103,5 \\
\hline & & $1962\left(7^{\circ}\right)$ & 170,7 & $1957\left(5^{\circ}\right)$ & 113,4 \\
\hline \multirow{3}{*}{$\begin{array}{c}\text { 1032 Villabona } \\
\text { (sd 1937, 1938, } \\
1945,1959)\end{array}$} & \multirow{3}{*}{$1926-1987$} & $1958\left(3^{\circ}\right)$ & 203,5 & $1955\left(1^{\circ}\right)$ & 32,2 \\
\hline & & $1965\left(7^{\circ}\right)$ & 193,3 & $1953\left(6^{\circ}\right)$ & 72,3 \\
\hline & & $1951\left(12^{\circ}\right)$ & 166,4 & $1957\left(10^{\circ}\right)$ & 82,3 \\
\hline
\end{tabular}


Tabla 26 (continuación): Años con precipitaciones máximas y mínimas:

\begin{tabular}{|c|c|c|c|c|c|}
\hline Indicativo & Duración serie & Año Máximo & $\begin{array}{l}\text { Precipitación } \\
\left(1 / \mathrm{m}^{2}\right)\end{array}$ & $\begin{array}{c}\text { Año } \\
\text { Mínimo }\end{array}$ & $\begin{array}{l}\text { Precipitación } \\
\left(1 / \mathrm{m}^{2}\right)\end{array}$ \\
\hline \multirow{3}{*}{$\begin{array}{l}1035 \text { Lasarte (sd } \\
1953)\end{array}$} & \multirow{3}{*}{$1946-2012$} & $1965\left(1^{\circ}\right)$ & 226,8 & $1955\left(1^{\circ}\right)$ & 43,9 \\
\hline & & $1958\left(2^{\circ}\right)$ & 214,9 & $1957\left(8^{\circ}\right)$ & 89,5 \\
\hline & & $1964\left(8^{\circ}\right)$ & 181,8 & & \\
\hline \multirow{3}{*}{1046 Aránzazu } & \multirow{3}{*}{$1921-1968$} & $1958\left(2^{\circ}\right)$ & 206,7 & $1955\left(1^{\circ}\right)$ & 51,5 \\
\hline & & $1959\left(7^{\circ}\right)$ & 166,5 & $1960\left(3^{\circ}\right)$ & 105,1 \\
\hline & & $1968\left(8^{\circ}\right)$ & 163,1 & $1961\left(4^{\circ}\right)$ & 108,9 \\
\hline \multirow{3}{*}{1052 Motrico } & \multirow{3}{*}{$\begin{array}{c}1955-1974(\mathrm{sd} \\
1972)\end{array}$} & $1958\left(1^{\circ}\right)$ & 157,7 & $1955\left(1^{\circ}\right)$ & 43,0 \\
\hline & & $1965\left(2^{\circ}\right)$ & 136,3 & $1957\left(3^{\circ}\right)$ & 66,6 \\
\hline & & $1964\left(3^{\circ}\right)$ & 125,7 & $1966\left(4^{\circ}\right)$ & 73,8 \\
\hline
\end{tabular}

a) Se observa coincidencia en los mínimos $(1953,1955,1957)$ y en los máximos de precipitación (1958, 1962, 1964, 1965).

b) Los máximos y mínimos registrados de precipitación con coherentes entre sí y con la orografía.

c) En este intervalo se da una alternancia de años muy secos $(1955,1957)$ con años con un máximo relativo de precipitación $(1958,1962,1964,1965)$.

d) Afecta a un número elevado de series (entre el 13 y el 28\%) situadas principalmente en la Comarca de San Sebastián.

Por tanto, se la considera como inhomogeneidad "climatológica".

5.- Inhomogeneidades de 1962 a 1975 en 1017,1963 a 1973 en 9268, 1964 a 1973 en 1023:

Tabla 27: Años con precipitaciones máximas y mínimas:

\begin{tabular}{|c|c|c|c|c|c|}
\hline Indicativo & Duración serie & Año Máximo & $\begin{array}{c}\text { Precipitación } \\
\left(1 / \mathrm{m}^{2}\right)\end{array}$ & Año Mínimo & $\begin{array}{c}\text { Precipitación } \\
\left(1 / \mathrm{m}^{2}\right)\end{array}$ \\
\hline \multirow{3}{*}{$\begin{array}{c}1017 \\
\text { Oyarzun }\end{array}$} & $1954-1980$ & $1972\left(3^{\circ}\right)$ & 236,1 & $1973\left(3^{\circ}\right)$ & 128,8 \\
\cline { 3 - 6 } & $(\mathrm{sd} \mathrm{1956)}$ & $1971\left(4^{\circ}\right)$ & 225,7 & $1967\left(5^{\circ}\right)$ & 146,9 \\
\cline { 3 - 6 } & & $1962\left(5^{\circ}\right)$ & 212,9 & $1966\left(8^{\circ}\right)$ & 150,6 \\
\cline { 3 - 6 } 9268 & $1958-1973$ & $1969\left(1^{\circ}\right)$ & 213,9 & $1973\left(2^{\circ}\right)$ & 99,5 \\
\cline { 3 - 6 } Otzaurte & $(\mathrm{sd} \mathrm{1960,}$ & $1972\left(2^{\circ}\right)$ & 205,7 & $1963\left(3^{\circ}\right)$ & 112,8 \\
\cline { 3 - 6 } & $1961,1966)$ & $1965\left(4^{\circ}\right)$ & 172,9 & $1970\left(4^{\circ}\right)$ & 118,6 \\
\hline \multirow{3}{*}{$\begin{array}{c}1023 \\
\text { Astigarraga }\end{array}$} & \multirow{2}{*}{$1964-1983$} & $1971\left(6^{\circ}\right)$ & 199,3 & $1967\left(5^{\circ}\right)$ & 119,0 \\
\cline { 3 - 6 } & & $1972\left(8^{\circ}\right)$ & 173,8 & $1973\left(1^{\circ}\right)$ & 93,1 \\
\cline { 3 - 6 } & & $1969\left(9^{\circ}\right)$ & 168,4 & $1967\left(3^{\circ}\right)$ & 113,8 \\
\hline
\end{tabular}


a) Se observa coincidencia en los mínimos $(1966,1967,1973)$ y en los máximos $(1969,1971,1972)$ así como una alternancia entre los mismos.

b) Las cantidades de precipitación son coherentes con el aumento de precipitación de W a E y con el aumento de precipitación con la altitud.

c) El test indica una única inhomogeneidad en 9268.

d) Se detectan en 2 series de la comarca de San Sebastián y una del alto Oria.

Por tanto, cabe clasificarla como inhomogeneidad "climatológica".

6.- Inhomogeneidades de 1967 a 1976 en 1036,1967 a 1977 en 1037 y en 1050 y 1968 a 1977 en $1023:$

Tabla 28: Años con precipitaciones máximas y mínimas:

\begin{tabular}{|c|c|c|c|c|c|}
\hline Indicativo & Duración serie & Año Máximo & $\begin{array}{c}\text { Precipitación } \\
\left(1 / \mathrm{m}^{2}\right)\end{array}$ & Año Mínimo & $\begin{array}{c}\text { Precipitación } \\
\left(1 / \mathrm{m}^{2}\right)\end{array}$ \\
\hline \multirow{3}{*}{$\begin{array}{c}1036 \\
\text { Zarauz }\end{array}$} & \multirow{3}{*}{$1955-1986$} & $1975\left(3^{\circ}\right)$ & 161,5 & $1973\left(6^{\circ}\right)$ & 84,1 \\
\hline & & $1972\left(7^{\circ}\right)$ & 140,0 & $1970\left(8^{\circ}\right)$ & 92,5 \\
\hline & & $1971\left(9^{\circ}\right)$ & 131,7 & $1967\left(9^{\circ}\right)$ & 93,2 \\
\hline \multirow{3}{*}{$\begin{array}{c}1037 \\
\text { Legazpia }\end{array}$} & \multirow{3}{*}{$1946-1980$} & $1975\left(7^{\circ}\right)$ & 184,2 & $1967\left(4^{\circ}\right)$ & 94,9 \\
\hline & & $1971\left(8^{\circ}\right)$ & 171,7 & $1973\left(6^{\circ}\right)$ & 108,0 \\
\hline & & $1969\left(12^{\circ}\right)$ & 151,4 & $1974\left(9^{\circ}\right)$ & 113,9 \\
\hline \multirow{3}{*}{$\begin{array}{l}1050 \\
\text { Eibar }\end{array}$} & \multirow{3}{*}{$1965-1997$} & $1975\left(1^{\circ}\right)$ & 226,0 & $1973\left(2^{\circ}\right)$ & 75,8 \\
\hline & & $1972\left(2^{\circ}\right)$ & 216,5 & $1967\left(4^{\circ}\right)$ & 86,3 \\
\hline & & $1971\left(6^{\circ}\right)$ & 179,3 & $1976\left(11^{\circ}\right)$ & 120,0 \\
\hline \multirow{3}{*}{$\begin{array}{c}1023 \\
\text { Astigarraga }\end{array}$} & \multirow{3}{*}{$1964-1983$} & $1975\left(4^{\circ}\right)$ & 201,9 & $1973\left(1^{\circ}\right)$ & 93,1 \\
\hline & & $1974\left(5^{\circ}\right)$ & 200,5 & $1970\left(4^{\circ}\right)$ & 122,0 \\
\hline & & $1971\left(6^{\circ}\right)$ & 192,5 & $1977\left(5^{\circ}\right)$ & 128,3 \\
\hline
\end{tabular}

a) Inhomogeneidades localizadas en 3 zonas: Comarca de San Sebastián, Alto Urola y Medio Deba.

b) Simultaneidad de los mínimos $(1967,1970,1073)$ y máximos $(1971,1972,1975)$ registrados.

c) Coherencia entre los valores registrados: la precipitación aumenta de Oeste a Este y de Norte a Sur.

Por tanto, se la clasifica como inhomogeneidad "climatológica". 
7.- Inhomogeneidades de 1979 a 1988 y 1981 a 1991 en $1025 \mathrm{E}, 1979$ a 1992 en 1046 y en 1022A, 1980 a 1992 en 1050, 1981 a 1992 en 1037O:

Tabla 29: Años con precipitaciones máximas y mínimas:

\begin{tabular}{|c|c|c|c|c|c|}
\hline Indicativo & Duración serie & Año Máximo & $\begin{array}{c}\text { Precipitación } \\
\left(1 / \mathrm{m}^{2}\right)\end{array}$ & Año Mínimo & $\begin{array}{l}\text { Precipitación } \\
\left(1 / \mathrm{m}^{2}\right)\end{array}$ \\
\hline \multirow{3}{*}{$\begin{array}{c}1025 \mathrm{E} \\
\text { Mutiloa } \\
\end{array}$} & \multirow{3}{*}{1977 - 1993} & $1979\left(2^{\circ}\right)$ & 190,1 & $1982\left(1^{\circ}\right)$ & 77,8 \\
\hline & & $1991\left(3^{\circ}\right)$ & 178,8 & $1987\left(2^{\circ}\right)$ & 86,2 \\
\hline & & $1985\left(4^{\circ}\right)$ & 170,2 & $1984\left(3^{\circ}\right)$ & 101,4 \\
\hline \multirow{4}{*}{$\begin{array}{c}1046 \\
\text { Aranzazu }\end{array}$} & \multirow{4}{*}{$\begin{array}{c}1969 \text { - } 2001 \\
(\mathrm{sd} 1991 \mathrm{a} \\
1998 \text { y } 2000)\end{array}$} & $1979\left(2^{\circ}\right)$ & 223,7 & $1987\left(3^{\circ}\right)$ & 112,0 \\
\hline & & $1980\left(7^{\circ}\right)$ & 189,9 & $1982\left(5^{\circ}\right)$ & 125,6 \\
\hline & & $1983\left(8^{\circ}\right)$ & 182,8 & $1984\left(8^{\circ}\right)$ & 147,7 \\
\hline & & $1988\left(10^{\circ}\right)$ & 176,4 & $1989\left(10^{\circ}\right)$ & 152,1 \\
\hline \multirow{4}{*}{$\begin{array}{c}1022 \mathrm{~A} \\
\text { Hernani }\end{array}$} & \multirow{4}{*}{$\begin{array}{c}1946-1992 \\
\text { (sd 1956 a } \\
1975,1983, \\
1986,1990)\end{array}$} & $1985\left(1^{\circ}\right)$ & 196,2 & $1982\left(3^{\circ}\right)$ & 74,8 \\
\hline & & $1991\left(3^{\circ}\right)$ & 167,6 & $1987\left(7^{\circ}\right)$ & 97,5 \\
\hline & & $1979\left(8^{\circ}\right)$ & 156,0 & $1981\left(10^{\circ}\right)$ & 112,1 \\
\hline & & $1980\left(10^{\circ}\right)$ & 141,2 & $1992\left(12^{\circ}\right)$ & 118,3 \\
\hline \multirow{3}{*}{$\begin{array}{l}1050 \\
\text { Eibar }\end{array}$} & \multirow{3}{*}{$1965-1997$} & $1991\left(4^{\circ}\right)$ & 180,2 & $1987\left(3^{\circ}\right)$ & 81,8 \\
\hline & & $1985\left(6^{\circ}\right)$ & 174,2 & $1982\left(5^{\circ}\right)$ & 92,8 \\
\hline & & $1988\left(7^{\circ}\right)$ & 171,0 & $1981\left(10^{\circ}\right)$ & 119,6 \\
\hline \multirow{3}{*}{$\begin{array}{c}10370 \\
\text { Azcoitia }\end{array}$} & \multirow{3}{*}{$\begin{array}{c}1977-2001 \\
(\text { sd 1995) }\end{array}$} & $1991\left(2^{\circ}\right)$ & 173,1 & $1982\left(1^{\circ}\right)$ & 40,5 \\
\hline & & $1992\left(7^{\circ}\right)$ & 148,4 & $1987\left(3^{\circ}\right)$ & 70,5 \\
\hline & & $1988\left(9^{\circ}\right)$ & 139,7 & $1983\left(4^{\circ}\right)$ & 84,9 \\
\hline
\end{tabular}

a) Las inhomogeneidades están localizadas en el Alto y Medio Deba, en el Alto Oria, en el Medio Urola y en la Comarca de San Sebastián, afectando al 15- 18\% de las series.

b) Simultaneidad de los mínimos $(1982,1984,1987)$ y de los máximos $(1979,1980$, 1985, 1988, 1991).

c) En los emplazamientos analizados en la tabla 29, a los muy lluviosos 1979 y 1980 le sigue un mínimo de precipitaciones de 1981 a 1987 interrumpido por un máximo secundario de precipitación en 1985, para terminar la década con un máximo relativo de precipitación.

d) Estas alternancias en la precipitación MAM en torno a su mediana originan un número de rachas elevado, causa de las inhomogeneidades detectadas por el test de rachas.

e) Coherencia espacial entre las precipitaciones registradas en los diferentes emplazamientos.

Por tanto, se la considera como inhomogeneidad "climatológica". 
8.- Inhomogeneidades de 1984 a 1994,1987 a 1997 y 1989 a 1999 en 10370,1985 a 1995 y 1989 a 1998 en 1049 U, 1988 a 1999 en 1037Q:

Tabla 30: Años con precipitaciones máximas y mínimas:

\begin{tabular}{|c|c|c|c|c|c|}
\hline Indicativo & Duración serie & Año Máximo & $\begin{array}{c}\text { Precipitación } \\
\left(1 / \mathrm{m}^{2}\right)\end{array}$ & Año Mínimo & $\begin{array}{c}\text { Precipitación } \\
\left(1 / \mathrm{m}^{2}\right)\end{array}$ \\
\hline \multirow{3}{*}{$\begin{array}{c}10370 \\
\text { Azcoitia }\end{array}$} & \multirow{3}{*}{$\begin{array}{l}1977-2001 \\
\quad(\text { sd 1995) }\end{array}$} & $1991\left(2^{\circ}\right)$ & 173,1 & $1996\left(2^{\circ}\right)$ & 68,2 \\
\hline & & $1994\left(3^{\circ}\right)$ & 168,3 & $1987\left(3^{\circ}\right)$ & 70,5 \\
\hline & & $1993\left(4^{\circ}\right)$ & 160,6 & $1999\left(5^{\circ}\right)$ & 88,0 \\
\hline \multirow{4}{*}{$\begin{array}{l}1049 \mathrm{U} \\
\text { Ermua }\end{array}$} & \multirow{4}{*}{$1984-2005$} & $1994\left(1^{\circ}\right)$ & 198,7 & $1996\left(1^{\circ}\right)$ & 64,9 \\
\hline & & $1991\left(2^{\circ}\right)$ & 188,7 & $1987\left(2^{\circ}\right)$ & 74,9 \\
\hline & & $1985\left(4^{\circ}\right)$ & 164,5 & $1997\left(3^{\circ}\right)$ & 85,5 \\
\hline & & $1988\left(5^{\circ}\right)$ & 162,1 & $1995\left(6^{\circ}\right)$ & 101,7 \\
\hline \multirow{3}{*}{$\begin{array}{c}\text { 1037Q } \\
\text { Azcoitia }\end{array}$} & \multirow{3}{*}{$\begin{array}{c}1986-1999 \\
(\text { sd 1992) }\end{array}$} & $1991\left(1^{\circ}\right)$ & 238,6 & $1997\left(1^{\circ}\right)$ & 68,9 \\
\hline & & $1988\left(2^{\circ}\right)$ & 142,0 & $1996\left(2^{\circ}\right)$ & 72,1 \\
\hline & & $1990\left(3^{\circ}\right)$ & 140,5 & $1995\left(4^{\circ}\right)$ & 91,8 \\
\hline
\end{tabular}

a) Las estaciones se encuentran en el Medio Urola y Medio Deba, a una distancia inferior a $16 \mathrm{Km}$.

b) Simultaneidad de los mínimos $(1987,1996,1997)$ y de los máximos $(1988,1991$, 1994).

c) Resulta sospechosa la diferencia de precipitación recogida en $1037 \mathrm{O}$ y en $1037 \mathrm{Q}$ en 1991.

d) Se prolonga la inhomogeneidad de 10370 hasta 1999.

Por tanto, se la califica como inhomogeneidad "climatológica".

9.- Inhomogeneidades de 1990 a 2011 en 1026B:

Tabla 31: Años con precipitaciones máximas y mínimas:

\begin{tabular}{|c|c|c|c|c|c|}
\hline Indicativo & Duración serie & Año Máximo & $\begin{array}{c}\text { Precipitación } \\
\left(1 / \mathrm{m}^{2}\right)\end{array}$ & Año Mínimo & $\begin{array}{c}\text { Precipitación } \\
\left(1 / \mathrm{m}^{2}\right)\end{array}$ \\
\hline \multirow{3}{*}{$\begin{array}{c}\text { 1026B } \\
\text { Lareo }\end{array}$} & \multirow{2}{*}{$1989-2012$} & $2008\left(1^{\mathbf{o}}\right)$ & 288,2 & $1997\left(3^{\mathbf{o}}\right)$ & 121,3 \\
\cline { 3 - 6 } & & $2007\left(2^{\mathbf{o}}\right)$ & 228,3 & $2003\left(4^{\mathbf{o}}\right)$ & 125,3 \\
\cline { 2 - 5 } & $1991\left(3^{\mathbf{o}}\right)$ & 224,9 & $2001\left(5^{\mathbf{o}}\right)$ & 125,9 \\
\hline
\end{tabular}

a) El mínimo de 1997 y el máximo de 1991 son coherentes con los reflejados en las tablas 29 y 30 .

Por tanto, se considera el periodo hasta 2001 (esto es, de 1990 a 2000) como inhomogeneidad "climatológica", simultáneo al mismo intervalo temporal analizado en el punto 8 en 1037O, 1037Q y 1049U.

Se clasifica el periodo posterior de inhomogeneidades de 1026B (2001 a 2011) como inhomogeneidad "no climatológica". 
10.- Inhomogeneidades de 1992 a 2001 en 1021E:

Tabla 32: Años con precipitaciones máximas y mínimas:

\begin{tabular}{|c|c|c|c|c|c|}
\hline Indicativo & Duración serie & Año Máximo & $\begin{array}{c}\text { Precipitación } \\
\left(1 / \mathrm{m}^{2}\right)\end{array}$ & Año Mínimo & $\begin{array}{c}\text { Precipitación } \\
\left(1 / \mathrm{m}^{2}\right)\end{array}$ \\
\hline \multirow{3}{*}{$\begin{array}{c}\text { 1021E } \\
\text { Añarbe }\end{array}$} & \multirow{3}{*}{$1989-2012$} & $1994\left(4^{\mathbf{o}}\right)$ & 221,4 & $1996\left(1^{\mathbf{o}}\right)$ & 104,2 \\
\cline { 3 - 5 } & & $1992\left(6^{\circ}\right)$ & 203,3 & $1993\left(2^{\circ}\right)$ & 117,1 \\
\cline { 3 - 5 } & & $1999\left(8^{\circ}\right)$ & 192,9 & $1997\left(4^{\circ}\right)$ & 132,8 \\
\cline { 3 - 5 } & $2001\left(9^{\circ}\right)$ & 171,9 & $1995\left(6^{\circ}\right)$ & 136,2 \\
\hline
\end{tabular}

a) El test indica sólo una inhomogeneidad en 15 pruebas del test de rachas.

b) Mínimos $(1996,1997)$ y máximo (1994) coherentes temporal y espacialmente con los de la tabla 30.

c) El intervalo analizado comienza en 2 años lluviosos (1992 y 1994) separados por el seco 1993; prosigue con una sucesión de años secos para finalizar con 2 años lluviosos 1999 y 2001.

Esta alternancia de valores de precipitación en torno a la mediana de precipitaciones en MAM es la causa de la inhomogeneidad detectada por el test de las rachas.

Por tanto, se la puede considerar como inhomogeneidad "climatológica", dada la excelente calidad de la serie y la concordancia de los valores extremos de precipitación con los expuestos en la tabla 30 .

11.- Inhomogeneidades de 2000 a 2012 en 1044D:

Tabla 33: Años con precipitaciones máximas y mínimas:

\begin{tabular}{|c|c|c|c|c|c|}
\hline Indicativo & Duración serie & Año Máximo & $\begin{array}{c}\text { Precipitación } \\
\left(1 / \mathrm{m}^{2}\right)\end{array}$ & Año Mínimo & $\begin{array}{c}\text { Precipitación } \\
\left(1 / \mathrm{m}^{2}\right)\end{array}$ \\
\hline 1044D & $1995-2012$ & $2008\left(1^{\mathbf{o}}\right)$ & 238,1 & $2010\left(1^{\mathbf{o}}\right)$ & 72,0 \\
\cline { 3 - 6 } Aramayona & $(\mathrm{sd} 2001$, & $2007\left(2^{\mathbf{o}}\right)$ & 205,1 & $2006\left(2^{\mathbf{o}}\right)$ & 85,8 \\
\cline { 3 - 6 } & $2002,2003)$ & $2005\left(3^{\mathbf{o}}\right)$ & 149,0 & $1996\left(4^{\mathbf{o}}\right)$ & 91,8 \\
\hline
\end{tabular}

a) Mínimo de 1996 coherente con los resultados de las tablas 30 y 32, detectándose un incremento de las precipitaciones en MAM hacia el Este y el Sur.

a) Se detecta una homogeneidad en 6 pruebas del test.

b) 1044D no destaca por su homogeneidad.

Por tanto, se la pueda considerar, albergando ciertas dudas, como inhomogeneidad "climatológica". 
Como conclusiones del análisis temporal de las rachas de precipitación en MAM,

Tras detectar las rupturas de las series de precipitación, se aplica el test de las rachas a cada intervalo (caso de rupturas) y a la serie completa (caso de no rupturas) de precipitación en el periodo MAM, encontrándose:

1.- Un número muy pequeño de inhomogeneidades "no climatológicas": 1045 (1946 a 1983), 1026B (2001 a 2011).

2.- Dos máximos en las inhomogeneidades: Entre 1954 y 1959 (correspondientes al periodo 1954 a 1968) y entre 1979 y 1983 (correspondientes al periodo 1979 a 1992, tras los máximos históricos de precipitación en MAM).

La primera inhomogeneidad afecta principalmente a series de la Comarca de San Sebastián y del Medio Oria, mientras que la segunda a series situadas en el interior de la provincia, en las comarcas del Alto y Medio Deba y Alto Oria.

3.- Gran semejanza entre los comportamientos de series próximas (reflejado en las tablas 26, 28, 29 y 30), pudiendo hablar no sólo de inhomogeneidades "climatológicas" a nivel provincial, sino de inhomogeneidades "climatológicas" a nivel comarcal.

Por ejemplo en el intervalo de 1984 a 1999, con inhomogeneidades exclusivamente en 1037O, 1037Q y 1049U (Medio Urola y Medio Deba), distantes entre sí menos de 16 $\mathrm{Km}$.

4.- De las tablas 29 y 30, se insinúa un mínimo pluviométrico en el Urola Medio en MAM en los años 90.

5.- Al incrementarse el número de series, de 1926 hasta 1936 se puede hablar de inhomogeneidades a nivel de la provincia. A partir de 1946, se insinúan "inhomogeneidades" a nivel comarcal.

6.- De los datos de las tablas 4, 5 bis, 8 y 23 a 33, se insinúa una periodicidad en la precipitación MAM de 10 años. Las tablas 34 y 34 bis reflejan los años con precipitaciones máximas y mínimas desde 1878.

Tabla 34: Años con máximos pluviométricos en precipitación MAM:

\begin{tabular}{|l|c|c|c|c|c|c|c|}
\hline Máximos & 1879 & 1884 & $1889-90$ & $1894-95$ & $1900-01$ & & 1908 \\
\hline Máximos & 1917 & 1922,23 & 1925 & $1930-31$ & 1933 & $1939-40$ & 1942 \\
\hline Máximos & 1951 & 1954 & 1958 & $1964-65$ & 1969 & $1972-74$ & $\mathbf{1 9 7 8 , 7 9 , 8 0}$ \\
\hline Máximos & $1985-86$ & 1991 & 1994 & 2000 & & $2007-08$ & $\mathbf{2 0 1 3}$ \\
\hline
\end{tabular}


Tabla 34 bis: Años con mínimos pluviométricos en precipitación MAM:

\begin{tabular}{|l|c|c|c|c|c|c|c|}
\hline Mínimos & & 1882 & 1888 & $1892-93$ & $1898-99$ & 1904 & 1909 \\
\hline Mínimos & 1915 & 1921 & 1924 & 1929 & 1934 & 1938 & $\mathbf{1 9 4 3 - 4 4}$ \\
\hline Mínimos & $1947-48$ & 1953 & 1957 & 1963 & $1966-67$ & $\mathbf{1 9 7 3}$ & \\
\hline Mínimos & 1984 & 1987 & $1992-93$ & $1996-97$ & 2001 & $\mathbf{2 0 0 3}$ & $2010-11$ \\
\hline
\end{tabular}

Se señalan en negrita los años con valores extremos de la serie de datos. En cursiva con fondo azul se marcan los máximos y mínimos secundarios.

Se dejan en blanco los años en que no parece cumplirse la cadencia del ciclo; por ejemplo de 1973 a 1984 no afloran mínimos de precipitación, debido al efecto de 1978, 1979 y 1980 efemérides de precipitación.

Por su duración y elevada homogeneidad, los datos no incluidos en tablas 34 y 34 bis se han extraído de los correspondientes a 1024D (Siglo XIX). Los resultados de las tablas 34 y 34 bis son comprobados en las series 1024B, 1032, 1036O, 1046, 1049 y 1077C.

6.A) Se insinúa un doble ciclo de 10 años: 2 ciclos de aproximadamente 10 años en la precipitación MAM, con sucesivos periodos lluviosos y secos.

La cadencia del primer ciclo de máximos sería: 1879, 1889-90, 1900-01 ...

La cadencia del segundo ciclo de máximos sería: 1884, 1894-95, 1917, 1925 ...

La cadencia del primer ciclo de mínimos sería: 1882, 1992-93, 1904, 1915, 1924

La cadencia del segundo ciclo de mínimos sería: 1888, 1898-99, 1909, $1921 \ldots$

6.B) Se insinúa un ciclo de aproximadamente 30 años en la precipitación, con la cadencia en mínimos: $1943-44,1973,2003$.

6.C) Los huecos parecen producirse en situaciones de precipitaciones muy elevadas (década de los 70) y de sequías (primeros cinco años del siglo XX)

6.D) Se observa una sucesión de años muy lluviosos (en verde) y años secos: 1888, 1889, 1893, 1894, 1899, 1900, 1908, 1909, 1910, 1921, 1923, 1924, 1925, 1928, 1930,... apareciendo correlativos periodos MAM secos y lluviosos.

Respecto a 2013 , es el $8^{\circ}$ marzo más lluvioso desde 1981 en 1037 , el $7^{\circ}$ más lluvioso desde 1989 en $1021 \mathrm{E}$ y el $16^{\circ}$ más lluvioso en 1014 desde 1969.

Se analiza con más detalle este ciclo de 10 y 30 años en la precipitación MAM tras el análisis de Mann Kendall de las tendencias de la precipitación MAM. 


\subsubsection{4.- Precipitación AMJ de 1941 a 2012:}

La gráfica 12 expone la evolución temporal de las inhomogeneidades detectadas aplicando el test de las rachas a la precipitación AMJ de 1941 a 2012.

Gráfica 12: Evolución temporal inhomogeneidades test rachas de las series de precipitación AMJ desde 1941 a 2012:

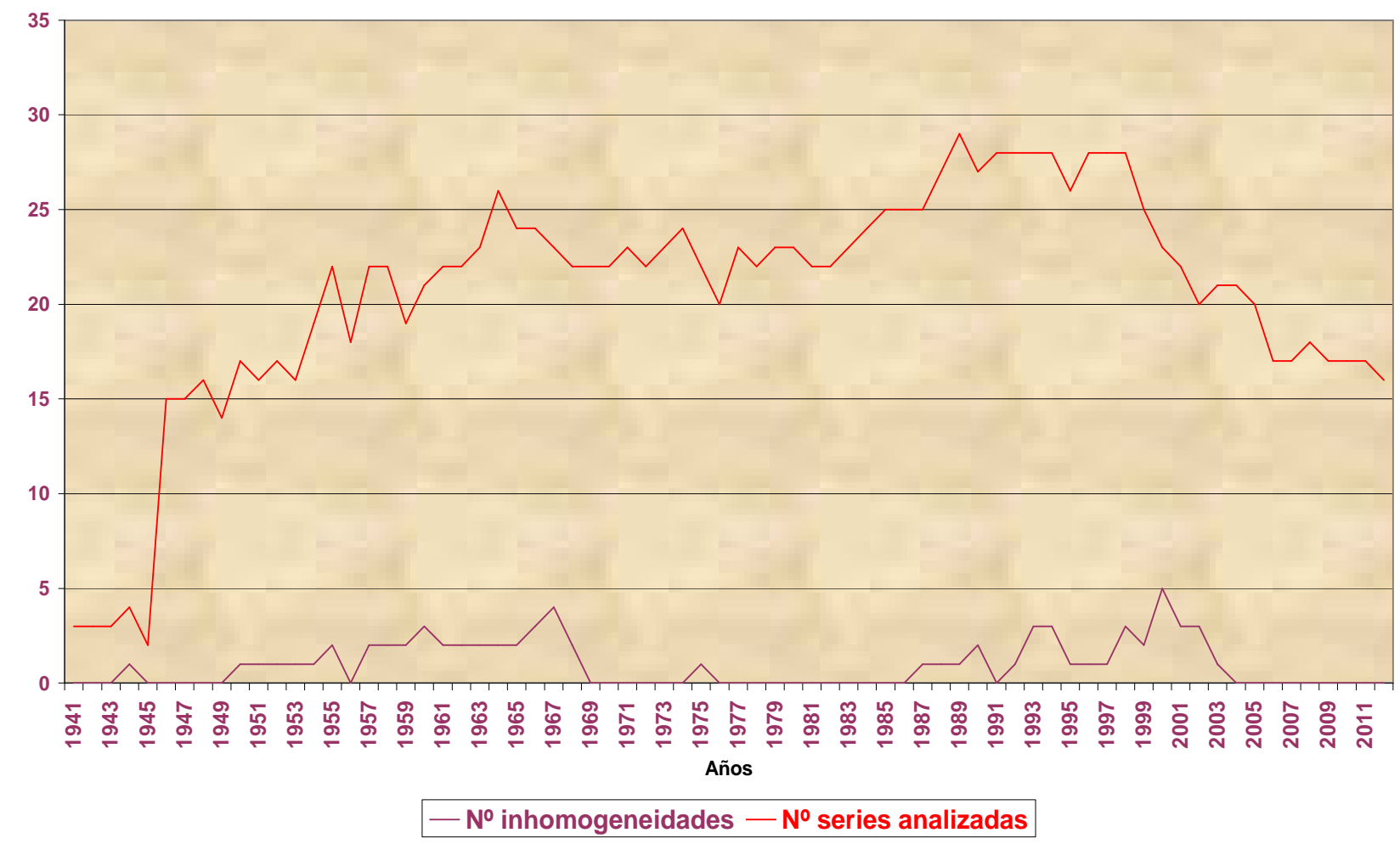

Se observan 2 periodos principales de inhomogeneidades: entre 1957 y 1968 (correspondientes al periodo 1957 a 1977) y entre 1993 y 2002 (correspondientes al periodo 1993 a 2011).

Se representan las inhomogeneidades detectadas en un periodo de 10 años. Así, una inhomogeneidad detectada en 1966 abarca desde 1966 a 1975.

Al aplicar el test de las rachas se considera el periodo de 10 años de datos consecutivos. Cuando aparecen lagunas en las series (como en 1016) el periodo anotado se amplía hasta alcanzar el de 10 años consecutivos de datos.

Por brevedad, en la tabla 35 se agrupan en la columna de la izquierda periodos en que las inhomogeneidades se solapan y en la columna de la derecha se agrupan el \% de series que se solapan en el mismo periodo de años. 
Tabla 35 Inhomogeneidades detectadas aplicando el test de rachas a las medidas de precipitación AMJ desde 1941 a 2012:

\begin{tabular}{|c|c|c|c|}
\hline $\begin{array}{c}\text { Periodo } \\
\text { inhomogeneidad (Años) }\end{array}$ & Indicativos & $\begin{array}{l}\text { Inhomogeneidad } \\
\text { "climatológica" }\end{array}$ & $\begin{array}{c}\% \text { series sobre } \\
\text { total }\end{array}$ \\
\hline $1944-1955$ & 9268 & Sí & $25(4)$ \\
\hline $1950-1962$ & 1037 & $\overline{\text { Sí }}$ & 6 \\
\hline $1954-1963$ & 1024E & Sí & 5 \\
\hline $1955-1964$ & $1024 \mathrm{E}, 1037$ & Sí & 9 \\
\hline $1957-1968$ & 1017,1018 & Sí & $9-10$ \\
\hline $1960-1969$ & $1017,1018,1024$ & Sí & 14 \\
\hline $1961-1973$ & 1017,1024 & Sí & $8-9$ \\
\hline $1965-1974$ & $1016,1024 \mathrm{E}$ & Sí & 8 \\
\hline $1966-1975$ & 1024E, 1032, 1036 & Sí & 13 \\
\hline $1967-1976$ & 1018A, 1024E, 1032, 1036 & Sí & 17 \\
\hline $1968-1977$ & $1018 \mathrm{~A}, 1032$ & Sí & 9 \\
\hline $1975-1986$ & 10210 & No & 5 \\
\hline $1987-1996$ & 1019A & Sí & 4 \\
\hline $1988-1999$ & 1037Q & Sí & 4 \\
\hline $1989-1999$ & 1019A & Sí & 4 \\
\hline $1990-2001$ & 1041 & Sí & 4 \\
\hline $1993-2003$ & $1024 \mathrm{E}, 1025 \mathrm{~N}, 1041$ & Sí & 11 \\
\hline $1995-2006$ & $1025 \mathrm{~N}$ & $\overline{\text { Sí }}$ & 4 \\
\hline $1998-2007$ & 1041 & Sí & 4 \\
\hline $1998-2012$ & $1025 \mathrm{~N}, 1044 \mathrm{D}$ & Sí & $7-8$ \\
\hline $2000-2009$ & 1024 & Sí & 4 \\
\hline $2000-2011$ & 1026B, 1037 & Sí & $9-10$ \\
\hline $2003-2012$ & 1037 & Sí & 5 \\
\hline
\end{tabular}

Las tablas 36 a 44 reflejan:

a) Indicativo y nombre de la serie.

b) Duración en años detallando los años sin datos sd.

c) Los años en que se registran precipitaciones elevadas y escasas en el intervalo detectado por la inhomogeneidad, con el ordinal entre paréntesis referido al intervalo anual total de medidas de la serie.

d) La precipitación media mensual en el periodo MAM.

Al analizar un periodo de inhomogeneidades, se emplearán las series de precipitaciones teniendo en cuenta las rupturas detectadas en el apartado 4.1. 
1.- 1944 a 1955 en 9268 :

Tabla 36: Años con precipitaciones máximas y mínimas:

\begin{tabular}{|c|c|c|c|c|c|}
\hline Indicativo & Duración serie & Año Máximo & $\begin{array}{c}\text { Precipitación } \\
\left(1 / \mathrm{m}^{2}\right)\end{array}$ & Año Mínimo & $\begin{array}{c}\text { Precipitación } \\
\left(1 / \mathrm{m}^{2}\right)\end{array}$ \\
\hline \multirow{2}{*}{$\begin{array}{c}9268 \\
\text { Otzaurte }\end{array}$} & $\begin{array}{c}1944-1957 \\
(\mathrm{sd} 1955)\end{array}$ & $1954\left(1^{\circ}\right)$ & 142,0 & $1947\left(1^{\circ}\right)$ & 62,3 \\
\cline { 3 - 6 } & $1951\left(2^{\circ}\right)$ & 137,8 & $1944\left(2^{\circ}\right)$ & 66,0 \\
\hline
\end{tabular}

1.1.- Los máximos $(1954,1951)$ y mínimos $(1944,1947)$ abarcan el periodo de sequía de los años 40 y la recuperación de la precipitación en la década de los 50.

1.2.- Sólo se detecta en una serie de las 4 activas en 1944.

Por tanto, se la considera como inhomogeneidad "climatológica".

2.- 1950 a 1962 y 1955 a 1964 en 1037 y 1954 a 1964 en $1024 \mathrm{E}:$

Tabla 37: Años con precipitaciones máximas y mínimas:

\begin{tabular}{|c|c|c|c|c|c|}
\hline Indicativo & Duración serie & Año Máximo & $\begin{array}{c}\text { Precipitación } \\
\left(1 / \mathrm{m}^{2}\right)\end{array}$ & Año Mínimo & $\begin{array}{c}\text { Precipitación } \\
\left(1 / \mathrm{m}^{2}\right)\end{array}$ \\
\hline \multirow{3}{*}{$\begin{array}{c}1037 \\
\text { Legazpia }\end{array}$} & \multirow{2}{*}{$1946-1980$} & $1951\left(1^{\circ}\right)$ & 190,2 & $1955\left(1^{\circ}\right)$ & 39,1 \\
\cline { 3 - 5 } & & $1950\left(3^{\circ}\right)$ & 175,1 & $1960\left(3^{\circ}\right)$ & 71,7 \\
\cline { 3 - 5 } & $1956\left(4^{\circ}\right)$ & 174,4 & $1963\left(7^{\circ}\right)$ & 90,9 \\
\hline \multirow{3}{*}{$\begin{array}{c}\text { 1024E } \\
\text { Igueldo }\end{array}$} & \multirow{2}{*}{$1928-2012$} & $1964\left(13^{\circ}\right)$ & 151,8 & $1955\left(2^{\circ}\right)$ & 57,3 \\
\cline { 3 - 5 } & & $1961\left(19^{\circ}\right)$ & 142,2 & $1963\left(14^{\circ}\right)$ & 86,7 \\
\cline { 3 - 5 } & & & $1954\left(15^{\circ}\right)$ & 88,3 \\
\hline
\end{tabular}

2.1.- Mínimos de precipitación concordantes en 1955 y 1963. 1955 lo fue también en 9268 (tabla 36). 1951 fue máximo en 1037 y en 9268 (tabla 36).

2.2.- En el análisis de estas inhomogeneidades:

2.2.1.- 1037 abarca un periodo de un máximo significativo en 1951 y en 1950, una sequía en 1954-1955 y la posterior recuperación.

2.2.2.- El intervalo analizado en 1024E arranca en 1954 y 1955, años de sequía y finaliza con los máximos secundarios pluviométricos en 1961 y en 1964, con un mínimo secundario de precipitación en 1963.

2.3.- Se produce en 2 series de excelente calidad: en 1037, el test señala 5 inhomogeneidades en 26 pruebas y en 1024E, 7 inhomogeneidades en 76 pruebas.

Por tanto, se la considera como inhomogeneidad "climatológica". 
3.- 1957 a 1973 en 1017,1957 a 1969 en 1018 y 1960 a 1973 en $1024:$

Tabla 38: Años con precipitaciones máximas y mínimas:

\begin{tabular}{|c|c|c|c|c|c|}
\hline Indicativo & Duración serie & Año Máximo & $\begin{array}{c}\text { Precipitación } \\
\left(1 / \mathrm{m}^{2}\right)\end{array}$ & Año Mínimo & $\begin{array}{c}\text { Precipitación } \\
\left(1 / \mathrm{m}^{2}\right)\end{array}$ \\
\hline \multirow{3}{*}{$\begin{array}{c}1017 \\
\text { Oyarzun }\end{array}$} & $\begin{array}{c}1954-1980 \\
(\mathrm{sd} \mathrm{1956)}\end{array}$ & $1957\left(1^{\circ}\right)$ & 259,5 & $1967\left(5^{\circ}\right)$ & 124,4 \\
\cline { 3 - 6 } & & $1961\left(3^{\circ}\right)$ & 223,7 & $1973\left(6^{\circ}\right)$ & 128,8 \\
\hline \multirow{3}{*}{$\begin{array}{c}1018 \\
\text { Rentería }\end{array}$} & \multirow{3}{*}{$1950-1972$} & $1969\left(4^{\circ}\right)$ & 211,2 & $1970\left(7^{\circ}\right)$ & 144,9 \\
\cline { 3 - 6 } & & $1958\left(4^{\circ}\right)$ & 176,6 & $1967\left(3^{\circ}\right)$ & 100,1 \\
\cline { 3 - 6 } & & $1961\left(6^{\circ}\right)$ & 161,5 & $1963\left(4^{\circ}\right)$ & 105,5 \\
\hline \multirow{3}{*}{$\begin{array}{c}1024 \\
\text { San Sebastián }\end{array}$} & \multirow{3}{*}{$1960-1985$} & $1962\left(7^{\circ}\right)$ & 156,8 & $1959\left(7^{\circ}\right)$ & 112,1 \\
\cline { 3 - 6 } & & $1971\left(4^{\circ}\right)$ & 152,4 & $1967\left(2^{\circ}\right)$ & 84,6 \\
\cline { 3 - 6 } & & $1961\left(7^{\circ}\right)$ & 143,0 & $1963\left(3^{\circ}\right)$ & 89,0 \\
\cline { 3 - 6 } & & $1964\left(11^{\circ}\right)$ & 140,9 & $1960\left(4^{\circ}\right)$ & 92,1 \\
\hline
\end{tabular}

3.1.- Coinciden máximos $(1958,1961)$ y mínimos $(1960,1963,1967)$ de precipitación. Los máximos de 1964 y 1961 y los mínimos de 1960 y 1963 los refleja también la tabla 37.

3.2.- De las tablas 37 y 38 , se observa que las precipitaciones son coherentes, reflejando que aumentan de Oeste a Este.

3.3.- Las 3 series están sobre una línea recta, orientada de W a Este, con extremos en 1024 (W) y 1017 (E) cubriendo una distancia de 8,5 Km.

Por tanto, se la clasifica como inhomogeneidad "climatológica", reflejo de una variación del clima a nivel comarcal.

4.- 1965 a 1974 en 1016, 1965 a 1976 en 1024E, 1966 a 1977 en 1032, 1966 a 1976 en 1036 y 1967 a 1977 en 1018A:

Tabla 39: Años con precipitaciones máximas y mínimas:

\begin{tabular}{|c|c|c|c|c|c|}
\hline Indicativo & Duración serie & Año Máximo & $\begin{array}{c}\text { Precipitación } \\
\left(1 / \mathrm{m}^{2}\right)\end{array}$ & Año Mínimo & $\begin{array}{l}\text { Precipitación } \\
\left(1 / \mathrm{m}^{2}\right)\end{array}$ \\
\hline \multirow{3}{*}{$\begin{array}{c}1016 \\
\text { Oyarzun }\end{array}$} & \multirow{3}{*}{$1947-1984$} & $1972\left(10^{\circ}\right)$ & 213,0 & $1967\left(5^{\circ}\right)$ & 124,4 \\
\hline & & $1971\left(12^{\circ}\right)$ & 202,5 & $1974\left(6^{\circ}\right)$ & 137,5 \\
\hline & & & & $1970\left(9^{\circ}\right)$ & 144,9 \\
\hline \multirow{2}{*}{$\begin{array}{l}\text { 1024E } \\
\text { Igueldo }\end{array}$} & \multirow[t]{2}{*}{$1928-2012$} & $1971\left(12^{\circ}\right)$ & 151,9 & $1976\left(16^{\circ}\right)$ & 89,8 \\
\hline & & $1972\left(16^{\circ}\right)$ & 149,1 & & \\
\hline \multirow{4}{*}{$\begin{array}{c}1032 \\
\text { Villabona }\end{array}$} & \multirow{4}{*}{$\begin{array}{c}1926-1987 \\
\text { (sd 1937, } \\
1938,1945, \\
1959,1983)\end{array}$} & $1977\left(1^{\circ}\right)$ & 190,2 & $1968\left(6^{\circ}\right)$ & 71,3 \\
\hline & & $1972\left(5^{\circ}\right)$ & 168,0 & $1967\left(8^{\circ}\right)$ & 75,8 \\
\hline & & & & $1976\left(9^{\circ}\right)$ & 76,1 \\
\hline & & & & $1974\left(15^{\circ}\right)$ & 90,8 \\
\hline
\end{tabular}


Tabla 39 (continuación): Años con precipitaciones máximas y mínimas:

\begin{tabular}{|c|c|c|c|c|c|}
\hline Indicativo & Duración serie & Año Máximo & $\begin{array}{c}\text { Precipitación } \\
\left(1 / \mathrm{m}^{2}\right)\end{array}$ & Año Mínimo & $\begin{array}{c}\text { Precipitación } \\
\left(1 / \mathrm{m}^{2}\right)\end{array}$ \\
\hline \multirow{3}{*}{$\begin{array}{c}1036 \\
\text { Zarauz }\end{array}$} & \multirow{3}{*}{$1955-1986$} & $1971\left(4^{\circ}\right)$ & 131,1 & $1974\left(3^{\circ}\right)$ & 69,4 \\
\cline { 3 - 5 } & & $1972\left(5^{\circ}\right)$ & 121,7 & $1976\left(4^{\circ}\right)$ & 73,6 \\
\cline { 3 - 5 } & $1973\left(10^{\circ}\right)$ & 171,0 & $1967\left(7^{\circ}\right)$ & 80,6 \\
\hline \multirow{3}{*}{$\begin{array}{c}\text { 1018A } \\
\text { Hernani }\end{array}$} & \multirow{3}{*}{$1964-1977$} & $1977\left(1^{\circ}\right)$ & 201,2 & $1967\left(1^{\circ}\right)$ & 112,6 \\
\cline { 3 - 5 } & & $1972\left(2^{\circ}\right)$ & 185,0 & $1976\left(2^{\circ}\right)$ & 112,9 \\
\cline { 3 - 5 } & $1971\left(3^{\circ}\right)$ & 178,6 & $1968\left(4^{\circ}\right)$ & 127,4 \\
\hline
\end{tabular}

4.1.- Coinciden máximos $(1971,1972,1977)$ y mínimos secundarios $(1967,1974$, 1976) de precipitación. Los máximos de 1971 y de 1972 y los mínimos de 1967 y de 1970 también los muestra la tabla 38.

4.2.- Resulta sospechosa la coincidencia de valores en MAM en los años 1967 y 1970 en 1016 y en 1017.

4.3.- Todas las series están en la comarca de San Sebastián.

4.4- Afecta entre el 8 y el $17 \%$ de las series analizadas.

Por tanto, se la considera como inhomogeneidad "climatológica".

\section{5.- 1975 a 1986 en $10210:$}

Tabla 40: Años con precipitaciones máximas y mínimas:

\begin{tabular}{|c|c|c|c|c|c|}
\hline Indicativo & Duración serie & Año Máximo & $\begin{array}{c}\text { Precipitación } \\
\left(1 / \mathrm{m}^{2}\right)\end{array}$ & Año Mínimo & $\begin{array}{c}\text { Precipitación } \\
\left(1 / \mathrm{m}^{2}\right)\end{array}$ \\
\hline \multirow{2}{*}{$1021 \mathrm{O}$} & $1974-1995$ & $1978\left(2^{\circ}\right)$ & 198,7 & $1982\left(1^{\circ}\right)$ & 48,5 \\
\cline { 3 - 6 } Hernani & $(\mathrm{sd} \mathrm{1976,1977,}$ & $1979\left(3^{\circ}\right)$ & 197,9 & $1975\left(4^{\circ}\right)$ & 111,5 \\
\cline { 3 - 6 } & $1993,1994)$ & $1986\left(6^{\circ}\right)$ & 191,7 & $1981\left(6^{\circ}\right)$ & 122,1 \\
\hline
\end{tabular}

5.1.- El máximo de precipitación fue en 1991, no coincidente con el resto de series.

5.2.- Es la única serie en la que se detecta inhomogeneidad.

Por tanto, se la considera como inhomogeneidad "no climatológica". 
6.- 1987 a 1996 y 1989 a 1999 en 1019A y 1988 a 1999 en 1037Q:

Tabla 41: Años con precipitaciones máximas y mínimas:

\begin{tabular}{|c|c|c|c|c|c|}
\hline Indicativo & Duración serie & Año Máximo & $\begin{array}{c}\text { Precipitación } \\
\left(1 / \mathrm{m}^{2}\right)\end{array}$ & Año Mínimo & $\begin{array}{c}\text { Precipitación } \\
\left(1 / \mathrm{m}^{2}\right)\end{array}$ \\
\hline \multirow{3}{*}{$\begin{array}{l}\text { 1019A } \\
\text { Pasajes }\end{array}$} & \multirow{3}{*}{1987 - 1999} & $1990\left(1^{\circ}\right)$ & 185,2 & $1995\left(1^{\circ}\right)$ & 64,7 \\
\hline & & $1994\left(2^{\circ}\right)$ & 180,8 & $1996\left(2^{\circ}\right)$ & 93,9 \\
\hline & & $1989\left(3^{\circ}\right)$ & 141,7 & $1987\left(3^{\circ}\right)$ & 103,9 \\
\hline \multirow{3}{*}{$\begin{array}{c}\text { 1037Q } \\
\text { Azcoitia }\end{array}$} & \multirow{3}{*}{$\begin{array}{c}1986-1999 \\
(\operatorname{sd} 1992,1995)\end{array}$} & $1991\left(1^{\circ}\right)$ & 161,2 & $1996\left(1^{\circ}\right)$ & 59,1 \\
\hline & & $1994\left(2^{\circ}\right)$ & 140,1 & $1999\left(2^{\circ}\right)$ & 65,2 \\
\hline & & $1993\left(3^{\circ}\right)$ & 130,7 & $1997\left(4^{\circ}\right)$ & 92,1 \\
\hline
\end{tabular}

6.1.- Ambas series abarcan un intervalo temporal similar.

6.2.- Coinciden máximos (1994) y mínimos (1996) de precipitación. 1994 también fue máximo señalado en la tabla 42; 1995 y 1996 fueron también años de mínimos de precipitación en la tabla 42.

6.3.- En ambas series, se observa una disminución de la precipitación AMJ en los años centrales de la década de los 90 .

6.4.- Los máximos y mínimos de precipitación de las tablas 41 y 42 son coherentes: la precipitación aumenta de Oeste a Este y de Norte a Sur.

Por tanto, cabe considerarla como inhomogeneidad "climatológica".

7.- 1990 a 2001 y 1993 a 2003 en 1041 y 1993 a 2003 en 1024 E y en $1025 \mathrm{~N}$ :

Tabla 42: Años con precipitaciones máximas y mínimas:

\begin{tabular}{|c|c|c|c|c|c|}
\hline Indicativo & Duración serie & Año Máximo & $\begin{array}{c}\text { Precipitación } \\
\left(1 / \mathrm{m}^{2}\right)\end{array}$ & Año Mínimo & $\begin{array}{c}\text { Precipitación } \\
\left(1 / \mathrm{m}^{2}\right)\end{array}$ \\
\hline \multirow{3}{*}{$\begin{array}{c}1041 \\
\text { Zumaya }\end{array}$} & \multirow{3}{*}{$\begin{array}{c}1987-2007 \\
(\text { sd 1991) }\end{array}$} & $1994\left(1^{\circ}\right)$ & 154,6 & $1995\left(1^{\circ}\right)$ & 56,1 \\
\hline & & $2002\left(2^{\circ}\right)$ & 123,1 & $1996\left(2^{\circ}\right)$ & 64,1 \\
\hline & & $1993\left(4^{\circ}\right)$ & 111,5 & $2003\left(3^{\circ}\right)$ & 65,2 \\
\hline \multirow{4}{*}{$\begin{array}{c}1024 \mathrm{E} \\
\text { Igueldo }\end{array}$} & \multirow{4}{*}{$1928-2012$} & $1997\left(1^{\circ}\right)$ & 196,8 & $1995\left(5^{\circ}\right)$ & 65,7 \\
\hline & & $1994\left(7^{\circ}\right)$ & 165,2 & $2003\left(7^{\circ}\right)$ & 76,6 \\
\hline & & $2002\left(10^{\circ}\right)$ & 157,1 & $2001\left(9^{\circ}\right)$ & 79,4 \\
\hline & & & & $1996\left(11^{\circ}\right)$ & 80,5 \\
\hline \multirow{3}{*}{$\begin{array}{l}\text { 1025N } \\
\text { Arriarán }\end{array}$} & \multirow{3}{*}{$\begin{array}{c}1993-2012 \\
(\text { sd 2007) }\end{array}$} & $1993\left(2^{\circ}\right)$ & 151,6 & $1995\left(1^{\circ}\right)$ & 45,2 \\
\hline & & $1994\left(4^{\circ}\right)$ & 121,8 & $1996\left(2^{\circ}\right)$ & 55,7 \\
\hline & & $2002\left(6^{\circ}\right)$ & 112,7 & $2001\left(5^{\circ}\right)$ & 65,9 \\
\hline
\end{tabular}


7.1.- Coinciden máximos $(1994,2002)$ y mínimos $(1995,2003)$. comunes.

Las tablas 41 y 42 señalan máximo (1994) y mínimos (1995 y 1996) de precipitación

7.2.-Afecta al $11 \%$ de las series, siendo una de ellas (1024E) de calidad excelente.

Por tanto, del análisis conjunto de los puntos 7 y 8 y de las tablas 41 y 42 se la califica como inhomogeneidad "climatológica".

\section{$\underline{\text { 8.- } 1995 \text { a } 2006 \text { en } 1025 \mathrm{~N} \text { y } 1998 \text { a } 2007 \text { en } 1041:}$}

Tabla 43: Años con precipitaciones máximas y mínimas:

\begin{tabular}{|c|c|c|c|c|c|}
\hline Indicativo & Duración serie & Año Máximo & $\begin{array}{c}\text { Precipitación } \\
\left(1 / \mathrm{m}^{2}\right)\end{array}$ & Año Mínimo & $\begin{array}{l}\text { Precipitación } \\
\left(1 / \mathrm{m}^{2}\right)\end{array}$ \\
\hline \multirow{3}{*}{$\begin{array}{l}1025 \mathrm{~N} \\
\text { Arriarán }\end{array}$} & \multirow{3}{*}{$\begin{array}{l}1993-2012 \\
\quad(\text { sd 2007) }\end{array}$} & $2002\left(6^{\circ}\right)$ & 112,7 & $1995\left(1^{\circ}\right)$ & 45,2 \\
\hline & & $1998\left(7^{\circ}\right)$ & 109,2 & $1996\left(2^{\circ}\right)$ & 55,7 \\
\hline & & $2000\left(8^{\circ}\right)$ & 102,6 & $2004\left(4^{\circ}\right)$ & 65,7 \\
\hline \multirow{3}{*}{$\begin{array}{c}1041 \\
\text { Zumaya }\end{array}$} & \multirow{3}{*}{$\begin{array}{c}1987-2007 \\
(\text { sd 1991) }\end{array}$} & $2002\left(2^{\circ}\right)$ & 123,1 & $2003\left(3^{\circ}\right)$ & 65,2 \\
\hline & & $1998\left(7^{\circ}\right)$ & 101,8 & $2001\left(4^{\circ}\right)$ & 65,7 \\
\hline & & $2000\left(8^{\circ}\right)$ & 111,5 & $2004\left(5^{\circ}\right)$ & 65,9 \\
\hline
\end{tabular}

8.1.- Ambas series comienzan en años muy cercanos.

8.2.- Coinciden máximos (1998, 2000, 2002) y mínimos (2004). 1995 y 1996 fueron el $1^{\circ}$ y el $2^{\circ}$ año más secos en el periodo AMJ de 1987 a 2012 en 1041. Las tablas 41 y 42 muestran como en 2002 se registra máximo de precipitación y en 1995 y 1996 mínimos de precipitación.

Por tanto, se considera que es una inhomogeneidad "climatológica".

9.- 1998 a 2012 en $1025 \mathrm{~N}$ y en $1044 \mathrm{D}, 2000$ a 2009 en 1024,2000 a 2011 en $1026 \mathrm{~B}$ y en 1037 y 2003 a 2012 en 1037:

Tabla 44: Años con precipitaciones máximas y mínimas:

\begin{tabular}{|c|c|c|c|c|c|}
\hline Indicativo & Duración serie & Año Máximo & $\begin{array}{c}\text { Precipitación } \\
\left(1 / \mathrm{m}^{2}\right)\end{array}$ & Año Mínimo & $\begin{array}{c}\text { Precipitación } \\
\left(1 / \mathrm{m}^{2}\right)\end{array}$ \\
\hline \multirow{3}{*}{$\begin{array}{l}1025 \mathrm{~N} \\
\text { Arriarán }\end{array}$} & \multirow{3}{*}{$\begin{array}{c}1993-2012 \\
(\text { sd 2007) }\end{array}$} & $2008\left(1^{\circ}\right)$ & 176,6 & $2011\left(3^{\circ}\right)$ & 63,6 \\
\hline & & $2010\left(3^{\circ}\right)$ & 122,6 & $2004\left(4^{\circ}\right)$ & 65,7 \\
\hline & & $2012\left(5^{\circ}\right)$ & 120,4 & $2001\left(5^{\circ}\right)$ & 65,9 \\
\hline \multirow{3}{*}{$\begin{array}{c}\text { 1044D } \\
\text { Aramayona }\end{array}$} & \multirow{3}{*}{$\begin{array}{c}1995-2012 \\
(\text { sd } 2001 \\
2002,2003)\end{array}$} & $2012\left(1^{\circ}\right)$ & 130,6 & $2011\left(1^{\circ}\right)$ & 54,3 \\
\hline & & $1998\left(2^{\circ}\right)$ & 130,0 & $2004\left(3^{\circ}\right)$ & 74,5 \\
\hline & & $2005\left(3^{\circ}\right)$ & 126,4 & $2006\left(4^{\circ}\right)$ & 76,7 \\
\hline
\end{tabular}


Tabla 44 (continuación): Años con precipitaciones máximas y mínimas:

\begin{tabular}{|c|c|c|c|c|c|}
\hline Indicativo & Duración serie & Año Máximo & $\begin{array}{l}\text { Precipitación } \\
\left(1 / \mathrm{m}^{2}\right)\end{array}$ & Año Mínimo & $\begin{array}{c}\text { Precipitación } \\
\left(1 / \mathrm{m}^{2}\right)\end{array}$ \\
\hline \multirow{3}{*}{$\begin{array}{c}1024 \\
\text { Ategorrieta }\end{array}$} & \multirow{3}{*}{$1986-2012$} & $2002\left(5^{\circ}\right)$ & 178,9 & $2003\left(4^{\circ}\right)$ & 98,0 \\
\hline & & $2008\left(7^{\circ}\right)$ & 175,1 & $2006\left(5^{\circ}\right)$ & 101,6 \\
\hline & & $2000\left(10^{\circ}\right)$ & 148,2 & $2004\left(6^{\circ}\right)$ & 104,3 \\
\hline \multirow{3}{*}{$\begin{array}{l}\text { 1026B } \\
\text { Lareo }\end{array}$} & \multirow{3}{*}{$1989-2012$} & $2008\left(2^{\circ}\right)$ & 203,3 & $2001\left(2^{\circ}\right)$ & 94,9 \\
\hline & & $2002\left(3^{\circ}\right)$ & 198,6 & $2006\left(3^{\circ}\right)$ & 105,9 \\
\hline & & $2010\left(6^{\circ}\right)$ & 176,2 & $2004\left(6^{\circ}\right)$ & 116,7 \\
\hline \multirow{3}{*}{$\begin{array}{c}1037 \\
\text { Legazpia }\end{array}$} & \multirow{3}{*}{$1981-2012$} & $2008\left(2^{\circ}\right)$ & 156,8 & $2006\left(2^{\circ}\right)$ & 62,7 \\
\hline & & $2012\left(6^{\circ}\right)$ & 137,9 & $2001\left(4^{\circ}\right)$ & 68,8 \\
\hline & & $2010\left(9^{\circ}\right)$ & 128,5 & $2011\left(6^{\circ}\right)$ & 73,9 \\
\hline
\end{tabular}
2011).

9.1.- Coinciden máximos $(2002,2008,2010,2012)$ y mínimos $(2001,2004,2006$,

Las tablas 43 y 44 muestran máximos (2002) y mínimos (2003, 2004) de precipitación comunes.

9.2.- Hay coherencia espacial entre las precipitaciones registradas en los diferentes emplazamientos.

9.3.- Las inhomogeneidades afectan al $23 \%$ de las series analizadas en el periodo $2000-2009$.

9.4.- La mayoría de las inhomogeneidades se detectan en el Alto Oria, apareciendo también en el Alto Urola, el Alto Deba y en la Comarca de San Sebastián.

9.5.- En el periodo analizado en la tabla 44, hay alternancia entre AMJ muy secos (2004) y lluvioso (2002, 2008 y 2012).

Por tanto, se la clasifica como inhomogeneidad "climatológica".

Como conclusiones del análisis temporal de las rachas de precipitación en AMJ,

Tras detectar las rupturas de las series de precipitación, se aplica el test de las rachas a cada intervalo (caso de rupturas) y a la serie completa (caso de no rupturas) de precipitación en el periodo AMJ, encontrándose:

1.- Una inhomogeneidad "no climatológica": 10210 de 1975 a 1986.

2.- Se observan 2 máximos de inhomogeneidades: entre 1957 y 1968 (correspondientes al periodo 1966 a 1977) y entre 1993 y 2002 (correspondientes al periodo 2002 a 2011). 
La primera inhomogeneidad afecta principalmente a las series de la comarca de San Sebastián, mientras que la segunda, a las series situadas en la comarca de San Sebastián, en el Alto Oria, el Alto Urola y el Alto Deba.

3.- Gran similitud entre los comportamientos de las series próximas, tal y como se desprende de las tablas 38, 39 y 44, pudiendo hablar no sólo de inhomogeneidades "climatológicas" a nivel provincial, sino de inhomogeneidades "climatológicas" a nivel comarcal.

Por ejemplo, en el intervalo de 1957 a 1973, las inhomogeneidades se detectan exclusivamente en 1017 (Oyarzun), 1018 (Rentería) y 1024 (Ategorrieta), situadas a una distancia máxima de $8,5 \mathrm{Km}$.

4.- De los datos de las tablas 5,9 y 36 a 44, se insinúa un periodo de 10 años en la precipitación AMJ. Las tablas 45 y 45 bis reflejan los años con precipitaciones máximas y mínimas desde 1878.

Tabla 45: Años con máximos pluviométricos en precipitación AMJ:

\begin{tabular}{|l|c|c|c|c|c|c|c|}
\hline Máximos & $1879-80$ & $\mathbf{1 8 8 4 - 8 5}$ & $\mathbf{1 8 8 8} \mathbf{- 8 9}$ & & 1900 & & $\mathbf{1 9 1 0}$ \\
\hline Máximos & $1917-18$ & $1922-23$ & 1925,1927 & $1930-31$ & $\mathbf{1 9 3 3}$ & $\mathbf{1 9 4 0}$ & 1942 \\
\hline Máximos & 1951 & 1956 & 1961 & 1964 & 1969 & $1971-72$ & $\mathbf{1 9 7 8 , 7 9 , 8 0}$ \\
\hline Máximos & 1986 & 1990 & $\mathbf{1 9 9 7}$ & 2002 & 2008 & 2012 & \\
\hline
\end{tabular}

Tabla 45 bis: Años con mínimos pluviométricos en precipitación AMJ:

\begin{tabular}{|l|c|c|c|c|c|c|c|}
\hline Mínimos & & 1882 & 1887 & $1892-93$ & $\mathbf{1 8 9 6 - 9 8}$ & $1903-04$ & 1909 \\
\hline Mínimos & $1915-16$ & 1921 & 1924 & 1928 & 1934 & 1938 & $\mathbf{1 9 4 3 - 4 4}$ \\
\hline Mínimos & $\mathbf{1 9 4 7 - 4 8}$ & $1952, \mathbf{5 5}$ & $1959-60$ & 1963 & 1967 & 1974 & 1976 \\
\hline Mínimos & $\mathbf{1 9 8 2}$ & 1987 & $\mathbf{1 9 9 5}-96$ & 2001 & $\mathbf{2 0 0 3 - 0 4}$ & 2011 & \\
\hline
\end{tabular}

Se señalan en negrita los años con valores extremos de la serie de datos. En cursiva con fondo azul se marcan los máximos y mínimos secundarios. Se dejan en blanco los años en que no parece cumplirse la cadencia del ciclo.

Por su duración y elevada homogeneidad, los datos no incluidos en tablas 9 y 36 a 44 se han extraído de los correspondientes a 1024D (Siglo XIX).

Los resultados de la tabla 45 son verificados en las series 1024B, 1024E, 1032, 1036O, 1049 y 1077C.

6.1.- Se insinúa un doble ciclo de 10 años: 2 ciclos de aproximadamente 10 años en la precipitación AMJ, con sucesivos periodos lluviosos y secos. 
La cadencia del primer ciclo de máximos sería: 1879, 1889-89, 1900, $1910 \ldots$

La cadencia del segundo ciclo de máximos sería: $1884, \ldots, \ldots, 1917-8,1925,27 \ldots$

La cadencia del primer ciclo de mínimos sería: 1882, 1992-93, 1903-04, 1917-8, ...

La cadencia del segundo ciclo de mínimos sería: 1888, 1898-99, 1909, 1921 ...

6.2.- Los huecos parecen asociarse a situaciones de precipitaciones muy elevadas (década de los 70) y de sequías (última década del siglo XIX, primeros cinco años del siglo $\mathrm{XX)}$.

6.3.- Asimismo, parece insinuarse un ciclo de aproximadamente 20 años de máximos significativos de precipitación: 1890, 1910, 1933, 1956, 1977, 1997 (hacia 1955 hubo un periodo de años muy secos en AMJ).

No se percibe un ciclo superior a 10 años para las sequías en AMJ.

Se analiza con más detalle este ciclo de 10 y 20 años en la precipitación AMJ tras el análisis de Mann Kendall de las tendencias de la precipitación AMJ. 


\subsection{2.- Evolución temporal inhomogeneidades Test Mann-Kendall:}

En las tablas siguientes $(46,49,50$ y 51$)$ se describen:

a) Los intervalos de tendencias detectados.

b) Los indicativos de las series.

c) El periodo - anual, MAM o AMJ - que detecta la tendencia.

d) La causa de la tendencia:

Climatológica: debida a variaciones atmosféricas

No climatológica: producida por cambios de emplazamiento, de entorno, de colaborador, caída de calidad en últimos años de la serie...

e) Se emplean signos de interrogación cuando se sospecha sobre la naturaleza de la tendencia -climatológica o no -, si bien las evidencias son escasas para clasificarla.

f) Tipo de tendencia indicada por el test de Mann-Kendall: Positiva o negativa.

g) La última columna indica el \% de series en que se produce sobre el total de series analizadas en ese periodo de años - con un intervalo cuando se abarca un periodo de años-. bajo.

Un número entre paréntesis indica el total de series analizadas, cuando éste es muy

\subsubsection{1.- Periodo de 1878 a 1940:}

Debido al bajo número de series existentes con más de 10 años existentes anteriores a 1940, se estudian conjuntamente los resultados del test de Mann-Kendall aplicados a la precipitación anual, MAM y AMJ.

En las gráficas 13 a 15 se representa la evolución temporal de las inhomogeneidades detectadas aplicando el test de Mann-Kendall a la precipitación anual, MAM y AMJ, desde 1878 a 1940. 
Gráfica 13: Evolución temporal tendencias test de Mann Kendall de las series de precipitación anual de 1878 a 1940:

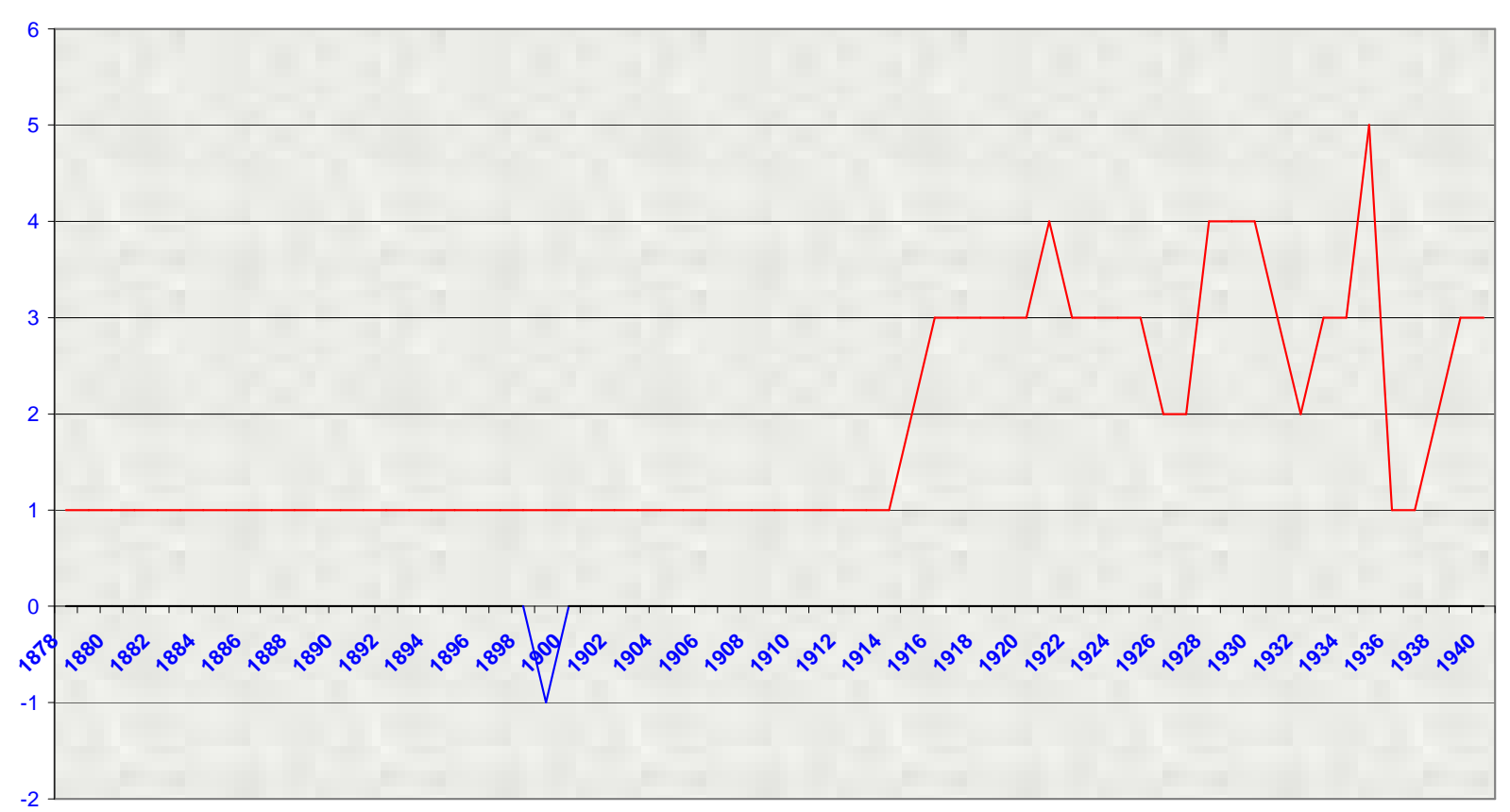

Años

Gráfica 14: Evolución temporal tendencias Mann-Kendall de las series de precipitación MAM de 1878 a 1940:

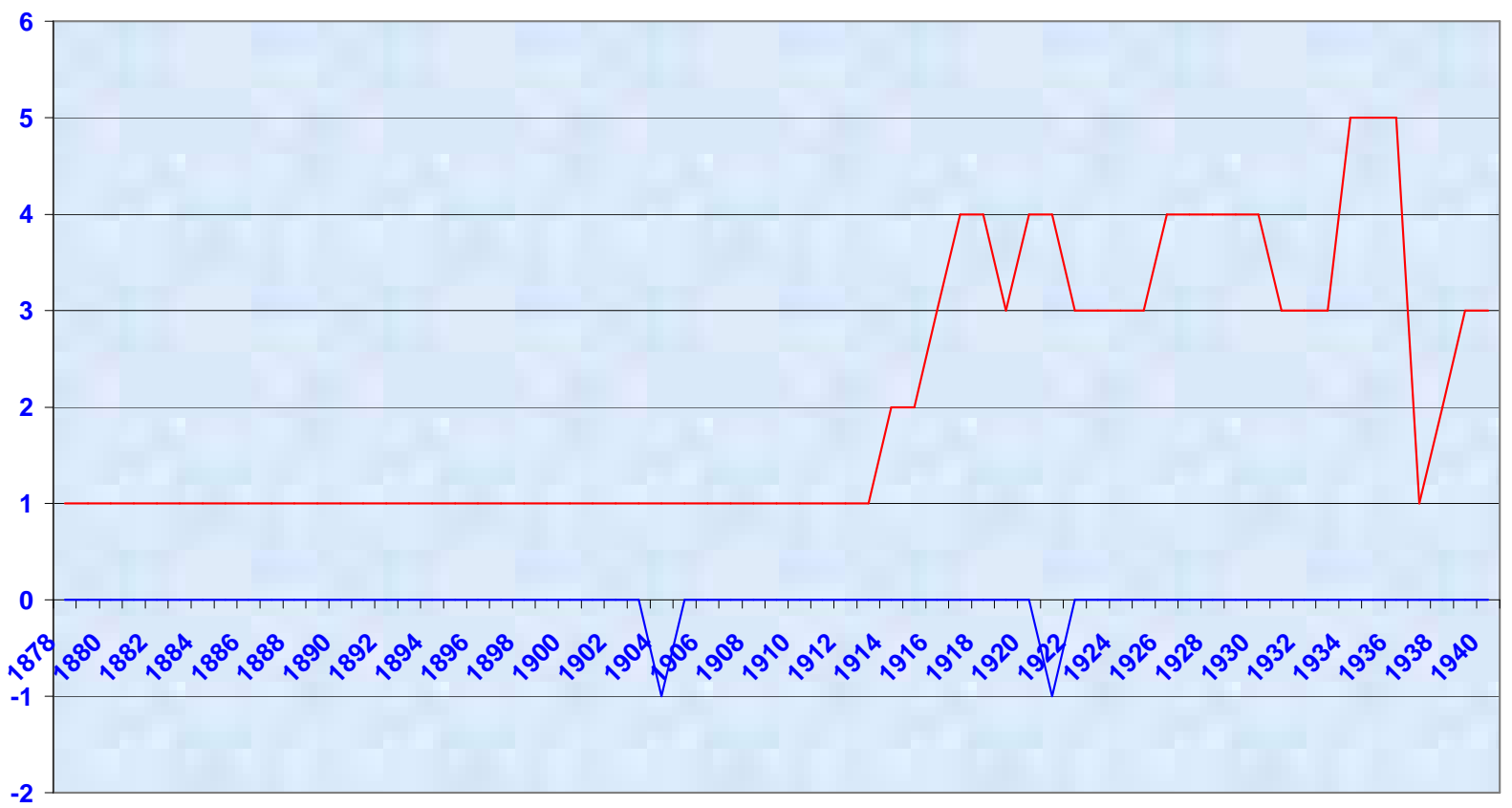

Años

— № series — Suma Tendencias 
Gráfica 15: Evolución temporal tendencias Mann-Kendall de las series de precipitación AMJ de 1878 a 1940:

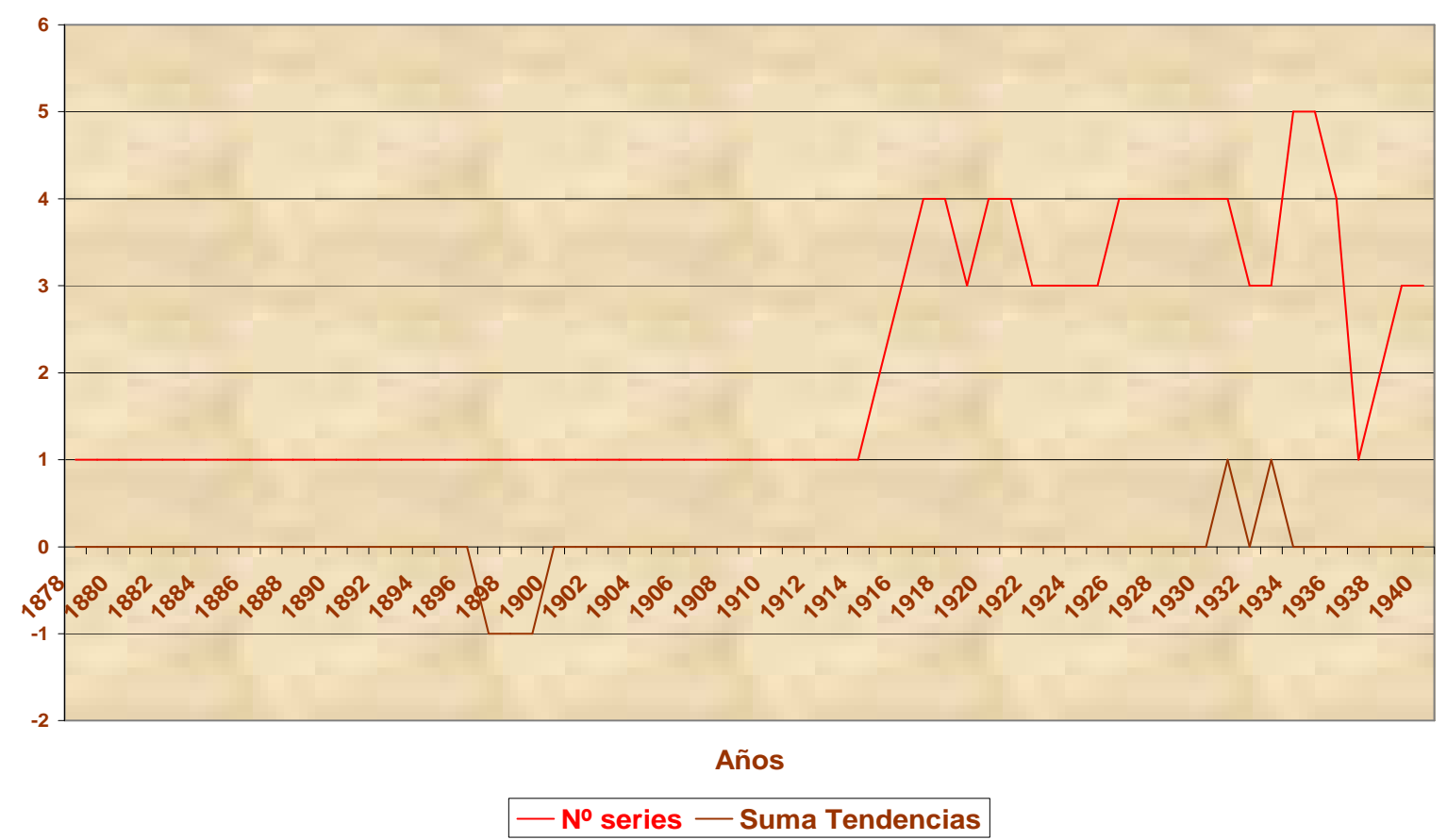

Tabla 46: Inhomogeneidades y tendencias detectadas aplicando el test de Mann Kendall a las medidas de precipitación anual, MAM y AMJ desde 1878 a 1940:

\begin{tabular}{|c|c|c|c|c|c|}
\hline $\begin{array}{c}\text { Años } \\
\text { inhomogeneidad }\end{array}$ & Indicativos & $\begin{array}{c}\text { Detectado en } \\
\text { periodo }\end{array}$ & Tendencia & $\begin{array}{c}\text { Inhomogeneidad } \\
\text { "climatológica" }\end{array}$ & $\begin{array}{c}\% \text { series } \\
\text { sobre total }\end{array}$ \\
\hline 1897,1898 & 1024D & AMJ & - & Sí & $100(1)$ \\
\hline 1899 & $1024 \mathrm{D}$ & Anual, AMJ & - & Sí & $100(1)$ \\
\hline 1904 & $1024 \mathrm{~F}$ & MAM & - & Sí & $100(1)$ \\
\hline 1921 & $1024 \mathrm{~F}$ & MAM & - & Sí & $25(4)$ \\
\hline 1931,1933 & $1024 \mathrm{E}$ & AMJ & + & Sí & $25-33(3-4)$ \\
\hline
\end{tabular}

1.- Finales del s. XIX: Sólo hay datos en Guipúzcoa en 1024D. En la tabla 4, se indica que el test de rachas indica inhomogeneidad climatológica en el periodo AMJ (disminución en un periodo de 10 años de la precipitación u oscilación en un periodo de 10 años de los valores en torno a la mediana).

Esta inhomogeneidad es corroborada por los resultados de las tablas 5 y 5 bis:

a) En AMJ 4 de los 5 años más secos de 1878 a 1900 (1892, 1893, 1896 y 1898) se registran entre 1890 y 1900.

b) En MAM 4 de los 6 años más secos de 1878 a 1900 (1892, 1893, 1898 y 1899) se miden entre 1890 y 1900.

El test de Mann-Kendall muestra una disminución de la precipitación de 1897 a 1899, coherente con las tablas 5 y 5 bis. 
Las tablas 47,48 y 52 reflejan:

a) Indicativo y nombre de la serie.

b) Duración en años detallando los años sin datos sd.

c) Los años en que se registran precipitaciones elevadas y escasas en el intervalo detectado por la tendencia, con el ordinal entre paréntesis referido al intervalo anual total de medidas de la serie.

d) La precipitación media mensual en el periodo MAM.

Al analizar un intervalo de tendencias, se emplearán las series de precipitaciones teniendo en cuenta las rupturas detectadas en el apartado 4.1.

La tabla 47 refleja los años con precipitaciones anuales medias de 1890 a 1900.

Tabla 47: Años con precipitaciones medias mensuales máximas y mínimas:

\begin{tabular}{|c|c|c|c|c|c|}
\hline Indicativo & Duración serie & Año Máximo & $\begin{array}{c}\text { Precipitación } \\
\left(1 / \mathrm{m}^{2}\right)\end{array}$ & Año Mínimo & $\begin{array}{c}\text { Precipitación } \\
\left(1 / \mathrm{m}^{2}\right)\end{array}$ \\
\hline \multirow{3}{*}{$\begin{array}{c}\text { 1024D } \\
\text { San Sebastián }\end{array}$} & \multirow{3}{*}{$1878-1900$} & $1900\left(3^{\mathbf{0}}\right)$ & 139,6 & $1899\left(1^{\mathbf{o}}\right)$ & 81,1 \\
\cline { 3 - 5 } & & $1896\left(6^{\mathbf{0}}\right)$ & 130,9 & $1891\left(2^{\mathbf{o}}\right)$ & 88,8 \\
\cline { 3 - 5 } & & & $1894\left(4^{\mathbf{o}}\right)$ & 93,9 \\
\cline { 3 - 5 } & & & $1898\left(5^{\circ}\right)$ & 100,2 \\
\hline
\end{tabular}

La tabla 47 muestra cómo 4 de los 5 años más secos se registran de 1890 a 1900.

Por lo expuesto y dada la excelente calidad de 1024D, se considera como tendencia "climatológica", fruto de la sequía de los últimos años del siglo XIX.

Asimismo, se resalta la importancia y la potencia de aplicar conjuntamente los 2 $\underline{\text { tests. }}$

\section{2.- 1904 en 1024F en el periodo MAM:}

Tabla 48: Años con precipitaciones en MAM máximas y mínimas de 1900 a 1910:

\begin{tabular}{|c|c|c|c|c|c|}
\hline Indicativo & Duración serie & Año Máximo & $\begin{array}{c}\text { Precipitación } \\
\left(1 / \mathrm{m}^{2}\right)\end{array}$ & Año Mínimo & $\begin{array}{c}\text { Precipitación } \\
\left(1 / \mathrm{m}^{2}\right)\end{array}$ \\
\hline \multirow{3}{*}{$\begin{array}{c}\text { 1024F } \\
\text { San Sebastián }\end{array}$} & \multirow{3}{*}{$1901-1918$} & $1901\left(5^{\circ}\right)$ & 113,7 & $1909\left(1^{\circ}\right)$ & 75,3 \\
\hline & & $1908\left(6^{\circ}\right)$ & 101,7 & $1904\left(2^{\circ}\right)$ & 75,6 \\
\cline { 3 - 6 } & $1907\left(7^{\circ}\right)$ & 96,7 & $1903\left(6^{\circ}\right)$ & 81,6 \\
\hline \multirow{3}{*}{$\begin{array}{c}\text { 1077C } \\
\text { Bilbao }\end{array}$} & \multirow{3}{*}{$1859-1920$} & $1908\left(10^{\circ}\right)$ & 130,0 & $1909\left(3^{\circ}\right)$ & 60,3 \\
\cline { 3 - 5 } & & $1900\left(16^{\circ}\right)$ & 118,0 & $1907\left(17^{\circ}\right)$ & 82,7 \\
\cline { 3 - 5 } & & $1901\left(21^{\circ}\right)$ & 106,7 & $1905\left(20^{\circ}\right)$ & 84,2 \\
\cline { 3 - 5 } & & & $1904\left(23^{\circ}\right)$ & 91,0 \\
\hline
\end{tabular}


a) De 1900 a 1910 sólo hay registros de 1024F y de 1077C.

b) Se observa cierta similitud entre los años con precipitaciones máximas (1901, 1908) y mínimas $(1904,1909)$. En ambas, tras un 1901 con precipitaciones relativamente abundantes, éstas pasan a disminuir en 1904 (1024F) y en 1905 (1077C), se recuperan en 1908 y marcan mínimo en 1909.

c) La precipitación media en San Sebastián es superior a la de Bilbao (Font). Sin embargo, en 1904 y en 1908 la precipitación media en Bilbao es superior a la de San Sebastián, lo cuál alberga dudas sobre las cantidades registradas en 1024F.

Esta sospecha refuerza la cautela sobre los datos de 1024F, recogidos en el comentario de la tabla 6.

Por tanto, se la clasifica como tendencia "climatológica."

\section{3.- 1921 en 1024F en el periodo MAM:}

a) De la tabla 8,1921 fue un año seco en 1013 ( $4^{\circ}$ de 1914 a 1930) y en $1024 \mathrm{~F}$ ( $2^{\circ}$ de 1918 a 1936). Ambas series están en la misma comarca (a $15 \mathrm{Km})$ y tienen el mismo clima.

b) El test de Thom aplicado a MAM muestra en la tabla 4 inhomogeneidades en este periodo, calificadas como "climatológicas" en el punto 4 del apartado 4.2.1.1.

d) De la tabla 34 bis 1921 fue un año con mínimo de precipitación.

Por tanto, se la considera como una tendencia "climatológica."

\section{4.- 1931-1933 en 1024E en el periodo AMJ:}

Indica tendencia positiva en 1931 y 1933 en AMJ.

a) De la tabla 9, 1933 y 1931 fueron el $3^{\circ}$ y $11^{\circ}$ más lluviosos en AMJ en 1024E de 1928 a 2012 y el $3^{\circ}$ y el $12^{\circ}$ más lluviosos de 1926 a 1987 en 1032.

b) La serie 1932 detecta inhomogeneidad climatológica de 1926 a 1935 (tabla 4).

c) 1024E es una serie de una homogeneidad excelente: El test de Mann-Kendall sólo detecta tendencia en AMJ en 1024E en 1931 y en 1933; 1024E tiene medidas de 1928 a 2012.

Por tanto, se la califica como tendencia climatológica, al haber sido 1929 un año "con escasa precipitaciones" en 1013 y en 1024F. Sin embargo, en ninguna de estas series se marca tendencia ni en 1931 ni en 1933.

Al incrementarse el número de series en 1946, se desglosan los resultados en precipitaciones anuales, en MAM y en AMJ. 


\subsubsection{2.- Precipitación anual periodo de 1941 a 2012:}

Gráfica 16: Evolución temporal tendencias Mann-Kendall series precipitación anual de 1941 a 2012:

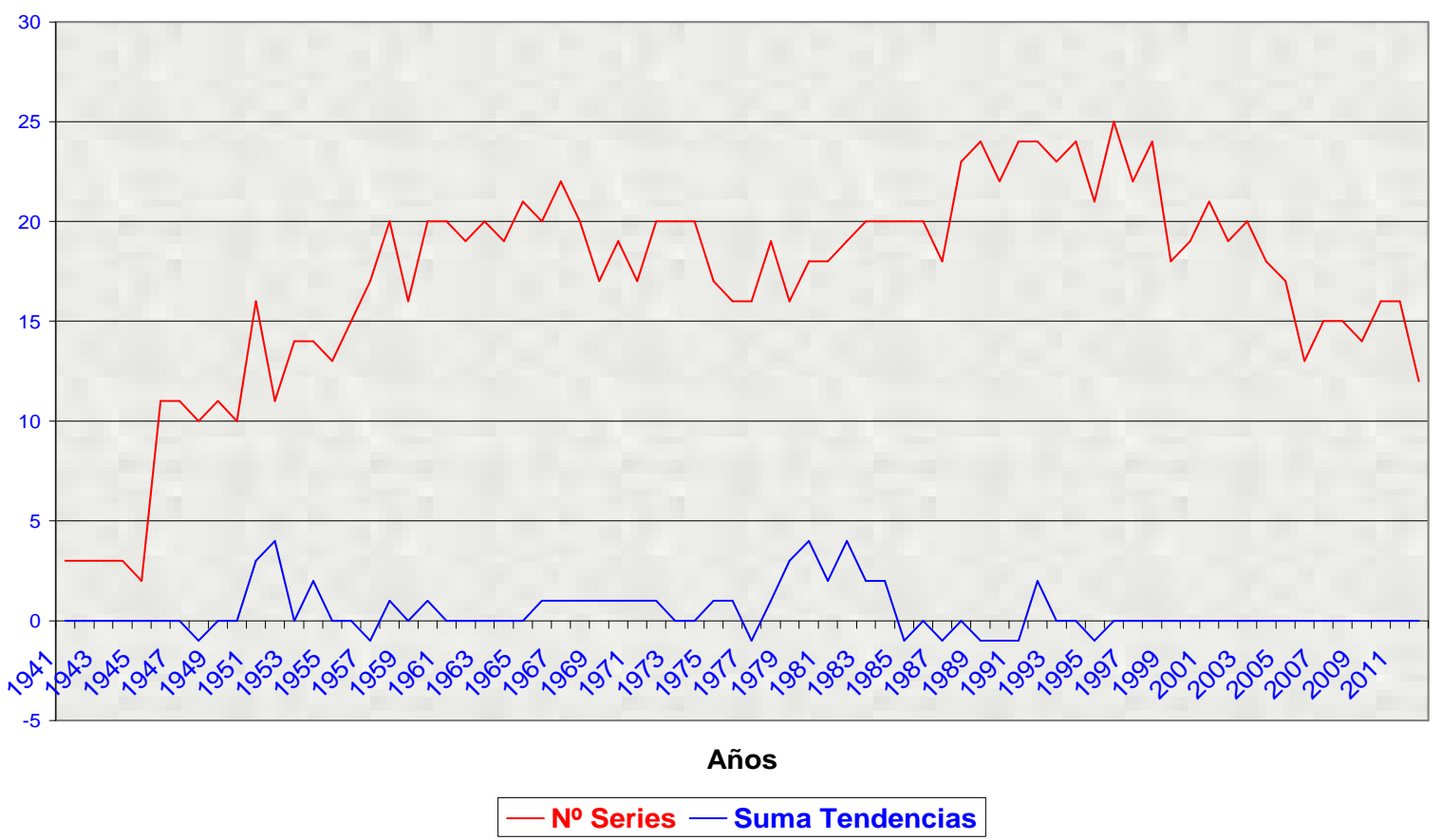

De la gráfica 16, se observan 2 máximos en las tendencias: 1951 a 1954 y 1978 a 1984, siendo más significativo el primero, al ser menor el número de series analizadas.

Tabla 49: Inhomogeneidades y tendencias detectadas aplicando el test de Mann Kendall a la precipitación anual de 1941 a 1979:

\begin{tabular}{|c|c|c|c|c|}
\hline $\begin{array}{c}\text { Años } \\
\text { inhomogeneidad }\end{array}$ & Indicativos & Tendencia & $\begin{array}{c}\text { Inhomogeneidad } \\
\text { "climatológica" }\end{array}$ & $\begin{array}{c}\text { \% series } \\
\text { sobre total }\end{array}$ \\
\hline 1948 & $1024 \mathrm{E}$ & - & Sí & 10 \\
\hline 1951 & $1015,1022 \mathrm{~A}, 1037$ & + & Sí & 19 \\
\hline 1952 & $1015,1016,1035,1037$ & + & Sí & 36 \\
\hline 1954 & 1016,1031 & + & Sí & 14 \\
\hline 1957 & 1032 & - & Sí & 6 \\
\hline 1958 & 1031 & + & Sí & 5 \\
\hline 1960 & 1014 & + & Sí & 5 \\
\hline $1966-1972$ & 1026 & + & Sí & $5-6$ \\
\hline 1975,1976 & $1018 \mathrm{~A}$ & + & Sí & 6 \\
\hline $1977,1978,1979$ & 1017 & - & No & $5-6$ \\
\hline 1978 & 1022,1023 & + & Sí & 11 \\
\hline 1979 & $1014,1022,1023,1026$ & + & Sí & 25 \\
\hline
\end{tabular}


Tabla 49 (continuación) : Inhomogeneidades y tendencias detectadas aplicando el test de Mann Kendall a la precipitación anual de 1980 a 2012:

\begin{tabular}{|c|c|c|c|c|}
\hline $\begin{array}{c}\text { Años } \\
\text { inhomogeneidad }\end{array}$ & Indicativos & Tendencia & $\begin{array}{c}\text { Inhomogeneidad } \\
\text { "climatológica" }\end{array}$ & $\begin{array}{c}\text { \% series } \\
\text { sobre total }\end{array}$ \\
\hline 1980 & $1014,1022,1023,1024$ & + & Sí & 17 \\
\hline 1981 & 1014,1026 & + & Sí & 11 \\
\hline 1982 & $1014,1022,1023,1024$ & + & Sí & 21 \\
\hline 1983 & $1022,1023,1026$ & + & Sí & 25 \\
\hline 1984 & 1024,1026 & + & Sí & 10 \\
\hline $\begin{array}{c}1983,1985,1987, \\
1990,1991\end{array}$ & $1025 \mathrm{E}$ & - & & $4-5$ \\
\hline 1989 & 1024 & - & Sí & 4 \\
\hline 1992 & $1021 \mathrm{E}, 1031$ & + & Sí & 8 \\
\hline 1995 & 1038 & - & Sí & 5 \\
\hline
\end{tabular}

\section{1.- 1948 a 1954:}

De los datos de las tablas 22 y 22 bis, hubo una sequía de 1945 a 1948, seguida de 1950 a 1954 por unos años de precipitaciones elevadas.

En 1948 hay una tendencia negativa en 1024E debida a la sequía.

La tendencia positiva de 1951, 1952 y 1954 es de tipo climatológico: es una recuperación a los valores normales de precipitación tras la sequía de los años 40, siendo 1952 cuando la "recuperación" es más acusada.

De los datos de la tabla 49, esta recuperación en la precipitación se detecta en las series de las comarca de San Sebastián, del alto Urola y del Oria medio y llega a afectar al $36 \%$ de las series.

Por tanto, se trata de tendencias "climatológicas".

\section{2.- 1957 en 1032,1958 en 1031 y 1960 en $1014:$}

a) De la tabla 10, aflora una inhomogeneidad "climatológica" en 1016 de 1950 a 1961 y en 1024E de 1951 a 1961.

b) De los datos de las tablas 11, 22 y 22 bis, en 1956 y 1957 hubo precipitaciones inferiores a lo normal, recuperándose las precipitaciones de 1958 a 1960. El test de MannKendall lo detecta: 1957 tendencia negativa, 1958 y 1960 positiva.

Por tanto, se considera a las 3 tendencias como "climatológicas".

En 1958 y 1960 se insinúa un máximo secundario de precipitación en el extremo oriental de Guipúzcoa (1014, 1024E). 
3.- 1966 a 1972 en 1026: La tendencia positiva de 1026 se extiende desde 1966 a 1972 (sin datos de 1973 a 1978). No hay evidencias de cambio de emplazamiento ni de cambio de colaborador.

La tabla 10 muestra una inhomogeneidad "climatológica" en 1026 en este periodo. De la tabla 14, 1026 registra máximos secundarios de precipitación en 1967, 1968 y 1969 y un máximo significativo en 1972.

Este aumento de la precipitación anual, aunque sin llegar a señalar tendencia, se observa también en 1050 .

Cabe considerarla como una tendencia "climatológica".

\section{4.- 1975 y 1976 en 1018 A:}

a) La tabla 10 indica una inhomogeneidad "climatológica" de 1970 a 1981 en 1016 (Oyarzun Arditurri) y de 1970 a 1980 en 1022 (Hernani), las cuáles distan 8,5 Km de 1018A Rentería.

b) De las tablas 13, 15, 22 y 22 bis, se observa un máximo de precipitación en 1974 y en 1976, siendo más acusado en 1016 y en 1022. Este máximo también se detecta en 1024, 1024E y 1036. Todas las series están en la comarca de San Sebastián

Por tanto, se trata de una tendencia "climatológica".

\section{5.- 1977,1978 y 1979 en 1017 :}

a) 1977, 1978 y 1979 son los 3 últimos años con precipitación anuales completas en 1017.

b) En el punto 4.2.1.2.- (Precipitación anual Período 1941 a 2012) en el punto 2 se analiza la serie 1017, detectando una inhomogeneidad "no climatológica en 1017" de 1962 a 1975.

c) De la tabla 49, esta tendencia negativa sólo se observa en 1017 en 1977, 1978 y 1979: el resto de series o no marca tendencia o tienen tendencia positiva.

Por tanto, cabe considerarla como tendencia "no climatológica".

\section{6.- 1978 a 1984:}

A partir de 1977 se empieza a detectar un incremento de precipitación anual en las comarcas de San Sebastián y en el Alto Oria (1026 es la única serie activa en el Alto Oria en esas fechas, sin datos en 1026 en 1980 y en 1982). 
La gráfica 16 y las tablas 14, 15, 22 y 22 bis reflejan un máximo de precipitación de 1978 a 1984, siendo 1979, 1980 y 1982 los años con mayores tendencias positivas de la precipitación anual.

La tabla 10 refleja inhomogeneidades solapándose en el tiempo con las inhomogeneidades de la tabla 49: en 1022 Hernani (de 1970 a 1980 y de 1973 a 1985) y en 1014 OMA Fuenterrabía y en 1024 E Igueldo (de 1981 a 1994).

En este periodo registran efemérides de precipitación media anual series como 1014, $1016,1022,1024,1024 \mathrm{E}$ y 1026.

Las inhomogeneidades aplicando los test de Thom (tabla 10) y de Mann-Kendall (tabla 49) muestran que las inhomogeneidades sólo afloran en las comarcas de San Sebastián y del Alto Oria.

1026 es la única serie del resto de Guipúzcoa que registra este comportamiento, similar a la comarca de San Sebastián. Asimismo, desde 19791026 coincide con el incremento a nivel "provincial" de precipitación anual.

Esto es congruente con lo expuesto al analizar la precipitación anual aplicando el test de rachas en 1026 (punto 4.2.1.2 punto 3), en que se detecta un comportamiento similar entre 1024E y 1026 en máximos y entre 1026 y 1016, 1022 y 1024 en los mínimos de precipitación.

Por tanto, se considera como tendencia "climatológica" este aumento de precipitación anual de 1978 a 1984, al coincidir con los máximos de precipitación anuales y producirse simultáneamente en gran número de series. (entre el 11 y el 25\%).

\section{7.- 1983 a 1991 en $1025 \mathrm{E}:$}

1025E Mutiloa (1978 a 1992, sin datos en 1986, 1988 y 1989) es la única serie en que se detecta esta tendencia negativa de precipitación anual.

La serie de precipitación anual no muestra tendencia considerando el periodo de datos 1980 a 1992 (esto es, descartando los 2 primeros años).

Al comenzar 1025E en 1978, un año muy lluvioso ( $2^{\circ}$ de los registrados en $\left.1025 \mathrm{E}\right)$ y ser 1979 el máximo histórico de precipitación en 1025E, se explica la tendencia negativa hasta 1984.

Por tanto, cabe pensar que se trata de una tendencia "climatológica", debida a que los primeros años de 1025E fueron muy lluviosos y que 1983, 1985 y 1987 se registran mínimos de precipitación en $1025 \mathrm{E}$.

No obstante, al manifestarse esta tendencia únicamente en esta serie y por ser de cierta extensión temporal, hace que se alberguen dudas. 


\section{8.- 1989 en 1024:}

1981 a 1994.

En la tabla 10 se refleja una inhomogeneidad "climatológica" en 1014 y en 1024E de

De las tablas 15, 16, 16 bis, 17, 18, 22 y 22 bis, en 1989 hubo un mínimo relativo de la precipitación. La tendencia negativa de 1024 refleja esta disminución de la precipitación: fue un mínimo secundario, congruente con el hecho de que sólo se detecte en una serie.

1024 es una serie muy homogénea:

a) Al aplicar el test de Thom a la precipitación anual de 1024 no se advierte ninguna inhomogeneidad, según refleja la tabla 10.

b) Al aplicar el test de Mann-Kendall, sólo se detecta una inhomogeneidad desde 1960 a 2012.

Por tanto, se trata de una tendencia "climatológica".

\section{9.- 1992 en $1021 \mathrm{E}$ y en 1031:}

a) En 1992 hubo un máximo relativo de la precipitación (tablas 15, 16, 18, 22 y 22 bis). 1021E y 1031 están muy cerca de la raya con Navarra y a 12 Km. de separación entre sí.

b) De 1989 a 1999 hubo una inhomogeneidad "climatológica" en 1031.

c) Las dos series presentan una elevada homogeneidad: El test de Thom aplicado a la precipitación anual detecta en:

c1) 1021E 1 inhomogeneidad en 31 veces que se aplica el test de Thom.

c2) 10313 inhomogeneidades en 52 veces en que se analizan las precipitaciones anuales con el test de Thom.

Por tanto, se la califica como tendencia "climatológica".

\section{0.-1995 en 1038:}

a) 1038 comienza en 1992, año con un máximo relativo de precipitación anual. En 1995 hay un mínimo de precipitación (tablas 16, 18, 22 y 22 bis).

b) De la tabla 10, 10370 muestra tendencia "climatológica" de 1990 a 2001.10370 y 1038 están en el Medio Urola, a 9 Km de distancia y con diferencia de altitud de 40 metros.

Por tanto, se la considera tendencia "climatológica". 
Como conclusiones del análisis temporal de las tendencias del test de Mann- Kendall de la precipitación anual,

1.-De las series analizadas, sólo se observa una tendencia no climatológica: 1977 a 1979 en 1017.

2.- Se detectan 2 máximos positivos en las tendencias: 1951-1952 y de 1979 a 1984.

3.- Los máximos se producen tras los periodos de sequía de 1945 a 1948 y de 1970 a 1972 (tablas 22 y 22 bis).

Este hecho sugiere que la transición de un período de sequía a uno de precipitaciones elevadas es mucho más abrupta, más breve en el tiempo, que la transición de un periodo de precipitaciones elevadas a uno seco.

4.- De la gráfica 16, se observa que el número de tendencias positivas de la precipitación anual es muy superior al de tendencias negativas, pudiendo ser debido a: o bien a

4.1.- La transición de un periodo de sequía a uno de precipitaciones elevadas es breve

4.2.- En 1946 el número de series analizadas asciende de 2 a 11. De 1945 a 1948 hubo una serie de sequías muy severas (tabla 22 bis), lo cuál le da un sesgo positivo al análisis de las tendencias del test de Mann-Kendall de las 9 series que comienzan en 1946 (el $18 \%$ del total de las analizadas).

5.- Los resultados son coherentes en los intervalos temporales de las inhomogeneidades detectadas por el test de Thom (tablas 4 y 10) y de las tendencias detectadas por el test de Mann-Kendall (tablas 46 y 49) de la precipitación media anual.

Se resalta la importancia y potencia de un análisis de la precipitación aplicando conjuntamente los 2 tests.

6.- De las tablas 46 y 49 , se observa:

6.1.- La mayoría de las tendencias se detectan en la comarca de San Sebastián.

6.2.- Similitud de las tendencias detectadas en emplazamientos próximos; por ejemplo, las tendencias positivas de 1978 a 1984 exclusivamente se presentan en la comarca de San Sebastián y en el Alto Oria.

7.- Al incrementarse el número de series, de 1926 hasta 1936 se puede hablar de tendencias a nivel de la provincia. A partir de 1946, se insinúan "tendencias" a nivel comarcal.

Se observan comportamientos globales, propios de una región con clima oceánico, con comportamientos específicos a escala comarcal.

8.- Se destaca la importancia de realizar una comparativa de las tendencias detectadas con el comportamiento de la precipitación en los emplazamientos cercanos. 
Así, es importante incluir en el análisis a las series de datos antiguas, para ayudar a calificar una tendencia como "climatológica" o "no climatológica",

9.- El análisis de Mann-Kendall (tablas 46 y 49) indica los siguientes mínimos y máximos en la precipitación anual, correspondientes a un:

9.1.- Ciclo de aproximadamente 30 años de máximos de precipitación: de 1950 a $1954(1015,1016,1022$ A, 1031, 1035, 1037) y de 1978 a $1984(1014,1022,1023,1024$, 1024E, 1026).

Este ciclo se identifica por el elevado número de emplazamientos en que se detecta tendencia positiva.

El test de Mann-Kendall aplicado a la precipitación anual sólo revela una tendencia positiva acusada en un número pequeño de localidades y en los breves intervalos temporales descritos.

Las tablas 49 bis y 49 tris muestran:

a) Año de precipitación máxima.

b) Precipitación anual total $\left(1 / \mathrm{m}^{2}\right)$.

c) Indicativo.

d) Nombre emplazamiento.

Referidos a 1013 Irún, 1013I Fuenterrabía Zubieta, 1014 OMA Fuenterrabía y en 1015 Guadalupe, situadas a menos de 4 Km. de distancia entre sí. Hay datos de precipitación anual en el entorno de Irún - Fuenterrabía desde 1915 hasta 2012.

Tabla 49 bis Máximos de precipitación anual:

\begin{tabular}{|c|c|c|c|}
\hline $\begin{array}{c}\text { Año de precipitación } \\
\text { máxima }\end{array}$ & $\begin{array}{c}\text { Precipitación anual } \\
\left(1 / \mathrm{m}^{2}\right)\end{array}$ & Indicativo & Nombre \\
\hline 1923 & 2560,8 & 1013 & Irún Fitosanitaria \\
\hline 1917 & 2416,8 & 1013 & Irún Fitosanitaria \\
\hline 1960 & 2416,8 & 1014 & OMA Fuenterrabía \\
\hline 1960 & 2409,6 & 1013 & Irún Fitosanitaria \\
\hline 1979 & 2292,0 & 1014 & OMA Fuenterrabía \\
\hline
\end{tabular}

La precipitación media anual en 1923 es la más elevada registrada desde 1915 a 2012 en 1013, 1013I, 1014 y en 1015. De 1915 a 2012 hay 119 años completos de precipitación entre las 4 series de datos.

Los datos de la tabla 49 bis son concordantes con los expuestos en las tablas 22 y 22 bis. 
Tabla 49 tris: Máximos de precipitación acumulada de Enero a Mayo:

\begin{tabular}{|c|c|c|c|}
\hline $\begin{array}{c}\text { Año de precipitación } \\
\text { máxima }\end{array}$ & $\begin{array}{c}\text { Precipitación acumulada } \\
\text { Enero-Mayo }\left(1 / \mathrm{m}^{2}\right)\end{array}$ & Indicativo & Nombre \\
\hline 1978 & 1355,5 & 1014 & OMA Fuenterrabía \\
\hline 1979 & 1244,0 & 1014 & OMA Fuenterrabía \\
\hline 2013 & 1207,1 & 1014 & OMA Fuenterrabía \\
\hline 1917 & 1071,4 & 1013 & Irún Fitosanitaria \\
\hline $1923\left(8^{\circ}\right)$ & 1022,1 & 1013 & Irún Fitosanitaria \\
\hline
\end{tabular}

1923 es el $8^{\circ}$ año con precipitación acumulada en enero a mayo desde 1915 a 2013.

La precipitación recogida de 01 de enero a 31 de mayo de 2013 en 1014 es la $3^{\text {a }}$ mayor desde 1915. Se disponen de 132 registros de precipitación acumulada de 01 de enero a 31 de mayo.

A fecha de 31 de mayo de 2013, las precipitaciones en 1014 son superiores a las registradas en 1013 en el mismo periodo enero-mayo de 1923.

La gráfica 17 representa la precipitación acumulada desde enero a mayo en los años 2013, 1979, 1960, 1923 y 1917 en 1013 y en 1014. También se dibuja en la gráfica 17 la media de las precipitaciones acumuladas de enero a mayo recogidas en 1013, 1013I, 1014 y 1015 desde 1915 a 2013.

Gráfica 17: Máximos de precipitación acumulada de enero a mayo:

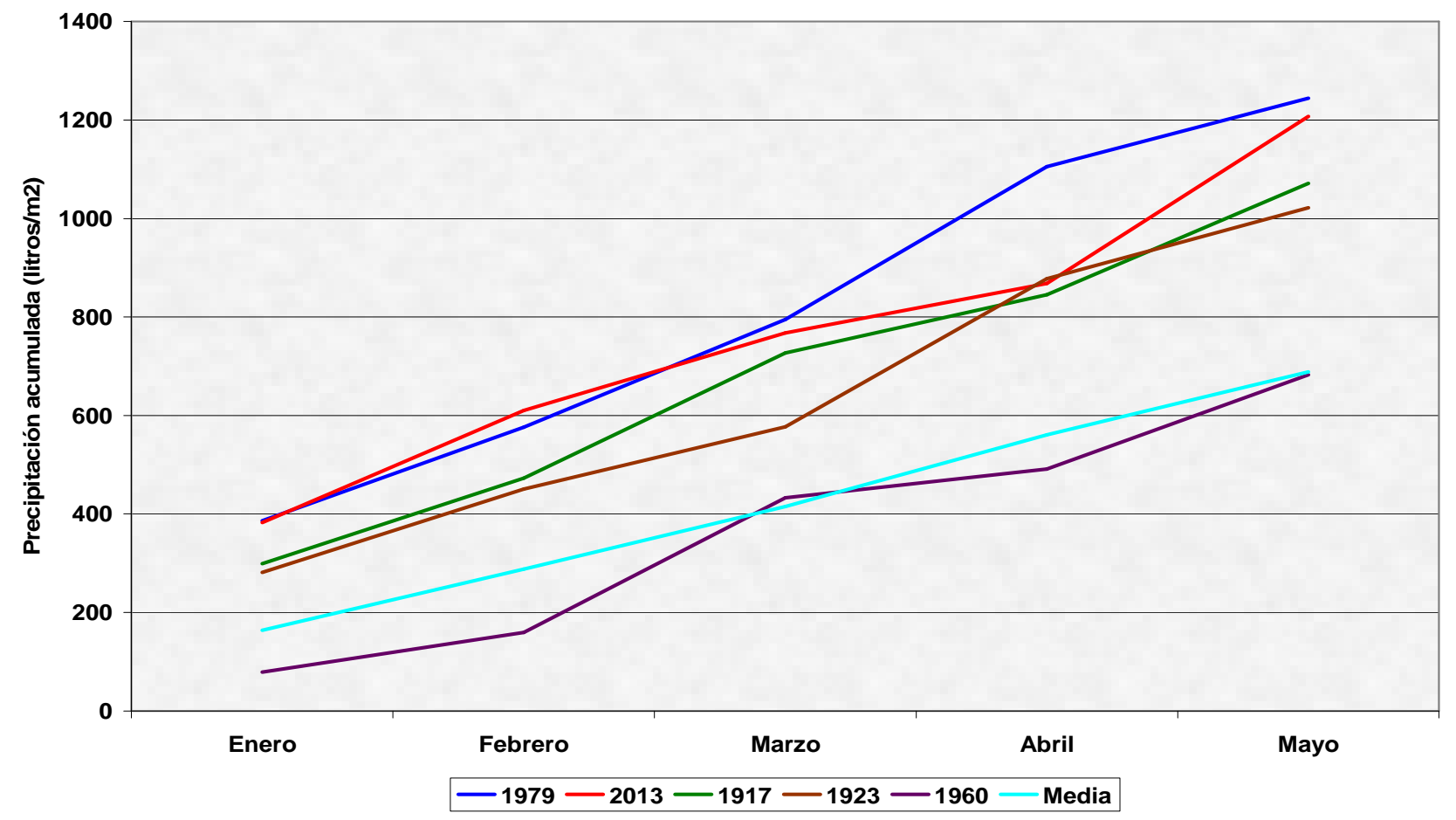


El $\underline{08 \text { de abril de } 1923}$ se registran $\underline{141,11 / \mathrm{m}^{2} \text { en Irún. Es el registro de precipitación }}$ máxima recogida en 24 horas en Irún y en Fuenterrabía desde mayo de 1913 a mayo de 2013.

1953 fue tan lluvioso que las inundaciones de octubre provocaron la quiebra de la compañía del Plazaola, ferrocarril entre San Sebastián y Pamplona.

Asimismo en Cestona un autobús fue arrastrado por la crecida del río Urola, pereciendo casi todos sus ocupantes.

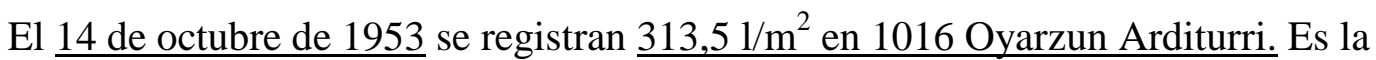
precipitación máxima recogida en 24 horas en las provincias de Guipúzcoa, Vizcaya y Álava desde enero de 1859 a mayo de 2013.

En agosto de 1983 se produjeron inundaciones con 34 muertos y 6 desaparecidos.

9.2.- Intervalo de sequías severas: 1945 a 1948.

9.3.- Ciclo de 10 años de máximos secundarios de precipitación: 1951- 1952, 1958 1960, 1966, 1969, 1974, 1978 a 1984, 1992.

9.4.- Mínimos secundarios de la precipitación: 1899, 1948, 1957, 1989, 1995.

Los resultados expuestos de 9.1 a 9.4. verifican y corroboran los ciclos a 10 y 30 años detectados en las tablas 22 y 22 bis de la precipitación anual.

9.5.- Este ciclo anual en la precipitación ya fue comentado en la ponencia de Álvarez Usabiaga J.I. "Variaciones observadas en el Observatorio de Igueldo en 60 años" en el curso de las XX jornadas de la Asociación Meteorológica Española en Mayo de 1989 en San Sebastián Mayo 1989, en la cuál menciona:

“... aparecen los máximos relativos en las inmediaciones al comienzo de década" , “... periodicidad de máximo pluviométrico cada 10 años aproximadamente" y “ ..., es digno de reseñarse la posible aparición de un ciclo de treinta años, con una década sumamente anómala de cada 3, casi siempre seguida de una década lluviosa". 


\subsubsection{3.- Precipitación MAM periodo de 1941 a 2012:}

La gráfica 18 muestra la evolución de las tendencias detectadas aplicando el test de Mann-Kendall a las series de precipitación MAM desde 1941.

Gráfica 18: Evolución temporal tendencias Mann-Kendall series precipitación MAM de 1941 a 2012:

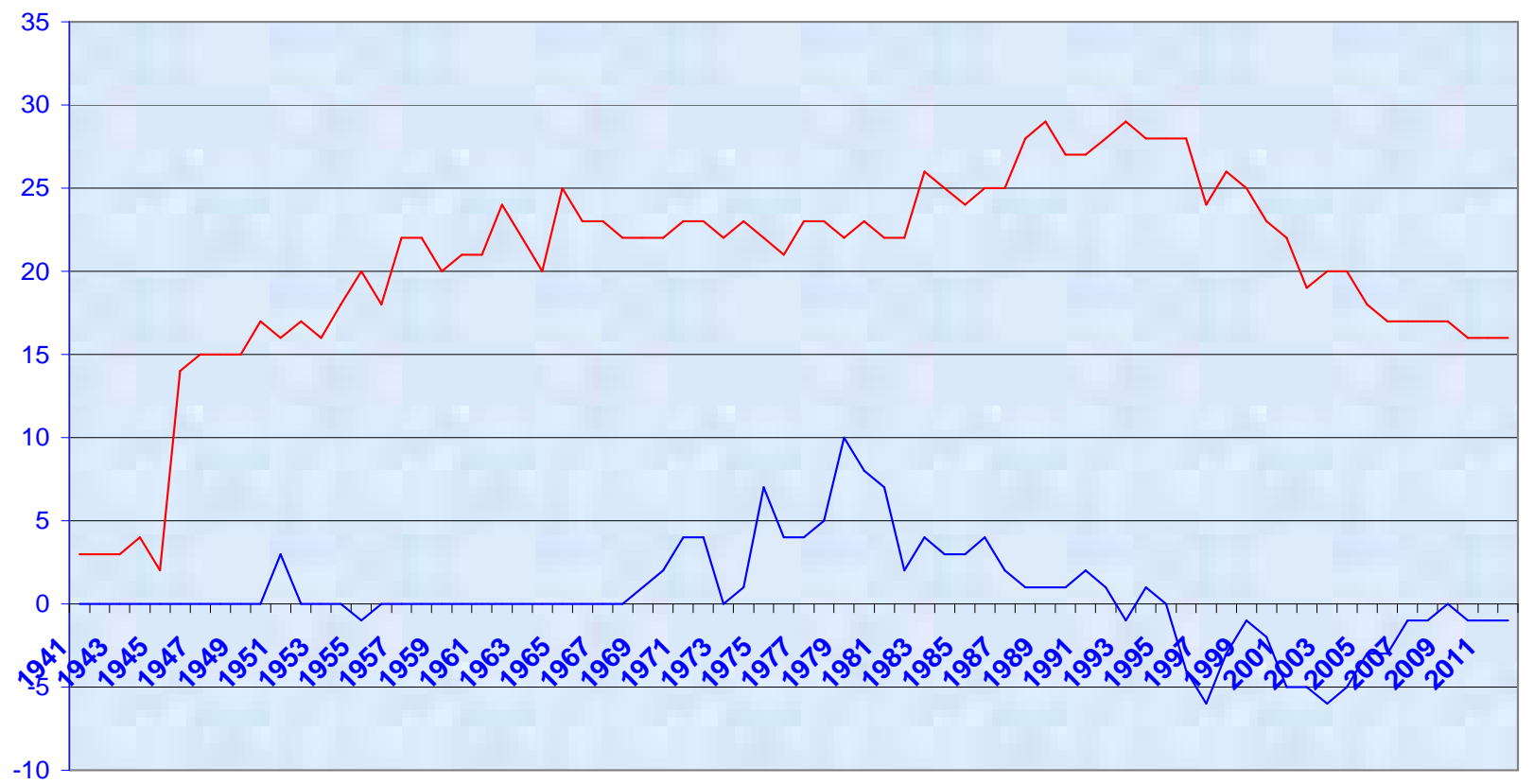

Años

- № series — Suma Tendencias

De la gráfica 18 se observa un máximo de tendencia positiva de la precipitación MAM muy acusado entre 1979 y 1986 y dos máximos de tendencia negativa entre 1996 y 1998 y entre 2000 y 2006.

Tabla 50: Inhomogeneidades y tendencias detectadas aplicando el test de Mann Kendall a la precipitación MAM de 1941 a 1974:

\begin{tabular}{|c|c|c|c|c|}
\hline $\begin{array}{c}\text { Años } \\
\text { inhomogeneidad }\end{array}$ & Indicativos & $\begin{array}{c}\text { Tendenci } \\
\mathrm{a}\end{array}$ & $\begin{array}{c}\text { Inhomogeneidad } \\
\text { "climatológica" }\end{array}$ & $\begin{array}{c}\text { \% series } \\
\text { sobre total }\end{array}$ \\
\hline 1951 & $1022 \mathrm{~A}, 9268,1037$ & + & Sí & 19 \\
\hline 1955 & 1026 & - & Sí & 5 \\
\hline 1969 & 1044 & + & Sí & 9 \\
\hline 1970 & 1018,1026 & + & Sí & 9 \\
\hline 1971 & $1018,1026,1044,1044 \mathrm{~A}$ & + & Sí & 17 \\
\hline 1972 & $1018,1026,1036,1044 \mathrm{~A}$ & + & Sí & 17 \\
\hline 1974 & 1026 & + & Sí & 4 \\
\hline
\end{tabular}


Tabla 50 (Continuación): Inhomogeneidades y tendencias detectadas aplicando el test de Mann Kendall a la precipitación MAM de 1975 a 2012:

\begin{tabular}{|c|c|c|c|c|}
\hline $\begin{array}{c}\text { Años } \\
\text { inhomogeneidad }\end{array}$ & Indicativos & Tendencia & $\begin{array}{l}\text { Inhomogeneidad } \\
\text { "climatológica" }\end{array}$ & $\begin{array}{c}\% \text { series } \\
\text { sobre total }\end{array}$ \\
\hline 1975 & $\begin{array}{c}\text { 1016, 1018A, 1024, 1026, } \\
1032 \mathrm{~A}, 1036,1044 \mathrm{~A}\end{array}$ & + & Sí & 32 \\
\hline 1976 & $1016,1024,1026,1036$ & + & Sí & 19 \\
\hline 1977 & $1016,1022,1026,1036$ & + & Sí & 17 \\
\hline 1978 & $1016,1022,1024,1026,1036$ & + & Sí & 22 \\
\hline 1979 & $\begin{array}{c}1016,1021 \mathrm{O}, 1022,1023 \\
1024,1024 \mathrm{E}, 1026,1031,1036 \\
1044 \mathrm{~A}\end{array}$ & + & Sí & 45 \\
\hline 1980 & $\begin{array}{c}1016,1022,1023,1024,1024 \mathrm{E}, \\
1026,1035,1036\end{array}$ & + & Sí & 35 \\
\hline 1981 & $\begin{array}{c}1016,1022,1023,1024,1024 \mathrm{E}, \\
1026,1036\end{array}$ & + & Sí & 32 \\
\hline 1982 & 1016, 1024E, 1026, 1036 & + & Sí & 18 \\
\hline 1982 & $1025 \mathrm{E}, 1037 \mathrm{O}$ & - & Sí & 9 \\
\hline 1983 & $1016,1024,1024 \mathrm{E}, 1026$ & + & Sí & 15 \\
\hline 1984 & $1016,1024,1026$ & + & Sí & 12 \\
\hline 1985 & 1024, 1024E, 1026 & + & Sí & 17 \\
\hline 1986 & 1024E, 1026, 1035, 1036 & + & Sí & 16 \\
\hline 1987 & $1024 \mathrm{E}, 1026$ & + & Sí & 8 \\
\hline $\begin{array}{c}1988-1990 y \\
1993-1995\end{array}$ & $1024 \mathrm{E}$ & + & Sí & 3 \\
\hline $1991-1992$ & $1024 \mathrm{E}, 1035$ & + & Sí & 7 \\
\hline 1992 & $1013 \mathrm{I}$ & - & Sí & 4 \\
\hline 1993 & 1013I, 1019A & - & Sí & 7 \\
\hline 1995 & $1013 \mathrm{I}$ & - & Sí & 4 \\
\hline 1996 & $1013 \mathrm{I}, 1025 \mathrm{~N}, 1033 \mathrm{U}, 1038$ & - & Sí & 14 \\
\hline 1997 & $\begin{array}{c}\text { 1013I, 1019A, 1031, 1033U, } \\
1038,1048\end{array}$ & - & Sí & 25 \\
\hline 1998 & 1013I, 1019A, 1038 & - & Sí & 12 \\
\hline 1999 & $1026 \mathrm{~A}$ & - & Sí & 4 \\
\hline 2000 & $1026 \mathrm{~A}, 1036 \mathrm{O}$ & - & Sí & 9 \\
\hline 2001 & $\begin{array}{c}\text { 1026A, 1031, 1036O, 1048, } \\
10490\end{array}$ & - & Sí & 23 \\
\hline 2002 & $\begin{array}{c}\text { 1026A, 1036O, 1048, 1049O, } \\
1049 \mathrm{U}\end{array}$ & - & Sí & 26 \\
\hline 2003 & $\begin{array}{l}\text { 1026A, 1031, 1036O, 1048, } \\
10490,1049 \mathrm{U}\end{array}$ & - & Sí & 30 \\
\hline 2004 & $\begin{array}{c}\text { 1026A, 1036O, 1048, 1049O, } \\
1049 \mathrm{U}\end{array}$ & - & Sí & 25 \\
\hline 2005,2006 & $1014,1026 \mathrm{~A}, 1036 \mathrm{O}$ & - & Sí & $17-18$ \\
\hline $\begin{array}{c}2007,2008 \text { y } \\
2010-2012\end{array}$ & 1014 & - & Sí & 6 \\
\hline
\end{tabular}




\section{1.- 1951 en $1022 \mathrm{~A}$, en 9268 y en 1037 y 1955 en 1026 :}

De las tablas 25, 26, 34 y 34 bis se observa que tras la sequía de la segunda mitad de los años 40 hubo una recuperación de la precipitación, registrándose en 1951 un máximo secundario, tras el cuál descienden las precipitaciones hasta 1955 (el más seco en 1016 de 1947 a 1984, en 1018 de 1950 a 1972, en 1032 de 1926 a 1987, en 1035 de 1946 a 2012).

Si bien el test de Mann-Kendall sólo señala tendencia en 1022A, 9268, 1037 y 1026 (el 19\% de las series analizadas en 1951), se perciben a su vez incrementos de la precipitación en 1016, 1018, 1032 y 1035, sin llegar a marcar tendencia en estas 4 últimas.

Por tanto, las tendencias positivas de 1951 y negativa de 1955 son "climatológicas", reflejando el ciclo de precipitaciones y sequías de 10 años ya analizado.

\section{2.- 1969 a 1972 en 1018 , en 1026 , en 1036 , en 1044 y en $1044 \mathrm{~A}:$}

a) De las tablas 27, 28, 34 y 34 bis se observan en la precipitación MAM una serie de máximos en 1969, 1971 y 1972 (1017, 9268, 1023, 1036, 1050), si bien no alcanzan a señalar tendencia.

b) La tendencia se registra en un máximo del 17\% de las series, situadas en la comarcas de San Sebastián, Alto Oria y Medio Deba.

Por tanto, se la cataloga como tendencia "climatológica".

\section{3.- 1974 a 1987:}

3.1.- De las tablas 28, 29, 30, 34 y 34 bis a partir de 1975 se empieza a detectar un incremento de la precipitación anual más acusado en la comarca de San Sebastián y en el Alto Oria; se observan máximos de precipitación en 1974 y de 1978 a 1980, sin un periodo seco claramente definido entre ambos.

En 1981 y 1982 se registra un mínimo de la precipitación, seguido de un máximo secundario en 1985.

3.2.- Esta tendencia se manifiesta principalmente en la Comarca de San Sebastián, el Alto y Medio Oria y, de un modo menor en el Medio Urola y en el Medio Deba, indicando que el incremento de la precipitación fue más evidente en las series de las comarcas de San Sebastián y el Alto Oria, llegando a detectarse en el 35\% de las series estudiadas.

3.3.- En 1024E, se encuentran en este intervalo algunos de los 10 años más lluviosos registrados de 1928 a 2012: $1979\left(1^{\circ}\right), 1985\left(3^{\circ}\right), 1978\left(5^{\circ}\right), 1975\left(6^{\circ}\right), 1986\left(8^{\circ}\right), 1974\left(9^{\circ}\right)$, $1980\left(10^{\circ}\right)$.

3.4.- La tabla 23 refleja inhomogeneidades al aplicar el test de Thom en el periodo MAM en 1036 de 1967 a 1976. 
3.5.- La gráfica 18 muestra un pico de tendencia positiva muy acusado en el intervalo 1974 a 1986, el más significativo desde 1878 a 2012: 1978, 1979, 1980, 1981 y 1982 son los años con mayores tendencias positivas de la precipitación MAM.

3.6.- En 1016 se detecta una tendencia positiva en la precipitación MAM desde 1975 a 1984 (fin serie); esta tendencia coincide con la mostrada por series del resto de Guipúzcoa y del entorno, según refleja la tabla 50. Por tanto, cabe considerarla como tendencia climatológica.

3.7.- La tendencia positiva de 1026 en la precipitación MAM se extiende de 1974 a 1987 ( $\sin$ datos en 1973; fin de serie en 1987).

Sin embargo, coincide con 1024 (tendencia positiva en 1975, 1976, 1978 a 1981 y de 1983 a 1985), con 1024E (tendencia positiva de 1979 a 1983 y de 1985 a 1995), con 1016 (tendencia positiva de 1975 a 1984), con 1018 (tendencia positiva de 1970 a 1972), con 1044A (tendencia positiva en 1973, 1974 y 1975) y con 1036 (tendencia positiva en 1972, de 1975 a 1982 y en 1985 y 1986).

No hay evidencias registradas de cambio de emplazamiento ni de colaborador. Excepto de 1970 a 1972, la tendencia registrada en MAM coincide con la detectada en las series de la comarca de San Sebastián.

Al hallarse 1026 en un valle abierto al NE, sin obstáculos a los vientos y precipitaciones procedentes de San Sebastián (cosa que no ocurre en 1037, próxima a 1026, ni en 1031, sita entre 1026 y la comarca de San Sebastián, pero al abrigo de los vientos del $\mathrm{NE}$ ), cabe considerarla como una tendencia "climatológica" de 1974 a 1987.

3.8.- 1024E: El test de Mann-Kendall indica tendencia positiva de 1980 a 1987, coincidente con 1016, con 1024 y con 1026.

3.9.- Se resalta la importancia de un análisis conjunto de los observatorios y colaboradores cercanos, para no desechar tendencias positivas de precipitaciones MAM como "no climatológicas", al producirse en tantos emplazamientos cercanos simultáneamente.

Al producirse en tantos lugares próximos situados no sólo en la misma provincia, sino en la misma comarca, se la considera como una tendencia "climatológica".

\section{4.- 1982 en $1025 \mathrm{E}$ y en $1037 \mathrm{O}$ :}

4.1.- 1025E (1977 a 1993) y 1037 (1977 a 2001, sin datos en 1995) son las únicas series en que se detecta esta tendencia negativa en la precipitación MAM.

Las series $1025 \mathrm{E}$ y $1037 \mathrm{O}$ no muestran tendencia considerando respectivamente, el periodo de datos 1980 a 2003 (esto es, descartando los tres primeros años) y 1978 a 2001 (esto es, descartando el primer año). Oeste - Este. 
4.3.- Ambas comienzan en años muy lluviosos $1025 \mathrm{E}\left(1978-1^{\circ}-\right.$ y $\left.1979-2^{\circ}-\right)$ y $10370\left(1977-6^{\circ}-\right.$ y $\left.1979-3^{\circ}-\right)$.

4.4.- De la tabla 23, 1025E también indica inhomogeneidad al aplicar el test de Thom de 1979 a 1988 y de 1981 a 1991. 1037 la muestra de 1981 a 1991.

4.5.- Asimismo, $1025 \mathrm{E}$ revela una tendencia negativa en la precipitación anual, analizada en el punto 7 del apartado 4.2.2.2.- (Evolución temporal inhomogeneidades MannKendall en el periodo 1941 a 2012).

4.6.- Se remarca la importancia de un análisis conjunto de los observatorios y colaboradores cercanos, para no desechar tendencias negativas de precipitaciones MAM como "no climatológicas".

Si bien 1025E y 1037 O indican tendencia negativa en 1982, año en que 4 series la indican positiva, la tendencia negativa se detecta en 2 enclaves cercanos simultáneamente y esta tendencia es coherente con la evolución de las precipitaciones de las tablas 34 y 34 bis.

4.7.- Por tanto, cabe pensar que se trata de una inhomogeneidad climatológica, debida a que los primeros años de $1025 \mathrm{E}$ y de $1037 \mathrm{O}$ fueron muy lluviosos.

Así, la tendencia negativa de 1982 muestra el fin del periodo de precipitaciones máximas de 1978 a 1981.

\section{5.- 1988 a 1995:}

Esta tendencia positiva en la precipitación MAM sólo se detecta en 1024E y en 1035, separadas $4 \mathrm{Km}$.

Por tanto, se la considera como tendencia "climatológica".

\section{6.- 1992 a 1998:}

\section{1.- 1992 a 1995 en 1013I y en 1019A:}

6.1.1.- De la gráfica 18, se observa una tendencia negativa en la precipitación MAM en los años 90. Esta tendencia negativa se manifestó primero en 1013I y en 1019A.

6.1.2.- 1013I y 1019A son series muy cortas (1985 a 1999 y 1988 a 2000) que arrancan tras los máximos de precipitación MAM. Ambas están situadas en la comarca de San Sebastián a 8,5 Km de distancia entre sí.

La "discrepancia" de los resultados al aplicar el test de Mann-Kendall a la precipitación MAM entre 1993 y 1995 de 1013I y 1019A respecto a la tendencia obtenida en 1024E no es tal, al comenzar 1013I y 1019A en años con precipitaciones en MAM muy elevadas. 
Además, aplicando el test de rachas a precipitación anual, se observa que las inhomogeneidades en este periodo de 1013I y de 1019A son "climatológicas" (tabla 10 y punto 5 del apartado 4.2.1.2. Análisis de la evolución temporal inhomogeneidades test Thom, precipitación anual de 1941 a 2012).

Por tanto, cabe clasificarla como tendencia "climatológica".

\section{2.- 1996 a 1998:}

6.2.1.- La tendencia negativa de la precipitación MAM se extiende al Oria medio, Urola medio y al Alto Deba, llegando a afectar al 25\% de las series analizadas.

6.2.2.- De las tablas 30, 31, 34 y 34 bis, 1996 y 1997 fueron años con mínimos de precipitación en MAM.

6.2.3.- La gráfica 18 refuerza la evidencia mostrando una tendencia negativa entre 1996 y 1998.

Por tanto, se la considera tendencia "climatológica".

\section{7.- 1999 a 2006:}

7.1.- De las tablas 32, 33, 34 y 34 bis, la precipitación MAM disminuye hasta el año 2006, que fue un mínimo relativo de la precipitación.

La gráfica 18 corrobora este mínimo de la precipitación mostrando una tendencia negativa entre 2000 y 2006.

7.2.- De 2000 a 2006 la tendencia negativa sólo afecta al Alto Oria, Alto Urola y al interior occidental de Guipúzcoa, siendo idéntico el comportamiento entre el Alto Oria (1026A), el Alto Urola (1036O) y el Alto Deba $(1048,10490$ y 1049 U) y no produciéndose en ninguna otro lugar de Guipúzcoa, salvo en 1031 (Medio Oria) en 2001.

Así indican tendencia negativa de 2000 a 2006: 10490 de 2001 a 2005, 1048 de 2001 a 2004, 1049U de 2002 a 2004, 1044D de 1997 a 2006, 10360 de 2000 a 2006 y 1026A Ordizia de 1999 a 2006) y no se produce en ninguna más.

7.3.- Esta tendencia negativa de la precipitación llega a detectarse en 2003 en el 30\% de las series estudiadas.

Por consiguiente, se trata de una "tendencia climatológica a nivel comarcal".

\section{8.- 2007 a 2012 en $1014:$}

8.1.- 1014 es una serie con una excelente calidad.

8.2.-De las tablas 34 y 34 bis, la precipitación disminuye desde 2007-2008 al 20102011. Esta tendencia negativa de la precipitación en 1014 es coherente con ello. 
Por tanto, se la califica como tendencia "climatológica".

Como conclusiones del análisis temporal de las tendencias del test de Mann- Kendall de la precipitación MAM,

1.- De las series analizadas, no se observa ninguna tendencia "no climatológica".

2.- Se detecta un máximo de tendencia positiva muy acusado entre 1979 y 1986 y dos máximos de tendencia negativa: entre 1996 y 1998 y entre 2000 y 2006.

3.- De la gráfica 18 y de las tablas 34 y 34 bis:

3.1.- El máximo de la tendencia positiva se produce tras la sequía de 1973.

3.2.- Se observan máximos secundarios de la tendencia positiva tras las sequías de 1947-1948 y de 1967.

Este hecho sugiere que la transición de un período de sequía a uno de precipitaciones es mucho más abrupta, más breve en el tiempo, que la transición de un periodo de precipitaciones elevadas a uno seco.

4.- De la gráfica 18 se observa que el número de tendencias positivas indicadas por el test de Mann-Kendall es superior al de tendencias negativas. Puede ser debido a:

4.1.- En MAM, la transición de sequía a periodos de precipitaciones elevadas es muy breve o bien a

4.2.- El número de serie analizadas asciende de 2 a 14 en 1946. De 1947 a 1948 hubo una serie de sequías muy severas (tabla 34 bis), lo cuál le da un sesgo positivo al análisis de las tendencias del test de Mann-Kendall debido a las 12 series que comienzan en 1946 (el $22 \%$ del total de las estudiadas).

5.- Los resultados son coherentes entre las inhomogeneidades detectadas por el test de Thom (tablas 4 y 23) y las tendencias indicadas por el test de Mann-Kendall de la precipitación en MAM (tablas 46 y 50).

6.- De la tabla 50, se observa un comportamiento muy semejante en las tendencias detectadas en enclaves cercanos, llegando a ser idéntico el comportamiento de 2000 a 2006 en la cabecera de los 3 ríos de Guipúzcoa (Alto Oria, Alto Deba y Alto Urola).

7.- Al incrementarse el número de series, de 1926 a 1936 se puede hablar de tendencias a nivel de la provincia. A partir de 1946 se insinúan "tendencias" a nivel comarcal, mostrándose con rotundidad de 1995 a 2006.

8.- Se resalta la importancia de un análisis conjunto de los observatorios y colaboradores cercanos, para no desechar tendencias positivas de la precipitación MAM como "no climatológicas", al producirse en tantos emplazamientos simultáneamente. 
9.- De la tabla 50, la tendencia negativa en la precipitación MAM en los 90 comienza en la costa (1013I y 1019A), de 1995 a 1998 se detecta en las comarcas de San Sebastián, Medio Oria y de 2000 a 2006 se muestra en el interior de la provincia, en el Alto Oria, Alto Urola y Alto Deba.

10.-El análisis de Mann-Kendall (tablas 46 y 50) indica los siguientes mínimos y máximos en la precipitación media en MAM, correspondientes a un:

10.1.- Ciclo de 10 años de máximos de precipitación: 1951, 1969, 1972 a 1982 (éste último con máximos relativos entre 1978 y 1981), 1985-1986 y 1991.

La tabla 50 bis muestra los máximos de la precipitación registrada en el periodo MAM en las series 1013, 1013I, 1014 y 1015. Se incluye entre paréntesis el ordinal referido al total de intervalos de precipitación MAM en las 4 series desde 1915 a 2013 (132 registros).

Tabla 50 bis: Máximos de precipitación acumulada en el periodo MAM en 1013, 1013I, 1014 y $1015:$

\begin{tabular}{|c|c|c|c|}
\hline $\begin{array}{c}\text { Año de precipitación } \\
\text { máxima }\end{array}$ & $\begin{array}{c}\text { Precipitación acumulada } \\
\text { Marzo-Mayo }\left(1 / \mathrm{m}^{2}\right)\end{array}$ & Indicativo & Nombre \\
\hline $1978\left(1^{\circ}\right)$ & 704,2 & 1014 & OMA Fuenterrabía \\
\hline $1979\left(2^{\circ}\right)$ & 668,1 & 1014 & OMA Fuenterrabía \\
\hline $1980\left(3^{\circ}\right)$ & 663,1 & 1014 & OMA Fuenterrabía \\
\hline $1917\left(7^{\circ}\right)$ & 598,3 & 1013 & Irún Fitosanitaria \\
\hline $2013\left(8^{\circ}\right)$ & 597,2 & 1014 & OMA Fuenterrabía \\
\hline $1923\left(14^{\circ}\right)$ & 571,1 & 1013 & Irún Fitosanitaria \\
\hline $1960\left(24^{\circ}\right)$ & 523,5 & 1013 & Irún Fitosanitaria \\
\hline
\end{tabular}

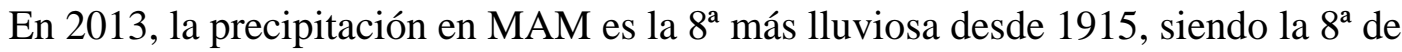
132 datos de precipitación en MAM en el entorno de Irún - Fuenterrabía.

En 1024E Igueldo, la precipitación acumulada en MAM en 2013 es 537, 6 1/m².

Se trata de la $5^{\text {a }}$ precipitación más elevada registrada desde 1928 en MAM ( el máximo de precipitación en MAM fue en 1024E en 1979 con 598,01/ $\mathrm{m}^{2}$ ).

La gráfica 19 representa la precipitación acumulada de marzo a mayo en los años 2013, 1980, 1979, 1978 y 1917 en 1013 y en 1014.

Se incluye en la gráfica 19 la media de las precipitaciones acumuladas de marzo a mayo recogidas en 1013, 1013I, 1014 y 1015 desde 1915 a 2013. 
Gráfica 19: Máximos de precipitación acumulada de enero a mayo:

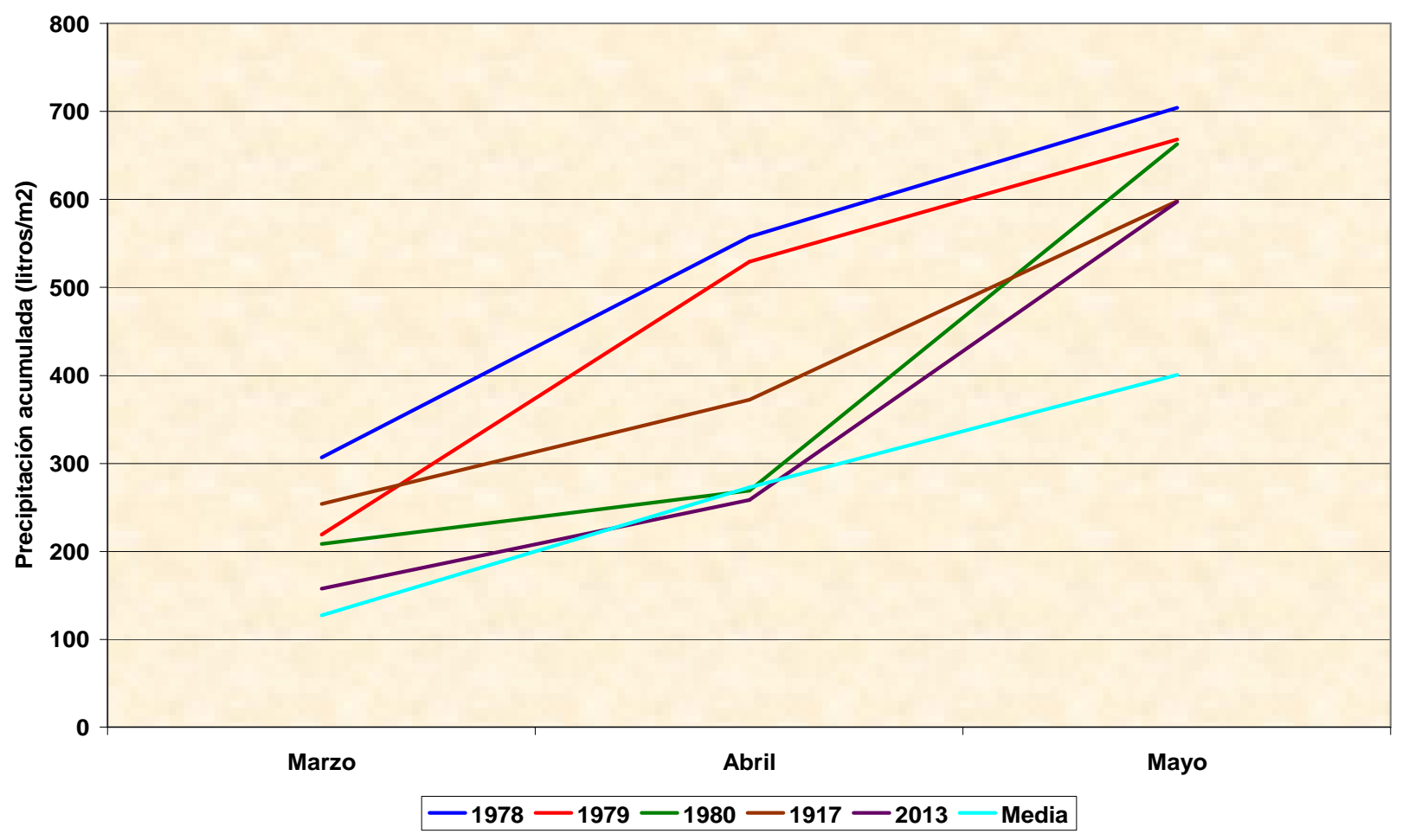

10.2.- Ciclo de 10 años de mínimos pluviométricos: 1904, 1921, 1955, 1996 - 1997, 2001-2004.

Esto corrobora los datos de las tablas 34 y 34 bis, en la que afloran los ciclos a 10 años en la precipitación MAM.

11.- No se han podido apreciar ciclos de la precitación MAM superiores a 10 años. 


\subsubsection{4.- Precipitación AMJ periodo de 1941 a 2012:}

La gráfica 20 representa la evolución de las tendencias detectadas aplicando el test de Mann-Kendall a las series de precipitación AMJ desde 1941 a 2012.

Gráfica 20: Evolución temporal tendencias Mann-Kendall series precipitación AMJ de 1941 a 2012:

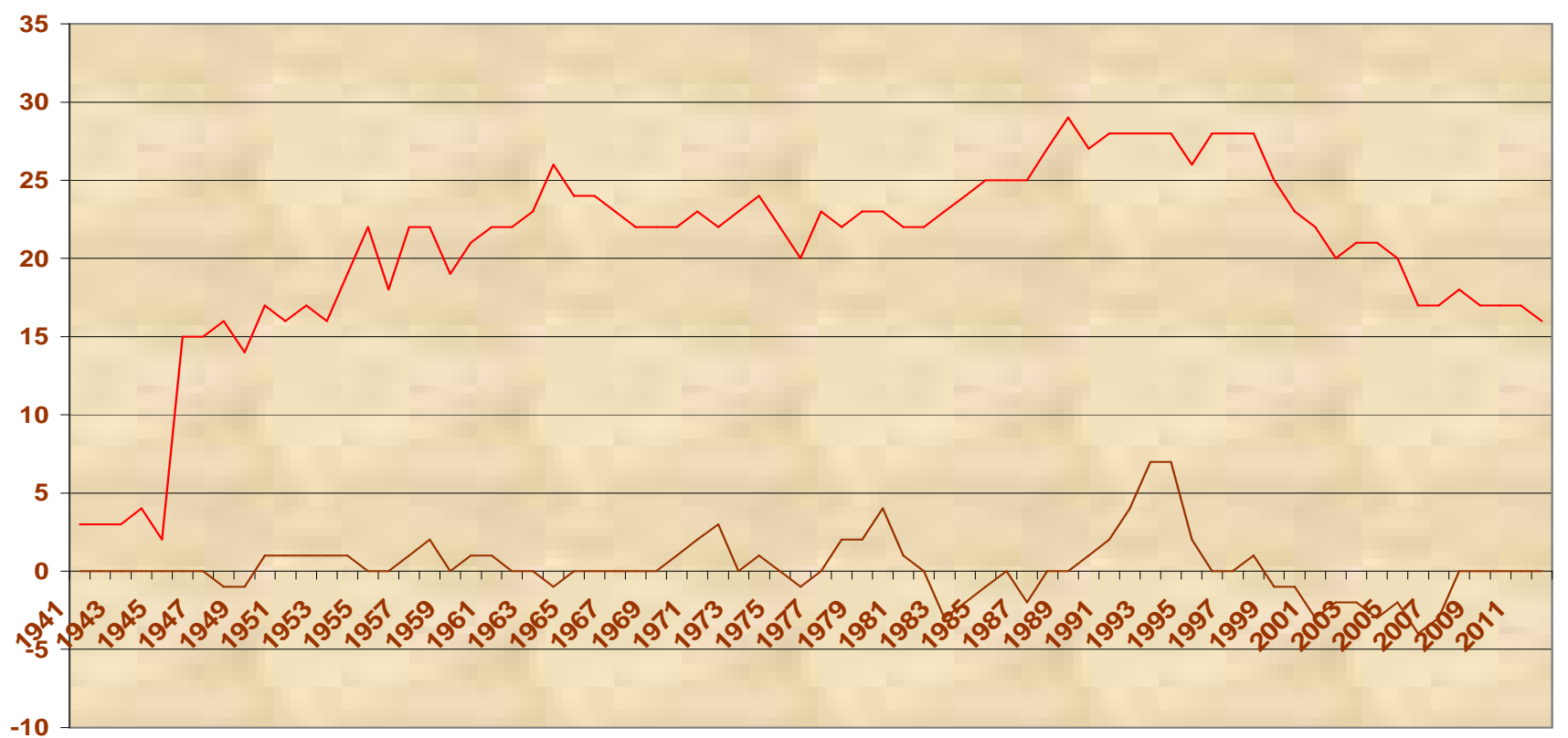

Años

- № series - Suma Tendencias

De la gráfica 20 se observan un máximo de tendencia positiva de la precipitación AMJ muy acusado entre 1991 y 1995, dos máximos secundarios de tendencia positiva de la precipitación AMJ entre 1978 y 1980 y entre 1971 y 1972 y dos máximos de tendencia negativa: entre 1983 y 1984 y entre 2001 y 2007.

Tabla 51: Inhomogeneidades y tendencias detectadas aplicando el test de Mann Kendall a la precipitación AMJ de 1946 a 2012:

\begin{tabular}{|c|c|c|c|c|}
\hline $\begin{array}{c}\text { Años } \\
\text { inhomogeneidad }\end{array}$ & Indicativos & Tendencia & $\begin{array}{c}\text { Tipo } \\
\text { inhomogeneidad }\end{array}$ & $\begin{array}{c}\text { \% series } \\
\text { sobre total }\end{array}$ \\
\hline 1948 y 1949 & 1013 & - & Sí & 13 \\
\hline $1950-1954$ & $1032 \mathrm{~A}$ & + & Sí & $5-6$ \\
\hline 1957 & 1016 & + & Sí & 5 \\
\hline 1958 & 1016,1031 & + & Sí & 10 \\
\hline $1960-1961$ & $1032 \mathrm{~A}$ & + & Sí & 5 \\
\hline 1964 & 9268 & - & No & 4 \\
\hline 1970 & 1026 & + & Sí & 5 \\
\hline
\end{tabular}


Tabla 51 (continuación): Inhomogeneidades y tendencias detectadas aplicando el test de Mann Kendall a la precipitación AMJ de 1946 a 2012:

\begin{tabular}{|c|c|c|c|c|}
\hline $\begin{array}{c}\text { Años } \\
\text { inhomogeneidad }\end{array}$ & Indicativos & Tendencia & $\begin{array}{c}\text { Tipo } \\
\text { inhomogeneidad }\end{array}$ & $\begin{array}{l}\% \text { series } \\
\text { sobre total }\end{array}$ \\
\hline 1971 & $1026,1044 \mathrm{~A}$ & + & Sí & 9 \\
\hline 1972 & $1018,1026,1044 \mathrm{~A}$ & + & Sí & 14 \\
\hline $1974-1977$ & 1026 & + & Sí & $4-5$ \\
\hline 1976 & 1037 & - & Sí & 5 \\
\hline $1975,1976,1977$ & 1017 & - & No & $4-5$ \\
\hline $1978-1979$ & 1022,1026 & + & Sí & 9 \\
\hline 1980 & $1016,1022,1023,1026$ & + & Sí & 17 \\
\hline 1981 & 1022,1026 & + & Sí & 9 \\
\hline $1981,1982,1985$ & $1025 \mathrm{E}$ & - & Sí & 5 \\
\hline 1982 & 1026 & + & Sí & 5 \\
\hline 1983 & $1025 \mathrm{E}, 1037 \mathrm{O}, 1048$ & - & Sí & 13 \\
\hline 1984 & $1025 \mathrm{E}, 1037 \mathrm{O}$ & - & Sí & 8 \\
\hline 1987 & 1025E, 1044D & - & Sí & 8 \\
\hline 1990 & 1019A & + & Sí & 4 \\
\hline 1991 & 1037, 1037Q & + & Sí & 7 \\
\hline 1992 & $1036 \mathrm{O}, 1037,1044 \mathrm{U}, 1049 \mathrm{U}$ & + & Sí & 14 \\
\hline 1993 & $\begin{array}{c}\text { 1026A, 1036O, 1037, 1037Q, } \\
\text { 1044U, 1049, 1049U }\end{array}$ & + & Sí & 25 \\
\hline 1994 & $\begin{array}{c}\text { 1026B, 1036O, 1037, 1037Q, } \\
\text { 1044U, 1049, 1049U }\end{array}$ & + & Sí & 25 \\
\hline 1995 & $1037,1049 \mathrm{U}$ & + & Sí & 8 \\
\hline 1998 & 1044D & + & ¿Sí? & 4 \\
\hline $1999-2000$ & 1046 & - & Sí & 5 \\
\hline 2001 & 1026A, 1046, 1048 & - & Sí & 14 \\
\hline $2002-2003,2005$ & $1026 \mathrm{~A}, 1048$ & - & Sí & 10 \\
\hline 2004 & 1026A, 1031, 1048 & - & Sí & 14 \\
\hline 2006 & 1026A, 1031, 1036O, 1048 & - & Sí & 24 \\
\hline 2007 & 1026A, 1031, 1048 & - & Sí & 18 \\
\hline
\end{tabular}

\section{1.- 1948 a 1949 en 1013 y 1950 a 1954 en $1032 \mathrm{~A}:$}

De los datos de las tablas 36, 37, 45 y 45 bis, 1947 y 1948 fueron años muy secos en MAM; de 1950 a 1954 se produjo una recuperación de las precipitaciones.

La tendencia negativa de 1013 se debe a la sequía de los años 40.

La tendencia positiva de 1032A es de tipo climatológico: es la recuperación a los valores normales de precipitación.

Se tratan de sendas tendencias climatológicas. 
En AMJ, al igual que en MAM (tabla 50), la recuperación tras el periodo de sequía de los años 40 es más débil y sólo se presenta en una estación del Oria medio.

\section{2.- 1957 a 1958 en 1016,1958 en 1031 y 1960 a 1961 en $1032 \mathrm{~A}:$}

De los datos de las tablas 37, 38, 45 y 45 bis, 1955 fue muy seco en AMJ y en 1961 se registró un máximo secundario de la precipitación.

De la tabla 51, se observa cómo la tendencia positiva de la precipitación comenzó en la Comarca de San Sebastián en 1957 y en 1958 en 1016, trasladándose al Oria Medio (1031, 1032A) en 1958 y en 1960 y 1961.

Por tanto es una tendencia "climatológica".

\section{3.- 1964 en $9268:$}

De la tablas 37, 38, 45 y 45 bis, 1964 fue un año con un máximo relativo de precipitación.

Sin embargo, 9268 es la única serie de las 53 analizadas en AMJ que indica tendencia negativa de la precipitación en 1964.

Por tanto, se la considera como tendencia "no climatológica".

4.- 1970 a 1972 y 1974 a 1977 en 1026,1971 a 1972 en 1044 A, 1972 en 1018 y 1976 en 1037:

De las tablas 38, 39, 45 y 45 bis, el periodo AMJ fue muy lluvioso en 1969, 1971 y 1972.

La tendencia positiva de 1970, 1971 y 1972 es climatológica: refleja este incremento de la precipitación.

En 1026 no hay datos de 1973. La tendencia positiva de 1026 anticipa las precipitaciones intensas de 1977 a 1979 y, como tal, se la considera como tendencia "climatológica".

En 1037 se detecta un mínimo en 1976, correspondiente al mínimo de precipitación de la tabla 45 bis.

1037 y 1026 distan $11,4 \mathrm{Km}$. de distancia y tienen una diferencia de altitud de 200 metros.

Si se elimina el dato de 1973 en 1037, con objeto de poder comparar su tendencia con la de 1026, desaparece la tendencia negativa de 1037. 
Por tanto, se considera a su vez como tendencia climatológica la tendencia detectada en 1026.

5.- 1975 a 1977 en 1017: El test de Mann-Kendall únicamente muestra tendencia negativa en 1975, 1976 y 1977 en 1017; no se produce en ninguna serie más en ese periodo completo de años.

De las tablas 45 y 45 bis, 1977 fue un año con precipitaciones muy elevadas; de la tabla 39, 1018A y 1032 registran efemérides de precipitación en AMJ en 1977.

Por tanto, visto el dispar comportamiento con las series cercanas, cabe pensar en una inhomogeneidad no "climatológica".

\section{6.- 1978 a 1981 en 1022,1978 a 1982 en 1026,1980 en 1016 y en 1023:}

6.1.- De las tablas 45, 45 bis y 52, se observa que 1978, 1979 y 1980 fueron años en que se registran precipitaciones muy elevadas y 1982 fue un año de mínimo pluviométrico extremo.

La tabla siguiente incluye los años con precipitaciones máximas y mínimas de los emplazamientos en que se detecta tendencia.

Tabla 52: Años con precipitaciones máximas y mínimas de 1978 a 1982 de 1016, 1022, 1023, 1026 y 1024E:

\begin{tabular}{|c|c|c|c|c|c|}
\hline Indicativo & Duración serie & Año Máximo & $\begin{array}{c}\text { Precipitación } \\
\left(1 / \mathrm{m}^{2}\right)\end{array}$ & Año Mínimo & $\begin{array}{c}\text { Precipitación } \\
\left(1 / \mathrm{m}^{2}\right)\end{array}$ \\
\hline \multirow{2}{*}{$\begin{array}{c}1016 \\
\text { Oyarzun }\end{array}$} & \multirow{2}{*}{$\begin{array}{c}1947-1984 \\
(\mathrm{sd} 2007)\end{array}$} & $1978\left(1^{\circ}\right)$ & 279,7 & $1982\left(1^{\circ}\right)$ & 79,8 \\
\hline & & $1979\left(2^{\circ}\right)$ & 265,2 & $1981\left(2^{\circ}\right)$ & 149,3 \\
\hline \multirow{3}{*}{$\begin{array}{c}1022 \\
\text { Hernani }\end{array}$} & \multirow{3}{*}{$\begin{array}{c}1954-1986 \\
(\mathrm{sd} 1956- \\
1961,1963)\end{array}$} & $1978\left(2^{\circ}\right)$ & 216,4 & $1982\left(1^{\circ}\right)$ & 45,9 \\
\hline & & $1979\left(3^{\circ}\right)$ & 193,2 & $1981\left(9^{\circ}\right)$ & 122,5 \\
\hline & & $1980\left(7^{\circ}\right)$ & 167,2 & & \\
\hline \multirow{3}{*}{$\begin{array}{c}1023 \\
\text { Astigarraga }\end{array}$} & \multirow{3}{*}{$1964-1984$} & $1979\left(1^{\circ}\right)$ & 203,1 & $1982\left(1^{\circ}\right)$ & 51,3 \\
\hline & & $1978\left(2^{\circ}\right)$ & 189,1 & $1981\left(5^{\circ}\right)$ & 120,0 \\
\hline & & $1980\left(4^{\circ}\right)$ & 148,2 & & \\
\hline \multirow[b]{2}{*}{$\begin{array}{c}1026 \\
\text { Beasain }\end{array}$} & \multirow{2}{*}{$\begin{array}{c}1946-1987 \\
(\text { sd } 1947, \\
1951,1973) \\
\end{array}$} & $1979\left(4^{\circ}\right)$ & 139,5 & $1982\left(1^{\circ}\right)$ & 33,4 \\
\hline & & $1978\left(6^{\circ}\right)$ & 134,1 & $1981\left(12^{\circ}\right)$ & 79,3 \\
\hline \multirow{2}{*}{$\begin{array}{l}\text { 1024E } \\
\text { Igueldo }\end{array}$} & \multirow[t]{2}{*}{$1928-2012$} & $1979\left(8^{\circ}\right)$ & 162,7 & $1982\left(1^{\circ}\right)$ & 50,3 \\
\hline & & $1978\left(9^{\circ}\right)$ & 157,5 & & \\
\hline
\end{tabular}

Se adjunta 1024E a modo de referencia; si bien en 1024E no se detecta tendencia en AMJ de 1978 a 1982, se la incluye dada su excelente calidad. 
6.2.- De la tabla 52, se observa que:

6.2.1.- Coinciden los máximos (1978, 1979 y 1980) y los mínimos (1982, 1981), siendo coherentes entre sí las precipitaciones recogidas en los diferentes enclaves: las precipitaciones se incrementan de Oeste a Este y de Norte a Sur.

6.2.2.-1978, 1979 y 1982 fueron años con registros extremos de la precipitación en el periodo AMJ, siendo efemérides 1978 (en 1016), 1979 (en 1023) y 1982 (en 1016, 1022, 1023, 1024E y en 1026).

6.3.- De la gráfica 20 , se observa de 1978 a 1980 el $2^{\circ}$ máximo de tendencias positivas de 1878 a 2012.

6.4.- En 1980 afecta al 17\% de las series, todas en la Comarca de San Sebastián, Alto Oria y Alto Urola, no afectando a las series del resto de comarcas.

Por lo tanto, se la considera como tendencia climatológica, reflejo de las precipitaciones tan intensas de 1977 a 1981 y de la sequía de 1982.

\section{7.- 1981 a 1985 y 1987 en 1025 E, 1983 a 1984 en $1037 \mathrm{O}, 1983$ en 1048 y 1987 en} 1044D:

7.1.- 1025E, $1037 \mathrm{O}$ y 1044D comienzan en 1977, justo antes del periodo muy lluvioso de finales de los 70; 1048 arranca en 1979, año muy lluvioso en AMJ.

7.2.-. Están situadas en el Alto Oria, Urola Medio y Alto Deba, zonas climáticas similares. 1025E, 1048 y 1044D distan del mar 29,5 Km., $32 \mathrm{Km}$. y $32 \mathrm{Km}$. respectivamente.

7.3.- De las tablas 41, 45, 45 bis y 52, hubo mínimos de la precipitación en 1982 y en 1987.

7.4.- $1025 \mathrm{E}$ y en menor medida, 1037O, 1048 y 1044D indican tendencia negativa en la precipitación AMJ a mediados de los 80 .

Por consiguiente, se trata de una tendencia "climatológica" a escala "comarcal".

\section{8.- 1990 a 1995:}

8.1.- De la tabla 35, al aplicar el test de Thom al periodo AMJ:

a) 1019A presenta inhomogeneidad en 1987 a 1996 y en 1989 a 1999.

b) 1037Q muestra inhomogeneidad en 1987 a 1996.

8.2.- De las tablas 41, 42, 43, 45 y 45 bis, desde 1991-1992 a 1994-1995 se detecta una tendencia positiva de la precipitación en AMJ en el Urola y Deba medios y altos, siendo más acusada en 1993 y 1994 en que afecta al 25\% de las series. 
En 1993 y en 1994 la tendencia también se produce en el Alto Oria.

8.3.- De la gráfica 20, se observa el máximo de tendencias positivas de 1878 a 2012.

8.4.- El test de Mann-Kendall sólo indica esta tendencia en estas comarcas de Guipúzcoa.

Se la califica como tendencia "climatológica" a escala "comarcal".

\section{9.- 1998 en 1044D:}

9.1.- 1044D muestra inhomogeneidad según el test de Thom en AMJ de 1998 a 2012 (tabla 35).

9.2.- El test de Mann Kendall sólo detecta tendencia positiva en 1998 en 1044D de las 53 series AMJ estudiadas. 1041.

9.3.- De la tabla 43, 1998 fue un máximo relativo de precipitación en $1025 \mathrm{~N}$ y en

Cabe calificarla como "inhomogeneidad climatológica", con dudas.

10.- 1999 a 2000 en 1046, 2001 a 2007 en 1026 A y en 1048, 2004 y 2007 a 2007 en 1031 y 2006 en 10360 :

10.1.- De las tablas 41 a 45 y 45 bis, en 2001 y en los años 2003-2004 hubo un mínimo pluviométrico, más acusado en 2003-2004.

10.2.- La gráfica 20 muestra que entre 1999 y 2007 se detectó el máximo de tendencia negativa desde 1878 a 2012, llegando a aflorar en el $24 \%$ de las series analizadas en 2004 (tabla 51).

10.3.- 1046 fue la precursora de la tendencia negativa de precipitación, tendencia que a partir de 2001 se extiende hasta el 2007 al Alto y Medio Oria, al Alto Deba y al Alto Urola. Esta tendencia no se detecta en ninguna otra serie de la provincia fuera de las comarcas citadas.

10.4.- Se percibe una similitud extrema entre 1026A y 1048 marcando tendencias negativas simultáneamente entre 2001 y 2007. MAM.

A su vez, la tabla 50 revela un comportamiento idéntico entre 1026A y 1048 en

Por tanto, son tendencias "climatológicas" a escala comarcal. 
Como conclusiones del análisis temporal de las tendencias del test de Mann- Kendall de la precipitación AMJ,

1.- De las series analizadas, sólo se observan dos tendencias "no climatológicas": 1964 en 9268 y 1975 a 1977 en 1017.

2.- Se detectan:

2.1.- Un máximo de tendencia positiva muy acusado de la precipitación AMJ entre 1991 y 1995 y dos máximos secundarios de tendencia positiva de la precipitación AMJ entre $\underline{1978 \text { y } 1980 \text { y entre } 1971 \text { y } 1972 .}$

2.2.- Dos máximos de tendencia negativa entre 1983 y 1984 y entre 2001 y 2007 , éste último el más intenso.

3.- Los máximos se producen tras el periodo de sequía de 1973 y de 1987 (tablas 45 y 45 bis), lo cuál sugiere que la transición de un período de sequía a uno de precipitaciones es mucho más abrupta, más breve en el tiempo, que la transición de un periodo de precipitaciones elevadas a uno seco.

4.- Asimismo, de la gráfica 20 y de la tabla 51, se percibe que el número de tendencias positivas detectadas es superior al de de tendencias negativas, pudiendo deberse a:

4.1.- En AMJ, la transición de sequía a periodos de precipitaciones elevadas es muy breve o bien a

4.2.- El número de serie analizadas asciende de 2 a 15 en 1946. De 1947 a 1948 hubo una serie de sequías muy severas (tabla 34 bis), lo cuál le da un sesgo positivo al análisis de las tendencias del test de Mann-Kendall debido a las 13 series que comienzan en 1946 (el $25 \%$ del total de las estudiadas).

5.- Los resultados son congruentes entre las inhomogeneidades detectadas por el test de las rachas (tablas 4 y35) y las tendencias indicadas por el test de Mann-Kendall (tablas 46 y 51).

6.- De la tabla 51, se observa un comportamiento muy semejante en las tendencias detectadas en enclaves cercanos:

6.1.- Las tendencias positivas de 1931 y de 1933 sólo se detectan en 1024E; el resto de emplazamientos marcan un máximo pluviométrico, pero sin llegar a mostrar una tendencia positiva.

6.2.- La tendencia positiva de la década de los 50 se focaliza en los emplazamientos más cercanos a Navarra.

6.3.- La tendencia positiva de 1970 a 1972 se centra en el Alto Oria, Alto Deba y en la Comarca de San Sebastián, siendo su máximo el 14\% de series. 
6.4.- La tendencia positiva de 1978 a 1981 se detecta exclusivamente en las comarcas de San Sebastián y del Alto Oria, llegando a detectarse en el 17\% de las localidades.

6.5.- La tendencia negativa de 1983 a 1987 únicamente aflora en algunas localidades de las comarcas del Alto Oria, Alto Deba y Medio Urola, alcanzando un máximo del 13\% de los registros de precipitación.

6.6.- La tendencia positiva de 1992 a 1995 sólo se muestra en las comarcas del Alto y Medio Urola, Alto Oria, Alto Deba, con un pico del 25\% de series.

6.7.- La tendencia negativa de 1999 a 2007 refleja un comportamiento idéntico de 2000 a 2006 en la cabecera de los 3 ríos de Guipúzcoa (Alto Oria, Alto Deba y Alto Urola)

7.- Al incrementarse el número de series, de 1926 a 1936 se puede hablar de tendencias a nivel de la provincia.

A partir de 1946 se insinúan "tendencias" a nivel comarcal, mostrándose con rotundidad de 1995 a 2006.

8.- Se resalta la importancia de un análisis conjunto de los observatorios y colaboradores cercanos, para no desechar tendencias positivas de la precipitación AMJ como "no climatológicas", al producirse en tantos emplazamientos simultáneamente.

9.- El análisis de Mann-Kendall (tablas 46 y 51) indica los siguientes mínimos y máximos en la precipitación media en AMJ:

9.1.- Ciclo de 10 años de máximos de precipitación: 1931, 1933, 1951, 1958, 1961, 1971-72, 1978-79-80, 1991-93.

9.2.- Ciclo de 10 años de mínimos de precipitación: 1897 a 1899, 1948, 1976, 1983, 1987, 2001, 2003-04

Estos máximos y mínimos coinciden con los datos de las tablas 45 y 45 bis corroborándolos, en la cuál afloran los ciclos a 10 años en la precipitación AMJ. 


\subsection{3.- Caída homogeneidad últimos años de medida colaboradores antiguos.}

Del análisis realizado se observa que la calidad de las series de medida de los colaboradores actuales y antiguos es muy buena.

Sin embargo, se percibe una caída de la homogeneidad en los últimos años de medida de 2 series antiguas, inhomogeneidades ya analizadas en el punto 4.2.-Análisis evolución temporal inhomogeneidades. De estas inhomogeneidades se descarta su posible origen "climatológico".

Las 2 tablas siguientes reflejan estas inhomogeneidades:

Tabla 53: Inhomogeneidades en la precipitación anual, MAM y AMJ detectadas aplicando el test de Thom en los últimos años de series de colaboradores:

\begin{tabular}{|c|c|c|c|}
\hline Indicativo & Periodo años & Caída homogeneidad & Detectado en test \\
\hline $\begin{array}{c}\text { 1026B } \\
\text { Lareo }\end{array}$ & $1989-2012$ & $2001-2012$ & MAM \\
\hline
\end{tabular}

Tabla 54: Inhomogeneidades en la precipitación anual, MAM y AMJ detectadas aplicando el test de Mann-Kendall en los últimos años de series de colaboradores:

\begin{tabular}{|c|c|c|c|}
\hline Indicativo & Periodo años & Caída homogeneidad & Detectado en test \\
\hline $\begin{array}{c}1017 \\
\text { Oyarzun }\end{array}$ & $1954-1980$ & $1977-1979$ & Anual \\
\hline
\end{tabular}

1.- 1026B se cerró en marzo de 2013, al dejar de ascender diariamente el colaborador a Lareo.

2.- 1017 presenta inhomogeneidades “no climatológicas" de 1977 a 1979. En 1980 comienzan las lagunas en la precipitación, en 1981 continúan las lagunas y en 1982 faltan 6 meses. El último mes completo es diciembre de 1982.

El test de Mann-Kendall AMJ detecta de 1977 a 1979 una tendencia "no climatológica" en 1017 (tabla 51).

Se trata de un método para identificar cuando un colaborador va a dejar de serlo o la instalación va a ser cerrada, previendo la necesidad de un relevo o la búsqueda de un nuevo emplazamiento. 


\section{3.- Comparativa homogeneidad entre precipitación anual y primaveral:}

\subsection{1.- Comparativa homogeneidad entre la precipitación en MAM y en AMJ:}

La tabla 55 expone el periodo más homogéneo aplicando los test de Thom y de Mann-Kendall.

En las series con rupturas, se ha promediado el comportamiento de cada uno de los intervalos con datos iguales o superiores a 10 años.

Asimismo, se ha incluido el número de lagunas: La valoración de la homogeneidad es la media entre el \% de datos y el \% de datos que son homogéneos.

Tabla 55: Comparativa homogeneidad series de precipitación en los periodos MAM y AMJ aplicando los test de Thom y Mann-Kendall

\begin{tabular}{|c|c|c|c|c|c|c|}
\hline \multirow[t]{2}{*}{ Indicativo } & \multicolumn{3}{|c|}{ Periodo más homogéneo (Thom) } & \multicolumn{3}{|c|}{$\begin{array}{c}\text { Periodo más homogéneo (Mann- } \\
\text { Kendall) }\end{array}$} \\
\hline & MAM & AMJ & Igual & MAM & AMJ & Igual \\
\hline 1013 & & $X$ & & $\mathrm{X}$ & & \\
\hline 1013I & $\bar{X}$ & & & & $\bar{X}$ & \\
\hline 1014 & & $\mathrm{X}$ & & & $\mathrm{X}$ & \\
\hline 1015 & & & $\mathrm{X}$ & & & $\mathrm{X}$ \\
\hline 1016 & & $\mathrm{X}$ & & & $\mathrm{X}$ & \\
\hline 1017 & $X$ & & & $X$ & & \\
\hline 1018 & & $\mathrm{X}$ & & & $\mathrm{X}$ & \\
\hline $1018 \mathrm{~A}$ & $\mathrm{X}$ & & & & $\mathrm{X}$ & \\
\hline 1019A & $\mathrm{X}$ & & & & $\mathrm{X}$ & \\
\hline $1021 \mathrm{E}$ & & $\mathrm{X}$ & & & & $\mathrm{X}$ \\
\hline 10210 & $\mathrm{X}$ & & & & $\mathrm{X}$ & \\
\hline 1022 & & & $\mathrm{X}$ & & $\mathrm{X}$ & \\
\hline $1022 \mathrm{~A}$ & $\bar{X}$ & & & $\mathrm{X}$ & & \\
\hline 1023 & & $\mathrm{X}$ & & & $\mathrm{X}$ & \\
\hline 1024 & $\mathrm{X}$ & & & & $\mathrm{X}$ & \\
\hline 1024B & & & $\mathrm{X}$ & & & $\mathrm{X}$ \\
\hline 1024D & $\mathrm{X}$ & & & $\mathrm{X}$ & & \\
\hline $1024 \mathrm{E}$ & $\mathrm{X}$ & & & & $X$ & \\
\hline $1024 \mathrm{~F}$ & & $X$ & & & $X$ & \\
\hline 1025 & & & $\mathrm{X}$ & & & $\mathrm{X}$ \\
\hline $1025 \mathrm{E}$ & & $X$ & & $X$ & & \\
\hline $1025 \mathrm{~N}$ & $\mathrm{X}$ & & & & $\mathrm{X}$ & \\
\hline 1026 & $X$ & & & $\mathrm{X}$ & & \\
\hline $1026 \mathrm{~A}$ & $X$ & & & $X$ & & \\
\hline 1026B & & $X$ & & & & $\mathrm{X}$ \\
\hline 9268 & $X$ & & & & & $X$ \\
\hline 1031 & & $X$ & & $X$ & & \\
\hline
\end{tabular}


Tabla 55 (continuación): Comparativa homogeneidad series precipitación en los periodos MAM y AMJ aplicando los tests de Thom y Mann-Kendall

\begin{tabular}{|c|c|c|c|c|c|c|}
\hline \multirow[t]{2}{*}{ Indicativo } & \multicolumn{3}{|c|}{ Periodo más homogéneo (Thom) } & \multicolumn{3}{|c|}{$\begin{array}{l}\text { Periodo más homogéneo (Mann- } \\
\text { Kendall) }\end{array}$} \\
\hline & MAM & AMJ & Igual & MAM & AMJ & Igual \\
\hline 1032 & $\mathrm{X}$ & & & $\mathrm{X}$ & & \\
\hline $1032 \mathrm{~A}$ & & $\mathrm{X}$ & & & $\mathrm{X}$ & \\
\hline $1033 \mathrm{U}$ & $\bar{X}$ & & & & $\bar{X}$ & \\
\hline 1034 & & & $\mathrm{X}$ & & & $\mathrm{X}$ \\
\hline 1035 & & $X$ & & & $\mathrm{X}$ & \\
\hline $1035 \mathrm{U}$ & & $\mathrm{X}$ & & & $\mathrm{X}$ & \\
\hline 1036 & $\mathrm{X}$ & & & & $\mathrm{X}$ & \\
\hline 10360 & & & $\mathrm{X}$ & & $\mathrm{X}$ & \\
\hline 1037 & $\mathrm{X}$ & & & $\mathrm{X}$ & & \\
\hline 10370 & & $\mathrm{X}$ & & $\mathrm{X}$ & & \\
\hline 1037Q & $\mathrm{X}$ & & & $\mathrm{X}$ & & \\
\hline 1038 & & & $\mathrm{X}$ & & $\mathrm{X}$ & \\
\hline 1041 & $\mathrm{X}$ & & & & $\mathrm{X}$ & \\
\hline 1044 & $\mathrm{X}$ & & & & $\mathrm{X}$ & \\
\hline 1044A & & & $\mathrm{X}$ & & $\mathrm{X}$ & \\
\hline 1044D & & $\mathrm{X}$ & & $X$ & & \\
\hline 1044U & & & $\mathrm{X}$ & $\mathrm{X}$ & & \\
\hline 1045 & & $\mathrm{X}$ & & $\mathrm{X}$ & & \\
\hline 1046 & & $X$ & & $X$ & & \\
\hline 1048 & $\mathrm{X}$ & & & $X$ & & \\
\hline 1049 & & & $X$ & $X$ & & \\
\hline 10490 & & & $X$ & & $X$ & \\
\hline $1049 \mathrm{U}$ & $X$ & & & $X$ & & \\
\hline 1050 & & $X$ & & & $X$ & \\
\hline $1050 \mathrm{~L}$ & & & $X$ & & & $X$ \\
\hline 1052 & & $\bar{X}$ & & & & $\mathrm{X}$ \\
\hline
\end{tabular}

1.- Al aplicar el test de Thom, se observa un comportamiento similar en las series próximas respecto a la comparativa de la homogeneidad en los periodos MAM y AMJ.

Así, por poblaciones el comportamiento más homogéneo se produce en los meses:

1.1.- MAM: Fuenterrabía Zubieta, Oyarzun, Rentería Landarbarso, Pasajes, Hernani Santiago, Hernani Zicuñaga, Ategorrieta, San Sebastián Instituto, Igueldo, Arriarán, Beasain, Ordizia, Otzaurte, Villabona Fraisoro, Urnieta, Zarauz, Legazpia, Azcoitia Carmelitas, Zumaya, Escoriaza, Aretxabaleta, Ermua.

La figura 2 muestra los enclaves donde el Test de Thom indica un comportamiento más homogéneo en MAM. 


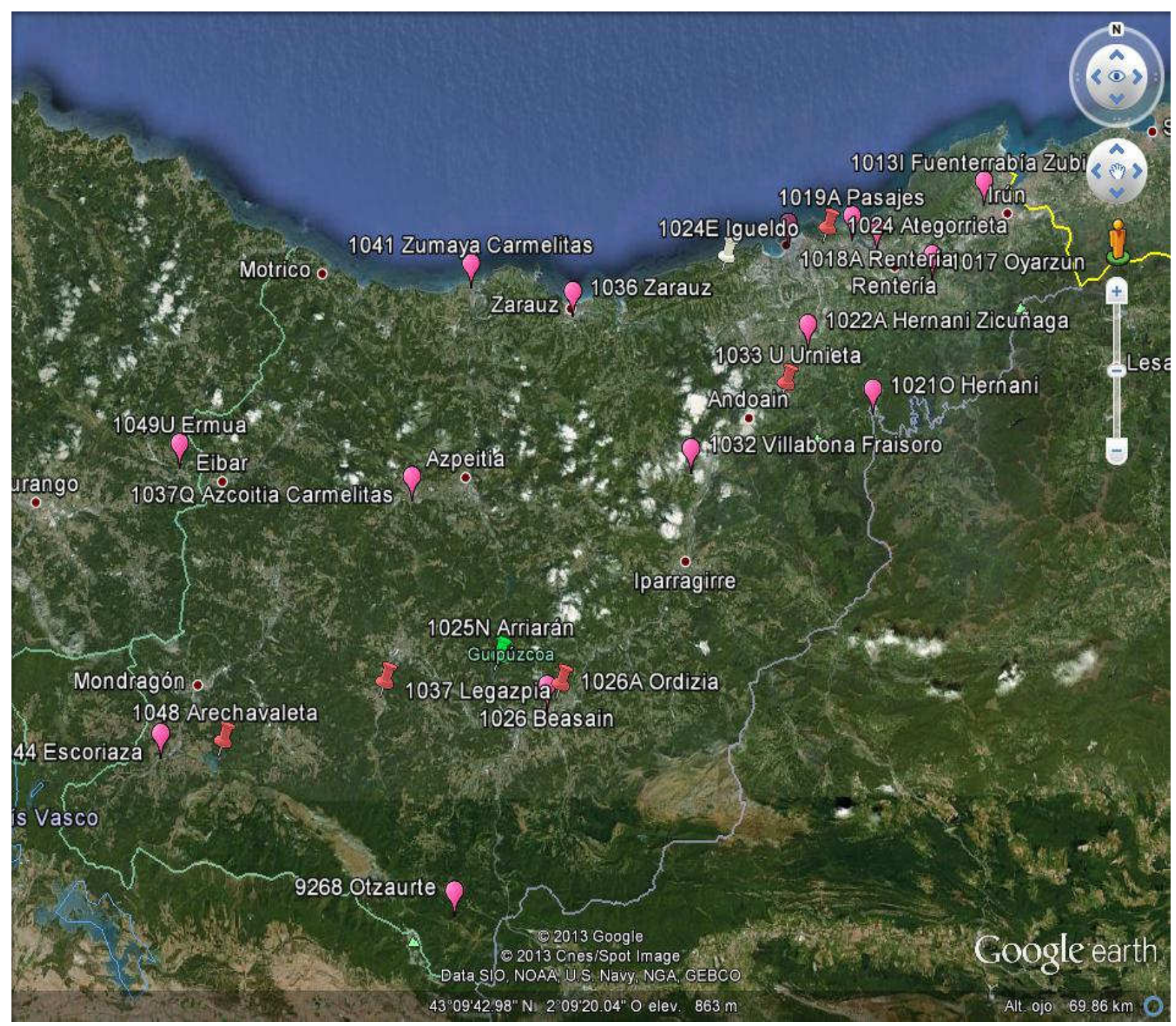

Todas estas poblaciones se encuentran en el litoral desde Fuenterrabía a Zumaya, en el Alto y Medio Oria, en el Urola y en el Alto Deba.

1.2.- AMJ: Irún, OMA Fuenterrabía, Oyarzun Arditurri, Rentería Villa, Añarbe, Astigarraga, San Sebastián Observatorio, Mutiloa, Lareo, Elduayen, Villabona, Lasarte, Aya, Aramayona, Mondragón, Aránzazu, Eibar, Motrico.

Todos estos enclaves están principalmente en la zona limítrofe con Francia, con Navarra y con Vizcaya.

La figura 3 muestra los enclaves donde el Test de Thom indica un comportamiento más homogéneo en AMJ. 


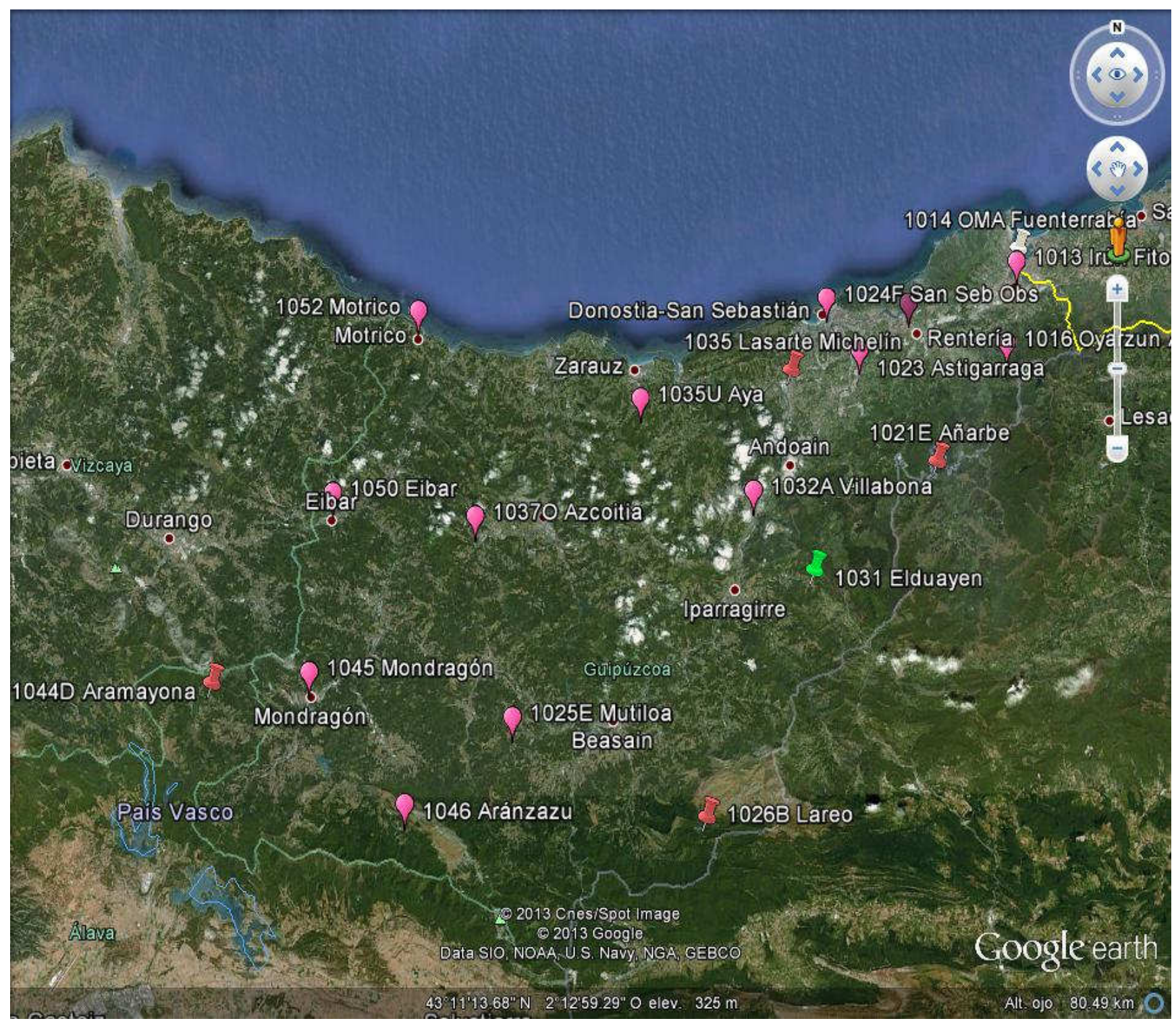

1.3.- Igual: Guadalupe, Hernani Ereñozu, San Sebastián Faro, Cerain, Andoain, Legazpia Barrendiola, Azcoitia, Beizama, Escoriaza Tesa, Mondragón Olandixo, Vergara, Elgueta, Elgoibar.

De la tabla 55 y de las figuras 2 y 3 , el carácter por los indicativos correlativos no es aleatorio, sino parece estar dispuesto en rachas, sugiriendo que la distribución del comportamiento mejor (MAM o AMJ) fuera por comarcas o por observatorios cercanos.

2.- Al aplicar el test de Mann-Kendall, se aprecia que la precipitación en el mes de marzo es más homogénea en el interior de Guipúzcoa y la precipitación de junio más homogénea en el litoral.

Las figuras 4 y 5 revelan los enclaves donde el Test de Mann-Kendall detecta un comportamiento más homogéneo en MAM y en AMJ, respectivamente. 


\section{Figura 4: Series más homogéneas en Mann-Kendall MAM}

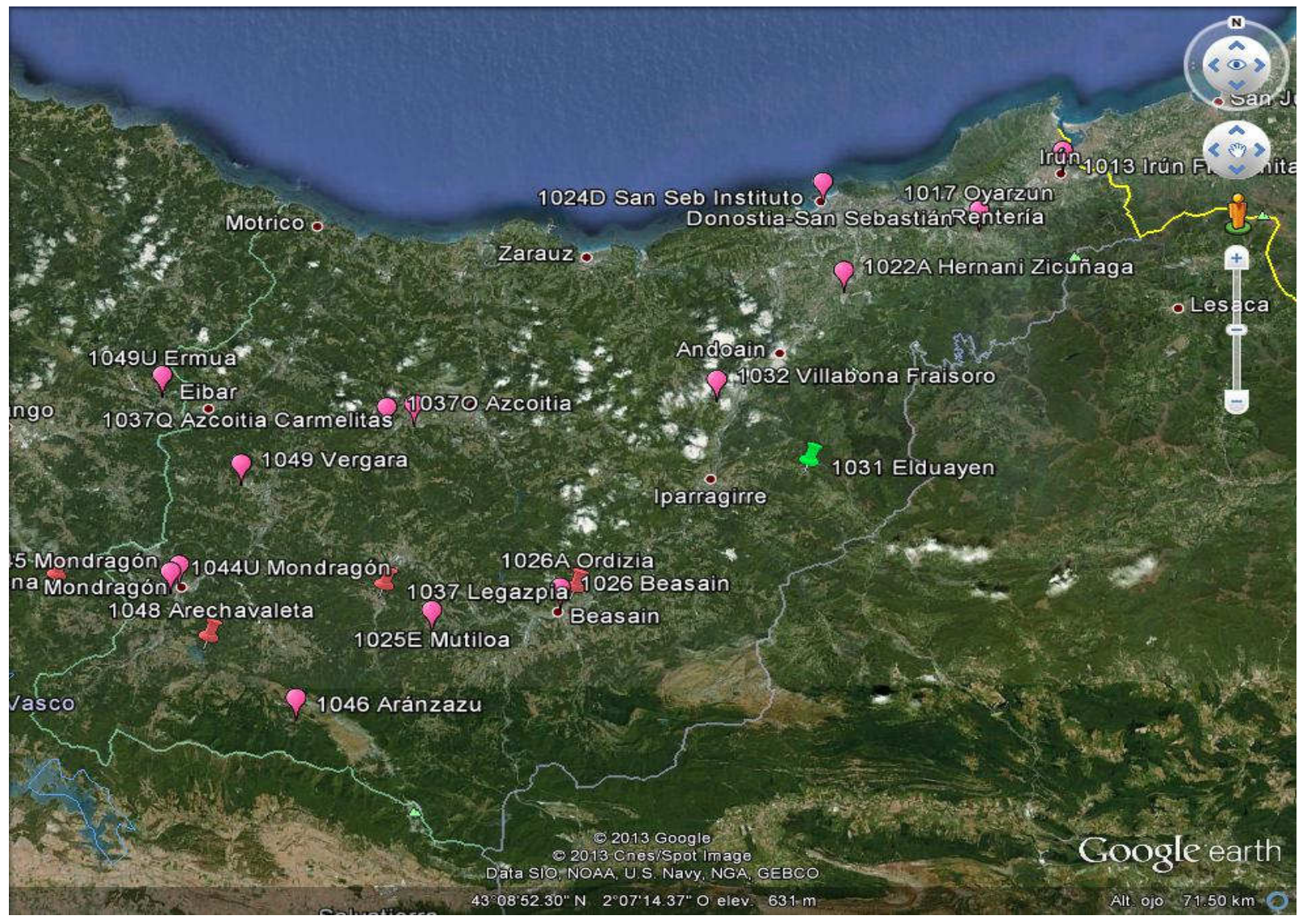

\section{Figura 5: Series más homogéneas en Mann-Kendall AMJ}

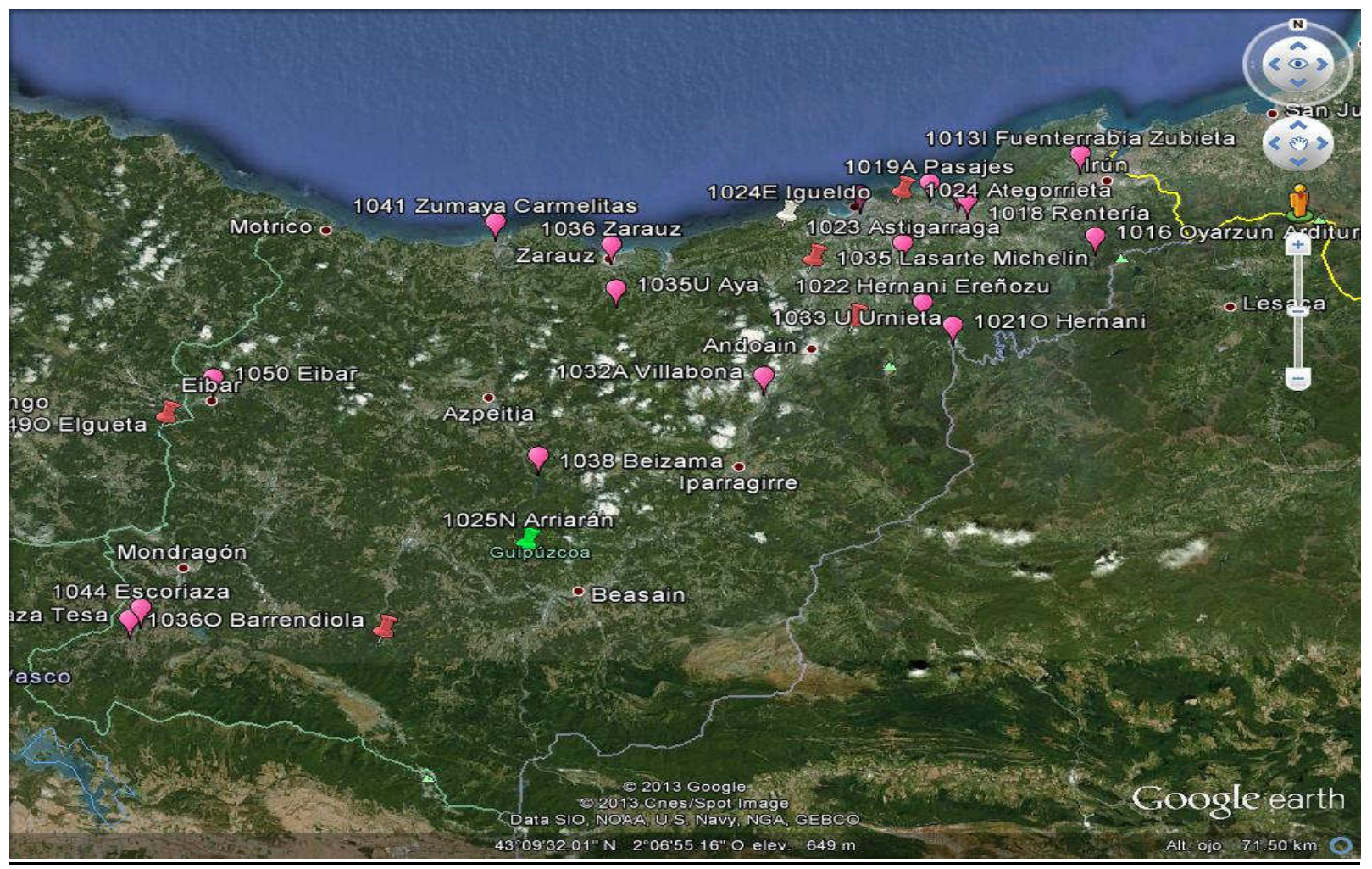


De la tabla 55 y de las figuras 4 y 5, se aprecia que, en promedio, el comportamiento es más homogéneo en el periodo MAM en el Alto y Medio Deba, en el Medio Urola, en el Alto Oria y en el periodo AMJ en la comarca de San Sebastián y en el litoral:

No se distingue un comportamiento claramente definido en el resto de la provincia.

La figura 6 refleja los emplazamientos donde, de acuerdo a los tests de Thom y de Mann-Kendall es más homogéneo el comportamiento de la precipitación en MAM (mes de marzo más homogéneo que el de junio).

\section{Figura 6: Series más homogéneas en MAM}

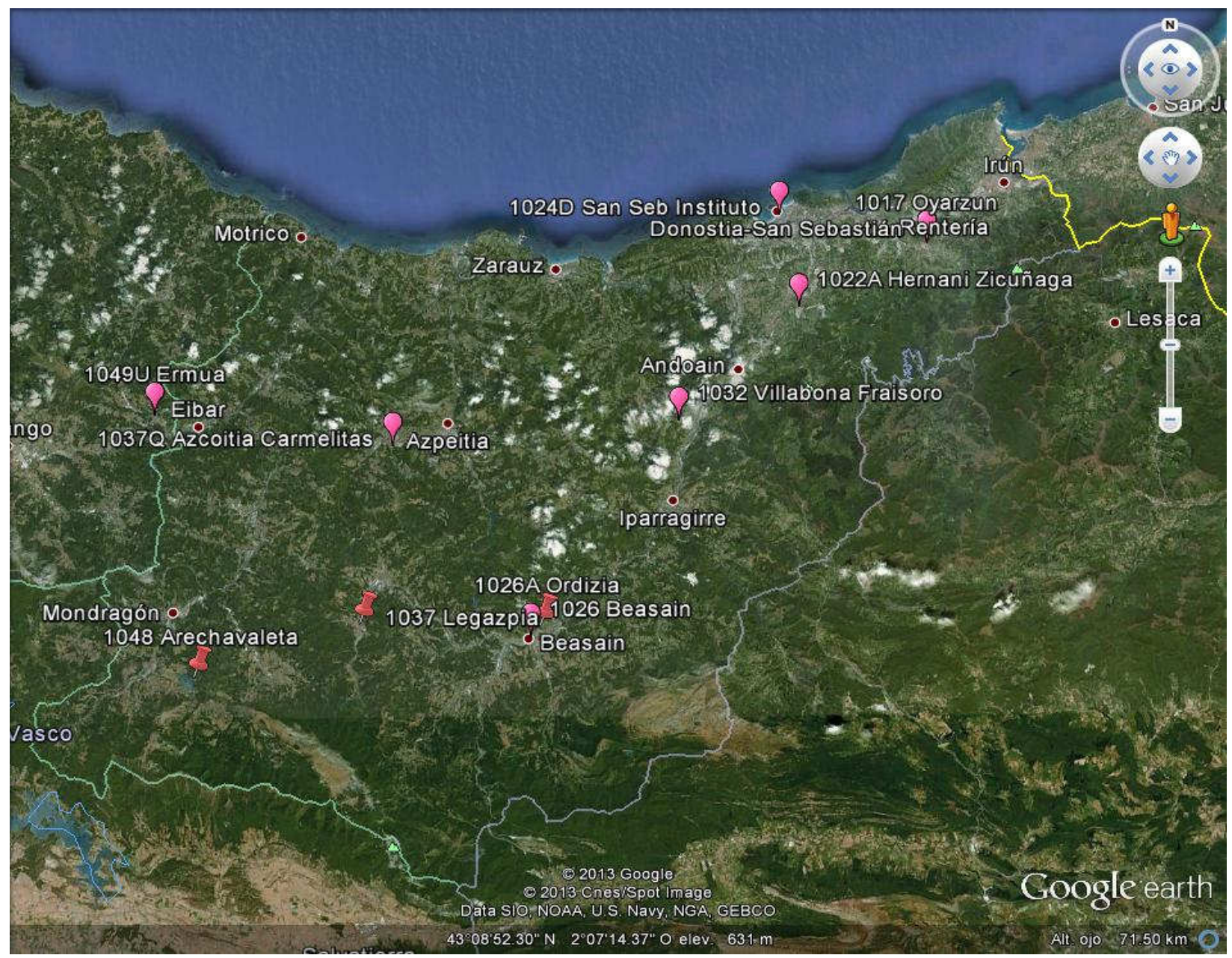

En 10 enclaves de los 53 analizados, los test de Thom y de Mann-Kendall coinciden en señalar como más homogéneo el periodo MAM.

De la tabla 55 y la figura 6, se observa que el periodo MAM es más homogéneo en el Alto Oria, Alto y Medio Urola y Alto Deba.

La figura 7 representa los emplazamientos donde, de acuerdo a los tests de Thom y de Mann-Kendall es más homogéneo el comportamiento de la precipitación en AMJ (precipitación en Junio más homogénea que en marzo). 


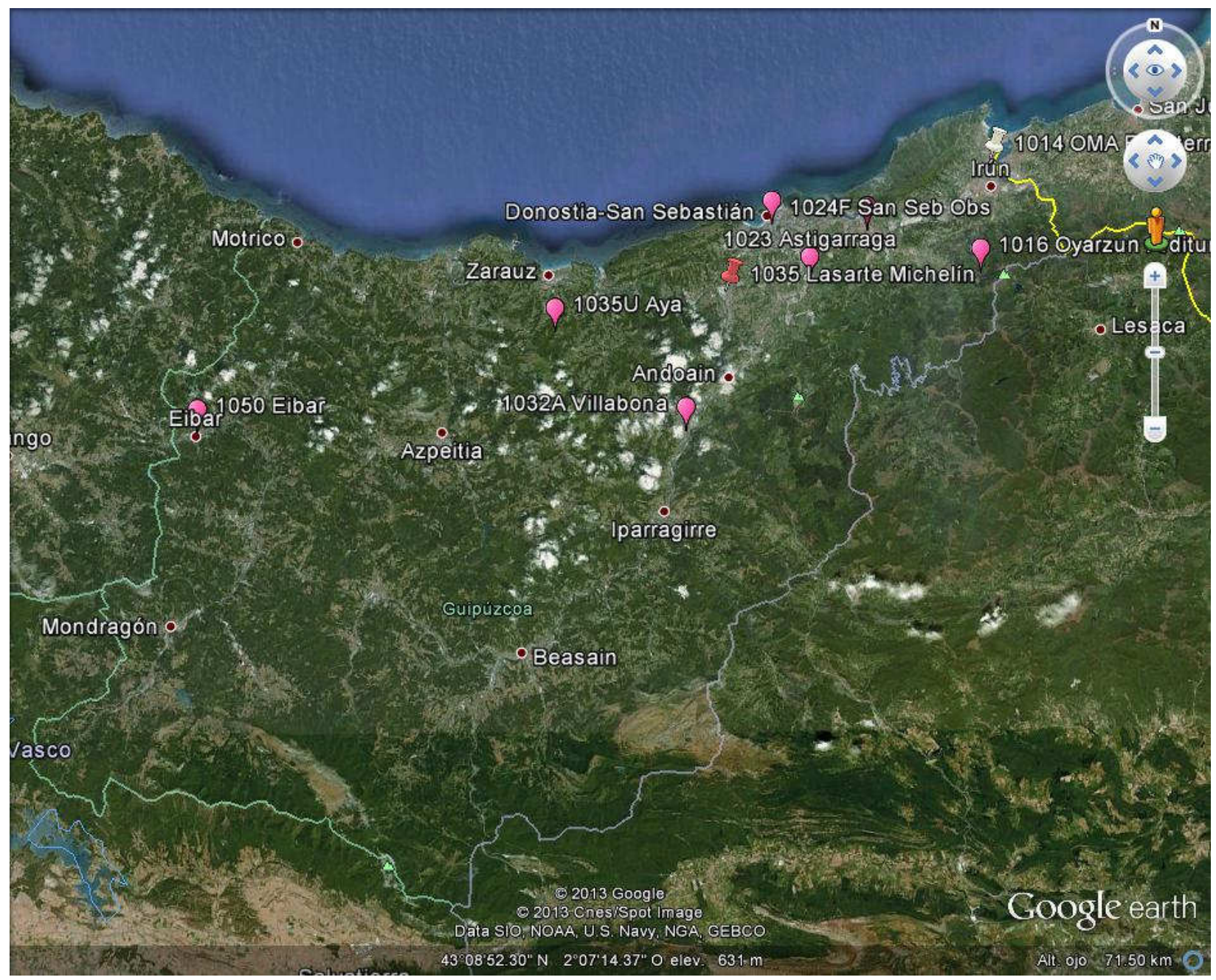

De la tabla 55 y la figura 7, se observa que el periodo AMJ es más homogéneo en el litoral y en la comarca de San Sebastián.

Al aplicar conjuntamente los tests de Thom y de Mann-Kendall, se observa (tabla 55 y figuras 6 y 7) que:

a) La precipitación en el mes de marzo es más homogénea en el interior de Guipúzcoa: en el Alto Oria, Alto Deba y Alto y Medio Urola.

b) La precipitación en el mes de junio es más homogénea en el litoral de Guipúzcoa: en las comarcas de litoral central y en la Comarca de San Sebastián.

La tabla 56 muestra las inhomogeneidades totales descubiertas por cada test en cada uno de los periodos analizados. 
Tabla 56: Número inhomogeneidades detectadas por los test de Thom y de Mann-Kendall en los periodos anual, MAM y AMJ:

\begin{tabular}{|c|c|c|c|c|c|c|}
\hline & \multicolumn{3}{|c|}{ Test Thom } & \multicolumn{3}{c|}{ Test Mann- Kendall } \\
\hline Número & Anual & MAM & AMJ & Anual & MAM & AMJ \\
\cline { 2 - 7 } Inhomogeneidades & 126 & 113 & 72 & 50 & 138 & 89 \\
\hline
\end{tabular}

De la tabla 56, se observa que el periodo AMJ es más homogéneo que el MAM. Esto es, según los tests de Thom y de Mann-Kendall, el comportamiento de la precipitación en Guipúzcoa en Junio es más homogéneo que en Marzo.

La tabla 57 muestra el número de tendencias positivas y negativas encontradas por el test de Mann-Kendall en la precipitación media anual, en MAM y en AMJ así como el porcentaje de tendencias positivas y negativas respecto a las tendencias totales del periodo.

Tabla 57: $\mathrm{N}^{\mathrm{o}}$ tendencias positivas y negativas detectadas por el test de Mann-Kendall en los periodos anual, MAM y AMJ:

\begin{tabular}{|c|c|c|c|c|c|c|}
\hline & \multicolumn{2}{|c|}{ Tendencias MK Anual } & \multicolumn{2}{c|}{ Tendencias MK MAM } & \multicolumn{2}{c|}{ Tendencias MK AMJ } \\
\hline \multirow{2}{*}{$\begin{array}{c}\mathrm{N}^{\mathbf{0}} \\
\text { tendencias }\end{array}$} & + & - & + & - & + & - \\
\cline { 2 - 7 } & 40 & 10 & 86 & 52 & 53 & 36 \\
\hline$\%$ & 80 & 20 & 62 & 38 & 60 & 40 \\
\hline
\end{tabular}

\subsubsection{1.- Características detectadas conjuntamente en los periodos MAM y AMJ:}

De lo expuesto en el apartado 4.2., especialmente en las gráficas 8, 9, 11, 12, 14, 15, 18 y 20 y en las tablas $4,23,34,34$ bis, $35,45,45$ bis, $46,50,51,56$ y 57 , se observa: pequeño.

A.- El número de inhomogeneidades y tendencias "no climatológicas" es muy

B.- El test de rachas aplicado a MAM y a AMJ señala máximos de las inhomogeneidades en 1954 a 1968 y de 1955 a 1977, respectivamente.

C- Los 2 tests aplicados en MAM y en AMJ detectan comportamientos similares a escala comarcal. Este hecho se ve claramente en las series del Alto Oria y del Alto Urola.

C.1.- De 1993 a 1995, la precipitación en AMJ tiene tendencia positiva en el Urola Medio y Alto y en Vergara; no aparece en la costa (San Sebastián, Irún), ni en el Medio Oria; sólo en el Alto Oria se detecta (en 1993 en 1026A y en 1994 en 1026B).

C.2.- 1026A (Ordizia), 10360 (Legazpia Barrendiola) y 1037 (Legazpia) tienen las mismas tendencias (negativas en 2000-06 MAM, 06 AMJ) y positivas en 1992 a 1994 en AMJ. Por tanto, se trata de 2 inhomogeneidades climatológicas a escala "comarcal". 
Así, en el Alto Oria y en el Alto Urola la precipitación en primavera aumenta de 1991 a 1995 (especialmente en Junio) y disminuye de 2000 a 2006.

D.- 1018 fue de las primeras series en manifestar la inhomogeneidad "climatológica" revelada por los test de rachas en MAM y en AMJ de 1954 a 1968. 1016 lo fue en la inhomogeneidad "climatológica" de 1965 a mediados de los 1970.

E.- De las tablas 34, 34 bis, 45 y 45 bis, aflora un doble ciclo de 10 años en la precipitación en MAM y en AMJ detectado por test Thom y corroborado por el test de Mann-Kendall; los máximos y mínimos del ciclo de 10 años concuerdan casi plenamente, salvo excepciones como en 1997.

F.- Los 2 tests detectan en MAM y en AMJ que las inhomogeneidades y tendencias de la década de los 90 se originan en la comarca de San Sebastián, pareciendo trasladarse al interior de la provincia al avanzar la década. De 1999 hasta 2004-2006 se concentran únicamente en las series de las cabeceras de los ríos.

G.- El test de Mann-Kendall en MAM y en AMJ presenta un número de tendencias positivas detectadas superior al de tendencias negativas, siendo en ambos similar el \% de tendencias positivas sobre las tendencias totales detectadas.

Esto es debido al espectacular incremento en 1946 y 1947 de las series analizadas de 3 a 15, reflejado en las gráficas 18 y 20. 1946 y 1947 fueron años con escasas precipitaciones en MAM y en AMJ.

H.- El test Mann-Kendall en MAM y en AMJ revela un aumento de la precipitación en primavera ente 1977 y 1981 y una disminución de la precipitación en primavera de 2001 a 2009.

\subsubsection{2.- Características diferentes de los periodos MAM y AMJ:}

De lo expuesto en el apartado 4.2., especialmente en las gráficas 8, 9, 11, 12, 14, 15, 18 y 20 y en las tablas 4, 23, 34, 34 bis, 35, 45, 45 bis, 46, 50, 51, 56 y 57 se aprecia la diferencia entre los periodos MAM y AMJ, según se incluyan los meses de marzo o de junio:

A.- El test de rachas en MAM detecta más inhomogeneidades que en AMJ de 1955 a 1966 y de finales de los 70 a finales de los 80; en AMJ muestra más de 1999 a 2011.

B.- El bajo número de series disponibles anteriores a 1940 (inferior a 5) origina que no coincidan los intervalos de inhomogeneidades en MAM y en AMJ anteriores a 1940.

C.- La tendencia positiva detectada por Mann-Kendall en la década de los 70, comienza en MAM en 1974 y en AMJ en 1978.

D.- La tendencia positiva detectada por Mann-Kendall a finales de la década de los 90, comienza en MAM 1996 y en AMJ en 1999. 
E.- De los puntos C y D y las gráficas $11,12,18$ y 20 parecen manifestarse antes los ciclos de precipitación en el mes de marzo que en el de junio.

F.- Mann-Kendall señala a finales de los 70 una tendencia positiva muy superior en MAM que en AMJ, fruto de unos meses de marzo muy lluviosos y más inhomogéneos que los meses de junio de fines de los 70 .

G.- Mann-Kendall en AMJ indica una tendencia negativa en la precipitación de 1982 a 1987. De 1982 a 1987 Mann-Kendall en MAM muestra tendencia positiva.

Cabe pensar que la tendencia negativa sea reflejo a mediados de los 80 , de una disminución de la precipitación en los meses de junio o de un incremento de la precipitación en los meses de marzo.

H.- Mann-Kendall en AMJ indica una tendencia positiva muy abrupta en la precipitación de 1992 a 1994, debida a una sucesión de meses de junio muy lluviosos.

I.- En junio de 1997 se produjeron inundaciones en Guipúzcoa. Mann-Kendall en MAM indica una tendencia negativa en 1997, mientras que en AMJ no muestra tendencia.

De este modo, incluir Junio y excluir Marzo en el estudio permite detectar las inundaciones de junio de 1997.

J.- En AMJ se insinúa un ciclo de precipitaciones máximas de 20 años, no vislumbrado en MAM.

K.- Comparando las tendencias de la precipitación MAM y AMJ a lo largo del tiempo (gráficas 18 y 20), se observa:

K.1.- El mes de junio parece ser más sensible al ciclo detectado en precipitación anual de 10 y de 30 años que el mes de marzo.

K.2.- El mes de marzo, detecta menos tendencias, pero son más acusadas.

L.- De las tablas 34, 34 bis, 45 y 45 bis, se observa que Junio muestra precipitaciones más intensas; de la tabla 56, que la variabilidad, la inhomogeneidad de marzo es superior a la de junio.

\subsection{2.- Comparativa entre la precipitación anual y la precipitación en primavera (MAM y AMJ):}

De lo expuesto en el apartado 4.2., especialmente en las gráficas 7, 8, 9, 10, 11, 12 , $13,14,15,16,18$ y 20 y en las tablas $4,10,23,34,34$ bis, 35, 45, 45 bis, 46, 49, 50, 51, 56 y 57, se observan : 
4.3.2.1.- Características detectadas conjuntamente en los periodos anual, MAM y AMJ:

A.- El número de inhomogeneidades y tendencias "no climatológicas" es muy pequeño.

B.- El test de rachas detecta en los 3 periodos inhomogeneidades de 1951 a 1962.

C- Los tests de Thom y de Mann-Kendall indican comportamientos similares a escala comarcal en los periodos anual, MAM y AMJ.

D.- 1016 Oyarzun Arditurri fue de las primeras series en manifestar la inhomogeneidad "climatológica" revelada por los test de las rachas en el periodo de 1965 a mediados de los 1970.

1016 es el lugar con el record de precipitación en 24 horas de toda Guipúzcoa, Álava y Vizcaya.

E.- De las tablas 22,22 bis, 34,34 bis, 45 y 45 bis se intuye un ciclo de 10 años en la precipitación, coincidiendo máximos y mínimos de precipitación .

F.- Los test de rachas y de Mann-Kendall detectan en la precipitación anual, MAM y AMJ que las inhomogeneidades y tendencias de la década de los 90 se originan en la Comarca de san Sebastián, trasladándose al interior de la provincia al avanzar la década. De 1999 hasta 2004-2006 se concentran únicamente en las series de las cabeceras de los ríos.

G.- El test de Mann-Kendall presenta en los periodos anual, MAM y AMJ un número de tendencias positivas detectadas superior al de tendencias negativas.

Esto es debido al espectacular incremento en 1946 y 1947 de las series analizadas de 3 a 15, reflejado en las gráficas 16, 18 y 20.1946 y 1947 fueron años con escasas precipitaciones anuales, en MAM y en AMJ.

H.- El test de Mann Kendall detecta tendencias positivas en las precipitaciones anual, MAM y AMJ, en los años 1951, 1979 a 1981 y en 1992.

\subsubsection{2.- Características diferentes de los periodos anual y primaveral:}

De lo expuesto en el apartado 4.2., especialmente en las gráficas 7, 8, 9, 10, 11, 12, 16,18 y 20 y en las tablas $4,10,22,22$ bis, $23,35,34,34$ bis, 45,45 bis, $49,50,51,56$ y 57 , se observan:

A.- De la tabla 56, el test de rachas detecta más inhomogeneidades en la precipitación anual que en la precipitación en primavera.

Por el contrario, el test de Mann-Kendall detecta un número de tendencias menor en la precipitación anual que en la precipitación en primavera. 
B.- En el periodo anterior a 1940, los resultados de Mann-Kendall en MAM, AMJ y anual, sólo coinciden en 1899 con tendencia negativa en AMJ y en anual. La sequía de los últimos años del siglo XIX ya fue analizada en el punto 4.2.

C.- El test de rachas detecta en el periodo anual un máximo de inhomogeneidades entre 1986 y 2006. El test de Thom en AMJ indica un máximo, menos acusado, de 1997 a 2011. El test de Thom en MAM no detecta nada significativo.

Este hecho sugiere que:

C1.- De 1997 a 2011 los meses de junio fueron más inhomogéneos que los meses de marzo.

C2.- De 1986 a 2006 las precipitaciones en primavera fueron más homogéneas que en el resto del año.

D.- El test de rachas aplicado a MAM y a AMJ señala máximos de las inhomogeneidades en 1954 a 1968 y de 1955 a 1977, respectivamente. El test de rachas aplicado a la precipitación media anual no señala inhomogeneidades de 1955 a 1970.

Esto insinúa que en ese periodo el comportamiento de la precipitación en primavera fue más homogéneo que el comportamiento de la precipitación en el resto del año.

E.- De la tabla 57, la proporción del número de tendencias negativas respecto al total de tendencias es inferior en el periodo anual que en primavera.

Este hecho sugiere que la transición de un período de sequía a uno de precipitaciones es mucho más abrupta, más breve en el tiempo, que la transición de un periodo de precipitaciones elevadas a uno seco en la precipitación anual que en la precipitación en primavera.

F.- En la precipitación anual aflora un ciclo de precipitaciones a 30 años; este ciclo no asoma en la precipitación en primavera.

En la precipitación AMJ se intuye un ciclo de 20 años, que no aflora en la precipitación anual.

G.- En 1951 el aumento de precipitación en MAM es más acusado en las comarcas del Alto Oria y del Alto Urola que en la precipitación anual. Asimismo, es en el Alto Oria donde es más acusada el aumento de precipitación en MAM.

H.- Al aplicar el test de Mann-Kendall, la tendencia de aumento de precipitación a finales de los 70 y comienzos 80 es superior en el periodo MAM que en el anual, siendo en este periodo el incremento más acusado de toda la serie histórica de datos.

I.- El aumento en precipitación MAM detectado por el test de Mann-Kendall comienza antes (1975) que en precipitación anual (1978-1979) y se prolonga en el Alto Oria y en la zona de San Sebastián (1016, 1021O, 1022, 1023, 1024, 1024E) hasta 1987 y los 90, siendo superior su duración al de precipitación anual. 
En este periodo de tiempo se han registrado los máximos históricos de precipitación en varios emplazamientos.

J.- El test de Mann-Kendall en AMJ indica una tendencia negativa en la precipitación de 1982 a 1987. Hay un débil reflejo en la precipitación anual con una tendencia negativa de 1984 a 1990.

K.- El test de Mann-Kendall aplicado a la primavera revela una disminución de la precipitación de 2001 a 2009; Mann-Kendall aplicado a la precipitación anual de 2001 a 2009 no detecta tendencia.

Por tanto, el test de Mann-Kendall detecta que entre 2001 a 2009 hubo una sucesión de primaveras menos lluviosas, sin que se detectara tendencia negativa en la precipitación anual.

\section{4.- Calificación de series. Propuesta de series de referencia.}

Para cada serie de datos de precipitaciones se calculan:

a) El \% de datos para cada periodo temporal (anual, MAM y AMJ).

b) El \% de datos homogéneos para cada test (Thom y Mann-Kendall) y para cada intervalo temporal (anual, MAM y AMJ).

c) La media aritmética y la media geométrica del $\%$ de datos y del $\%$ de datos homogéneos para cada periodo temporal.

d) Se promedian los resultados obtenidos en MAM y en AMJ para obtener los datos de calidad en primavera.

Es importante incluir en la valoración de la calidad de la serie el \% de años, ya que en alguna serie - de mediocre calidad - se ha detectado que su homogeneidad cambia radicalmente desechando 1 ó 2 datos.

La tabla 58 muestra una medida de la calidad de las series estudiadas. En la tabla 58,

1.- Se incluye el periodo de datos de precipitación anual para cada serie, detallando las rupturas en los casos detectados.

2.- En la serie anual, se presentan la media aritmética y la media geométrica del \% de datos homogéneos y del \% de datos de cada serie. AMJ.

3.- Para la primavera, se promedian los resultados obtenidos en los periodos MAM y

4.- En el caso de series con ruptura se considera la homogeneidad media en cada tramo, salvo en aquéllas series que tras la ruptura presenten en algún tramo un número de años inferior a 10, en que se representa sólo la homogeneidad del intervalo más largo considerando la ruptura. 
$\underline{\text { Tabla 58: Medida de la calidad de las series }}$

\begin{tabular}{|l|l|c|c|c|c|c|c|}
\hline \multicolumn{2}{|l|}{ Indicativo } & 1013 & 1013 & $1013 \mathrm{I}$ & 1014 & 1014 & 1015 \\
\hline Periodo & & $1915-30$ & $1938-63$ & $1988-98$ & $1957-68$ & $1969-12$ & $1946-63$ \\
\hline \multirow{2}{*}{ Anual } & Aritm & 8,98 & 8,90 & 6,75 & 9,80 & 9,73 & 9,45 \\
\cline { 2 - 8 } & Geom & 8,05 & 7,80 & 4,25 & 9,60 & 9,45 & 8,90 \\
\hline \multirow{2}{*}{ Primavera } & Aritm & 9,78 & 9,91 & 7,80 & 8,75 & 9,80 & 9,50 \\
\cline { 2 - 8 } & Geom & 9,05 & 9,83 & 5,71 & 7,50 & 9,60 & 9,00 \\
\hline
\end{tabular}

\begin{tabular}{|l|l|c|c|c|c|c|c|}
\hline \multicolumn{2}{|l|}{ Indicativo } & 1016 & 1017 & 1018 & 1018 & $1018 \mathrm{~A}$ & $1019 \mathrm{~A}$ \\
\hline Periodo & & $1947-84$ & $1954-79$ & $1951-72$ & $1973-83$ & $1965-76$ & $1988-99$ \\
\hline \multirow{2}{*}{ Anual } & Aritm & 9,03 & 8,70 & 10,00 & 10,00 & 9,58 & 7,10 \\
\cline { 2 - 7 } & Geom & 8,10 & 7,57 & 10,00 & 10,00 & 9,15 & 4,60 \\
\hline \multirow{2}{*}{ Primavera } & Aritm & 9,26 & 9,11 & 9,45 & 10,00 & 9,83 & 8,98 \\
\cline { 2 - 7 } & Geom & 8,53 & 8,29 & 8,90 & 10,00 & 9,65 & 8,04 \\
\hline
\end{tabular}

\begin{tabular}{|l|l|c|c|c|c|c|c|}
\hline \multicolumn{2}{|l|}{ Indicativo } & $1021 \mathrm{E}$ & $1021 \mathrm{E}$ & $1021 \mathrm{O}$ & 1022 & $1022 \mathrm{~A}$ & 1023 \\
\hline Periodo & $1972-88$ & $1989-12$ & $1974-92$ & $1955-85$ & $1946-92$ & $1964-83$ \\
\hline \multirow{2}{*}{ Anual } & Aritm & 9,70 & 9,90 & 7,90 & 8,03 & 8,20 & 8,85 \\
\cline { 2 - 8 } & Geom & 9,40 & 9,80 & 5,80 & 6,44 & 6,50 & 7,83 \\
\hline \multirow{2}{*}{ Primavera } & Aritm & 10,00 & 9,91 & 9,24 & 9,03 & 8,90 & 9,45 \\
\cline { 2 - 8 } & Geom & 10,00 & 9,83 & 8,52 & 8,14 & 7,83 & 8,94 \\
\hline
\end{tabular}

\begin{tabular}{|l|l|c|c|c|c|c|c|}
\hline \multicolumn{2}{|l|}{ Indicativo } & 1024 & 1024 & $1024 \mathrm{~B}$ & $1024 \mathrm{D}$ & $1024 \mathrm{E}$ & $1024 \mathrm{~F}$ \\
\hline Periodo & $1960-85$ & $1986-12$ & $1916-26$ & $1878-00$ & $1928-12$ & $1901-17$ \\
\hline \multirow{2}{*}{ Anual } & Aritm & 9,50 & 9,55 & 9,55 & 9,90 & 9,58 & 9,40 \\
\cline { 2 - 8 } & Geom & 9,02 & 9,11 & 9,10 & 9,80 & 9,15 & 8,80 \\
\hline \multirow{2}{*}{ Primavera } & Aritm & 9,76 & 9,68 & 9,60 & 9,68 & 9,59 & 9,70 \\
\cline { 2 - 8 } & Geom & 9,53 & 9,35 & 9,20 & 9,35 & 9,18 & 9,40 \\
\hline
\end{tabular}

\begin{tabular}{|l|l|c|c|c|c|c|c|}
\hline \multicolumn{2}{|l|}{ Indicativo } & $1024 \mathrm{~F}$ & 1025 & $1025 \mathrm{E}$ & $1025 \mathrm{~N}$ & 1026 & $1026 \mathrm{~A}$ \\
\hline Periodo & & $1918-35$ & $1935-60$ & $1978-92$ & $1993-12$ & $1954-84$ & $1988-11$ \\
\hline \multirow{2}{*}{ Anual } & Aritm & 9,70 & 9,05 & 8,58 & 8,00 & 7,18 & 9,40 \\
\cline { 2 - 8 } & Geom & 9,40 & 8,10 & 7,32 & 6,23 & 4,87 & 8,80 \\
\hline \multirow{2}{*}{ Primavera } & Aritm & 9,48 & 10,00 & 9,19 & 8,85 & 8,76 & 9,18 \\
\cline { 2 - 8 } & Geom & 8,95 & 10,00 & 8,38 & 7,83 & 7,64 & 8,40 \\
\hline
\end{tabular}

\begin{tabular}{|l|l|c|c|c|c|c|c|}
\hline \multicolumn{2}{|l|}{ Indicativo } & $1026 \mathrm{~B}$ & 9268 & 1031 & 1031 & 1031 & 1032 \\
\hline Periodo & & $1990-12$ & $1958-73$ & $1946-58$ & $1959-88$ & $1989-11$ & $1928-82$ \\
\hline \multirow{2}{*}{ Anual } & Aritm & 8,48 & 7,13 & 8,05 & 9,65 & 9,05 & 8,85 \\
\cline { 2 - 8 } & Geom & 7,14 & 4,78 & 6,39 & 9,30 & 8,16 & 7,72 \\
\hline \multirow{2}{*}{ Primavera } & Aritm & 9,16 & 7,26 & 9,19 & 9,89 & 9,64 & 9,63 \\
\cline { 2 - 8 } & Geom & 8,37 & 5,23 & 8,43 & 9,78 & 9,28 & 9,26 \\
\hline
\end{tabular}


$\underline{\text { Tabla } 58 \text { (continuación): Medida de la calidad de las series }}$

\begin{tabular}{|l|l|c|c|c|c|c|c|}
\hline \multicolumn{2}{|l|}{ Indicativo } & $1032 \mathrm{~A}$ & $1033 \mathrm{U}$ & $1033 \mathrm{U}$ & 1034 & 1035 & $1035 \mathrm{U}$ \\
\hline \multicolumn{2}{|l|}{ Periodo } & $1947-74$ & $1986-97$ & $1998-12$ & $1947-68$ & $1946-11$ & $1992-03$ \\
\hline \multirow{2}{*}{ Anual } & Aritm & 8,85 & 6,65 & 9,13 & 8,35 & 8,85 & 6,65 \\
\cline { 2 - 8 } & Geom & 7,70 & 4,15 & 8,32 & 6,70 & 7,78 & 4,15 \\
\hline \multirow{2}{*}{ Primavera } & Aritm & 9,29 & 9,15 & 10,00 & 9,60 & 9,51 & 9,8 \\
\cline { 2 - 8 } & Geom & 8,61 & 8,34 & 10,00 & 9,20 & 9,04 & 9,6 \\
\hline
\end{tabular}

\begin{tabular}{|l|l|c|c|c|c|c|c|}
\hline \multicolumn{2}{|l|}{ Indicativo } & 1036 & $1036 \mathrm{O}$ & 1037 & 1037 & 10370 & $1037 \mathrm{Q}$ \\
\hline Periodo & $1956-86$ & $1984-12$ & $1946-80$ & $1981-11$ & $1978-01$ & $1986-98$ \\
\hline \multirow{2}{*}{ Anual } & Aritm & 9,28 & 9,83 & 8,50 & 9,28 & 8,60 & 6,75 \\
\cline { 2 - 8 } & Geom & 8,58 & 9,65 & 7,10 & 8,60 & 7,28 & 4,25 \\
\hline \multirow{2}{*}{ Primavera } & Aritm & 9,46 & 9,55 & 9,71 & 9,68 & 9,19 & 9,06 \\
\cline { 2 - 8 } & Geom & 8,93 & 9,10 & 9,43 & 9,35 & 8,42 & 8,23 \\
\hline
\end{tabular}

\begin{tabular}{|l|l|c|c|c|c|c|c|}
\hline \multicolumn{2}{|l|}{ Indicativo } & 1038 & 1041 & 1044 & $1044 \mathrm{~A}$ & $1044 \mathrm{D}$ & $1044 \mathrm{D}$ \\
\hline \multicolumn{2}{|l|}{ Periodo } & $1992-03$ & $1988-07$ & $1955-76$ & $1956-99$ & $1986-94$ & $1995-12$ \\
\hline \multirow{2}{*}{ Anual } & Aritm & 9,03 & 8,33 & & & & 8,05 \\
\cline { 2 - 8 } & Geom & 8,12 & 6,88 & & & & 6,10 \\
\hline \multirow{2}{*}{ Primavera } & Aritm & 9,81 & 9,19 & 8,09 & 8,53 & 9,66 & 8,81 \\
\cline { 2 - 8 } & Geom & 9,63 & 8,42 & 6,24 & 7,16 & 9,33 & 7,74 \\
\hline
\end{tabular}

\begin{tabular}{|l|l|c|c|c|c|c|c|}
\hline \multicolumn{2}{|l|}{ Indicativo } & $1044 \mathrm{U}$ & 1045 & 1046 & 1046 & 1048 & 1049 \\
\hline \multicolumn{2}{|l|}{ Periodo } & $1983-96$ & $1946-75$ & $1935-68$ & $1969-01$ & $1987-12$ & $1984-08$ \\
\hline \multirow{2}{*}{ Anual } & Aritm & & 7,60 & 9,80 & 9,40 & 10,00 & 9,90 \\
\cline { 2 - 8 } & Geom & & 5,20 & 9,60 & 8,80 & 10,00 & 9,80 \\
\hline \multirow{2}{*}{ Primavera } & Aritm & 9,74 & 7,83 & 9,85 & 9,45 & 9,43 & 9,91 \\
\cline { 2 - 8 } & Geom & 9,48 & 6,01 & 9,70 & 8,93 & 8,85 & 9,83 \\
\hline
\end{tabular}

\begin{tabular}{|l|l|c|c|c|c|c|c|}
\hline \multicolumn{2}{|l|}{ Indicativo } & $1049 \mathrm{O}$ & $1049 \mathrm{U}$ & 1050 & 1050 & $1050 \mathrm{~L}$ & 1052 \\
\hline Periodo & $1985-03$ & $1983-05$ & $1951-64$ & $1965-91$ & $1987-07$ & $1956-74$ \\
\hline \multirow{2}{*}{ Anual } & Aritm & 8,85 & 9,80 & 8,15 & 8,75 & 8,63 & 8,35 \\
\cline { 2 - 8 } & Geom & 7,70 & 9,60 & 6,30 & 7,50 & 7,36 & 6,70 \\
\hline \multirow{2}{*}{ Primavera } & Aritm & 9,43 & 9,41 & 8,89 & 9,61 & 9,75 & 9,24 \\
\cline { 2 - 8 } & Geom & 8,87 & 8,83 & 7,91 & 9,23 & 9,50 & 8,49 \\
\hline
\end{tabular}

En las series 1044, 1044A, 1044D (hasta 1994) y 1044U se indican sólo los resultados MAM y AMJ, al no alcanzar 10 años completos de precipitación anual y la duración se refiere a los años con datos en MAM y en AMJ.

Las gráficas 21 y 22 muestran la medida de la calidad de la precipitación anual de la tabla 58, para las series 1013 a $1025 \mathrm{~N}$ y 1026 a 1052 , respectivamente. 
Gráfica 21: Calificación calidad series precipitación anual de 1013 a 1025N:

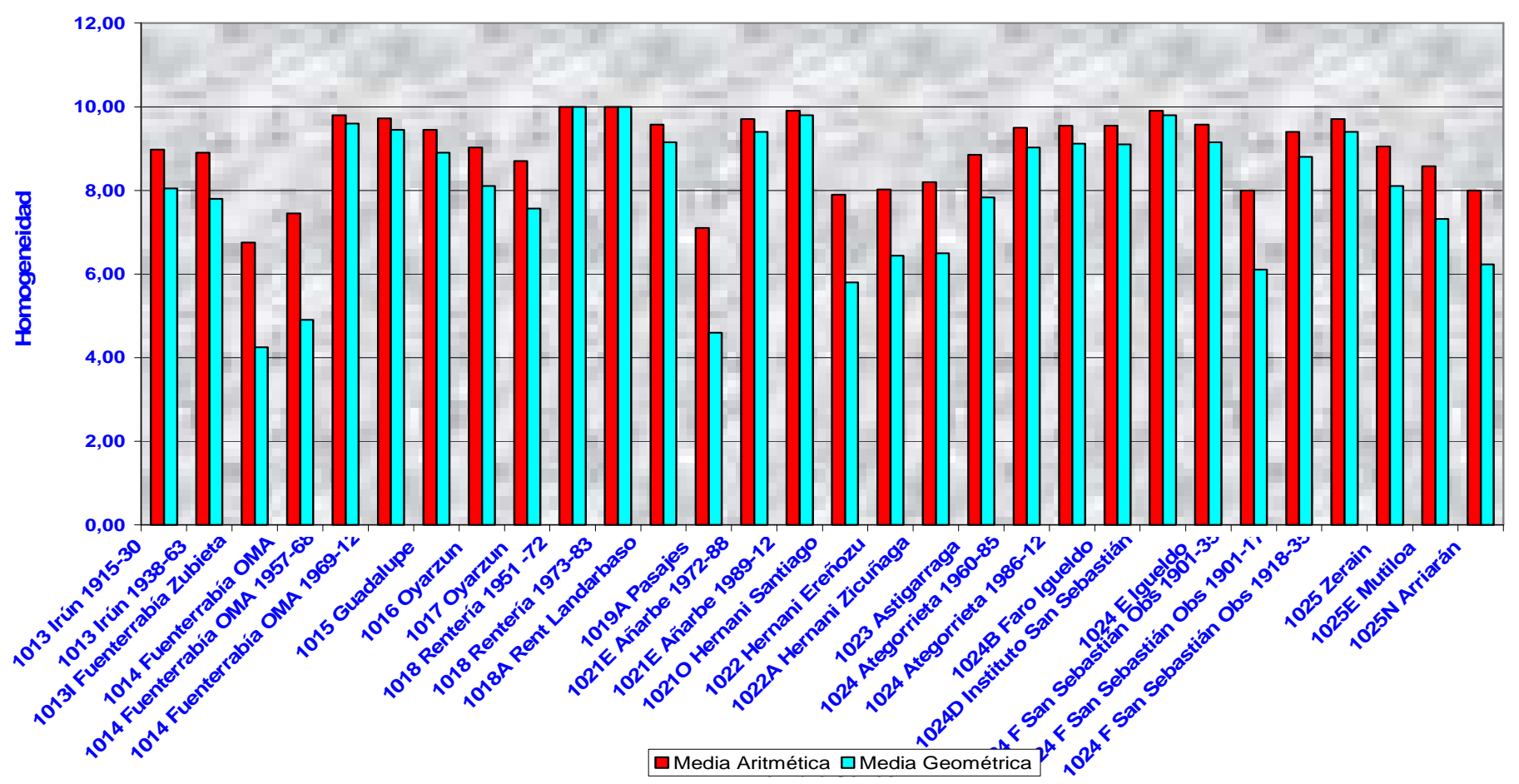

Nótese como la homogeneidad de la serie 1024F San Sebastián Observatorio, referida al periodo anual, se incrementa notablemente al considerar el efecto de la ruptura en febrero y marzo de 1918, respecto a la homogeneidad de la serie de datos sin considerar ruptura. Ítem ocurre con 1014 OMA Fuenterrabía, respecto a la ruptura de 1968.

Gráfica 22: Calificación calidad series precipitación anual de 1026 a 1052:

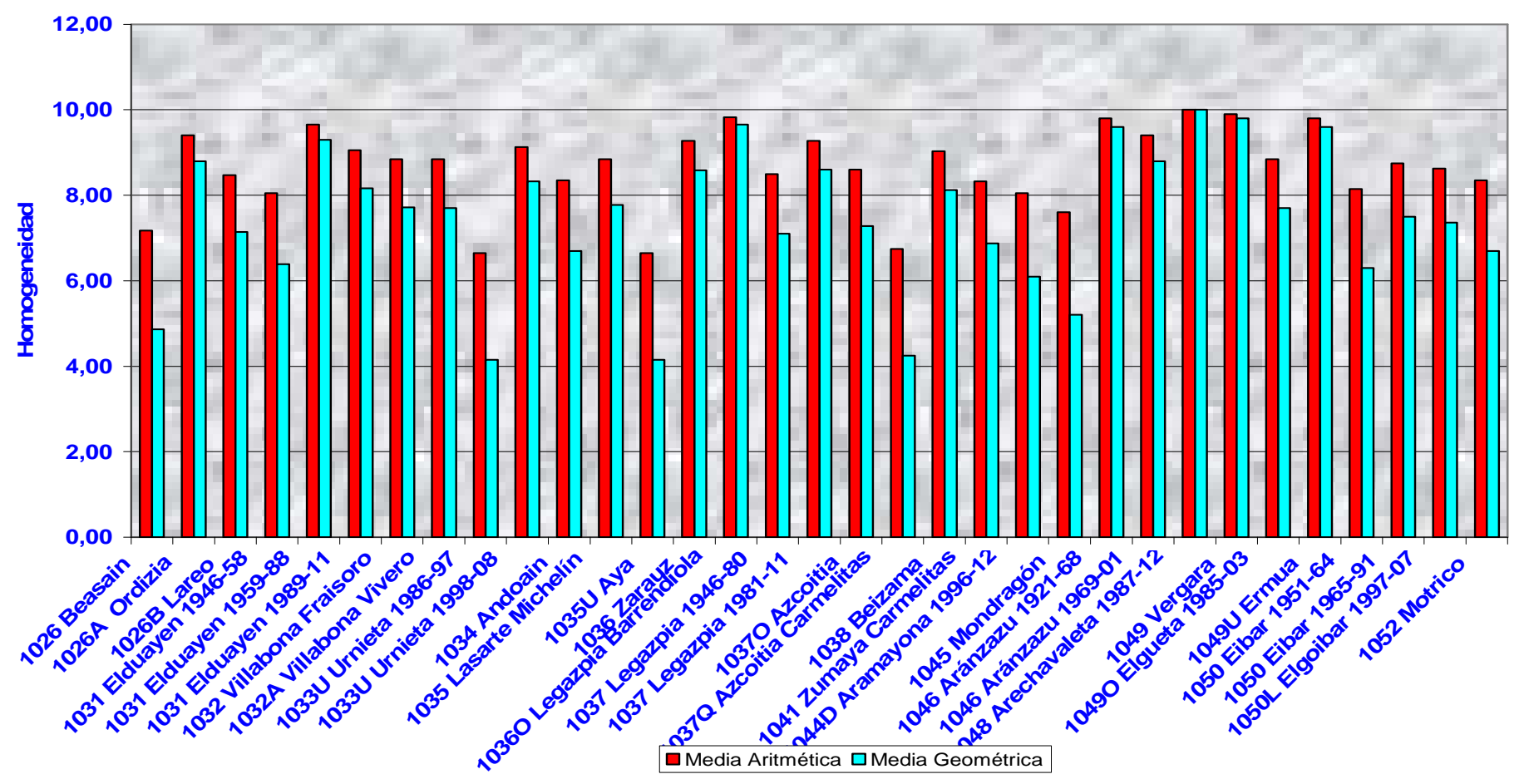


Las gráficas 23 y 24 muestran la medida de la calidad de la precipitación en primavera de la tabla 58, para las series 1013 a $1025 \mathrm{~N}$ y 1026 a 1052, respectivamente.

Gráfica 23: Calificación calidad series precipitación primaveral de 1013 a 1025N:

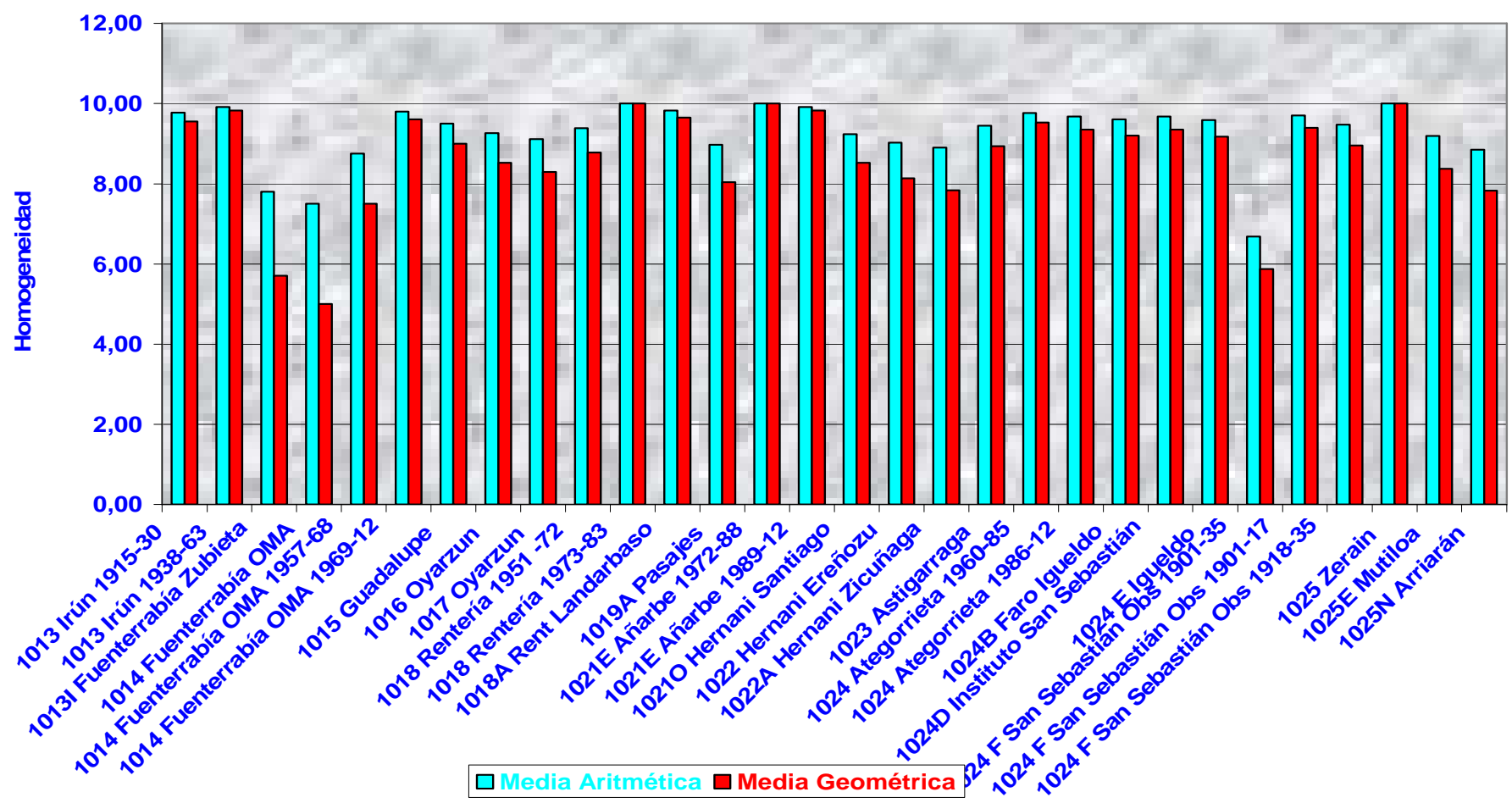

Gráfica 24: Calificación calidad series precipitación primaveral de 1026 a 1052:
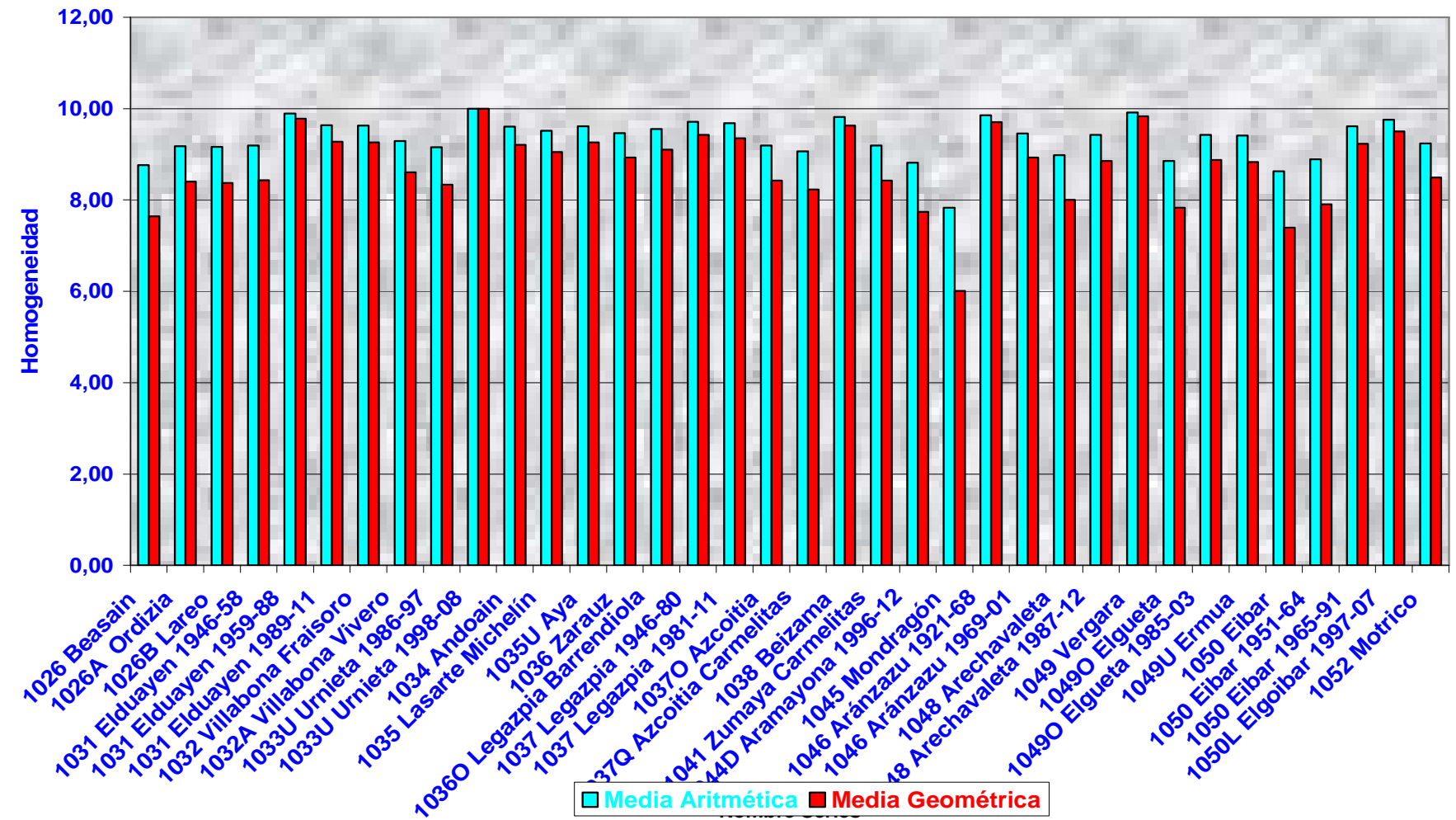
La homogeneidad de la serie 1014 OMA Fuenterrabía, referida a la primavera, se incrementa notablemente al considerar el efecto del cambio de jardín meteorológico a finales de 9168, respecto a la homogeneidad de la serie de datos sin considerar ruptura.

Ítem ocurre con 1024F San Sebastián Observatorio, respecto a la ruptura de febrero y marzo de 1918.

\section{Propuesta de series de referencia:}

Una serie de calidad debe ser homogénea en la precipitación anual y en la precipitación en primavera (MAM y AMJ).

A continuación se entresacan de la tabla 58 las series con una calidad superior a 9 empleando la media geométrica del \% de datos y del \% de datos homogéneos, para la precipitación anual y en primavera:

\section{A) Media geométrica:}

Anual: 1014, 1018, 1018A, 1021E, 1024, 1024B, 1024D, 1024E, 1024F (desde 1918), 1031 (de 1959 a 1988), 1036O, 1046 (hasta 1968), 1048, 1049 y 1049 U.

Primavera: 1013, 1014 (desde 1969), 1015, 1018 (desde 1973), 1018A, 1021E, 1024, 1024B, 1024D, 1024E, 1024F (hasta 1917), 1025, 1031 (desde 1959), 1032, 1033U (desde 1998), 1034, 1035, 1035U, 1036O, 1037, 1038, 1044D (hasta 1994), 1044U, 1046 (hasta 1968), 1049, 1050 (desde 1965) y 1050L.

Se proponen como series de referencia, por cumplirla en los 2 periodos (primavera y anual): 1014 (desde 1969), 1018 (desde 1973), 1018A, 1021E, 1024, 1024B, 1024D, 1024E, 1031 (de 1959 a 1988), 1036O, 1046 (hasta 1968) y 1049.

En la figura 8 se representa la localización geográfica de estos emplazamientos.

Se proponen como series de referencia que cumplen en los 2 periodos (primavera y anual) y superan los 30 años de duración en precipitación anual: 1014 (desde 1969), 1021E, 1024, 1024E y 1031 (de 1959 a 1988. En la figura 9 se representa la localización geográfica de estas series.

En la figura 9 se representa la localización geográfica de estas series. 
Figura 8: Propuesta de series de referencia (media geométrica)

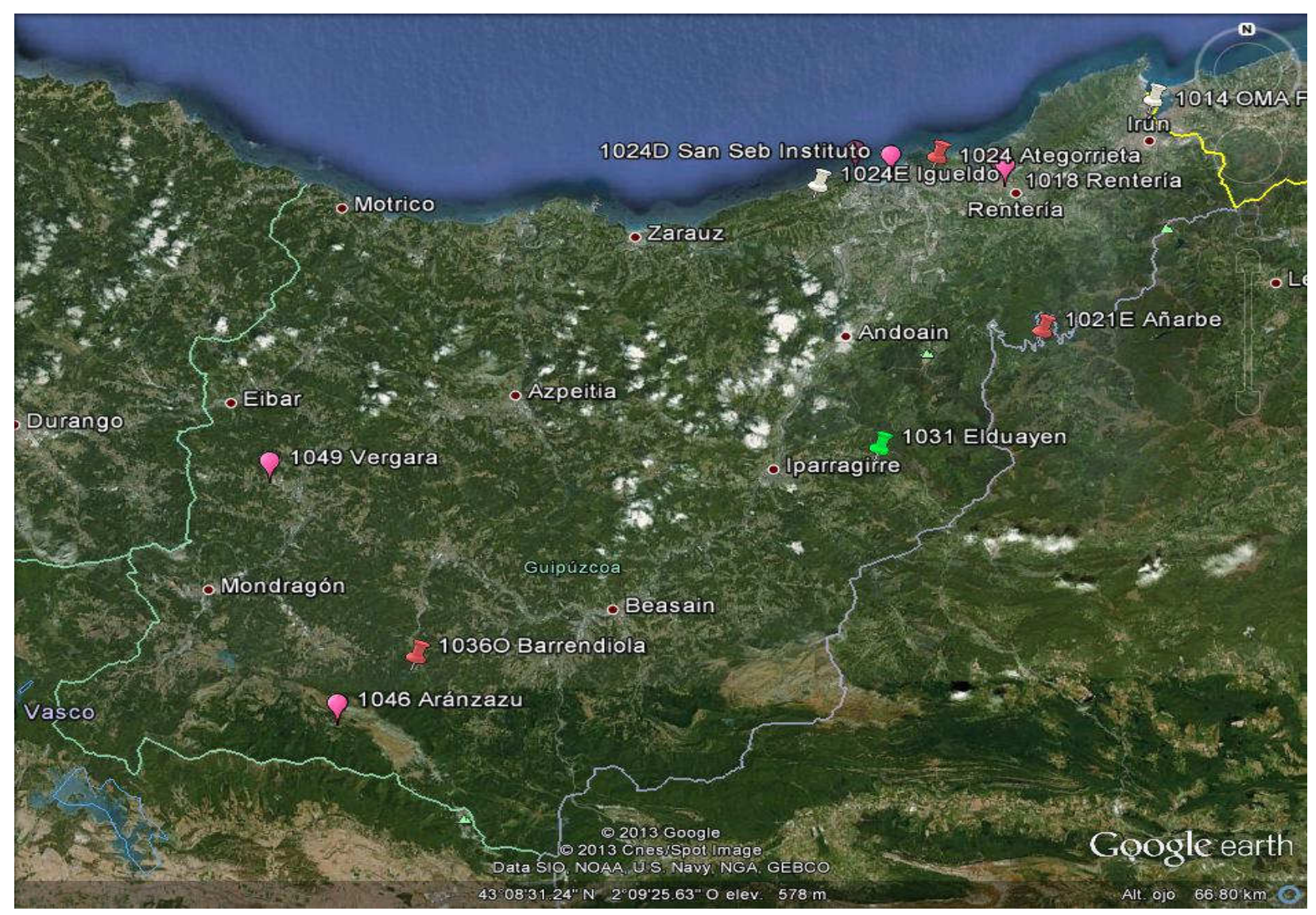

Figura 9: Propuesta de series de referencia (media geométrica) y superiores a 30 años

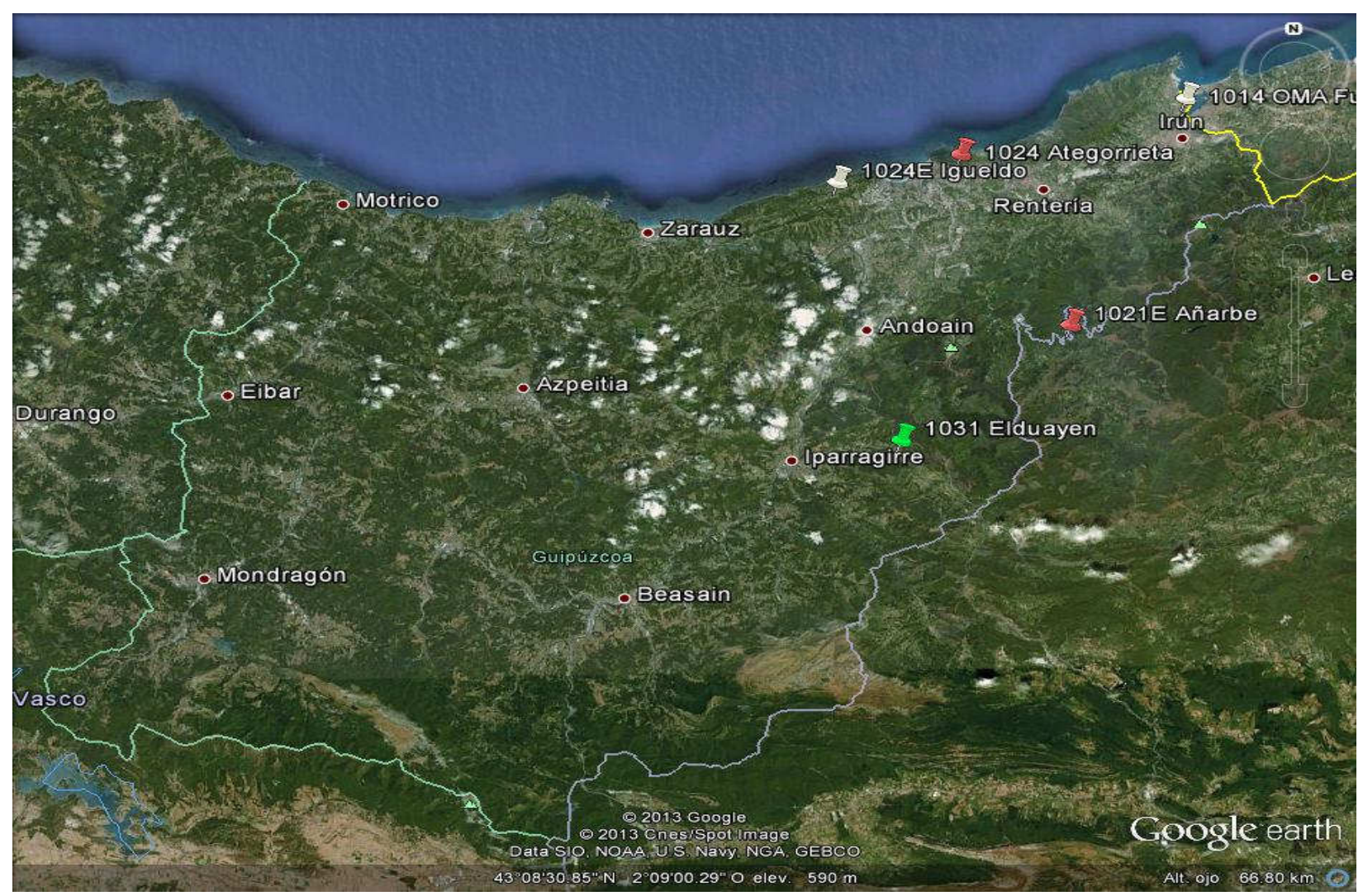




\section{B) Media aritmética:}

Anual: 1014, 1015, 1016, 1018, 1018A, 1021E, 1024, 1024B, 1024D, 1024E, 1024F, 1025, 1026A, 1031 (desde 1959), 1033U (desde 1998), 1036, 1036O, 1037 (desde 1981), $1038,1046,1048,1049$ y 1049 U.

Primavera: 1013, 1014 (desde 1969), 1015, 1016, 1017, 1018, 1018A, 1021E, 1021O, 1022, 1023, 1024, 1024B, 1024D, 1024E, 1024F, 1025, 1025E, 1026A, 1026B, 1031, 1032, 1032A, 1033U, 1034, 1035, 1035U, 1036, 1036O, 1037, 1037O, 1037Q, 1038, 1041, 1044D (hasta 1994), 1044U, 1046, 1048, 1049, 1049O, 1049U, 1050 (desde 1965), $1050 \mathrm{~L}$ y 1052.

Se proponen como series de referencia, por cumplirla en los 2 periodos (primavera y anual): 1014 (desde 1969), 1015, 1016, 1018, 1018A, 1021E, 1024, 1024B, 1024D, 1024E, 1024F, 1025, 1026A, 1031 (desde 1959), 1033U (desde 1998), 1036, 1036O, 1037 (desde 1981), 1038, 1046, 1048, 1049 y 1049 U.

En la figura 10 se representa la localización geográfica de estos emplazamientos.

\section{Figura 10: Propuesta de series de referencia (media aritmética)}

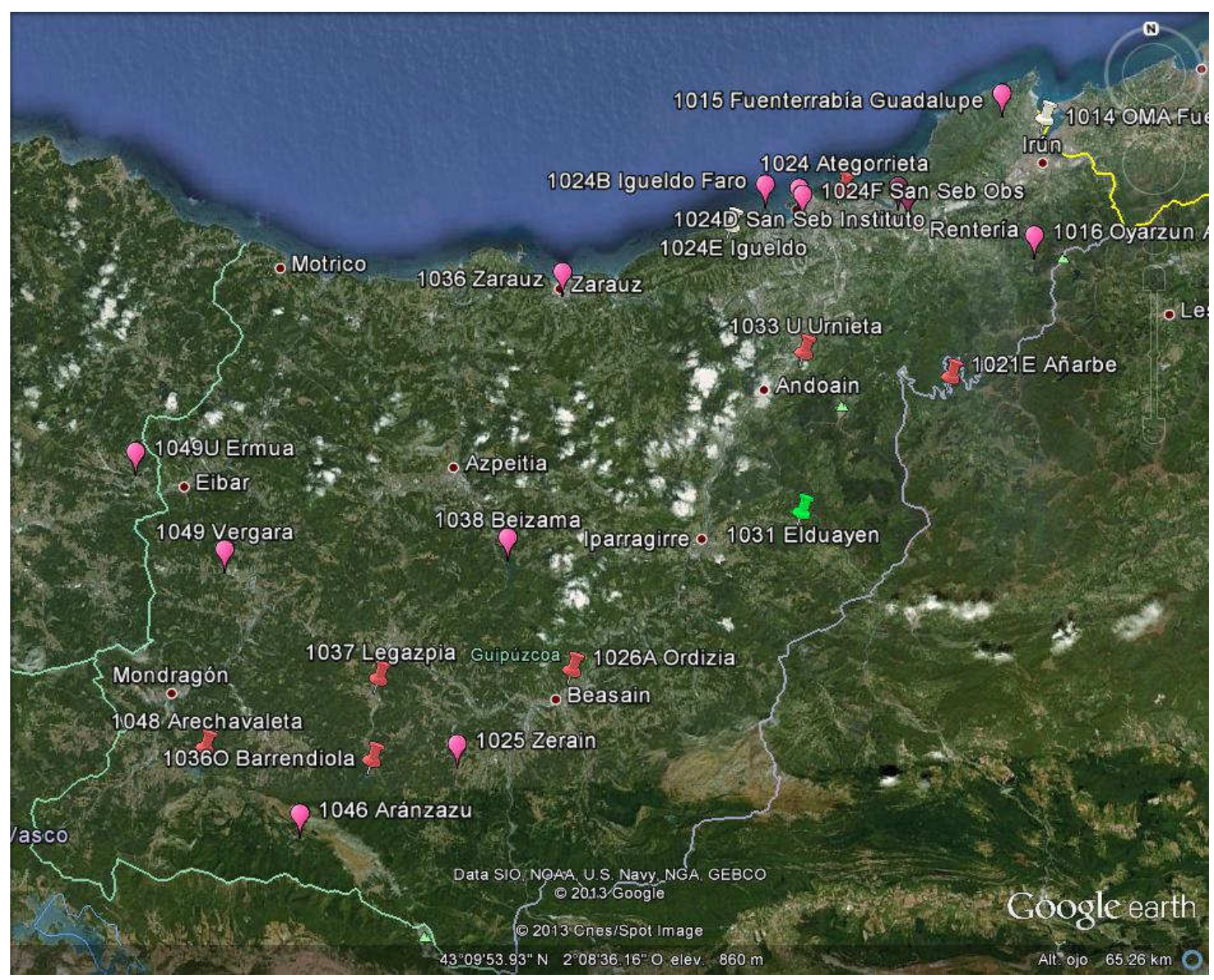


Se proponen como series de referencia que cumplen en los 2 periodos (primavera y anual) y superan los 30 años de duración en precipitación anual: 1014, 1016, 1018, 1021E, 1024, 1024E, 1031 (desde 1959), 1036, 1036O, 1037 (desde 1981) y 1046.

En la figura 11 se representa la localización geográfica de estas series.

\section{Figura 11: Propuesta de series de referencia (media aritmética) y superiores a 30 años}

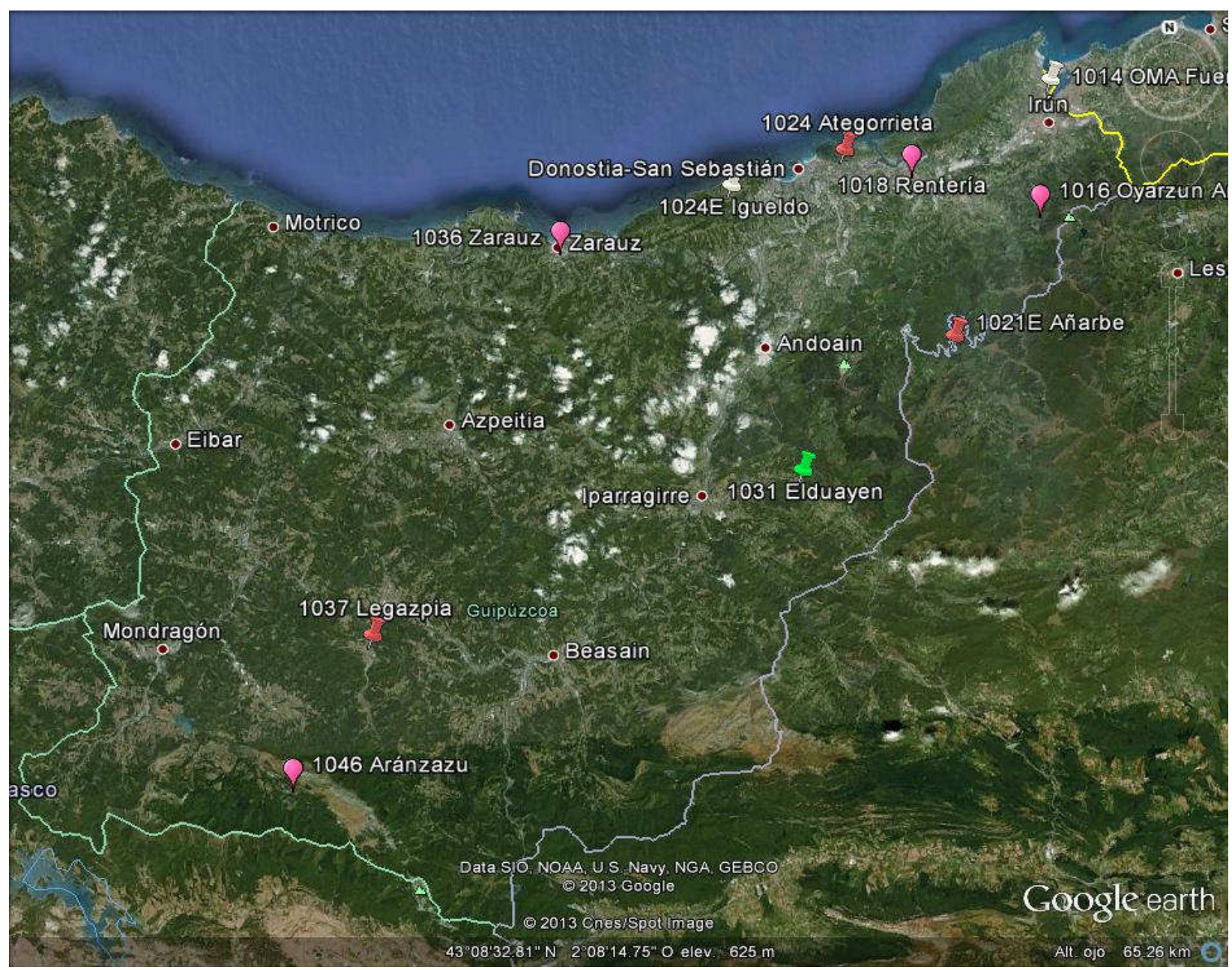

De la tabla 58 y de las figuras 10 y 11:

1.- La media geométrica permite discriminar más claramente entre las calidades de $\underline{\text { las series de datos. }}$

2.- En general, tienen una homogeneidad superior las series de precipitación en primavera que en el periodo anual; puede ser debido a que tengan un mayor número de datos o bien a que la precipitación media en primavera tenga un comportamiento más "homogéneo".

3.- De la tabla 58 y de las gráficas $21,22,23$ y 24 se insinúa, entre otras características, una mayor homogeneidad en aquellas series con una mayor precipitación. 


\section{5.- Conclusiones}

1.- Se destaca la importancia y potencia de realizar un análisis conjunto para detectar las rupturas en las series de datos aplicando:

1.1.- Los tests de Thom y de Mann-Kendall en cada periodo homogéneo de datos.

1.2.- Con una resolución anual y estacional (MAM y AMJ), ya que las rupturas (conocidas y documentadas) no son detectadas por todos los tests en todos los periodos, según reflejan las tablas 1,2 y 3 .

2.- Una mayor resolución temporal (aplicada a los periodos MAM y AMJ) detecta más rupturas contrastadas de series; se disponen de más registros de precipitación en primavera que de la precipitación anual.

El análisis estacional permite detectar cambios de emplazamiento, inadvertidos para el análisis anual, como se expone en las tablas 1, 2 y 3 . Esto es, el análisis con los dos tests es más preciso en el periodo de primavera que en el anual.

2.1.- El análisis conjunto de las series de datos por los test de Thom y de MannKendall aplicado a los 3 periodos temporales (anual, MAM y AMJ) coincide en la determinación en el tiempo de los puntos de ruptura de las series.

Estas rupturas son corroboradas al $100 \%$ con las evidencias registradas que se disponen de cambios de emplazamiento, de entorno, de colaboradores y/o de instrumentos de medida.

2.2.- Se determinan las rupturas en cada serie, permitiendo identificar los intervalos de medidas homogéneas y de calidad.

2.3- Se obtienen para cada serie de precipitación y para cada resolución temporal (anual, MAM y AMJ) los intervalos en que cada serie es homogénea.

2.4.- En los casos de ruptura de las series, la homogeneidad de cada intervalo se incrementa notablemente respecto a la homogeneidad de la serie completa.

2.5.- En general, es más severo el test de las rachas aplicado a la precipitación en primavera que a la precipitación anual.

2.6.- Se han detectado inhomogeneidades, probablemente debidas a una caída de la calidad de los datos, en los últimos años de medida de algunas series antiguas de colaboradores.

3.- El análisis de la evolución temporal de las inhomogeneidades detectadas por los test de Thom y de Mann-Kenndall permite diferenciar las inhomogeneidades de tipo climatológico, por variaciones del clima, de las producidas por alteraciones de la calidad de la medida: cambio de emplazamiento, alteración del entorno, reemplazo del colaborador... 
3.1.- Para distinguir entre inhomogeneidades "climatológicas" debidas a variaciones del clima y como tales, comunes a varios emplazamientos, de las no "climatológicas" en las series actuales, se realiza una comparación frente a los colaboradores y observatorios significativos (de calidad y similar altitud) más cercanos.

Para discernir entre inhomogeneidades "climatológicas" y "no climatológicas", es necesario incluir en el estudio a las series antiguas.

Así, se descartan series con comportamiento en precipitación diferente al entorno; por ejemplo, una serie que muestre tendencia positiva mientras todo el entorno disminuye o que sea la única serie de las analizadas que muestre inhomogeneidad según el test de Thom.

Se resalta la importancia de un análisis conjunto de los observatorios y colaboradores cercanos, para no desechar ni inhomogeneidades ni tendencias de la precipitación como "no climatológicas", al producirse en varios emplazamientos simultáneamente.

3.2.- El test de Thom se revela más efectivo para detectar inhomogeneidades por cambio de emplazamiento que el test de Mann Kendall. Mann Kendall se muestra más efectivo para detectar "inhomogeneidades climatológicas: sequías o periodos lluviosos de tipo climatológico, oscilaciones naturales del clima"

El test de Mann Kendall es muy crítico con los valores de los primeros años de la serie para detectar tendencia, incluso 50 ó 60 años.

4.- Se detectan, describen y analizan inhomogeneidades y tendencias de tipo climatológico, producidas simultáneamente en series vecinas: periodos de sequías y de precipitaciones elevadas a nivel provincial y comarcal.

Así, se observan comportamientos climáticos a escala comarcal: Mayores inhomogeneidades en la comarca de San Sebastián, tendencias similares en precipitación en las comarcas del Alto Oria y del Alto Urola y en Deba Alto y Medio.

Esto da pie a hablar de "microclimas" en Guipúzcoa, la provincia en extensión menor de España, con una orografía harto compleja.

4.1.- Se intuyen ciclos de 10 años en la precipitación media anual, MAM y AMJ, de 20 en la precipitación media AMJ y de 30 años en la media anual. El ciclo de 10 años se está cumpliendo en el año 2013.

4.2.- Se encuentran muy pocas inhomogeneidades de tipo no climatológico, lo cuál denota una elevada homogeneidad de las medidas realizadas por el $\mathrm{SMN}^{2}$-INM ${ }^{3}$-AEMET en Guipúzcoa.

Por ejemplo, en 84 años de registros de precipitación anual de 1024E, sólo se registra tendencia negativa en 1948.

\footnotetext{
${ }^{2}$ SMN: Servicio Meteorológico Nacional

${ }^{3}$ INM: Instituto Nacional de Meteorología
} 
5.- El análisis con el test de Mann Kendall de la precipitación anual, MAM y AMJ muestra que es más acusada la transición de un periodo de sequías a uno muy lluvioso que la transición de un periodo lluvioso o normal a uno seco.

5.1.- Las inhomogeneidades encontradas al aplicar el test de las rachas no son tan precisas como las detectadas al emplear el test de Mann - Kendall (al analizar rachas en 10 años se superponen periodos de sequía y de precipitaciones superiores).

5.2.- Las tendencias "climatológicas" detectadas se han revelado independientes del año de comienzo de las series.

5.3- Los aumentos en la precipitación en primavera parecen producirse desde los 70, primero en la comarca de San Sebastián para registrarse en los años posteriores en el interior de Guipúzcoa.

5.4.- Se observan tendencias de mayor duración temporal en la precipitación en primavera que en la precipitación anual.

5.5.- El periodo MAM indica más inhomogeneidades y tendencias que el periodo AMJ. La precipitación en junio en Guipúzcoa resulta más homogénea que en marzo.

En cuanto a comarcas, la precipitación en junio es más homogénea en el litoral y en la comarca de San Sebastián; la de marzo es más homogénea en la cabecera de los ríos (comarcas del Alto Oria, Alto Urola y Alto Deba), según la tabla 55 y las figuras 6 y 7.

5.6.- Se insinúa una relación entre la homogeneidad de las series de precipitación y las cantidades de precipitación recogidas: las series con precipitaciones más elevadas resultan presentar, en promedio, una homogeneidad más elevada, según reflejan la tabla 58 y las figuras 9 y 11.

5.7.- Se percibe una similitud de las tendencias detectadas por el test de MannKendall en los emplazamientos próximos. Se observan comportamientos parejos a escala provincial (propios de una provincia con clima oceánico) y características específicas a escala comarcal.

5.8.- Se destaca la importancia de realizar una comparativa de las tendencias detectadas en el comportamiento de la precipitación en enclaves cercanos.

6.- De la tabla 55, se percibe un comportamiento similar aplicando el test de Thom y el test de Mann-Kendall en las series de calidad próximas.

La distribución del comportamiento es más similar en comarcas y en emplazamientos cercanos.

7.- Se proponen series de referencia, por su calidad, homogeneidad detectada al aplicar los test de Thom y de Mann-Kendall, duración temporal y escaso o nulo número de lagunas, para la precipitación anual y en primavera. 


\section{6.- Agradecimientos}

- A la Delegada Territorial de AEMET en el País Vasco, por la atenta revisión del borrador de esta nota técnica.

- Al Supervisor de Sistemas Básicos de la Delegación Territorial de AEMET en el País Vasco, por la búsqueda de las evidencias de cambios de emplazamiento, de colaborador y/o de instrumental.

- A los colaboradores de AEMET en Guipúzcoa, por su labor de recogida diaria de datos de precipitación.

\section{7.- Referencias:}

Almarza, C; López-Díaz; J.A. y Flores C. (1996) "Homogeneidad y variabilidad de los registros históricos de precipitación de España.” Monografía Técnica A-143 Instituto Nacional de Meteorología, Ministerio de Medio Ambiente, ISBN 8449802210

Luna M.Y.; Guijarro J.A. y López Díaz J.A. (2012) “ RECONSTRUCCIÓN, HOMOGENEIDAD Y TENDENCIAS DE LAS SERIES HISTÓRICAS DE PRECIPITACIÓN MENSUAL ACUMULADA EN LA ESPAÑA PENINSULAR Y LAS ISLAS BALEARES" Ponencias $8^{\circ}$ Congreso Asociación Española de Climatología (AEC), Salamanca 25-28 Septiembre de 2012

Servicio de Aplicaciones Climatológicas del Instituto Nacional de Meteorología "Las precipitaciones máximas en 24 horas y sus periodos de retorno en España. Volumen 0 Introducción y Metodología" Publicación D50.0 Instituto Nacional de Meteorología, Ministerio de Medio Ambiente, ISBN 8483200430

Servicio de Aplicaciones Climatológicas del Instituto Nacional de Meteorología "Las precipitaciones máximas en 24 horas y sus periodos de retorno en España. Volumen 3 País Vasco" Publicación D50.3 Instituto Nacional de Meteorología, Ministerio de Medio Ambiente, ISBN 8483200465.

Sneyers, R. (1975) "Sobre el análisis estadístico de las series de observaciones" Nota Técnica No 143 Organización Meteorológica Mundial

Álvarez Usabiaga J.I. "Variaciones observadas en el Observatorio de Igueldo en 60 años" XX jornadas de la Asociación Meteorológica Española San Sebastián Mayo 1989 Publicación Fundación Cultural Caja de Guipúzcoa, ISBN 8450595053

Nuñez Corchero M; Sosa Cardo J.A. (2001) “Climatología de Extremadura” Publicación A153 Instituto Nacional de Meteorología 
Font I (2000) “Climatología de España y Portugal, 2nd edn.” Ediciones Universidad de Salamanca

García de Pedraza L; Reija Garrido A (1994): “Tiempo y Clima en España. Meteorología de las Autonomías" Ed. Dossat 2000 ISBN 8423708063

Peterson Thomas C., Aguilar, E. Auer I, Brunet M, Wieringa J."Guidelines on climate metadata and homogeneization” WCDMP No. 53 - WMO/TD No 1186

Uriarte Cantolla A: "Régimen de precipitaciones en la costa NW y N de la Península Ibérica" Caja de Ahorros Provincial de Guipúzcoa 1983, ISBN 8472319296

Doporto M. "Cincuenta y cinco años de observaciones pluviométricas en San Sebastián (1878-1932)" Imprenta de la Diputación de Guipúzcoa 1933.

Doporto M. "Resumen de las observaciones efectuadas en la red termopluviométrica durante el año 1934.” Imprenta de la Diputación de Guipúzcoa 1934

Doporto M. "La lluvia en Igueldo durante el año meteorológico 1928 (Diciembre 1927noviembre 1928)" Imprenta de la Diputación de Guipúzcoa 1928

Martínez Molina I( 1986): “Estadística aplicada a la Hidrometeorología” Publicación D-47 Instituto Nacional de Meteorología.

Llanos Aramburu F; Recalde Delgado A.I.; Sanz Garrido B; Urzainki Mikeleiz A (2011):

"El Observatorio de Igueldo Memoria” AEMET. ISBN 978847837085

Utrilla Navarro L.(2005) “Historia de los aeropuertos de San Sebastián” AENA ISBN 8496456188 


\section{8.- Anexo}

\section{$\underline{\text { Nomenclátor }}$}

Tabla 59: Nomenclátor: Indicativo climatológico, nombre y localización:

\begin{tabular}{|c|c|c|c|}
\hline Indicativo & Nombre estación & Longitud & Latitud \\
\hline 1013 & IRUN (FITOSANITARIA) & $0147 \mathrm{~W}$ & 4320 \\
\hline 1013I & $\begin{array}{l}\text { FUENTERRABIA- } \\
\text { ZUBIETA }\end{array}$ & 014844W & 432040 \\
\hline 1014 & $\begin{array}{c}\text { HONDARRIBIA- } \\
\text { MALKARROA }\left(\mathrm{OMA}^{4}\right)\end{array}$ & $014732 \mathrm{~W}$ & 432125 \\
\hline 1015 & $\begin{array}{l}\text { FUENTERRABIA } \\
\text { (GUADALUPE) }\end{array}$ & 0149W & 4322 \\
\hline 1016 & OYARZUN (ARDITURRI) & 014819W & 431703 \\
\hline 1017 & OYARZUN & $0151 \mathrm{~W}$ & 4318 \\
\hline 1018 & RENTERIA VILLA & $015357 \mathrm{~W}$ & 431845 \\
\hline 1018A & $\begin{array}{c}\text { RENTERIA } \\
\text { (LANDARBARSO) }\end{array}$ & $0154 \mathrm{~W}$ & 4319 \\
\hline 1019A & PASAJES (NAUTICA) & 015540W & 431927 \\
\hline $1021 \mathrm{E}$ & RENTERIA (AÑARBE) & $015247 \mathrm{~W}$ & 431240 \\
\hline 10210 & HERNANI (SANTIAGO) & $0154 \mathrm{~W}$ & 4313 \\
\hline 1022 & HERNANI (EREÑOZU) & $015607 \mathrm{~W}$ & 431415 \\
\hline $1022 \mathrm{~A}$ & HERNANI (ZICUÑAGA) & $015805 \mathrm{~W}$ & 431535 \\
\hline 1023 & ASTIGARRAGA & $015657 \mathrm{~W}$ & 431650 \\
\hline 1024 & $\begin{array}{l}\text { SAN SEBASTIAN } \\
\text { (ATEGORRIETA) }\end{array}$ & $015702 \mathrm{~W}$ & 431920 \\
\hline 1024B & $\begin{array}{l}\text { SAN SEBASTIAN (FARO } \\
\text { IGUELDO) }\end{array}$ & $020033 \mathrm{~W}$ & 431925 \\
\hline 1024D & $\begin{array}{l}\text { SAN SEBASTIAN } \\
\text { INSTITUTO }\end{array}$ & $015857 \mathrm{~W}$ & 431900 \\
\hline 1024E & $\begin{array}{c}\text { SAN } \\
\text { SEBASTIÁN,IGUELDO }\end{array}$ & 020228W & 431823 \\
\hline 1024F & $\begin{array}{l}\text { SAN SEBASTIAN } \\
\text { OBSERVATORIO }\end{array}$ & 020000W & 431900 \\
\hline 1025 & CERAIN & $021627 \mathrm{~W}$ & 430045 \\
\hline $1025 \mathrm{E}$ & MUTILOA & 021737W & 430207 \\
\hline $1025 \mathrm{~N}$ & ARRIARAN (PRESA) & 021417W & 430422 \\
\hline 1026 & BEASAIN & 021137W & 430300 \\
\hline $1026 \mathrm{~A}$ & $\begin{array}{c}\text { ORDIZIA CENTRAL } \\
\text { AGUAS }\end{array}$ & 021109W & 430323 \\
\hline 1026B & LAREO & $020635 \mathrm{~W}$ & 425833 \\
\hline 1031 & ELDUAYEN & 020007W & 430820 \\
\hline 1032 & $\begin{array}{l}\text { VILLABONA (GRANJA } \\
\text { FRAISORO) }\end{array}$ & 020411W & 431113 \\
\hline $1032 \mathrm{~A}$ & VILLABONA (VIVERO) & 0203W & 4311 \\
\hline
\end{tabular}

\footnotetext{
${ }^{4}$ OMA: Oficina Meteorológica Aeronáutica
} 
$\underline{\text { Tabla } 59 \text { (continuación): Nomenclátor: Indicativo climatológico, nombre y localización }}$

\begin{tabular}{|c|c|c|c|}
\hline Indicativo & Nombre estación & Longitud & Latitud \\
\hline $1033 \mathrm{U}$ & URNIETA (VIVERO) & $015925 \mathrm{~W}$ & 431355 \\
\hline 1034 & ANDOAIN & $0201 \mathrm{~W}$ & 4313 \\
\hline 1035 & LASARTE MICHELIN & 020116W & 431627 \\
\hline $1035 \mathrm{U}$ & AYA LAURGAIN & $021001 \mathrm{~W}$ & 431455 \\
\hline 1036 & ZARAUZ & 021014W & 431648 \\
\hline 10360 & $\begin{array}{c}\text { LEGAZPIA } \\
\text { (BARRENDIOLA) }\end{array}$ & 022034W & 430045 \\
\hline 1037 & LEGAZPIA & $022004 \mathrm{~W}$ & 430330 \\
\hline 10370 & AZCOITIA & 021948W & 431009 \\
\hline $1037 Q$ & AZKOITIA CARMELITAS & 0218W & 4310 \\
\hline 1038 & BEIZAMA (P.IBAI EDER) & $021331 \mathrm{~W}$ & 430746 \\
\hline 1041 & ZUMAYA CARMELITAS & 021530W & 431750 \\
\hline $1041 \mathrm{~A}$ & ZUMAYA, FARO & $021504 \mathrm{~W}$ & 431808 \\
\hline 1044 & ESCORIAZA & $0231 \mathrm{~W}$ & 4301 \\
\hline 1044A & ESCORIAZA (TESA) & 023139W & 430055 \\
\hline 1044D & $\begin{array}{c}\text { ARAMAYONA } \\
\text { ECHAGUEN }\end{array}$ & $023522 \mathrm{~W}$ & 430355 \\
\hline 1044U & $\begin{array}{l}\text { MONDRAGON } \\
\text { (OLANDIXO) }\end{array}$ & 022956W & 430338 \\
\hline 1045 & MONDRAGON & 022932W & 430355 \\
\hline 1046 & $\begin{array}{l}\text { ARANZAZU (NUESTRA } \\
\text { SENORA) }\end{array}$ & $022347 \mathrm{~W}$ & 425845 \\
\hline 1048 & $\begin{array}{l}\text { ARETXABALETA } \\
\text { URKULU }\end{array}$ & 022816W & 430128 \\
\hline 1049 & BERGARA (ALBITXU) & $022534 \mathrm{~W}$ & 430750 \\
\hline 10490 & ELGUETA (AIXOLA) & 023026W & 430950 \\
\hline $1049 \mathrm{U}$ & ERMUA & $023029 \mathrm{~W}$ & 431128 \\
\hline 1050 & $\begin{array}{l}\text { EIBAR BANCO DE } \\
\text { PRUEBAS }\end{array}$ & 022814W & 431108 \\
\hline $1050 \mathrm{~L}$ & $\begin{array}{l}\text { ELGOIBAR SANTA } \\
\text { CLARA }\end{array}$ & 022506W & 431257 \\
\hline 1052 & MOTRICO & $022313 \mathrm{~W}$ & 431832 \\
\hline 9268 & OTZAURTE & $021617 \mathrm{~W}$ & 425600 \\
\hline
\end{tabular}


$\underline{\text { Tabla } 60 \text { Distribución de series por comarcas: }}$

\begin{tabular}{|c|l|}
\hline Comarca & \multicolumn{1}{|c|}{ Indicativos } \\
\hline San Sebastián & $1013,1013 \mathrm{I}, 1014,1015,1016,1017,1018,1018 \mathrm{~A}$, \\
& $1019 \mathrm{~A}, 1021 \mathrm{E}, 1021 \mathrm{O}, 1022,1022 \mathrm{~A}, 1023,1024,1024 \mathrm{~B}$, \\
& $1024 \mathrm{D}, 1024 \mathrm{E}, 1024 \mathrm{~F}, 1035,1035 \mathrm{U}, 1036$ \\
\hline Alto Oria & $1025,1025 \mathrm{E}, 1025 \mathrm{~N}, 1026,1026 \mathrm{~A}, 1026 \mathrm{~B}, 9268$ \\
\hline Medio Oria & $1031,1032,1032 \mathrm{~A}, 1033 \mathrm{U}, 1034$ \\
\hline Alto Urola & $1036 \mathrm{O}, 1037$ \\
\hline Medio Urola & $1037 \mathrm{O}, 1037 \mathrm{Q}, 1038$ \\
\hline Litoral central y occidental & $1041,1041 \mathrm{~A}, 1052$ \\
\hline Alto Deba & $1044,1044 \mathrm{~A}, 1044 \mathrm{D}, 1044 \mathrm{U}, 1045,1046,1048$ \\
\hline Medio Deba & $1049,1049 \mathrm{O}, 1049 \mathrm{U}, 1050,1050 \mathrm{~L}$ \\
\hline
\end{tabular}

Figura 12: Series analizadas en comarca de San Sebastián.

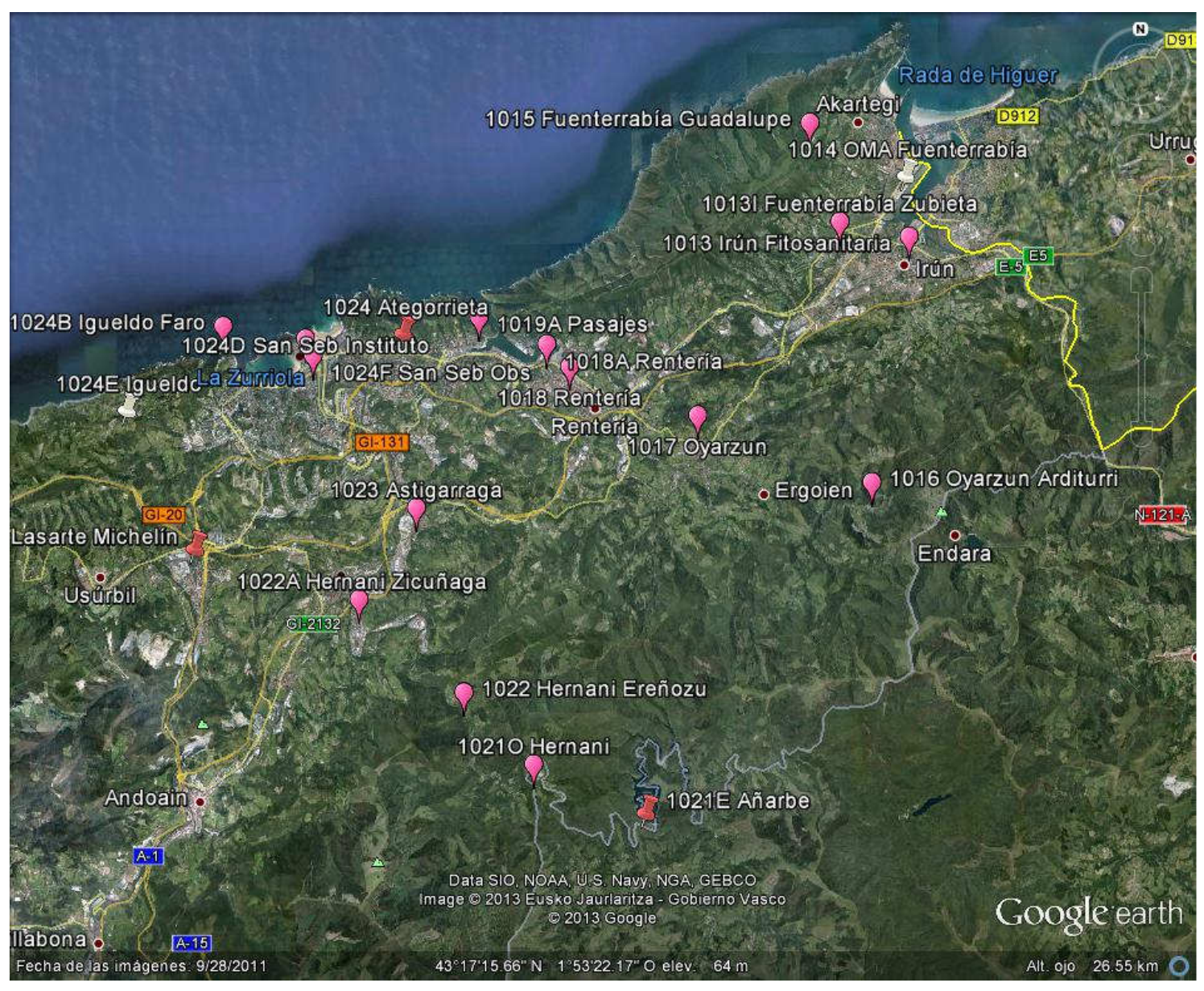


Figura 13.- Series analizadas en comarcas Alto Oria, Alto y Medio Urola, Alto y Medio Deba.

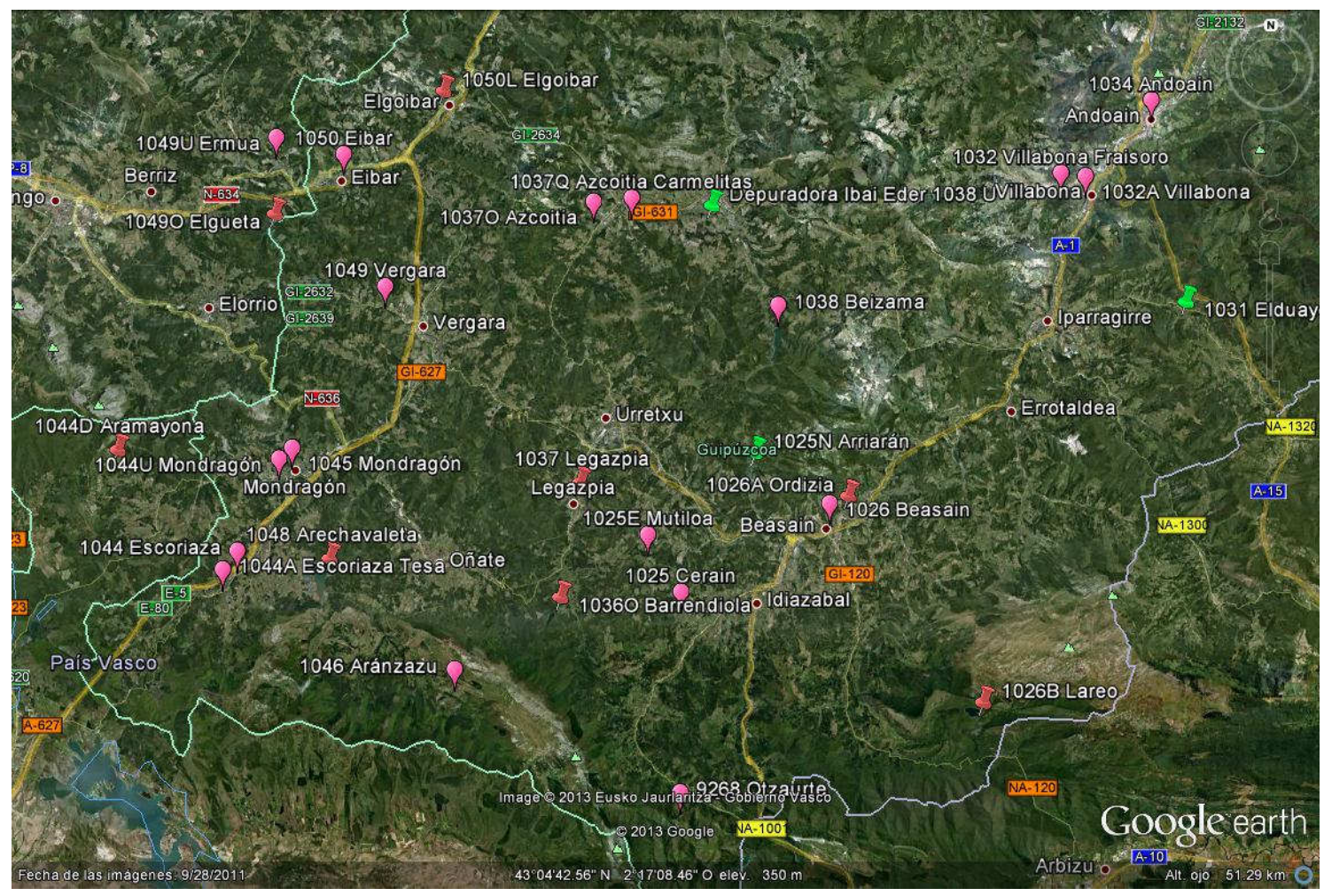

